MARCELO OTÁVIO DOS SANTOS

\title{
ESTUDO DA FORMAÇÃO DA REBARBA NO FRESAMENTO DE FACEAMENTO DE FERRO FUNDIDO VERMICULAR UTILIZADO EM BLOCOS DE MOTORES DIESEL
}




\section{ESTUDO DA FORMAÇÃO DA REBARBA NO FRESAMENTO DE FACEAMENTO DE FERRO FUNDIDO VERMICULAR UTILIZADO EM BLOCOS DE MOTORES DIESEL}

Dissertação apresentada à Escola Politécnica da Universidade de São Paulo para obtenção do título de Mestre em Engenharia.

Área de Concentração:

Engenharia Mecânica de Projeto e Fabricação.

Orientador: Prof. Dr. Gilmar Ferreira Batalha 
Este exemplar foi revisado e alterado em relação à versão original, sob responsabilidade única do autor e com a anuência de seu orientador.

São Paulo, 18 de janeiro de 2013.

Assinatura do autor

Assinatura do orientador

FICHA CATALOGRÁFICA

Santos, Marcelo Otávio dos

Estudo da formação da rebarba no fresamento de faceamento de ferro fundido vermicular utilizado em blocos de motores diesel / M.O. dos Santos. - ed.rev. -- São Paulo, 2013. $164 \mathrm{p}$.

Dissertação (Mestrado) - Escola Politécnica da Universidade de São Paulo. Departamento de Engenharia Mecatrônica e de Sistemas Mecânicos.

1.Fresagem 2.Ferro fundido 3.Motores diesel I.Universidade de São Paulo. Escola Politécnica. Departamento de Engenharia Mecatrônica e de Sistemas Mecânicos Il.t. 


\section{DEDICATÓRIA}

Dedico este trabalho ao meu pai Albertino, à minha mãe Conceição, à minha irmã Priscila, à minha noiva Estela e à minha avó Terezinha. 


\section{AGRADECIMENTOS}

Ao Prof. Dr. Gilmar Ferreira Batalha, pelo profissionalismo como professor e orientador, pelos conhecimentos adquiridos e pelo grande incentivo e motivação.

Ao Prof. Dr. Éd Claudio Bordinassi, pela contribuição dada em todas as fases do desenvolvimento deste trabalho, pela troca de experiências e pelo companheirismo.

Ao Sr. Christian Müller, Vice Presidente da empresa B. GROB do Brasil, por ter permitido a minha dedicação parcial as atividades na Escola Politécnica e por disponibilizar todos os recursos necessários para a realização deste trabalho.

À Empresa TUPY Fundições, especialmente ao Sr. Cássio L. F. de Andrade, MSc, doando os corpos de prova e principalmente, acreditando no propósito deste trabalho.

À empresa MWM International Motores, na pessoa do Eng ${ }^{\circ}$ Enrique Deviciente, ao incentivar a pesquisa e novos desenvolvimentos, visando aperfeiçoar ainda mais os processos de usinagem de sua empresa.

Ao Prof. Odair Maranho, por disponibilizar o Centro de Treinamento da B. GROB para a realização dos ensaios e pela parceria firmada em todo o desenvolvimento deste trabalho.

Ao Sr. Rogério de Paula, responsável pelo Centro de Aplicação Tecnológica da B. GROB do Brasil, pelo apoio técnico e troca de experiências durante a realização das etapas experimentais.

À minha família que sempre acreditou em mim e me incentivou a alcançar meus sonhos.

À minha noiva Estela, pela compreensão e apoio incondicional durante toda a minha trajetória acadêmica, em especial neste momento.

À Deus que me guiou durante todos os momentos da minha vida e me abençoou colocando em meu caminho as pessoas certas no momento certo. 
"Seja você quem for, seja qual for sua posição social, tenha sempre como meta muita força, muita determinação e sempre faça tudo com muito amor e com muita fé em Deus, que um dia você chega lá. De alguma maneira você chega lá." 


\section{RESUMO}

Visto o alto custo gasto nas linhas de usinagem com processos de rebarbação e a crescente demanda na utilização do ferro fundido vermicular, principalmente em motores diesel, este trabalho visou investigar as rebarbas formadas no fresamento de faceamento em uma face similar à face de fogo de um bloco de motor de ferro fundido vermicular FV450. Foram utilizados insertos de metal duro em fresas de facear com $100 \mathrm{~mm}$ de diâmetro. Os ensaios foram divididos em duas etapas. Na primeira etapa foi estudada a influência da geometria da ferramenta e a formação da rebarba remanescente. Na segunda etapa foram aplicados os melhores resultados obtidos durante os ensaios da primeira etapa. Um planejamento fatorial completo foi utilizado para a determinação da quantidade de ensaios desta etapa, variando-se a velocidade de corte, o avanço, a profundidade de corte e o desgaste de flanco. A medição da rebarba foi realizada em duas posições diferentes na borda da peça em questão, gerando assim dois ângulos diferentes de saída da ferramenta da peça. Verificou-se que a altura da rebarba foi menor quando se utilizou insertos de geometria mais positiva. $O$ desgaste e o ângulo de saída da peça interferiram de forma significativa no tamanho da rebarba. Também verificou-se a redução da rebarba com o aumento do avanço e da velocidade de corte e com a diminuição da profundidade de corte. Através do software STATISTICA 8.0 foram obtidos os valores dos efeitos principais e das interações, juntamente com o intervalo de confiança e erro padrão. Por fim o planejamento adotado permitiu a elaboração de um modelo empírico capaz de predizer a altura da rebarba.

Palavras-chave: Ferro fundido vermicular. Fresamento de faceamento. Rebarba. Parâmetros de corte. Planejamento fatorial completo. 


\begin{abstract}
Since the high cost spent on machining lines with deburring processes and the growing demand in the use of Compacted Graphite Iron (CGI), especially in diesel engines, this work aims to investigate the burr formation mechanisms during face milling of CGI FV450, in a face similar to the combustion face of an engine cylinder block. Carbide inserts were used in a $100 \mathrm{~mm}$ of diameter milling cutter. The tests were divided into two stages. In the first stage the following variables were studied: tool geometry and milling with remaining burrs from previous milling. In the second stage, were applied the best results obtained during the tests of the first stage. A Complete Factorial Planning was used to specify the amount of experiments, varying cutting speed, feed rate, cutting depth and the flank wear. The burrs measurement was performed in two different positions of the workpiece exit border, generating two different exit angle from the workpiece. It was found that the burr height was lower with more positive geometry. The wear of the tool and exit angle from the workpiece interfered significantly the burr height. It was observed the decrease of the burr height with the increase of the feed rate and cutting speed and with the decrease of the cutting depth. Through the software STATISTICA 8.0 values were obtained for main effects and interactions, along with confidence intervals and standard error. Finally, the plan adopted allowed the development of an empirical model capable of predicting the burr height.
\end{abstract}

Keywords: Compacted graphite iron. Face milling. Burr. Cutting parameters. Complete factorial planning. 


\section{LISTA DE ILUSTRAÇÕES}

Figura 1.1-Blocos de Motores em CGI produzidos na nova linha de usinagem da empresa MWM International, que atendem as novas especificações da norma EPA 07 (Euro 5)

Figura 1.2-Distribuição dos gastos no processo de rebarbação na indústria automotiva.

Figura 1.3-(a) Célula robotizada de rebarbação de blocos de motores, (b) Escovação da face de fogo do bloco de motor no do ciclo de usinagem.

Figura 2.1-(a) Bloco de motor V-8 em Ferro Fundido Vermicular. 31

Figura 2.2- Indicação da face de fogo em bloco de motor 6 cilindros em linha. 31

Figura 2.3 -Comparação de propriedades de materiais para blocos de motores: FC 250, FV 400, AISi9Cu3.

Figura 2.4-Para atender as exigências de emissões, a máxima pressão de combustão, em motores diesel, deve ultrapassar 200 bar, de acordo com a MAN

Figura 2.5-Limite de máxima pressão de explosão suportadas por blocos de motores Diesel, para vários tipos de materiais.

Figura 2.6-Morfologia da grafita em ferros fundidos a) cinzento, b) nodular, c) vermicular

Figura 2.7-Micrografia do ferro fundido vermicular. (a) Micrografia óptica atacada com Nital. (b) Forma espacial da grafita vermicular. MEV 395x. 39

Figura 2.8-A ferramenta (a) é uma fresa cilíndrica tangencial, a (b) é uma fresa cilíndrico-frontal e a (c) é uma fresa de topo com haste cilíndrica.

Figura 2.9-(a) Parte de corte de uma fresa,(b) Arestas de corte da fresa..... 43

Figura 2.10 - Ângulos de maior influência prática no fresamento. .44

Figura 2.11-(a)Representação da geometria duplo-negativa, (b) Esquema do esforço e fluxo de cavacos 44

Figura 2.12 - Representação da geometria duplo-positiva, (b) Esquema do esforço e fluxo de cavacos 
Figura 2.13 - Representação da geometria positiva-negativa, (b) Esquema do esforço e fluxo de cavacos

Figura 2.14-(a) Definição do ângulo de posição através dos planos de referência (b) exemplo de aplicação do ângulo de posição

Figura 2.15 - Influência ângulo de posição sobre largura e espessura do cavaco ...46

Figura 2.16 - (a) Fresamento concordante, (b) Fresamento discordante . 49

Figura 2.17 - Fresamento concordante e discordante no plano frontal 49

Figura 2.18 - Indicação vetorial da atuação da velocidade de corte, velocidade de avanço e velocidade efetiva de corte no fresamento tangencial. 51

Figura 2.19 - Representação de algumas grandezas físicas no fresamento.............52

Figura 2.20 - Geometria da rebarba conforme indicado na ISO $13715 \ldots \ldots \ldots \ldots \ldots \ldots . . . . . .55$

Figura 2.21 - Dimensões da rebarba 55

Figura 2.22-Principais dimensões consideradas na análise das rebarbas, altura "h", e espessura "b". .56

Figura 2.23 - Modelo geométrico da rebarba e seus parâmetros. 56

Figura 2.24 - Variáveis geométricas e o deslocamento da ferramenta do ponto A ao ponto A', e rotação do plano de cisalhamento negativo em torno de B..57

Figura 2.25 - Primeira etapa da formação da rebarba..........................................58

Figura 2.26 - Segunda etapa da formação da rebarba........................................59

Figura 2.27 - Terceira etapa da formação da rebarba.......................................59

Figura 2.28 - Quarta etapa da formação da rebarba .........................................60

Figura 2.29 - Quinta etapa da formação da rebarba ........................................60

Figura 2.30 - Sexta etapa da formação da rebarba em materiais ducteis ................61

Figura 2.31 - Sétima etapa da formação da rebarba em materiais dúcteis ..............61

Figura 2.32 - Oitava etapa da formação da rebarba em materiais dúcteis ...............62

Figura 2.33 - Sexta etapa da formação da rebarba em materiais frágeis................62

Figura 2.34 - Sétima etapa da formação da rebarba em materiais frágeis...............63

Figura 2.35 - Oitava etapa da formação da rebarba em materiais frágeis ...............63

Figura 2.36-(a) - Pressão da ferramenta sobre a superfície usinada, (b) - Penetração do cilindro (ferramenta de corte) .............................................64

Figura 2.37 - Rebarba de encurvamento gerada no fresamento ............................65

Figura 2.38 - Destacamento do cavaco e o surgimento da rebarba de estiramento.65 
Figura 2.39-Rebarba de Ruptura formada pela operação de sangramento no torneamento externo

Figura 2.40 - Rebarbas formadas no fresamento. (a) - fresamento de faceamento, (b) fresamento tangencial discordante e (c) fresamento de topo................66

Figura 2.41 - Transição da rebarba primaria para rebarba secundaria ...................67

Figura 2.42 - Identificação das arestas no fresamento de faceamento. ...................68

Figura 2.43 - Sequência de saída da ferramenta de corte influenciando na formação da rebarba. (a) Ordem de saída BCA, (b) Ordem de saída ABC ........69

Figura 2.44 - Localização das rebarbas e superfícies utilizadas na classificação.....70

Figura 2.45 - Cinco morfologias de rebarbas observadas no processo de fresamento de faceamento.

Figura 2.46 - Morfologias das rebarbas verificadas fresamento de faceamento do aço inoxidável AISI 304.

Figura 2.47 - Altura da rebarba em função do avanço por dente para ferramentas de PCBN e cerâmica, nas condições mostradas 73

Figura 2.48 - Altura da rebarba em função do da profundidade de corte, para as condições mostradas 74

Figura 2.49 - Formação dos ângulos $\psi$ e $\theta$ na entrada e saída da fresa, (a) borda de entrada, (b) borda de saída 75

Figura 2.50 - (a) Plano de cisalhamento negativo ligando a ponta da ferramenta ao ponto de pivotamento, (b) Breakout formado na saída da ferramenta 77

Figura 2.51 - Micrografia da raiz do cavaco mostrando a formação da rebarba negativa. .77

Figura 2.52 - Sistema representado pelo planejamento de experimento .................79

Figura 3.1 - Indicação do sentido do fresamento nos ensaios 97

Figura 3.2 - Descritivo das divisões impostas nas bordas de saída (a) e borda de entrada da peça (b) 98

Figura 3.3 - Indicação dos pontos de medição da altura da rebarba nos furos de entrada (a) e de saída da ferramenta da peça (b). .98

Figura 3.4 - Método de determinação dos ângulos de entrada e de saída nas respectivas bordas da peça .99

Figura 3.5 - Indicação da divisão entre rebarba de saída e rebarba de entrada na borda de saída da peça. 101 
Figura 3.6 - Descritivo dos pontos Ds e Fs, onde foram realizadas as medições de altura da rebarba na segunda etapa dos ensaios

Figura 3.7 - Placas em ferro fundido vermicular fornecidas pela Tupy Fundições, para preparo dos corpos de prova

Figura 3.8 - (a) Bloco de motor MWM - BigBore MAXXFORCE ${ }^{\mathrm{TM}} 11$ em CGI; (b) Modelo em 3D do corpo de prova similar a face de fogo do bloco de motor; (c) Corpo de prova pronto para os ensaios 82

Figura 3.9 - Micrografias mostrando a morfologia da grafita. .84

Figura 3.10 - Micrografias mostrando a estrutura da matriz metálica .84

Figura 3.11 - (a) Modelo 3D do bloco de motor diesel referência para este projeto; (b) Bloco de motor MWM Big Bore MaxxForce

Figura 3.13 - (a) Modelos em 3D dos corpos de prova, (b) Corpos de prova prontos para realização dos ensaios de usinagem da primeira etapa.

Figura 3.14. (a) Modelo 3D dos corpos de prova, (b) Corpo de prova preparado para a realização da segunda etapa dos ensaios de usinagem.

Figura 3.15 - Fresadora CNC utilizada para a realização dos ensaios da primeira etapa. .88

Figura 3.16 - Máquina utilizada para realização dos ensaios da segunda etapa. .....89

Figura 3.17 - (a) Modelo 3D esquematizando a fixação das placas na cantoneira. (b) Corpo de prova fixado na cantoneira sobre a mesa do centro de usinagem para a realização dos ensaios.

Figura 3.18 - (a) Ferramenta utilizada nos ensaios, (b) Inserto alisador YDA323L101 IN2010, (c) Inserto de desbaste NNE324-100 IN2004.

Figura 3.19 - (a) Ferramenta B utilizada nos ensaios, (b) Pastilha de corte ONMU090520ANTN - M14, MK1500 utilizada na ferramenta B .91

Figura 3-20. (a) Fresa utilizada nos ensaios 100A08RS90ED14D, (b) inserto de metal duro EDPT140408PDERHD - KCK15

Figura 3.21 - Equipamento para pre-set das ferramentas de corte utilizadas nos ensaios.

Figura 3.22 - Microscópio utilizado para inspecionar e medir o desgaste de flanco das pastilhas utilizadas nos ensaios. .94

Figura 3.23 - Perfilometro para medição altura da rebarba formada nos ensaios.....94

Figura 3.24 - Procedimento de medição da altura da rebarba. .95 
Figura 3.25 - Procedimento para aquisição da altura $\mathrm{h}$ da rebarba $(\mathrm{mm})$. .95

Figura 4.1 - Altura da rebarba em relação ao número de passadas para retirada da rebarba remanescente e com a rebarba remanescente para a ferramenta A.

Figura 4.2 - Altura da rebarba em relação ao número de passadas para retirada da rebarba remanescente e com a rebarba remanescente para a ferramenta B.

Figura 4.3 - Altura da rebarba em relação ao número de passadas para retirada da rebarba remanescente e com a rebarba remanescente para a ferramenta $\mathrm{C}$. 113

Figura 4.4 - Comparativo da altura da rebarba para as ferramentas A, B e C 115

Figura 4.5 - Aspecto da rebarba formada na borda do furo do cilindro de entrada. 118

Figura 4.6 - Rebarba tipo faca na borda de entrada, com a ferramenta A. 121

Figura 4.7 - Rebarba do tipo Rollover (em conjunto com Tear), formada na borda de saída da peça, e observada os ensaios com a ferramenta $A$. 121

Figura 4.8 - Variação da altura da rebarba no comprimento da borda de entrada e da borda de saída utilizando os valores médios - Ferramenta $A$.

Figura 4.9 - Rebarba formada durante o ensaio N2, para $\mathrm{V}_{\text {Bmáx }}=0,3 \mathrm{~mm}$. 124

Figura 4.10 - Diagrama de bloco com a identificação das variáveis de entrada e de saída aplicadas no planejamento de experimentos - DOE. 125

Figura 4.11 - Diagrama de Pareto para os efeitos principais e interações sobre a altura da rebarba $\mathrm{h}$ - Ferramenta $\mathrm{A}$. 126

Figura 4.12 - Diagrama de Pareto para os efeitos principais e interações sobre a altura da rebarba $\mathrm{h}$ - Ferramenta $\mathrm{C}$. 127

Figura 4.13 - Ilustra os efeitos das médias do fator $V_{B \text { máx }}$ sobre a altura da rebarba $h$ - Ferramenta A. 128

Figura 4.14 - Ilustra os efeitos das médias do fator $V_{\text {Bmáx }}$ sobre a altura da rebarba $\mathrm{h}$ - Ferramenta C. 129

Figura 4.15 - Ilustra os efeitos das médias do fator $v_{C}$ sobre a altura da rebarba $h$ Ferramenta A

Figura 4.16 - llustra os efeitos das médias do fator $v_{C}$ sobre a altura da rebarba $h$ Ferramenta C 
Figura 4.17 - Ilustra os efeitos das médias do fator $f_{z}$ sobre a altura da rebarba $h$ Ferramenta A

Figura 4.18 - Ilustra os efeitos das médias do fator $f_{Z}$ sobre a altura da rebarba $h$ Ferramenta C

Figura 4.19 - Ilustra os efeitos das médias do fator $a_{p}$ sobre a altura da rebarba $h$ Ferramenta A.

Figura 4.20 - llustra os efeitos das médias do fator $a_{p}$ sobre a altura da rebarba $h$ Ferramenta C

Figura 4.21 - llustra os efeitos das médias do fator $\theta$ sobre a altura da rebarba $\mathrm{h}$ Ferramenta A

Figura 4.22 - llustra os efeitos das médias do fator $\theta$ sobre a altura da rebarba $\mathrm{h}$ -

Ferramenta C 138

Figura 4.23 - Gráficos de superfície de resposta utilizando ferramentas com profundidade de corte $=0,7 \mathrm{~mm}$ e avanço $=0,05 \mathrm{~mm} /$ dente- Superfície com Confiança de 95\% (p-value=0,05) - Ferramenta A . 140

Figura 4.24 - Gráficos de superfície de resposta utilizando ferramentas com profundidade de corte $=0,7 \mathrm{~mm}$ e avanço $=0,05 \mathrm{~mm} /$ dente- Superfície com Confiança de 95\% (p-value=0,05) - Ferramenta C 141

Figura 4.25 - Resíduo entre os valores medidos e estimados. a) - Distribuição normal do resíduo, b) - Valor do resíduo para as 128 respostas Ferramenta A

Figura 4.26. Resíduo entre os valores medidos e estimados. (a) - Distribuição normal do resíduo, (b) - Valor do resíduo para as 128 respostas Ferramenta C. 


\section{LISTA DE TABELAS}

Tabela 2.1- Relação dos picos de pressão de combustão com a emissão de poluentes avaliados para motores Diesel.

Tabela 2.2- Propriedades mecânicas e físicas do ferro fundido vermicular comparado com o cinzento e nodular

Tabela 3.1- Valores dos ângulos com seus respectivos segmentos 100

Tabela 3.2- Variáveis utilizadas no planejamento fatorial e seus respectivos níveis.

Tabela 3.3- Sequência dos ensaios realizados com a Ferramenta A para um desgaste de flanco de $\mathrm{V}_{\mathrm{Bmax}}=0,00 \mathrm{~mm}$. 104

Tabela 3.4- Sequência dos ensaios realizados com a Ferramenta A para um desgaste de flanco de $\mathrm{V}_{\mathrm{Bmax}}=0,30 \mathrm{~mm}$. 105

Tabela 3.5- Sequência dos ensaios realizados com a Ferramenta $C$ para um desgaste de flanco de $\mathrm{V}_{\mathrm{Bmax}}=0,00 \mathrm{~mm}$ 106

Tabela 3.6- Sequência dos ensaios realizados com a Ferramenta $C$ para um desgaste de flanco de VBmax $=0,30 \mathrm{~mm}$

Tabela 3.7- Composição química do ferro fundido vermicular utilizado para realização dos ensaios.

Tabela 3.8 - Dureza Brinell média dos corpos de prova 83

Tabela 3.9 - Propriedades Mecânicas do material utilizado nos ensaios . 83

Tabela 3.10 - Porcentagem de Perlita, Forma da Grafita e Nodularidade na estrutura do material utilizado nos ensaios 83

Tabela 4.1 - Altura da rebarba posterior, sem a retirada da rebarba remanescente e com a retirada da rebarba remanescente, para a Ferramenta $A$, segmento Ds.

Tabela 4.2 - Altura da rebarba posterior, sem a retirada da rebarba remanescente e com a retirada da rebarba remanescente, para a Ferramenta B, segmento Ds. 
Tabela 4.3 - Altura da rebarba posterior, sem a retirada da rebarba remanescente e com a retirada da rebarba remanescente, para a Ferramenta C, segmento Ds.

Tabela 4.4- Altura da rebarba formada com a retirada da rebarba remanescente, para as Ferramentas A, B e C medidas no segmento Ds. 114

Tabela 4.5 - Resultados da altura da rebarba na borda dos furos - Ferramenta A .118

Tabela 4.6- Resultados da altura da rebarba na borda de entrada - Ferramenta A 120

Tabela 4.7 - Resultados da altura da rebarba na borda de saída - Ferramenta A ..120

Tabela 4.8- Resultados da altura da rebarba na borda de saída - Ferramenta A, $\mathrm{V}_{\mathrm{Bmax}}=0,3 \mathrm{~mm}$ 123

Tabela 4.9- Efeitos Principais da mudança de níveis das variáveis nos valores da altura da rebarba - Ferramenta A.

Tabela 4-10-Efeitos Principais da mudança de níveis das variáveis nos valores da altura da rebarba - Ferramenta $\mathrm{C}$

Tabela 4.11- Efeitos das Interações da mudança de níveis das variáveis nos valores da altura da rebarba - Ferramenta $A$.

Tabela 4.12- Efeitos das Interações da mudança de níveis das variáveis nos valores da altura da rebarba - Ferramenta $C$ 145

Tabela 4.13- Análise de variância para ajuste do modelo - Ferramenta A. 146

Tabela 4.14- Análise de variância para ajuste do modelo - Ferramenta C 148 


\section{LISTA DE ABREVIATURAS E SIGLAS}

\begin{tabular}{ll} 
ABNT & Associação Brasileira de Normas Técnicas \\
ANOVA & Análise de Variância \\
APC & Aresta Postiça de Corte \\
ASTM & American Society for Testing Materials \\
ASTME & American Society of Tool and Manufacturing Engineers \\
CAD & Desenho Assistido por Computador \\
CGI & Compacted Graphite Iron \\
CNC & Controle Numérico Computadorizado \\
CONAMA & Conselho Nacional do Meio Ambiente \\
CVD & Deposição Química a Vapor \\
DIN & Instituto Alemão de Normalização \\
EOS & Sequência da Ordem de Saída da aresta de corte \\
ISO & Organização Internacional para Padronização \\
MQ & Média Quadrática \\
PFC & Planejamento Fatorial Completo \\
PPGEM & Programa de pós-graduação em Engenharia Mecânica \\
PROCONVE & Programa de Controle da Poluição do Ar por Veículos \\
& Automotores \\
PVD & Deposição Física a Vapor \\
SAE & Society of Automotive Engineers \\
SQ & Soma Quadrática \\
TiAIN & Nitreto de alumínio e titânio \\
Ti(C,N) & Carbonitreto de titânio \\
& \\
\hline
\end{tabular}




\section{LISTA DE SÍMBOLOS}

Símbolo Denominação

Unidade

$\begin{array}{lll}\mathbf{a}_{\mathbf{e}} & \text { Profundidade radial de usinagem } & {[\mathrm{mm}]} \\ \mathbf{a}_{\mathbf{p}} & \text { Profundidade axial de usinagem } & {[\mathrm{mm}]} \\ \mathbf{b} & \text { Espessura da rebarba } & {[\mathrm{mm}]} \\ \mathbf{D} & \text { Diâmetro da fresa } & {[\mathrm{mm}]} \\ \mathbf{f}_{\mathbf{z}} & \text { Avanço por dente } & {[\mathrm{mm} / \mathrm{dente}]} \\ \mathbf{h} & \text { Altura da rebarba } & {[\mathrm{mm}]} \\ \hat{\mathbf{h}} & \text { Altura estimada da rebarba } & {[\mathrm{mm}]} \\ \mathbf{h}_{\mathbf{c}} & \text { Espessura do cavaco } & {[\mathrm{mm}]} \\ \mathbf{k} & \text { Número de fatores do planejamento experimental } & \\ \mathbf{n} & \text { Rotação } & {[\mathrm{rpm}]} \\ \mathbf{r}_{\mathbf{n}} & \text { Raio de Arredondamento da Ponta da Ferramenta } & {[\mathrm{mm}]} \\ \mathbf{R}_{\mathbf{z}} & \text { Rugosidade superficial } & {[\mathrm{mm}]} \\ \mathbf{t}_{\mathbf{b}} & \text { Espessura da Rebarba } & {[\mathrm{mm}]} \\ \mathbf{t}_{\mathbf{m a x}} & \text { Espessura Máxima da Rebarba } & {[\mathrm{mm}]} \\ \mathbf{t}_{\mathbf{m i n}} & \text { Espessura Mínima da Rebarba } & {[\mathrm{mm}]} \\ \mathbf{V}_{\mathbf{B}} & \text { Desgaste de flanco } & {[\mathrm{mm}]} \\ \mathbf{V}_{\mathbf{B m a x}} & \text { Desgaste de flanco máximo } & {[\mathrm{mm}]} \\ \mathbf{v}_{\mathbf{c}} & \text { Velocidade de corte } & {[\mathrm{m} / \mathrm{min}]} \\ \mathbf{V}_{\mathbf{f}} & \text { Velocidade de avanço } & {[\mathrm{mm} / \mathrm{min}]} \\ \mathbf{z} & \text { Número de insertos da fresa } & \end{array}$




\section{Letras gregas}

$\begin{array}{lll}\alpha_{0} & \text { Ângulo de folga da ferramenta } & {[9]} \\ \chi_{r} & \text { Ângulo de posição da ferramenta } & {[9]} \\ \varepsilon_{f} & \text { Deformação crítica a fratura } & {[\mathrm{mm}]} \\ \gamma & \text { Ângulo de saída da ferramenta } & {[9]} \\ \varphi & \text { Ângulo de cisalhamento negativo } & {[9]} \\ \theta & \text { Ângulo de borda de saída } & {[9]} \\ \omega & \text { Distância do inicio da rebarba até a borda da peça } & {[\mathrm{mm}]} \\ \psi & \text { Ângulo de borda de entrada } & {[9]}\end{array}$




\section{SUMÁRIO}

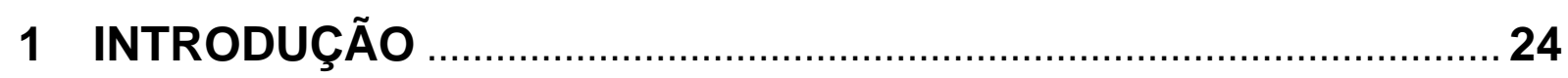

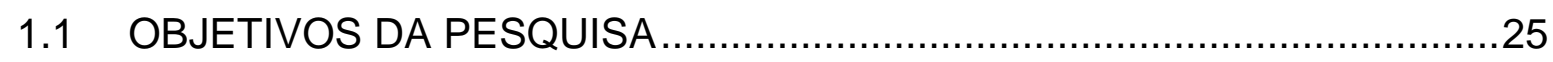

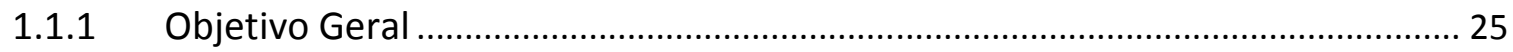

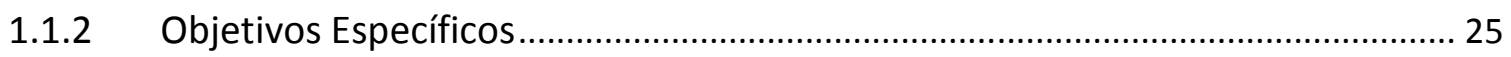

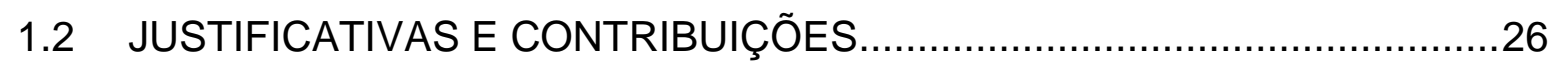

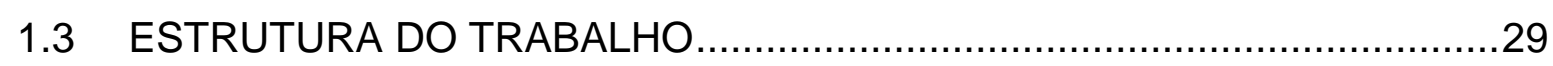

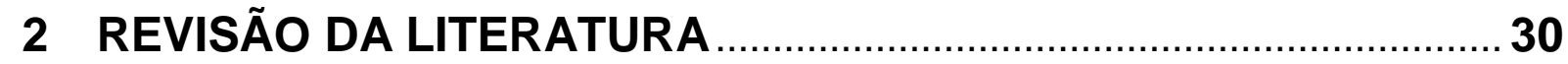

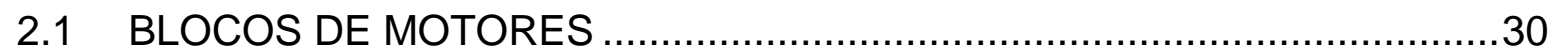

2.2 MATERIAIS PARA FABRICAÇÃO DOS BLOCOS DE MOTORES ..............32

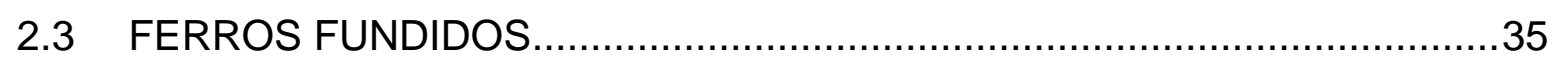

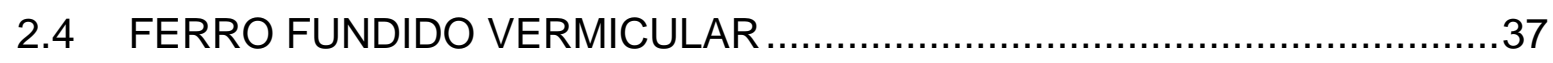

2.4.1 Métodos de obtenção do ferro fundido vermicular ............................................... 38

2.4.2 Propriedades físicas e mecânicas do ferro fundido vermicular ........................... 39

2.5 USINABILIDADE DO FERRO FUNDIDO VERMICULAR .......................41

2.6 O PROCESSO DE FRESAMENTO ................................................. 42

2.7 DIFICULDADES NA USINAGEM DE BLOCOS DE MOTORES .................52

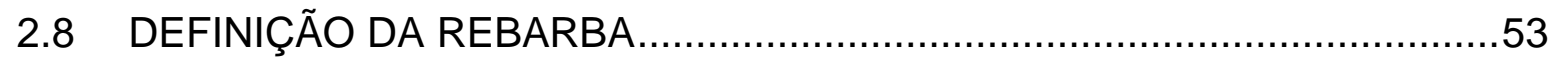

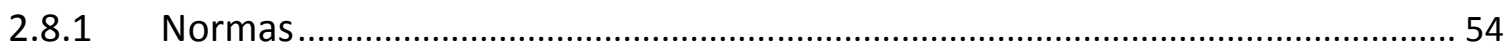

2.8.2 Descrição geométrica da rebarba ...................................................................... 55

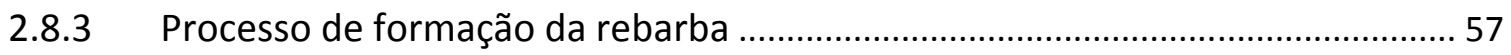

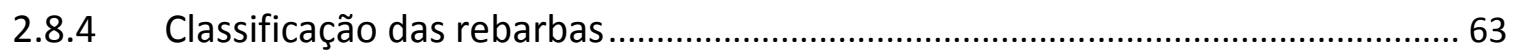

2.8.4.1 Classificação das rebarbas formadas no processo de fresamento.....................638

2.8.5 Influência dos parâmetros de usinagem na formação da rebarba....................... 71

2.8.5.1 Influência da velocidade de corte na formação da rebarba................................. 71

2.8.5.2 Influência do avanço na formação da rebarba.................................................. 73

2.8.5.3 Influência da profundidade de corte na formação da rebarba ............................ 74

2.8.5.4 Influência dos ângulos de entrada e de saída na formação da rebarba .............. 75

2.8.6 Formação do Breakout na usinagem dos metais ................................................... 76 
2.9 PLANEJAMENTO DE EXPERIMENTOS ……...................................

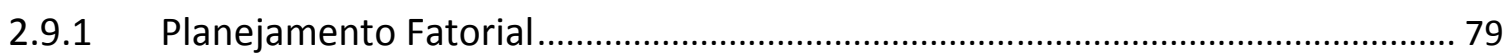

3 MATERIAIS E MÉTODOS ............................................................... 81

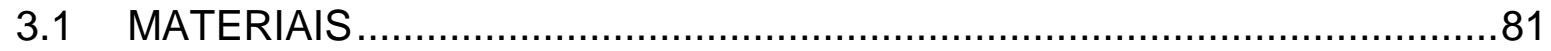

3.2 PROPRIEDADES E MICROESTRUTURA ……................................

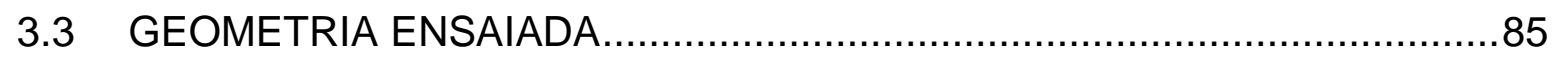

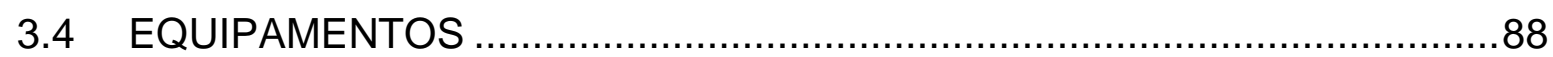

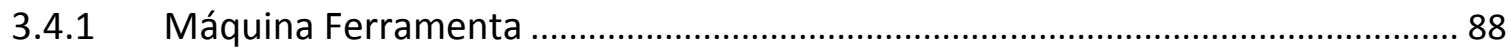

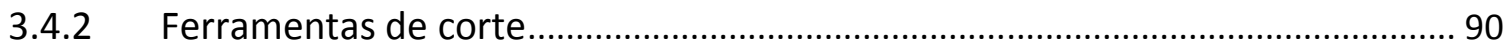

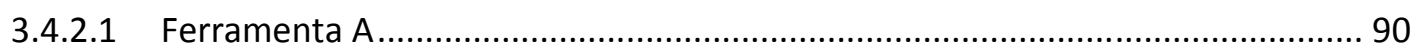

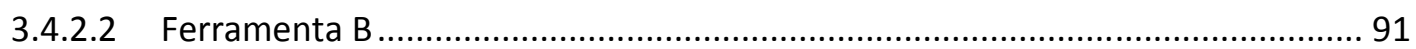

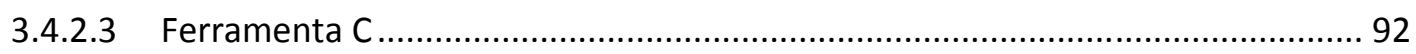

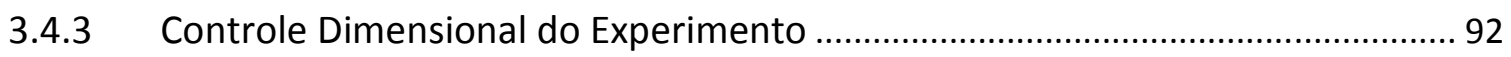

3.4.3.1 Pre-set das ferramentas de corte ……................................................................ 93

3.4.3.2 Medição do desgaste de flanco ............................................................................ 93

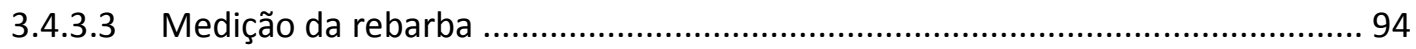

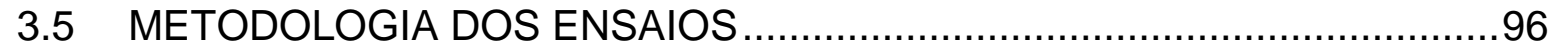

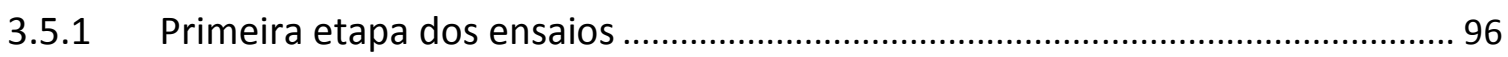

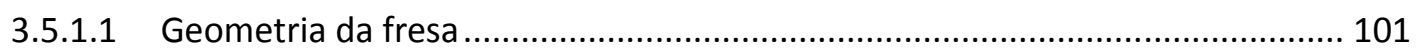

3.5.1.2 Dimensão da rebarba remanescente ............................................................... 102

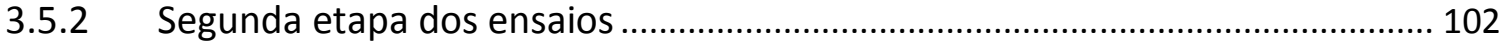

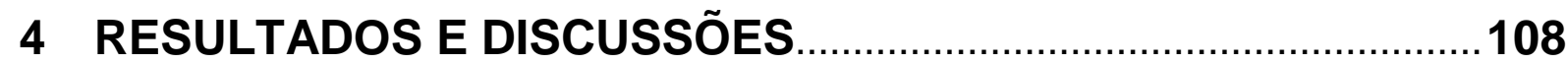

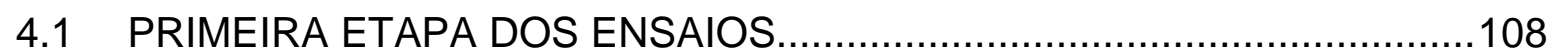

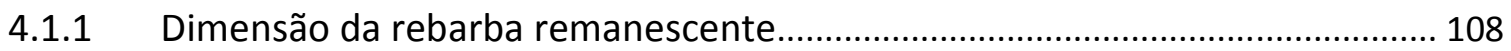

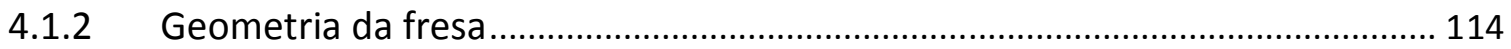

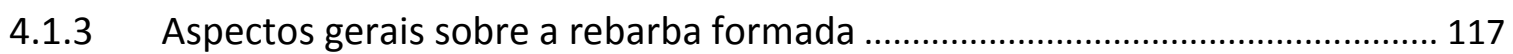

4.1.3.1 Rebarbas formadas nas bordas dos furos (cilindros) ....................................... 118

4.1.3.2 Rebarba na borda de entrada versus Rebarba na borda de saída .................... 120

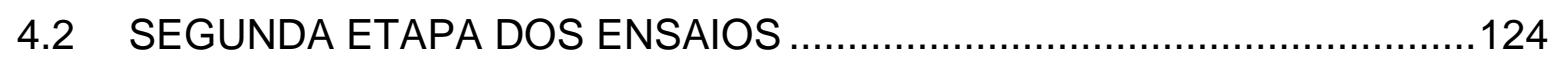

4.2.1 Análise de significância entre os efeitos............................................................. 126

4.2.1.1 Desgaste da ferramenta de corte .................................................................. 127

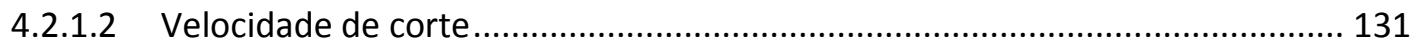




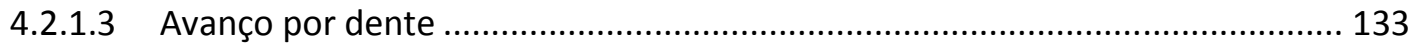

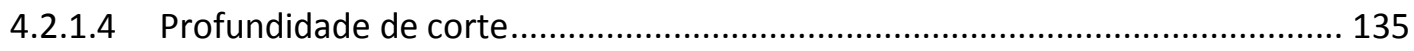

4.2.1.5 Ângulo de borda de saída ........................................................................ 138

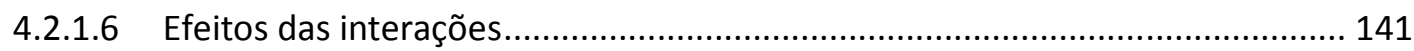

4.2.2 Modelo empírico para predição da altura da rebarba ........................................ 142

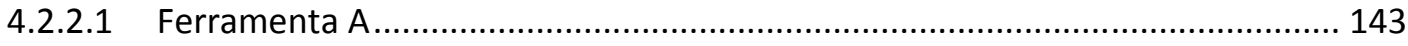

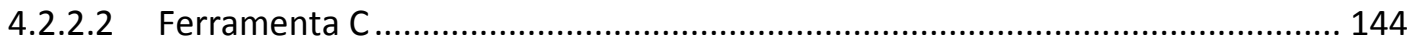

4.2.3 Influência dos efeitos principais e interações ................................................... 143

4.2.4 Análise de variância do modelo............................................................................... 145

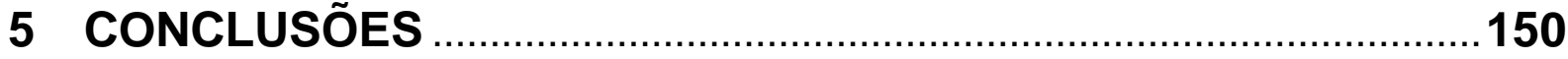

6 SUGESTÕES PARA TRABALHOS FUTUROS ……........................151

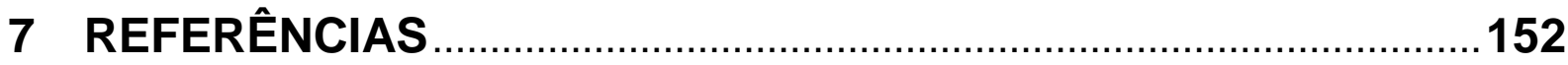

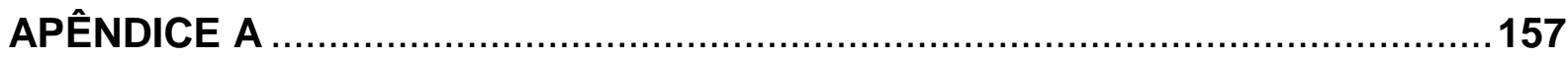

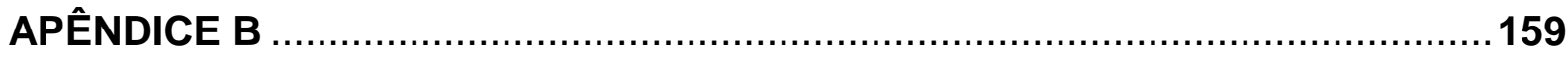

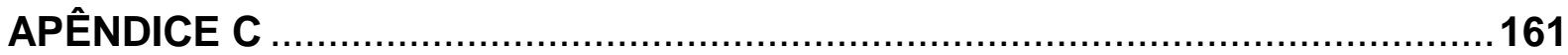




\section{INTRODUÇÃO}

A crescente busca das organizações por ampliar seus mercados, pela redução dos custos e agregação de valor ao produto tem sido acompanhada de soluções compromissadas com a redução da poluição ambiental, como a redução da emissão de poluentes atmosféricos e de ruídos. Neste contexto, a indústria automobilística e seus fornecedores vêm buscando cada vez mais melhorar seus processos e produtos, bem como desenvolver novos materiais e tecnologias que permitam alcançar a solução de compromisso entre lucro e baixo impacto ambiental.

As recentes evoluções tecnológicas dos motores a diesel, tanto em desempenho quanto na redução da emissão de poluentes, são resultantes de maiores pressões e temperaturas de trabalho, fazendo com que o bloco do motor sofra maiores solicitações, podendo gerar quebras prematuras. A fim de evitar tais problemas, o ferro fundido vermicular ou CGI (Compacted Graphite Iron), vem ganhando espaço no mercado automobilístico, onde é visto como um material que apresenta inúmeras possibilidades de aplicação em diversos setores da indústria, por combinar características mecânicas e físicas, situadas entre o ferro fundido cinzento e o nodular, principalmente na construção de blocos de motores a diesel.

Com material de maior resistência é possível fazer motores mais potentes do mesmo tamanho, ou motores mais compactos com a mesma potência. Além disso, estes motores apresentam a vantagem adicional de combustão mais eficiente e, portanto, são menos poluentes.

Entretanto, tais propriedades superiores deste material implicam num maior custo de usinagem em relação ao ferro fundido cinzento, devido aos tempos de processo e desgaste das ferramentas serem mais elevados. Em função destes problemas vem se pesquisando intensamente a usinabilidade deste material, de modo que ela possa se aproximar cada vez mais à do ferro fundido cinzento.

Mesmo com inúmeras pesquisas que envolvem os processos de usinagem nos blocos de motores, ainda são muitos os problemas enfrentados para se obter o produto final dentro dos parâmetros ideais de acabamento e tolerância. Dentre eles pode ser citada a falta de qualidade nas bordas das peças usinadas, problema este que leva em consideração a formação da rebarba. 
A rebarba é um resíduo indesejado que surge nas bordas das peças obtidas durante a manufatura, como na usinagem. A sua dimensão depende do processo e da operação de usinagem, do material da peça, das condições de corte, do material da ferramenta de corte, entre outros. Ao processo de sua retirada dá-se o nome de rebarbação, sendo este realizado através de ferramentas manuais ou escovas em processos automatizados na linha de produção.

Ainda são poucos os trabalhos que reportam o assunto e naqueles que têm aparecido pode-se perceber o grande interesse pelos processos de rebarbação, enquanto que os mecanismos de formação das rebarbas e a análise do comportamento de suas dimensões ainda precisam ser investigados.

A seguir, são apresentados os objetivos, as justificativas e as contribuições que motivaram a realização desta pesquisa, bem como a estrutura de apresentação deste trabalho.

\subsection{OBJETIVOS DA PESQUISA}

\subsubsection{Objetivo Geral}

Avaliar o comportamento da rebarba formada após o processo de fresamento de faceamento de um corpo de prova similar a face de fogo de um bloco de motor de ferro fundido vermicular.

\subsubsection{Objetivos Específicos}

$\checkmark$ Verificar a influência da geometria da ferramenta de corte na formação da rebarba.

$\checkmark$ Através do Planejamento de Experimentos (DOE), estudar o efeito das variáveis de entrada: avanço por dente, profundidade de corte, velocidade de corte, desgaste de flanco e ângulo de saída da peça, sobre a variável de resposta altura da rebarba. 


\subsection{JUSTIFICATIVAS E CONTRIBUIÇÕES}

Estudos recentes têm mostrado um grande impacto econômico das rebarbas e seus efeitos nos processos de usinagem como um todo. Não somente o processo de rebarbação, que acaba por não agregar valor ao produto, mas em muitos casos a formação da rebarba em si se torna um fator-chave para o desgaste da ferramenta de corte o que leva a sua substituição precoce, elevando ainda mais os custos do processo (PALMAN et al 2011).

Frente a este desafio de redução dos custos, fica claro a dedicação das empresas da indústria automobilística em se conseguir reduzir seus custos de produção a fim de vencer a concorrência seja no aspecto econômico quanto no tecnológico. E o produto que vem se tornando cada vez mais um desafio é o bloco de motor diesel, que com as novas normas regulamentadoras como a Euro 5, têm obrigado a indústria a produzir blocos de motores mais leves e mais eficientes, diminuindo a emissão de poluentes (Figura 1.1). Neste universo se destaca a utilização do Ferro Fundido Vermicular em substituição ao Ferro Fundido Cinzento. E junto a esta importante mudança no segmento, vêm junto novos desafios para se garantir a mesma qualidade no processo ou até melhorá-la, devendo-se destacar a minimização ou até eliminação das rebarbas formadas após os diversos processos de usinagem.

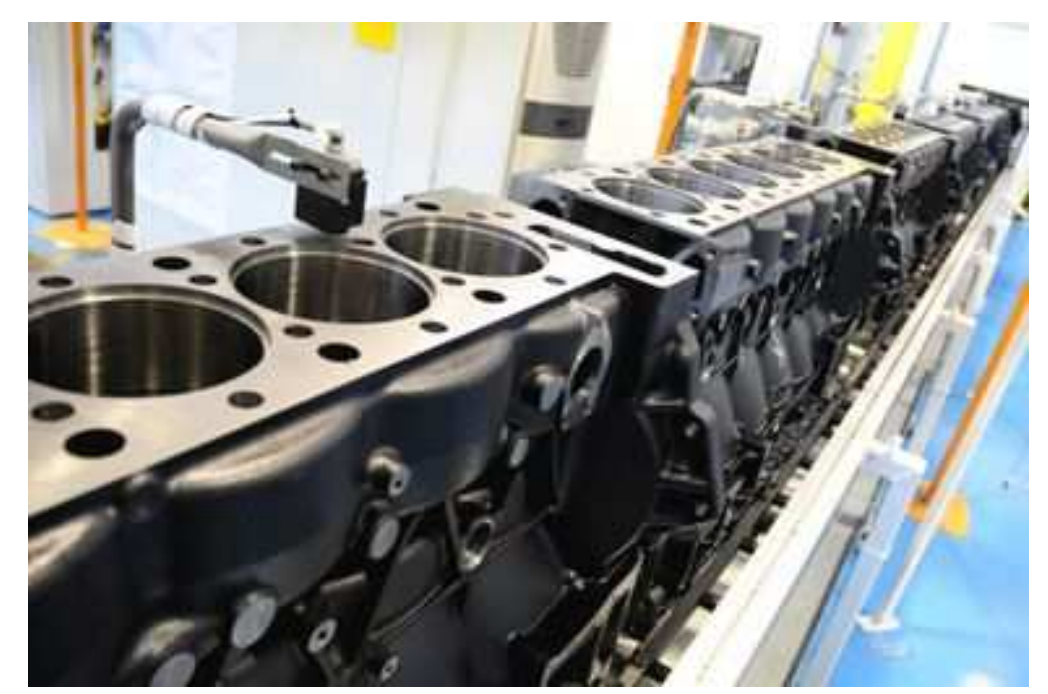

Figura 1.1 - Blocos de Motores em CGI produzidos na nova linha de usinagem da empresa MWM International, que atendem as novas especificações da norma Euro 5. 
Fornecedores da indústria automobilística muitas vezes consideram a rebarbação como uma operação sem importância ou secundária. Com isso os números referentes aos custos com processos de rebarbação, não estão facilmente disponíveis na literatura. No entanto, nos últimos anos algumas pesquisas foram apresentadas e publicadas. Os custos de rebarbação associados aos processos de usinagem de componentes automotivos podem contribuir significativamente para o custo total da usinagem. A porcentagem exata depende em grande medida das características específicas da peça em análise e da sua seqüência de fabricação. De acordo com Palman et al (2011) os custos com rebarbação da indústria automotiva podem variar entre $2 \%$ e $3 \%$ do custo total de produção de peças simples como bielas e mangas de eixo e entre $9 \%$ e $10 \%$ para peças complexas como blocos de motores (Figura 1.2).

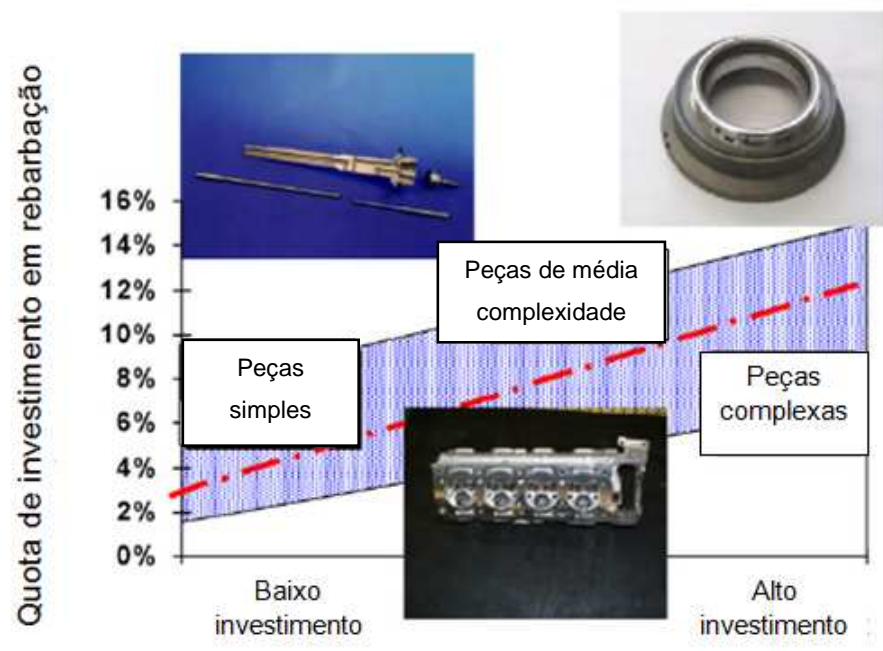

Figura 1.2 - Distribuição dos gastos no processo de rebarbação na indústria automotiva. (PALMAN, 2011)

Existem inúmeros métodos e processos de rebarbação para componentes da linha powertrain, como tamboreamento, através de jatos com partículas abrasivas ou rebarbação eletroquímica por exemplo. Mas as que se enquadram nas linhas de usinagem de blocos de motores, cabeçotes, carcaças de embreagem e de transmissão, concentram-se basicamente nos métodos mecânicos de escovação das faces usinadas em questão (BOGUE, 2009). Dependendo do investimento na 
linha de produção ou do tempo de ciclo do processo têm-se duas variantes principais destes métodos, podendo-se dedicar uma célula robotizada para manipular o bloco de motor até a unidade de rebarbação e o próprio robô escovar o bloco (Figura 1.3a), ou como no caso da Figura 1.3, onde a escovação da face do bloco de motor ocorre dentro do centro de usinagem, contemplando assim parte do tempo de ciclo do processo de usinagem.

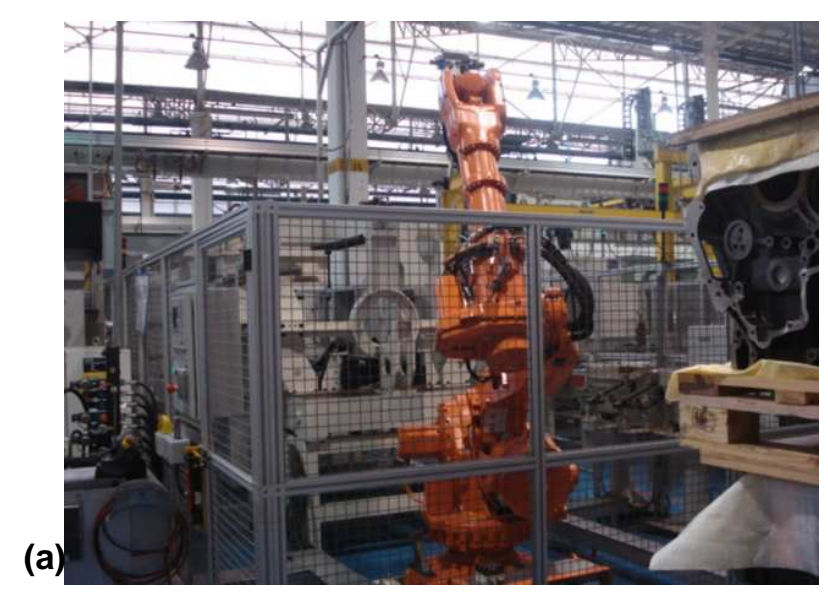

(b)

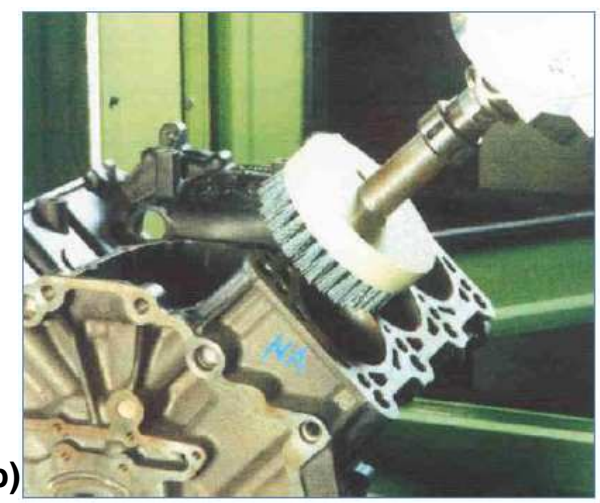

Figura 1.3 - (a) Célula robotizada de rebarbação de blocos de motores (Fonte: B. GROB 2012), (b) Escovação da face de fogo do bloco de motor no do ciclo de usinagem. (PALMAN et al 2011)

Dentre as principais desvantagens da célula robotizada, está o alto custo do investimento, que fica em torno de 3,5\% do custo do investimento total da linha de usinagem (Fonte: B. GROB do Brasil, 2012), e no caso de manutenção ou parada da célula, há a necessidade de se deslocar um operador para realizar a rebarbação manual, podendo gerar um gargalo no processo. Para o caso de acrescentar a escovação das faces do bloco de motor durante o processo de usinagem, tem-se como desvantagem o alto tempo demandado para esta operação, aproximadamente $50 \%$ do tempo dedicado ao fresamento da mesma face, sem contar o desgaste excessivo das cerdas da escova quando comparado com o desgaste das ferramentas de corte, gerando trocas constantes durante o processo.

Portanto este trabalho visa agregar mais conhecimento na usinagem do ferro fundido vermicular, especificamente no fresamento de faceamento, onde serão analisadas diferentes geometrias de ferramentas de corte e se verificará para a melhor condição a influência dos principais parâmetros de corte na formação das rebarbas, com o objetivo de minimizá-las. 


\subsection{ESTRUTURA DO TRABALHO}

O trabalho está estruturado em sete capítulos. Este primeiro capítulo apresenta uma breve explanação sobre o material em estudo e as pesquisas na área, assim como os fatores que justificam a pesquisa e os objetivos do trabalho.

Já o segundo capítulo apresenta a fundamentação teórica relacionada com pesquisas já realizadas no campo de estudo e necessárias para a interpretação dos resultados obtidos na presente pesquisa.

No terceiro capítulo apresentam-se os procedimentos experimentais, a metodologia, os equipamentos, os aparelhos de medição, ferramentas de corte e os materiais (geometrias e propriedades) utilizados nos ensaios. No quarto capítulo são apresentados os resultados obtidos nos ensaios realizados nas duas etapas deste trabalho, e as discussões dos mesmos. Serão confrontados os resultados para a análise de possíveis diferenças nas dimensões e tipos de rebarbas já encontradas na literatura.

O quinto capítulo aborda as conclusões obtidas nesta pesquisa, o sexto capítulo indica sugestões para trabalhos futuros, e o sétimo capítulo exibe a lista das referências utilizadas no trabalho.

Os Apêndices podem ser encontrados ao final no trabalho. 


\section{REVISÃO DA LITERATURA}

Apresentam-se neste capítulo assuntos capazes de proporcionar embasamento teórico e que serão explorados no restante do trabalho. O mesmo foi dividido em nove itens conforme descrito a seguir.

\subsection{BLOCOS DE MOTORES}

O bloco de motor é considerado o elemento estrutural mais importante e um dos mais complexos do motor de combustão interna. É nos cilindros, parte integrante de sua estrutura, que acontece a compressão e combustão da mistura arcombustível, necessária para a produção de energia pelo motor (BOFF, 2003). Por se tratar de um importante componente dos motores, o bloco do motor deve atender a características bastante rígidas de fabricação, para atingir assim todas as exigências de qualidade geométrica, dimensional e de superfície.

Localizado entre o cárter e o cabeçote, o bloco é uma peça fundida (Figura 2.1) na qual existem galerias e canais, relacionados ao sistema de lubrificação e arrefecimento. Contém também os cilindros onde trabalham os pistões, e os alojamentos para os tuchos e árvore de comando. É no bloco que estão acoplados quase todos os componentes do motor, e seu interior abriga o virabrequim, bielas e pistões. A função destes componentes é transformar a energia térmica gerada durante a combustão em energia mecânica, gerada com o deslocamento do pistão (devido ao aumento de pressão no cilindro). Este trabalho é transformado em torque útil pelo virabrequim e está disponível no eixo do motor. 


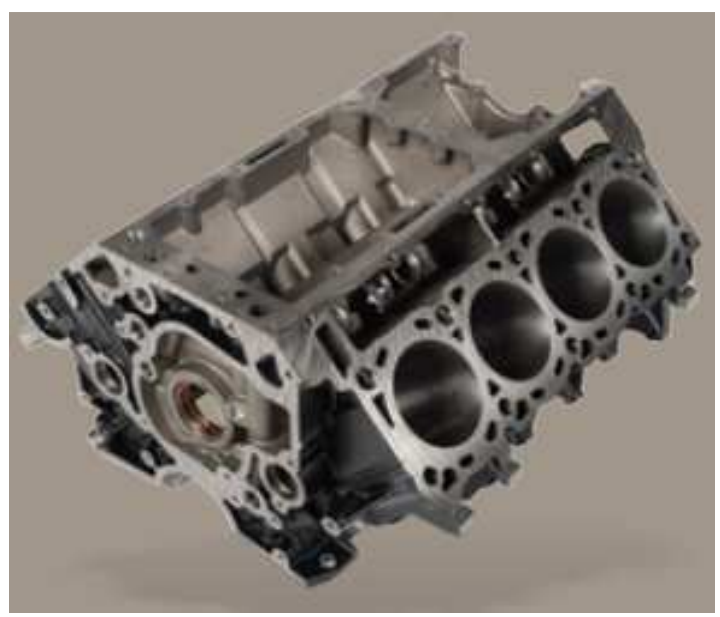

Figura 2.1 - Bloco de motor V-8 em Ferro Fundido Vermicular (REFERENCE GUIDE MWM, 2010)

Dentre as principais partes de um bloco de motor está à face de fogo ou face de combustão, conforme mostrada na Figura 2.2. Ela é a face de junção do bloco com o cabeçote. As juntas que são colocadas entre a face do fogo do bloco e do cabeçote, podem ser de cobre, alumínio ou papelão normalmente composto por folhas prensadas, cuja função é auxiliar na vedação. Estas juntas precisam resistir a altas temperaturas por um longo período de tempo e serem suficientemente elásticas para que possam compensar qualquer irregularidade das superfícies intermediadas (GABALDO, 2009).

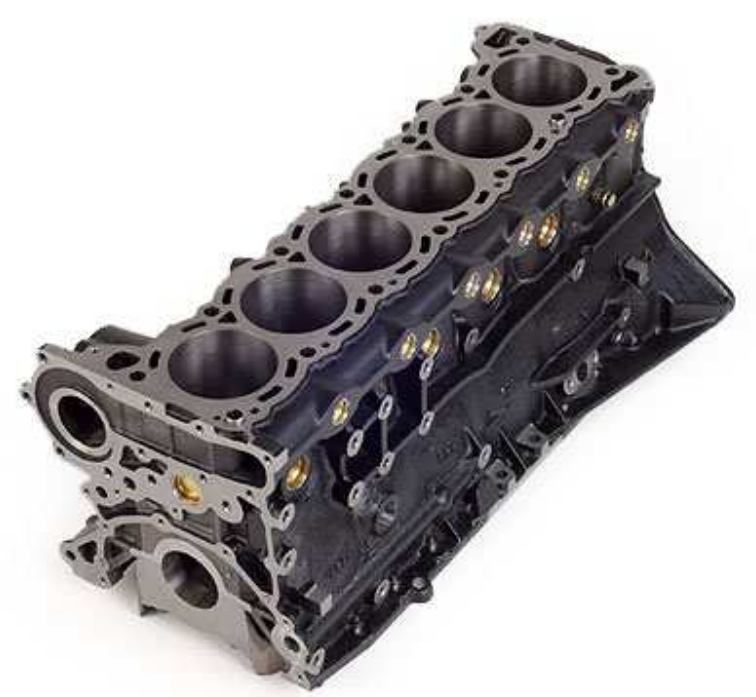

Figura 2.2 - Indicação da face de fogo em bloco de motor 6 cilindros em linha (REFERENCE GUIDE MWM, 2010) 
Frente à importância desta superfície nos blocos de motores e o grande desafio em se obter valores satisfatórios de tolerância de forma e posição após a usinagem, esta superfície do bloco será o objeto de estudo deste trabalho. Como mostra a Figura 2.2, sua usinagem apresenta uma dificuldade adicional que é o número de interrupções da superfície que geram choques entre ferramenta e peça.

\subsection{MATERIAIS PARA FABRICAÇÃO DOS BLOCOS DE MOTORES}

A necessidade de redução de consumo de combustível tem imposto uma pressão constante para a substituição de materiais em veículos, priorizando-se a utilização de materiais leves. O peso total dos veículos, entretanto, tem aumentado nos últimos anos, devido à incorporação de novos sistemas aos veículos, objetivando aumentar a segurança, o conforto e o desempenho (GUESSER, 2009). Este aumento de peso do veículo traduz-se em consumo de combustível crescente e conseqüentemente aumento na emissão de poluentes, o que aumenta a pressão sobre a substituição de materiais.

Para tanto existe a Euro 5, também conhecida como PROCONVE P7, que é uma evolução do PROCONVE (Programa de Controle da Poluição do Ar por Veículos Automotores), regulamentado pelo CONAMA (Conselho Nacional do Meio Ambiente), cujo principal objetivo é reduzir o nível de emissão de gases poluentes na atmosfera. No Brasil a norma Euro 5 é aplicável desde 1 de Setembro de 2009 no que diz respeito à homologação e desde de 1 de Janeiro de 2011 no que diz respeito à matrícula e venda de novos tipos de veículos. As principais metas do EURO 5 são: diminuir em cerca de $60 \%$ as emissões de Óxido de Nitrogênio (NOx) e em até $80 \%$ as emissões de partículas promovidas pelos atuais modelos com a tecnologia EURO 3 (CONAMA, 2002).

As recentes evoluções tecnológicas dos motores a diesel, tanto em desempenho quanto na redução da emissão de poluentes, são resultantes de maiores pressões e temperaturas de trabalho (WEBER, 2011), fazendo com que 0 bloco do motor sofra maiores solicitações mecânicas, conforme ilustra a Tabela 2.1. 
Tabela 2.1 - Relação dos picos de pressão de combustão com a emissão de poluentes avaliados para motores Diesel (SHÖNFELD, 2003)

\begin{tabular}{|c||c|c|}
\hline Norma de Emissão & Euro 3 & Euro 5 \\
\hline $\begin{array}{c}\text { Entrada em vigor } \\
\text { (na Europa) }\end{array}$ & 2002 & 2008 \\
\hline $\begin{array}{c}\text { Nível de Pressão de } \\
\text { Combustão exigido } \\
\text { [bar] }\end{array}$ & 150 & $>200$ \\
\hline \hline $\begin{array}{c}\text { Limites: } \\
\text { Partículas [g/kWh] }\end{array}$ & 0,1 & 0,02 \\
\hline NOx [g/kWh] & $---\ldots$ & 2 \\
\hline
\end{tabular}

Segundo Boff (2003) as principais características desejáveis a um material para a fabricação de um bloco de motor são:

- Elevada resistência mecânica;

- Boa condutividade térmica;

- Tenacidade;

- Ductilidade;

- Capacidade de amortecimento de vibrações.

Os candidatos a materiais para blocos de motores diesel são o ferro fundido cinzento classe FC 250, ligas de alumínio e o ferro fundido vermicular classes FV 400 e FV 450 (GUESSER, 2009). Na Figura 2.3 são comparados graficamente as propriedades de ferro fundido cinzento FC 250, ferro fundido vermicular FV 400 e uma liga de alumínio AISi9Cu. Pode-se verificar a vantagem térmica e de peso da liga de alumínio, enquanto o ferro fundido vermicular supera tanto o ferro fundido cinzento quanto a liga de alumínio no que diz respeito à resistência mecânica. 


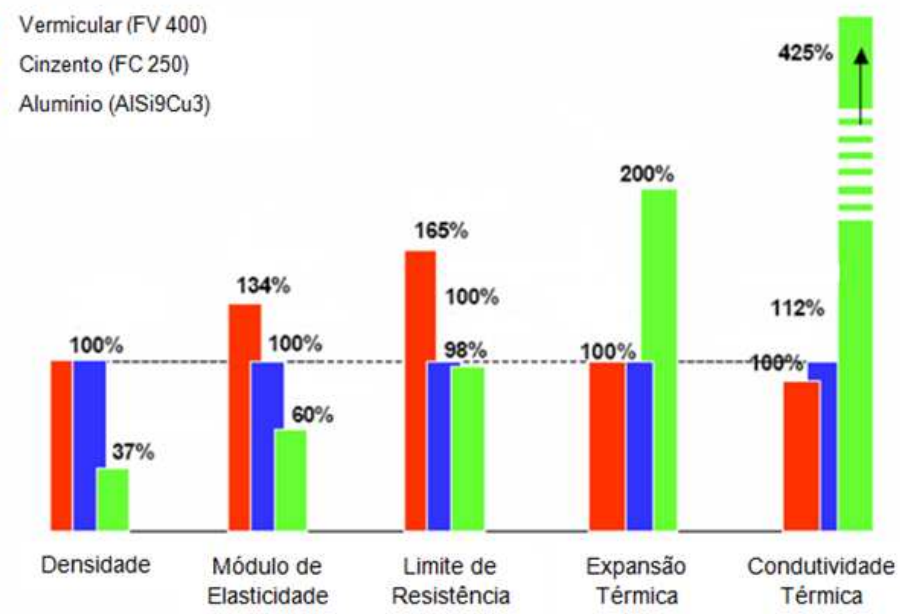

Figura 2.3 - Comparação de propriedades de materiais para blocos de motores: FC 250, FV 400, AISi9Cu3 (GUESSER, 2009).

O crescimento da utilização de motores diesel vem acompanhado de exigências de cada vez maiores de redução de consumo de combustível, redução de emissões, aumento de potência e torque, sempre acompanhando as revisões das normas regulamentadoras (Figura 2.4). E o aumento da eficiência do motor e de sua densidade de potência têm sido obtidos com o aumento da pressão de combustão. Em motores diesel, pressões de combustão acima de 180 bar ou ainda até de 200 bar podem ser esperadas em motores de automóveis, enquanto em motores para caminhões e ônibus são antecipadas pressões máximas em torno de 200 bar ou ainda até 250 bar (GUESSER, 2009).

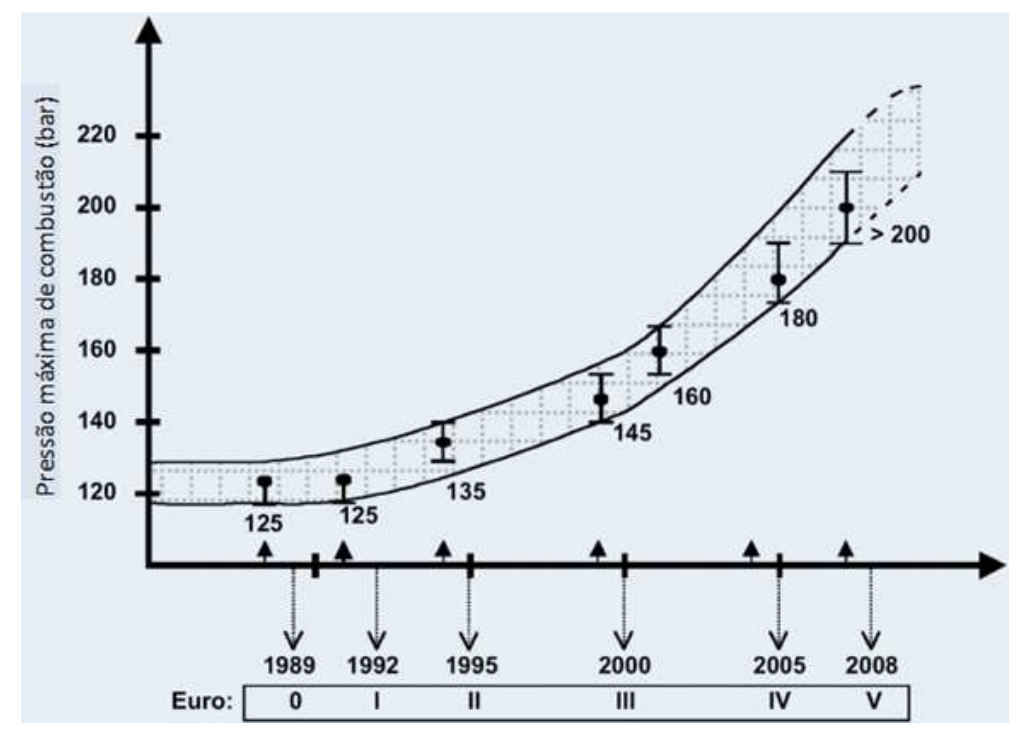

Figura 2.4. Para atender as exigências de emissões, a máxima pressão de combustão, em motores diesel, deve ultrapassar 200 bar, de acordo com a MAN (SHÖNFELD, 2003) 
Entretanto, com o aumento da pressão de combustão em motores diesel, as ligas de alumínio vêm encontrando dificuldades para manter sua posição, sendo as suas pressões de combustão limitadas em 170 bar para motores em linha e 150 bar para motores em V (WEBER, 2011). Devido a esta necessidade na redução do consumo de combustível e produção de altas potências específicas por litro, os desenvolvimentos nos novos blocos de motores diesel serão realizados predominantemente em ferro fundido, devido às características específicas deste material, conforme pode-se verificar na Figura 2.5.

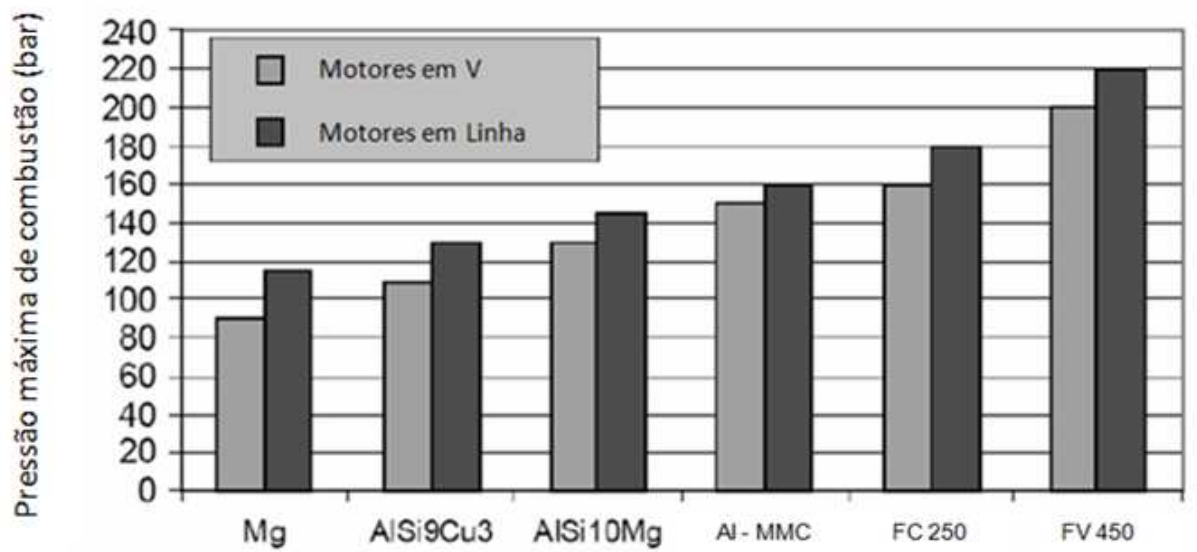

Figura 2.5 - Limite de máxima pressão de explosão suportadas por blocos de motores Diesel, para vários tipos de materiais. (GUESSER, 2009)

Neste contexto o ferro fundido vermicular vem encontrando aplicação crescente em blocos de motores diesel, permitindo o aumento da pressão de combustão e reduzindo-se assim as emissões. A classe FV 450 é selecionada na maioria dos novos projetos (GUESSER, 2009).

\section{$2.3 \quad$ FERROS FUNDIDOS}

Considera-se ferro fundido a liga ferrosa com teor de carbono acima de, aproximadamente, $2 \%$. Face à influência do silício nesta liga, o ferro fundido é normalmente considerado uma liga ternária $\mathrm{Fe}-\mathrm{C}-\mathrm{Si}$, pois o silício está freqüentemente presente em teores superiores ao do próprio carbono (GUESSER, 2009). 
De acordo com Guesser (2002), os ferros fundidos são classificados em diferentes famílias principalmente de acordo com a forma da grafita. O nome de cada família às vezes reflete a forma da grafita (nodular, vermicular), outras vezes tem relação com o aspecto da fratura (cinzento, branco) ou com alguma propriedade mecânica relevante (maleável). Assim as principais famílias de ferros fundidos são:

- Ferro fundido cinzento;

- Ferro fundido nodular;

- Ferro fundido maleável;

- Ferro fundido vermicular;

- Ferro fundido branco.

O ferro fundido é um dos materiais mais tradicionais aplicados na indústria automobilística e tem sido objeto de estudo em várias pesquisas tanto no desenvolvimento das suas propriedades quanto nos processos de fabricação. A necessidade de desenvolver motores com melhor desempenho que suportem elevadas pressões com um menor nível de emissão de poluentes gerou uma busca contínua por melhorias das propriedades deste material como resistência mecânica, tenacidade, condutividade térmica, capacidade de amortecimento de vibrações associadas a uma boa usinabilidade (DAWSON, 2002). Será discutido a seguir um pouco sobre as famílias de ferros fundidos mais aplicados na indústria automobilística.

Os ferros fundidos cinzentos (Figura 2.6a) apresentam grafita em forma de veios. A matriz pode ser ferrítica ou mais comumente perlítica. Conforme Guesser, 2009, os ferros fundidos cinzentos cobrem uma faixa de limite de resistência de 100 a $400 \mathrm{MPa}$ (mais comumente de 150 a $300 \mathrm{MPa}$ ), sendo que o alongamento por ser muito pequeno não é especificado. A grafita em forma de veios fornece ainda bons valores de condutividade térmica e amortecimento de vibrações, o que o torna um material muito empregado para componentes automotivos como tambores e discos de freio, cabeçotes e blocos de motores.

Os ferros fundidos nodulares (Figura 2.6b) apresentam a grafita em forma de nódulos, de modo que a ductilidade é uma propriedade importante deste material. Segundo Guesser (2009), ferros nodulares com matriz ferrítica possuem valores de limite de resistência entre 380 e $450 \mathrm{MPa}$, associados a valores de alongamento de 
10-22\%, enquanto em nodulares de matriz perlítica o limite de resistência pode atingir até $900 \mathrm{MPa}$, com valores de alongamento de $2 \%$. Aplicações típicas do ferro fundido nodular em componentes automotivos incluem virabrequins, eixos comandos de válvulas, cálipers, suportes de freio e coletores de exaustão.

O ferro fundido vermicular (Figura 2.6c) com suas propriedades mecânicas intermediárias às do ferro fundido cinzento e do nodular, tem sido especificado e aplicado fundamentalmente para a fabricação de blocos de motores diesel. $\mathrm{Na}$ construção dos blocos de motores a diesel, o ferro fundido vermicular tem se mostrado a melhor opção técnica da atualidade, pois, nesta aplicação, o material está sujeito a carregamentos térmicos e mecânicos simultaneamente, situação essa amplamente favorável a ele em relação ao ferro fundido cinzento e nodular (GUESSER, 2009).

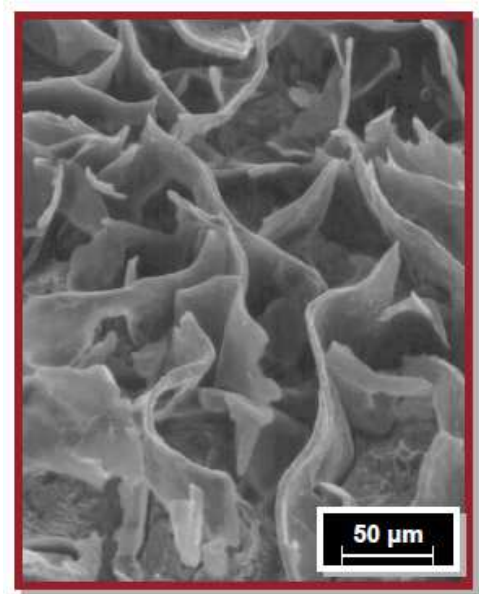

(a)

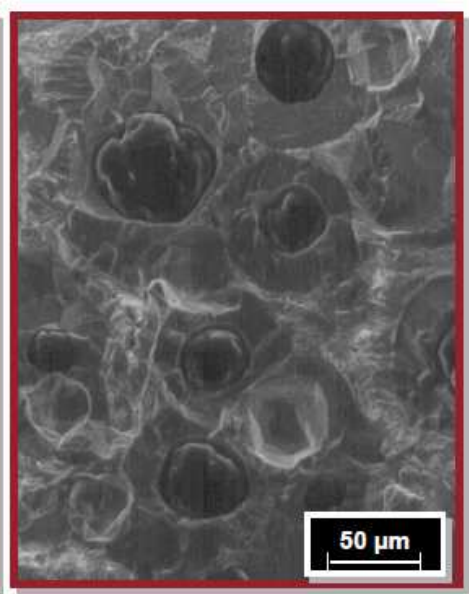

(b)

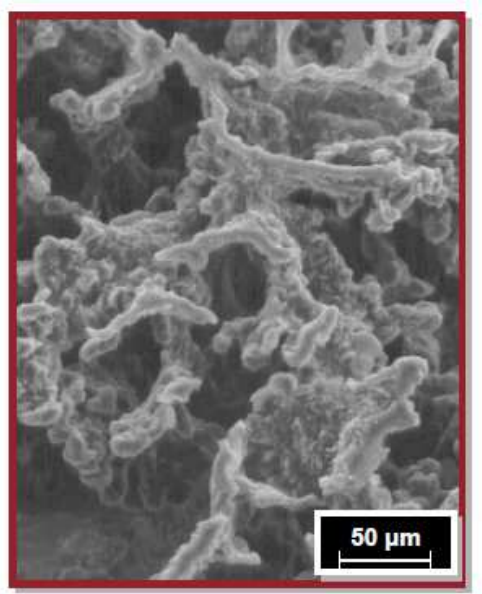

(c)

Figura 2.6 - Morfologia da grafita em ferros fundidos a) cinzento, b) nodular e c) vermicular (GUESSER, 2002)

\subsection{FERRO FUNDIDO VERMICULAR}

O ferro fundido vermicular ou CGI, do inglês Compacted Graphite Iron, é conhecido desde a década de 40 , porém a sua utilização em escala industrial teve início na década de 90, quando a empresa SinterCast passou a comercializar a tecnologia e os equipamentos necessários para romper a principal barreira para sua 
utilização na indústria: a falta de um processo confiável de controle aplicável a uma produção em larga escala (XAVIER, 2003).

A conjunção de boas características de resistência mecânica, resistência a choques térmicos, condutividade térmica, amortecimento, tenacidade e ductilidade atribui ao ferro fundido vermicular uma grande importância para aplicação industrial (DAWSON, 2009). As propriedades mecânicas do vermicular são superiores e possibilitam a fabricação de motores mais potentes, com o mesmo tamanho ou mais compactos, que atingem a mesma potência (MIURA, 2011). Outro fator que contribui para o desenvolvimento do CGI são as rígidas normas européias de controle de poluição atmosférica. A combustão mais eficiente é uma característica dos blocos de motores fabricados com esse material. Para cumprir as exigências dessas normas usando alumínio ou ferro fundido cinzento, seria necessário aumentar a espessura das paredes dos blocos de motores, o que acarretaria em problemas com o sistema de resfriamento, além de aumentar o volume e peso do bloco.

\subsubsection{Métodos de obtenção do ferro fundido vermicular}

Conforme Doré (2007) vários métodos foram pesquisados para garantir a obtenção do vermicular, mas apenas dois tiveram resultados positivos e são utilizados para a produção em escala industrial:

- Tratamento da liga com elementos nodularizantes (magnésio) e antinodularizantes (titânio);

- Tratamento da liga com quantidades controladas de elementos que promovem a nodularização da grafita, como o magnésio.

O primeiro processo desenvolvido para obtenção do CGI utiliza o magnésio como elemento de liga e adiciona o titânio como elemento anti-nodularizante. Enquanto o magnésio impede o crescimento da grafita lamelar o titânio suprime a formação de grafita nodular, entretanto este processo resulta na formação de carbonetos de titânio que prejudicam a usinabilidade do material. O segundo método não adiciona o titânio e trata de um controle rigoroso da solidificação da liga na qual o magnésio é adicionado em uma quantidade insuficiente para formar a grafita 
nodular. Este processo exige a habilidade de medir o comportamento do metal líquido após a adição do magnésio e interferir no processo antes do vazamento (GEIER et al, 2011).

O processo empregado pela empresa Tupy Fundições, é baseado na análise térmica durante a solidificação da liga após o tratamento inicial com magnésio. A adição inicial de $\mathrm{Mg}$ é intencionalmente baixa, de maneira que a análise térmica sempre determine a quantidade adicional de tratamento necessária para chegar à formação da grafita vermicular, grafita esta que pode ser vista na Figura 2.7.

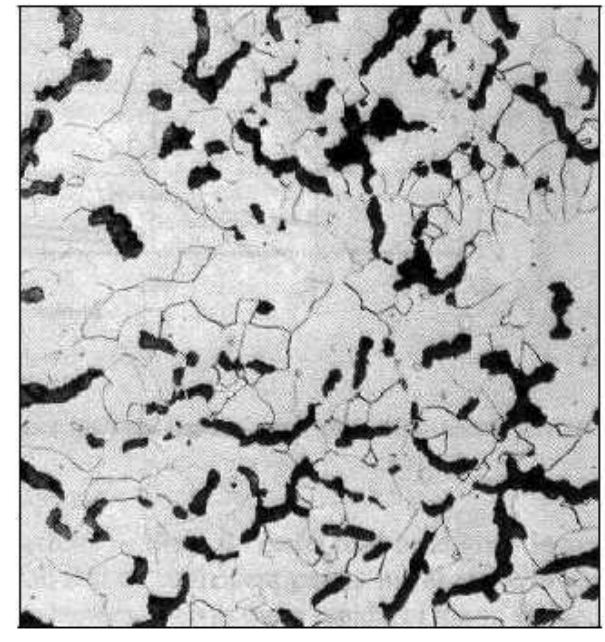

(a)

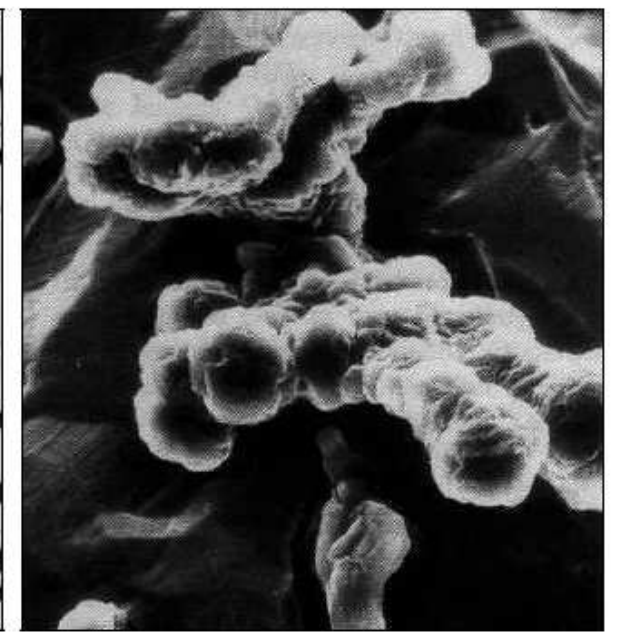

(b)

Figura 2.7 - Micrografia do ferro fundido vermicular. (a) Micrografia óptica atacada com Nital. (b) Forma espacial da grafita vermicular. MEV 395x (DAWSON, 2002).

\subsubsection{Propriedades físicas e mecânicas do ferro fundido vermicular}

O ferro fundido vermicular típico, do ponto de vista da faixa de composição química, não apresenta nenhuma diferença significativa do ferro fundido cinzento e nodular, cada um contém aproximadamente $94 \%$ de ferro ( $\mathrm{Fe}$ ), $3 \%$ de carbono (C), 2,5\% de silício ( $\mathrm{Si}$ ) e o restante está dividido entre elementos de liga e elementos residuais (XAVIER, 2003). A diferença entre as propriedades mecânicas dos três principais tipos de ferros fundidos, como pode ser visto na Tabela 2.2 ocorre principalmente em razão da diferença na morfologia da grafita (GUESSER, 2009). 
Tabela 2.2 - Propriedades mecânicas e físicas do ferro fundido vermicular comparado com o cinzento e nodular (GUESSER, 2009).

\begin{tabular}{|l|c|c|c|}
\hline \multicolumn{1}{|c|}{ Propriedade } & Cinzento & Vermicular & Nodular \\
\hline \hline Módulo de Elasticidade [GPa] & 110 & 140 & 165 \\
\hline Resistência à tração [MPa] & 235 & 500 & 650 \\
\hline Resistência à fadiga [MPa] & 100 & 205 & 265 \\
\hline Condutividade térmica [W/mK] & 48 & 35 & 28 \\
\hline Dureza [HB] & 200 & 225 & 270 \\
\hline Limite de escoamento 0,2\% & 160 & 380 & 425 \\
\hline
\end{tabular}

Com relação ao ferro fundido cinzento, o ferro fundido vermicular oferece as seguintes vantagens (DAWSON, 2002):

- Redução de espessuras de parede para um mesmo carregamento;

- Redução do fator de segurança devido à menor variação das propriedades do fundido;

- Redução de fraturas frágeis na manufatura, montagem e serviço, devido à maior ductilidade;

- Maior resistência, sem a necessidade de recorrer a elementos de liga;

- Menor profundidade de rosca necessária, portanto, parafusos menores podem ser utilizados.

Ainda segundo Dawson (2002), quando comparado ao ferro fundido nodular, as vantagens são:

- Melhor produção de peças complexas fundidas;

- Redução nas tensões residuais, devido à maior condutividade térmica e ao módulo de elasticidade menor;

- Melhor transferência de calor;

- Melhor usinabilidade. 


\subsection{USINABILIDADE DO FERRO FUNDIDO VERMICULAR}

Conforme Diniz, Marcondes e Coppini (2010), a usinabilidade pode ser definida como uma grandeza tecnológica que expressa, por meio de um numérico comparativo (índice de usinabilidade), um conjunto de propriedades de usinagem de um material em relação a outro tomado como padrão. Portanto entende-se usinabilidade como o grau de dificuldade de se usinar um determinado material. As propriedades de usinagem de um material são aquelas que expressam seu efeito sobre grandezas mensuráveis inerentes ao processo, tais como vida da ferramenta, acabamento superficial da peça, esforços de corte, temperatura de corte, produtividade, característica do cavaco e formação de rebarbas (MIURA, 2011).

O estudo da usinabilidade, como propriedade tecnológica do material, é de enorme significado econômico, pois se relaciona não apenas com o custo da ferramenta de corte, mas também com a produtividade de toda uma linha de usinagem, usualmente de investimento bastante alto. Estudos apresentados por Gabaldo (2009) mostram que as diferenças básicas entre a usinabilidade do CGI e do ferro fundido cinzento nos processos de usinagem são:

- A usinagem do CGI gera forças de corte de corte $20 \%$ maiores;

- O CGI é mais abrasivo, mesmo com a mesma dureza que o ferro fundido cinzento;

- Na usinagem do CGI há um ligeiro aumento das temperaturas de corte;

- Devido à maior ductilidade do CGI quando comparado com o ferro fundido cinzento, há um maior contato entre cavaco e superfície de saída da ferramenta;

- As melhores vidas das ferramentas de corte na usinagem do CGI são encontradas na usinagem com pastilhas de metal duro, tanto em operações de torneamento, quanto em fresamento;

- O cavaco de CGI tem maior tendência à adesão que os cavacos de ferro fundido cinzento;

- Na usinagem de CGI em alta velocidade há uma forte tendência a desgaste por craterização. 


\subsection{O PROCESSO DE FRESAMENTO}

É um processo de usinagem convencional capaz de gerar diversas superfícies utilizando uma ferramenta multicortante denominada por fresa ou porta ferramenta. Devido à rotação desta ferramenta, cada aresta de corte tem a função de remover uma certa quantidade de material em forma de cavaco.

Segundo Diniz, Marcondes e Coppini 2010 as principais diferenças, entre o fresamento e outros processos de usinagem são:

- A interrupção no corte que ocorre, com o corte alternado do dente da fresa, entrando e saindo da peça. Durante um giro a fresa apresenta dois ciclos característicos: ativo e inativo;

- Os pequenos tamanhos de cavacos que são removidos por cada dente da fresa;

- A variação da espessura do cavaco, durante o corte do material para cada dente da fresa, porque o avanço é medido em direção a mesa de movimento da fresadora (a peça movimenta em direção ao corte), enquanto a espessura do cavaco é medida ao longo do raio do corte.

Muitas operações de fresamento ainda são realizadas em fresadoras convencionais, mas com a modernização dos parques de máquinas, a evolução tecnológica e as exigências cada vez maiores de aumento de produtividade nas empresas, as operações de fresamento são realizadas cada vez mais em Centros de Usinagem, podendo ter até 5 eixos, onde é possível o fresamento em múltiplas direções e sentidos. Utilizando-se dos recursos avançados dos programas CNCs e da capacidade das máquinas, tem-se a flexibilidade de fresar por interpolação, com altíssimas velocidades de corte e avanços, garantindo-se assim a alta produtividade vinculada a confiabilidade do processo.

Existem três tipos de fresamento que são: Frontal, Tangencial e de Topo. No fresamento frontal e de topo, as arestas cortantes da ferramenta, são montados na superfície frontal da fresa (porta ferramenta), e o eixo da fresa é perpendicular à superfície a ser usinada. No fresamento tangencial, as arestas cortantes da ferramenta encontram-se na superfície cilíndrica da fresa e o seu eixo em um plano 
paralelo à superfície a ser usinada. A Figura 2.8 mostra o fresamento frontal (a), o fresamento tangencial (b) e o fresamento de topo (c).

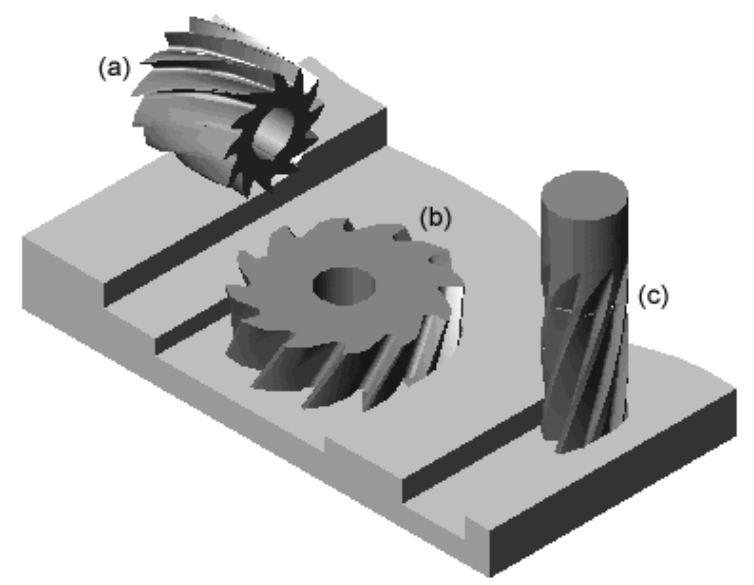

Figura 2.8 - A ferramenta (a) é uma fresa cilíndrica tangencial, a (b) é uma fresa cilíndrico-frontal e a (c) é uma fresa de topo com haste cilíndrica (ASM, 1997).

Os conceitos relativos à geometria da parte de corte das ferramentas estão contidos na norma brasileira ABNT NB-205 (registrada no INMETRO como NBR 6163), baseada na norma DIN 6581. A parte do corte é a parte ativa de uma ferramenta, onde encontram-se as cunhas de corte com as respectivas arestas de corte. A parte de corte é formada pelas superfícies de saída e folga. A cunha de corte é formada pelas superfícies de saída e principal de folga (Figura 2.9a). A intersecção entre as superfícies de saída e principal de folga forma a chamada aresta principal de corte $S$, e a intersecção das superfícies de saída e secundária de folga forma a aresta secundária de corte S', conforme ilustra a Figura 2.9b.

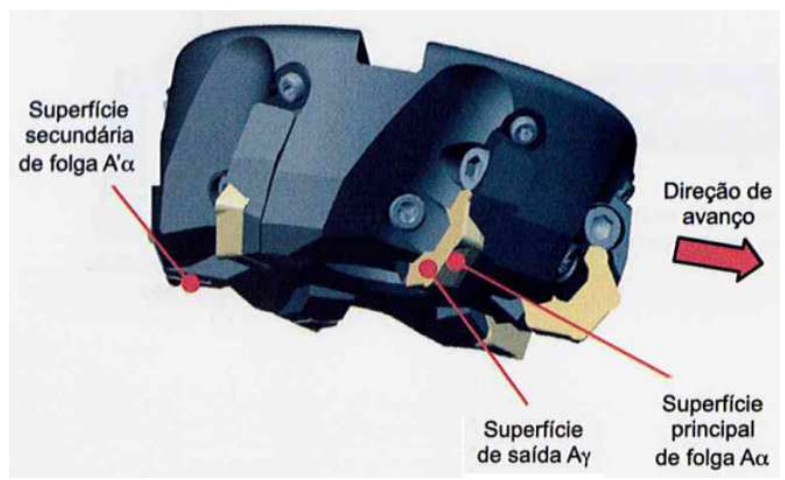

(a)

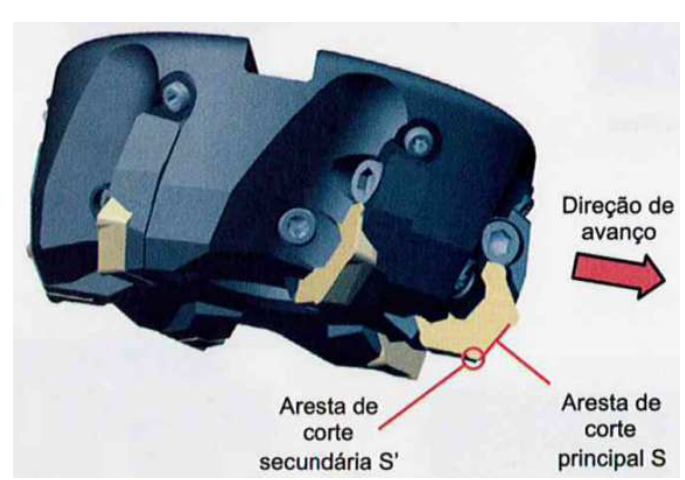

(b)

Figura 2.9- (a) Parte de corte de uma fresa, (b) Indicação das arestas de corte da fresa (CATÁLOGO SECO TOOLS, 2009) 
Os modernos cabeçotes para fresamento com pastilhas intercambiáveis apresentam uma geometria de corte combinada. Denomina-se geometria combinada porque a mesma resulta do somatório da geometria de corte da pastilha com a geometria de corte do cabeçote. No fresamento, os ângulos que mais influenciam os resultados práticos são: Ângulo de saída axial $\left(\gamma_{\mathrm{p}}\right)$, o ângulo de saída radial $\left(\gamma_{\mathrm{f}}\right)$ e o ângulo de posição ou ângulo de ataque $\left(\chi_{r}\right)$, conforme mostrado na Figura 2.10. $O$ ângulo resultante dos ângulos de saída axial e radial é o ângulo de saída efetivo $\left(\gamma_{0}\right)$.

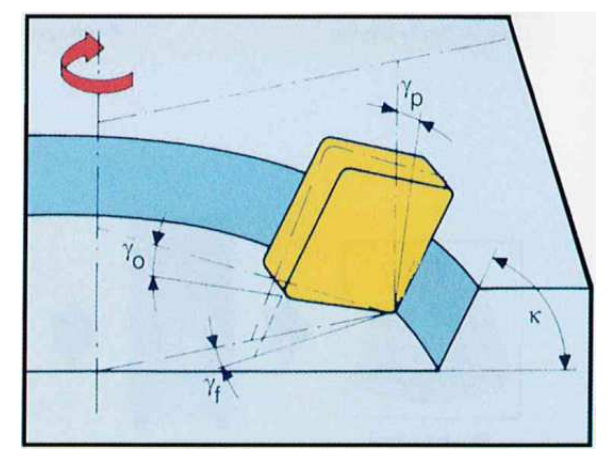

Figura 2.10 - Ângulos de maior influência prática no fresamento (ABNT - NBR-6162, 1989 )

A composição dos ângulos de saída axial e radial identifica as geometrias mais usuais para as ferramentas de fresar. A geometria composta por um ângulo de saída axial negativo e um ângulo de saída radial negativo caracteriza uma geometria duplo negativa, (Figura 2.11). Geometria recomendada para operações em materiais duros, materiais que produzem cavacos de ruptura ou aplicações onde existam exigências de elevada resistência a choques mecânicos. Como principais desvantagens possuem elevada exigência de potência da máquina, tendência a vibração e dificuldade na eliminação de cavacos longos.

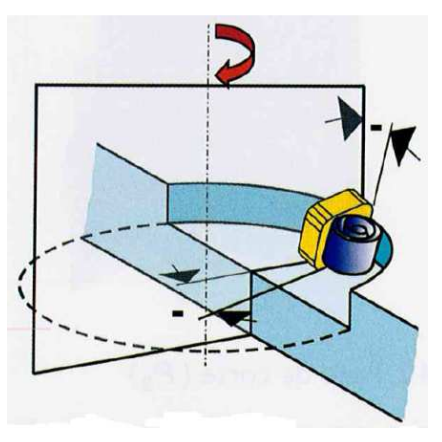

(a)

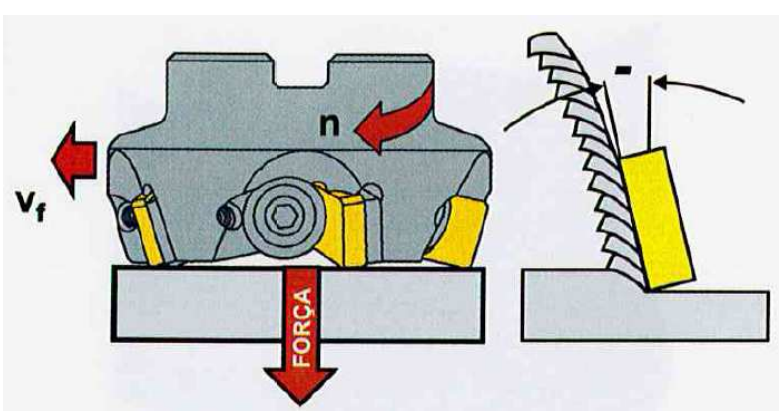

(b)

Figura 2.11 - (a) Representação da geometria duplo-negativa, (b) Esquema do esforço e fluxo de cavacos (CATÁLOGO SECO TOOLS, 2009) 
A geometria composta por um ângulo de saída axial positivo e um ângulo de saída radial positivo caracteriza uma geometria duplo positiva, (Figura 2.12). Indicada principalmente para a usinagem de materiais homogêneos com tendência a aderência e materiais dúcteis em geral. Exige baixo consumo de potência, e favorece o escoamento de cavacos. Como principal desvantagem possui maior exposição das arestas de corte, favorecendo o lascamento da aresta em operações mais severas.

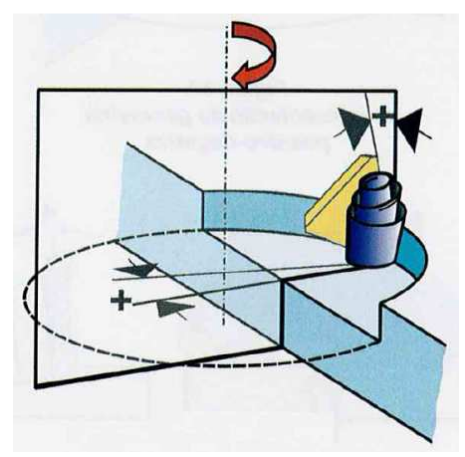

(a)

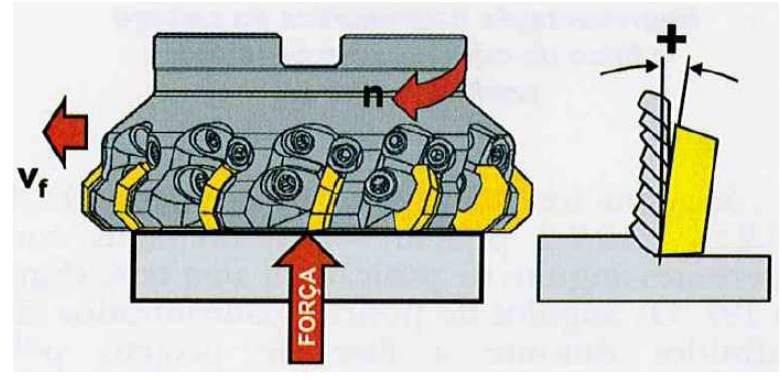

(b)

Figura 2.12 - Representação da geometria duplo-positiva, (b) Esquema do esforço e fluxo de cavacos (CATÁLOGO SECO TOOLS, 2009)

A geometria composta por um ângulo de saída axial positivo e um ângulo de saída radial negativo caracteriza a geometria positiva-negativa, (Figura 2.13). Geometria esta recomendada para aplicações gerais para todos os tipos de materiais em operações de desbaste e acabamento. Apresenta o melhor fluxo de cavacos dentre todas as geometrias e um baixo consumo de potência quando comparada com a geometria duplo negativa.

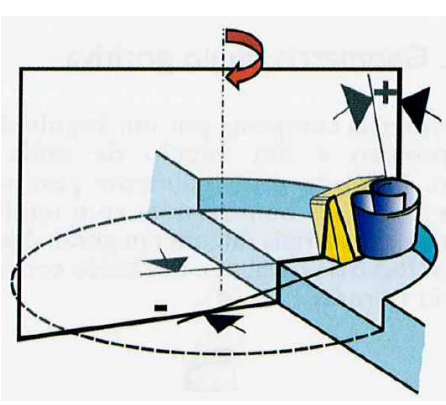

(a)
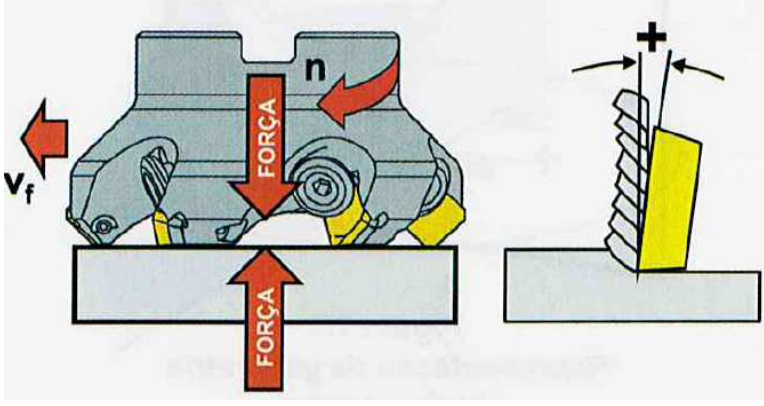

(b)

Figura 2.13 - Representação da geometria positiva-negativa, (b) Esquema do esforço e fluxo de cavacos (CATÁLOGO SECO TOOLS, 2009) 
O ângulo de posição ou ângulo de ataque $\left(\chi_{r}\right)$ é formado entre o plano de corte $\left(P_{s}\right)$, plano este tangente à aresta de corte, e o plano admitido de trabalho $\left(P_{f}\right)$, medido no plano de referência $\left(P_{r}\right)$, plano este perpendicular a direção de corte, conforme ilustra a Figura 2.14.
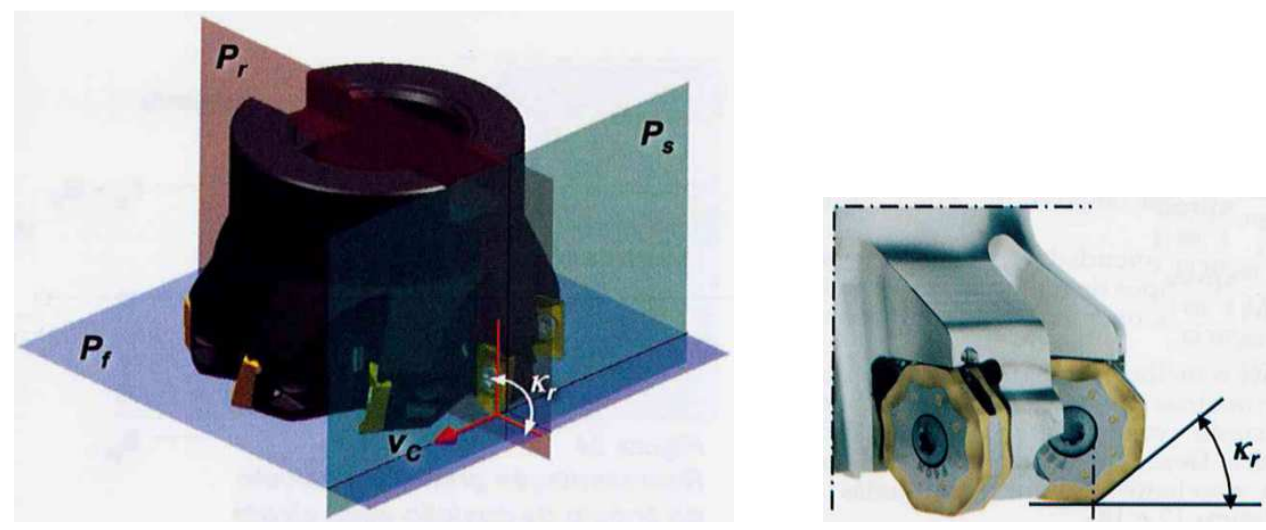

Figura 2.14 - (a) Definição do ângulo de posição através dos planos de referência (b) exemplo de aplicação do ângulo de posição (CATÁLOGO SECO TOOLS, 2009)

O ângulo de posição apresenta uma grande influência sobre a direção e amplitude dos esforços de corte, pois afeta diretamente a área da seção de corte, (Figura 2.15).

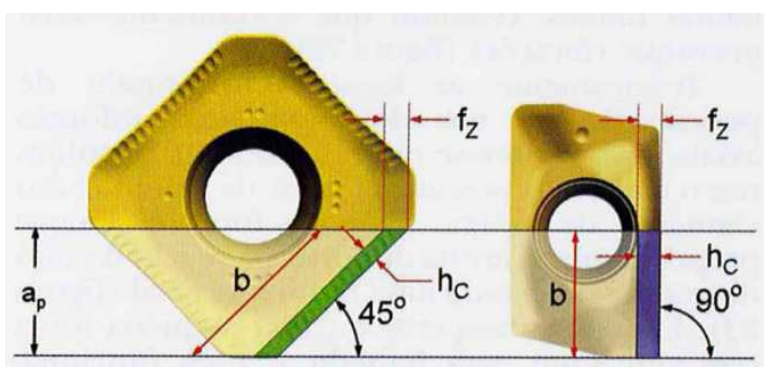

Figura 2.15 - Influência do ângulo de posição sobre a largura e espessura do cavaco (CATÁLOGO SECO TOOLS, 2009)

A área da seção de corte é o produto entre a largura de corte (b) e a espessura de corte $\left(h_{c}\right)$. A espessura média de corte $\left(h_{c m}\right)$ e a espessura máxima ( $h_{\text {cmáx }}$ ) são duas importantes grandezas que devem ser consideradas no processo de fresamento. Sendo importantes respectivamente para se determinar a força de corte e a limitação da ferramenta em determinada operação. A espessura de corte é a espessura máxima na direção radial que uma aresta de corte encontra durante a 
usinagem, e esta varia de acordo com a disposição da fresa em relação à peça, ou seja, em relação ao ângulo de posição $\chi_{\mathrm{r}}$.

A fresa com $\chi_{r}=90^{\circ}$, ou fresa para esquadrejar, geralmente é uti lizada somente quando é desejado fresar um rebaixo com paredes em esquadro (90\%), ou então quando não se deseja pressões axiais sobre a peça usinada. Não sendo necessária esta operação, é aconselhável usar uma fresa com um ângulo de posição menor (MACHADO et al, 2009). Segundo Machado et al (2009) as principais desvantagens de se usar uma fresa com ângulo de posição $\left(\chi_{r}\right)$ igual a $90^{\circ}$, são:

- A espessura do cavaco para um dado avanço está na medida máxima e, portanto, significa a máxima pressão contra a aresta;

- A saída dos cavacos se torna mais difícil;

- A grande força radial em relação à pequena força axial resulta num esforço desfavorável do fuso da fresadora, significando maior tendência a vibrações. $O$ fuso de uma fresadora tem a sua maior resistência em sentido axial;

- As pontas das arestas cortantes são mais fracas do que as pontas com ângulos de posição menores.

Fresas com $\chi_{r}=45^{\circ}$, em comparação com fresas de ângulo de posição maior, para uma mesma profundidade de corte, mantém um maior comprimento da aresta em contato com o material que está sendo usinado, distribuindo melhor o corte e a carga de cavacos ao longo da aresta principal (Figura 2.9). O ângulo de $45^{\circ}$ proporciona um excelente fluxo de cavaco para $m$ ateriais de cavacos longos, baixa força radial e uma aresta muito reforçada, a qual se adapta bem a usinagem da maioria dos diferentes tipos de materiais. É vantajoso no fresamento do ferro fundido, onde é necessário evitar o lascamento, danificando a superfície usinada, (MACHADO et. al, 2009). A desvantagem de se utilizar fresas com $\chi_{r}=45^{\circ}$ é que esta eleva o consumo de potência, mas isto pode ser facilmente resolvido com a seleção de um ângulo de saída adequado. O ângulo de posição de $45^{\circ}$ garante à fresa o balanceamento das forças axial e radial, tornando-se adequada para uma grande variedades de aplicações, em especial para aquelas que envolvem problemas específicos como os de vibrações causadas por excesso de balanço da ferramenta. 
No fresamento o corte pode ser por fresamento discordante ou concordante. Eles podem ser diferenciados pelo movimento de avanço da peça em relação ao sentido da velocidade de corte.

Durante o método de fresamento concordante a aresta inicia o corte repentinamente a partir de uma espessura de cavaco máxima, que vai diminuindo até chegar a uma espessura de corte igual a zero (Figura 2.16a). O fresamento concordante exige que duas importantes condições sejam satisfeitas. $\mathrm{O}$ avanço da mesa deve ser totalmente isento de qualquer folga. Deverá ter uma relação entre a quantidade de arestas e profundidade de penetração, de maneira que sempre haja no mínimo 2 (duas) arestas simultaneamente cortando, para se evitar vibrações e avarias aleatórias às pastilhas.

No método de fresamento discordante a aresta inicia o corte a partir de uma espessura zero, que vai aumentando até atingir uma espessura máxima (Figura 2.16b). Antes que a aresta efetivamente inicie o corte, ela tenderá a escorregar pelo material com uma certa pressão. Devido a esta pressão, tanto a peça quanto a ferramenta têm a tendência de se afastar. A distância pela qual a aresta escorrega, antes de iniciar o corte é resultado das propriedades da peça, da fixação e da rigidez da máquina. Este fenômeno de escorregamento gera um desgaste maior na ferramenta do que o próprio corte, e interfere, também, diretamente nos erros de forma da peça (MACHADO et al, 2009).

Durante o corte de seções muito delgadas, o fresamento discordante poderá tornar a entrada suficientemente suave, gerando um efeito de estabilização na operação, que proporcionará redução nos níveis de vibração. Quando não se observa qualquer problema de estabilidade, o fresamento concordante deverá ser utilizado como forma de redução dos desgastes tanto da ferramenta de corte quanto da máquina. 


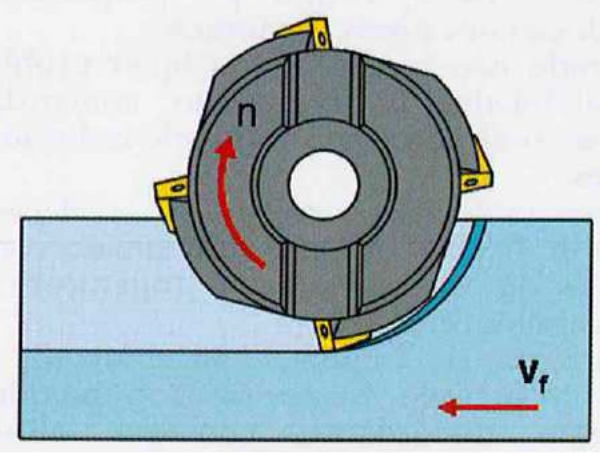

(a)

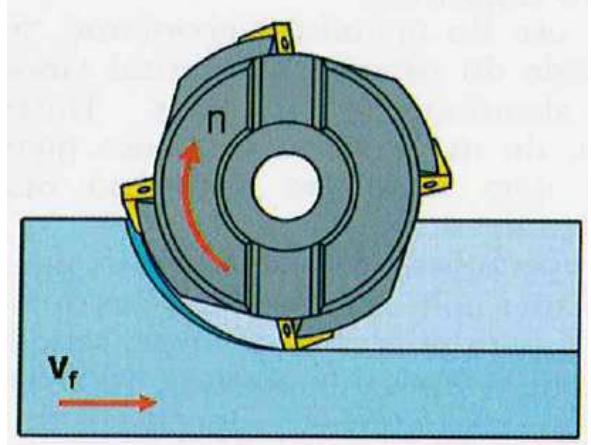

(b)

Figura 2.16 - (a) Fresamento concordante, (b) Fresamento discordante (CATÁLOGO SECO TOOLS, 2009)

Para o caso de fresamento plano frontal, admitindo o caso de operação onde exista o contato total do diâmetro da fresa, estando a mesma centrada com relação à peça, a distinção dos métodos de fresamento torna-se indiferente, porque ambos irão acontecer simultaneamente ao longo da trajetória do dente (Figura 2.17).

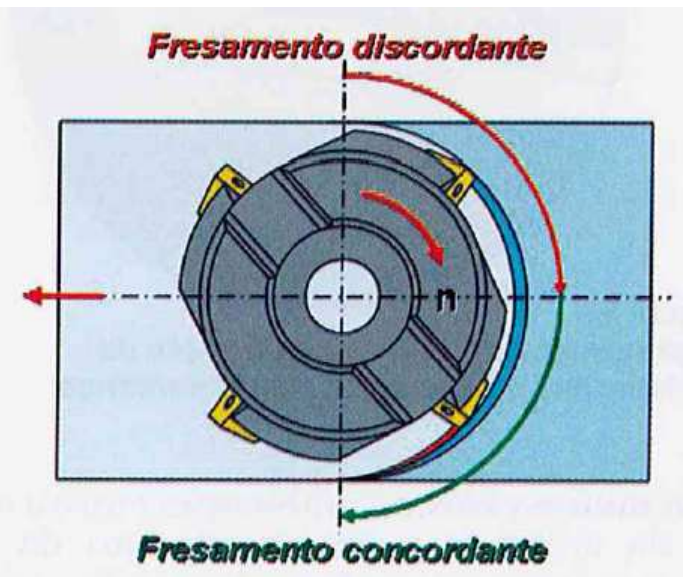

Figura 2.17 - Fresamento concordante e discordante no plano frontal (CATÁLOGO SECO TOOLS, 2009)

As condições de corte utilizadas em um fresamento são os fatores fundamentais para se conseguir acabamento superficial, taxa de remoção de cavaco, e erros de forma desejados na peça, aliado a uma vida longa da ferramenta.

Com relação ao parâmetro de corte velocidade, a Norma ABNT NBR 6162 , apresenta três definições: 


\section{I) Velocidade de corte $\left(v_{c}\right)$}

É a velocidade de um ponto na superfície externa da aresta de corte, na direção e sentido do corte, na Figura 2.18 é mostrado o vetor que representa a direção e o sentido da velocidade de corte, e ele é dado por:

$v_{c}=\pi D n \quad[\mathrm{~m} / \mathrm{min}]$

Onde,

$D=$ diâmetro da peça ou da ferramenta, em $\mathrm{mm}$.

$n=$ número de rotações por minuto

\section{II) Velocidade de avanço $\left(v_{f}\right)$}

É a velocidade com que um ponto na superfície externa da aresta de corte, na ferramenta, aproxima-se da peça, na direção e sentido do avanço, conforme Figura 2.18, e é dado por:

$V_{f}=f n \quad[\mathrm{~mm} / \mathrm{min}]$

Onde,

$f=$ avanço, em mm/volta.

$n=$ número de rotações por minuto

Para o fresamento, o avanço $f$, quase sempre, é medido em função do dente, então:

$V_{f}=f_{z} z n \quad[\mathrm{~mm} / \mathrm{min}]$

Onde,

$f_{z}=$ avanço por dente

$\mathrm{z}=$ número de dentes 
O movimento de avanço pode der feito pela própria peça em usinagem, que está fixada na mesa da máquina, ou como no caso de alguns modernos centros de usinagem, a ferramenta promove o avanço até a peça através do deslocamento do fuso da máquina.

\section{III) Velocidade efetiva de corte $\left(v_{e}\right)$}

É a velocidade de um ponto na superfície externa da aresta de corte, cujo módulo, direção e sentido são dados pela resultante da velocidade de corte com a velocidade de avanço, como mostra a Figura 2.18, e dado vetorialmente por:

$$
\overrightarrow{v_{e}}=\overrightarrow{v_{c}}+\overrightarrow{v_{f}} \quad[\mathrm{~m} / \mathrm{min}]
$$

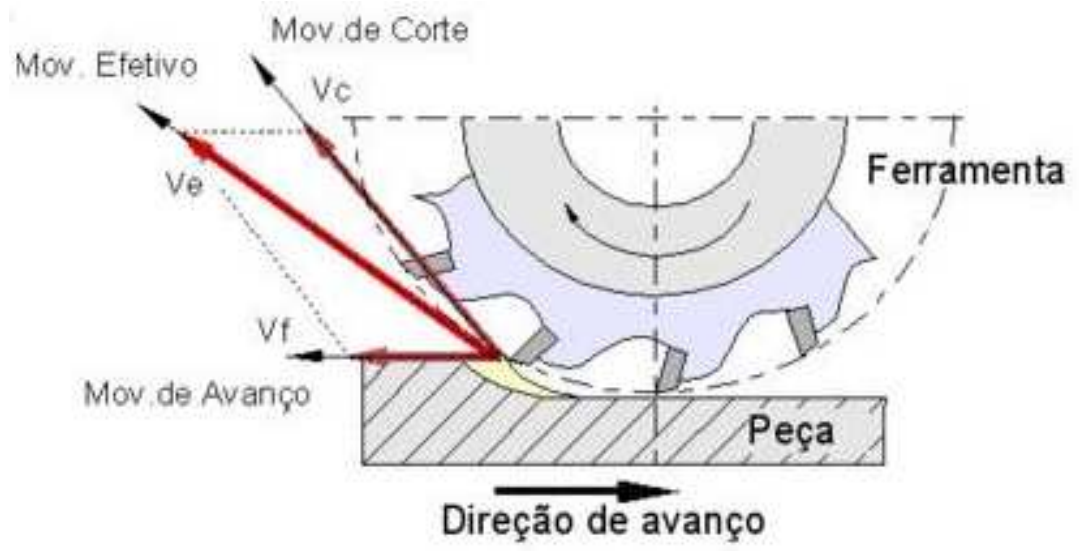

Figura 2.18 - Indicação vetorial da atuação da velocidade de corte, velocidade de avanço e velocidade efetiva de corte no fresamento tangencial (DINIZ, MARCONDES E COPPINI, 2010)

Conforme a norma NBR-6162, os outros dois parâmetros importantes utilizados no fresamento são a penetração de trabalho $\left(\mathrm{a}_{\mathrm{e}}\right)$ e a profundidade de corte $\left(a_{p}\right)$ :

\section{I) Largura de usinagem $\left(a_{e}\right)$}

É a penetração da ferramenta em relação à peça, medida no plano de trabalho, e numa direção perpendicular ao avanço, sempre tem o sentido radial da fresa, como é mostrado na Figura 2.19. 


\section{II) Profundidade de corte $\left(a_{p}\right)$}

É a profundidade ou largura de penetração da ferramenta na peça, sendo medida na direção perpendicular ao plano de trabalho e pode ser mostrado na Figura 2.19.

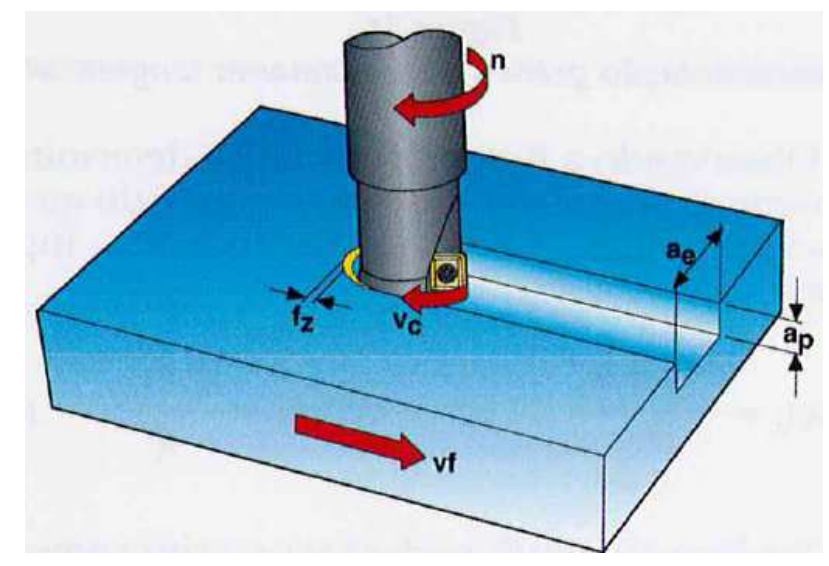

Figura 2.19 - Representação de algumas grandezas físicas no fresamento (CATÁLOGO SECO TOOLS, 2009)

\subsection{DIFICULDADES NA USINAGEM DE BLOCOS DE MOTORES}

No processo de usinagem das partes do bloco de motor, o processo de fresamento é de fundamental importância, principalmente o fresamento em acabamento da face de fogo. Esta face requer elevado grau de acabamento $\left(R_{z}\right)$, assim como precisão geométrica de forma e posição, porque é acoplada a outros componentes, com o objetivo de evitar vazamento de óleo do bloco do motor. Um fator que dificulta a usinagem desta parte do bloco é o grande número de interrupções na superfície devido às nervuras e bolachas para reforço da estrutura do bloco, assim como devido aos furos do cilindro e demais furações de refrigeração e fixação do cabeçote, além de alívios de peso.

Cuidados especiais são levados em conta na escolha da fresa, pois fresas muito positivas reduzem o esforço de corte da usinagem, reduzindo a tendência ao lascamento das bordas da superfície, porém têm uma vida relativamente baixa, quando comparada às fresas com geometria da aresta de corte negativa devido à pouca resistência ao impacto. 
$\mathrm{Na}$ usinagem de ferro fundido, um dos fatores que determinam o fim de vida de uma fresa é o lascamento de borda da superfície usinada, que é influenciado pelo aumento do desgaste frontal na aresta principal de corte da ferramenta e esforços de corte. Para se minimizar esta ocorrência, é necessário que se utilize avanço por dente pequeno. Sendo assim, as fresas de passo fino são indicadas para desbaste e acabamento nestas partes do bloco, que permitem grandes velocidades de avanço, mesmo com um pequeno avanço por dente, proporcionando uma economia grande no tempo de corte. Porém, o uso de fresas de passo fino e de geometrias negativas é limitado pela falta de estabilidade da peça, máquina e dispositivo, fazendo com que este tipo de fresa seja submetido a elevados esforços de corte, causando irregularidades dimensionais na superfície a ser usinada (GABALDO, 2009).

\subsection{DEFINIÇÃO DA REBARBA}

Rebarbas são resíduos indesejáveis que sempre irão aparecer nos produtos usinados e são praticamente impossíveis de serem eliminados, podendo, porém ser minimizadas. Seu surgimento compromete a qualidade das peças, pois altera suas dimensões e dificulta a montagem dos conjuntos mecânicos, elevando, portanto, o custo da peça usinada, além de oferecer riscos ao operador e acelerar o desgaste da ferramenta de corte.

Com isso o processo de rebarbação (processo de retirada de rebarbas nas bordas das peças) torna-se indispensável para dar acabamento às peças e garantir as tolerâncias dimensionais do projeto. O processo de rebarbação nem sempre pode ser automatizado, tornando-se um procedimento manual, e criando assim um obstáculo à redução de custos e ao aumento de produtividade, ou seja, cria um gargalo na produção, onerando a mesma (CORRÊA, 2002). A importância que a rebarba representa na usinagem, levou muitos pesquisadores a estudar seu mecanismo de formação, pois a partir dele torna-se possível obter condições favoráveis a minimização das suas dimensões.

Estudos desenvolvidos por Gillespie e Blotter (1976), Nakayama e Arai (1987), Lin (1999) e Ko e Dornfeld (1996), que serão detalhados posteriormente, deixaram enorme contribuição para o entendimento dos mecanismos de formação 
da rebarba, no entanto nenhum critério isolado é capaz de explicar o fenômeno da formação da rebarba totalmente (DORNFELD; CHANG; HASHIMURA, 1999).

\subsubsection{Normas}

Atualmente existem várias normas internacionais e nacionais, bem como normas próprias dependendo do tipo de aplicação do produto final de cada indústria para descrever rebarbas e avaliar a qualidade das bordas das peças. Na maioria dos casos, as rebarbas são definidas como projeções ou saliências indesejáveis do material, formadas como resultado da deformação plástica após operações de usinagem (AURICH et al, 2009). Schäfer (1978) descreve a rebarba como sendo parte de uma peça, que é produzida através de processos de usinagem em uma borda ou uma superfície, e que está fora da dimensão especificada.

Conforme a ASTME (American Society of Tool and Manufacturing Engineers), rebarbas são projeções indesejáveis do material da peça formada na frente da aresta de corte devido à deformação plástica durante a usinagem. A norma ISO 13715 (2000) define rebarba como sendo o "restante de material encontrado fora da forma geométrica nominal de uma borda externa, deixado como resíduo de usinagem ou de outro processo de fabricação".

Torna-se necessário realizar a operação de rebarbação de uma peça quando a altura da rebarba interfere nas suas dimensões. Para a norma DIN 6784 (1982) a "rebarba tolerável" irá depender do projeto da peça, e essa dependerá da função, da montagem, segurança e outros fatores que poderão surgir. Conforme Aurich et al (2009), uma pesquisa realizada em indústrias alemãs mostrou que devido à falta de uma classificação geral aceita para as rebarbas, aproximadamente $45 \%$ das companhias entrevistadas utilizam uma classificação interna, conforme suas necessidades. 


\subsubsection{Descrição geométrica da rebarba}

A norma ISO 13715 (2000) padroniza a utilização de apenas um valor para definir o desvio do contorno geométrico ideal da borda da peça, conforme Figura 2.20. Este valor é denominado de medida "a" pela norma, e é medida a partir de uma cota perpendicular a superfície livre da peça até a ponta da rebarba em questão.
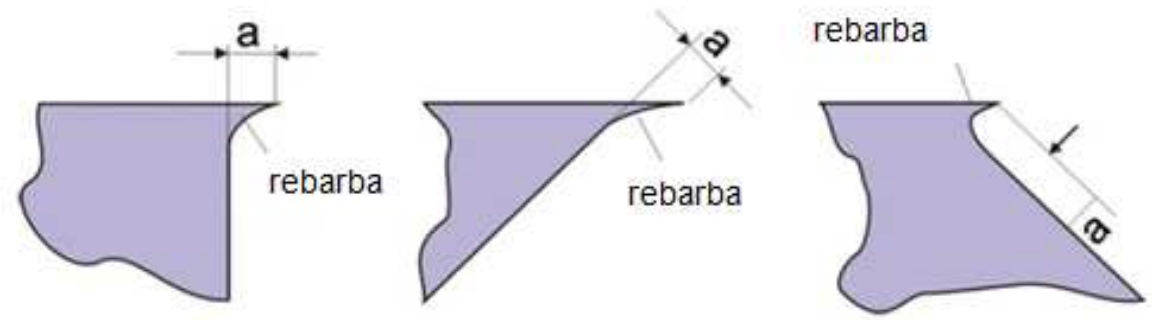

Figura 2.20 - Geometria da rebarba conforme indicado na ISO 13715 (ISO 13715, 2000)

Conforme Kishimoto et al (1981), para a análise das dimensões e descrição geométrica das rebarbas são consideradas a sua altura e a sua espessura. $\mathrm{Na}$ medição dessas duas grandezas pode-se usar desde simples relógios comparadores até complexos analisadores de imagem. Sabe-se que a espessura das rebarbas tem um perfil irregular tornando um pouco mais difícil a sua medição. A Figura 2.21 mostra a altura e a espessura de uma rebarba, onde $t_{b}$ é a espessura na raiz da rebarba, $t_{\min }$ é a espessura mínima, $t_{\text {máx }}$ é a espessura máxima e $\mathrm{h}$ a sua altura.
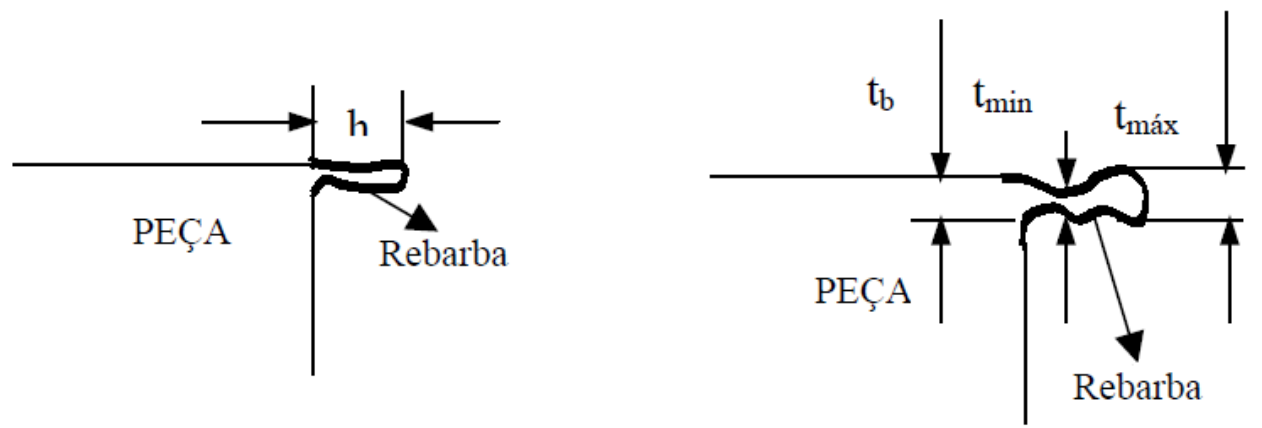

Figura 2.21 - Dimensões da rebarba (KISHIMOTO et al, 1981) 
Segundo Olvera e Barrow (1998), a principal dimensão da rebarba é a sua espessura, pois quanto maior for o valor de "b" (Figura 2.22), maior será a dificuldade em se removê-la na etapa de rebarbação.

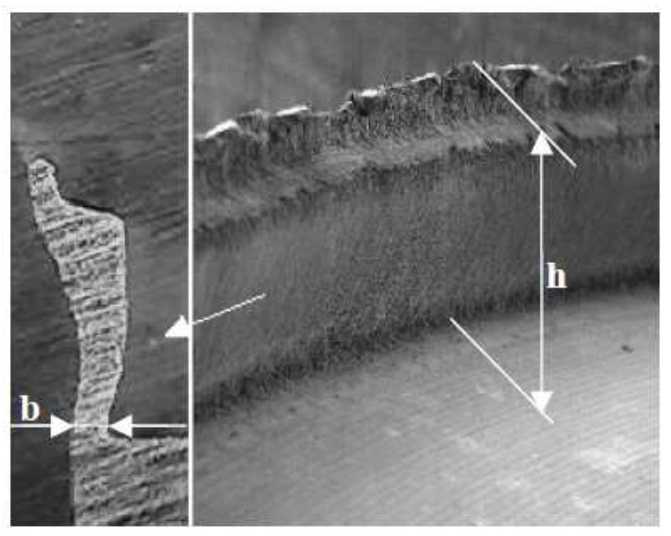

Figura 2.22 - Principais dimensões consideradas na análise das rebarbas, altura "h", e espessura "b" (KAMINISE et al, 2001)

Schäfer (1978) utiliza uma amostra aleatória de seção transversal para descrever parâmetros básicos da rebarba. Ele afirma que cada rebarba pode ser caracterizada pelo seu perfil longitudinal, transversal, e por seu raio de arredondamento na raiz, e define as seguintes descrições para as rebarbas (Figura 2.23).

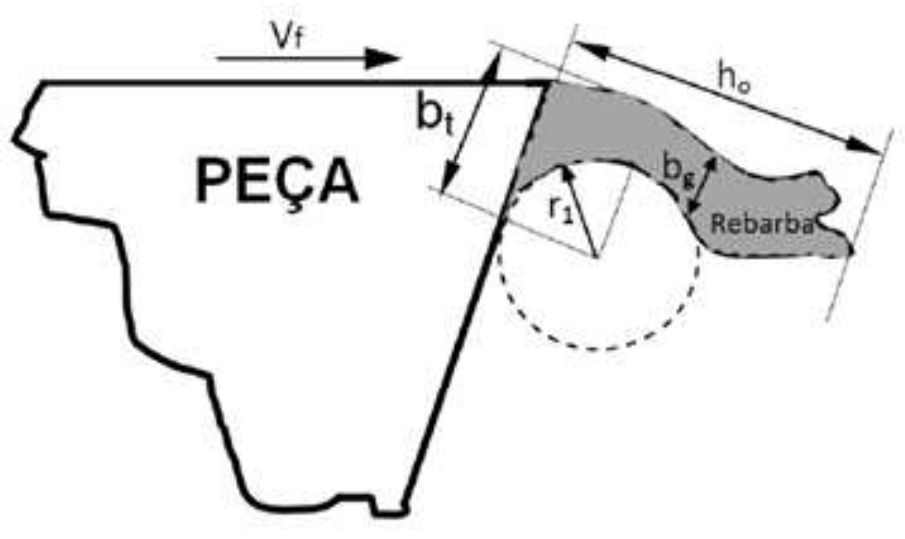

$h_{0}:$ Altura da rebarba

$b_{1}:$ Espessura da raiz da rebarba

$b_{g}$ : Espessura da rebarba

$r_{1}$ : Raio de arredondamento da raiz

Figura 2.23 - Modelo geométrico da rebarba e seus parâmetros (SCHÄFER, 1978). 


\subsubsection{Processo de formação da rebarba}

O processo de formação da rebarba é complexo porque envolve deformação plástica tridimensional com alto grau de liberdade, que é altamente dependente dos inúmeros parâmetros de usinagem. Portanto, análises teóricas da formação da rebarba tornam-se uma tarefa complexa (NAKAYAMA e ARAI, 1987).

Para simplificar as análises dos complexos mecanismos de formação de rebarbas, a maioria das investigações no assunto utiliza o corte ortogonal devido a sua simplicidade geométrica, para reduzir o número de variáveis envolvidas (HASHIMURA \& DORNFELD, 1995).

Segundo Ko \& Dornfeld (1991), no corte ortogonal, a rebarba ocorre em três etapas: iniciação, desenvolvimento e formação (Figura 2.24). A formação da rebarba inicia-se quando a ferramenta de corte aproxima-se do final da peça, proporcionando nesta região grandes deformações na borda da peça, gerando uma saliência se o material for dúctil, ou o destacamento total ou parcial da borda, se o material for frágil.

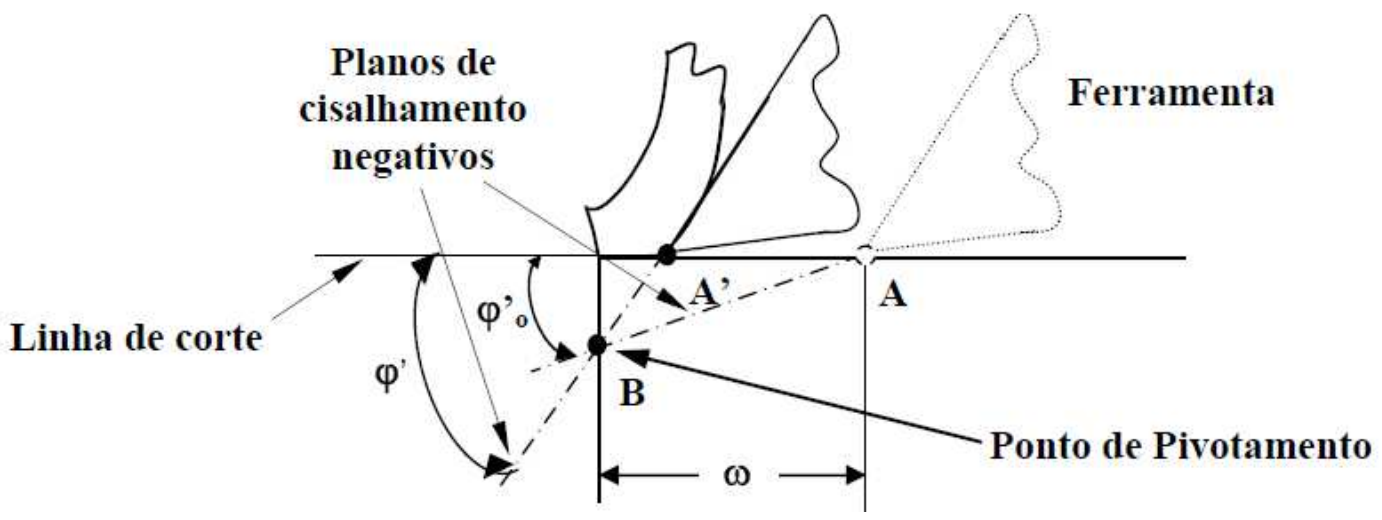

Figura 2.24 - Variáveis geométricas e o deslocamento da ferramenta do ponto A ao ponto A', e a rotação do plano de cisalhamento negativo em torno de B. (KO e DORNFELD, 1991)

Conforme Ko \& Dornfeld (1991), o início da formação da rebarba se dá no instante em que a formação do cavaco se encerra, quando a ferramenta de corte atinge o ponto $\mathbf{A}$. Assim a energia que seria destinada ao cavaco é transferida para a formação da rebarba. O deslocamento da ferramenta de corte do ponto $\mathbf{A}$ para o ponto A' gera a rotação do plano de cisalhamento negativo em torno do ponto de 
pivotamento B. Ocorre então a mudança do ângulo de cisalhamento para sua condição final $\left(\varphi^{\prime}\right)$. A partir deste ponto ocorre a formação da rebarba.

Hashimura et al (1999) propuseram um outro modelo do processo de formação da rebarba, que divide-se em oito etapas. A partir de certo estágio na formação da rebarba, o processo tem que ser considerado de forma separada para materiais dúcteis e frágeis.

Na primeira etapa (Figura 2.25), chamada de "corte contínuo", ainda não aparece a região de formação da rebarba. Pode-se verificar o processo cíclico da formação do cavaco, onde se tem o cavaco contínuo para materiais dúcteis e o cavaco descontínuo para materiais frágeis. Pode-se observar a zona de deformação plástica e elástica em torno da ponta da ferramenta de corte. O término dessa etapa ocorre quando a ferramenta de corte atinge o ponto $\mathbf{A}$, conforme mostrado na Figura 2.24 .

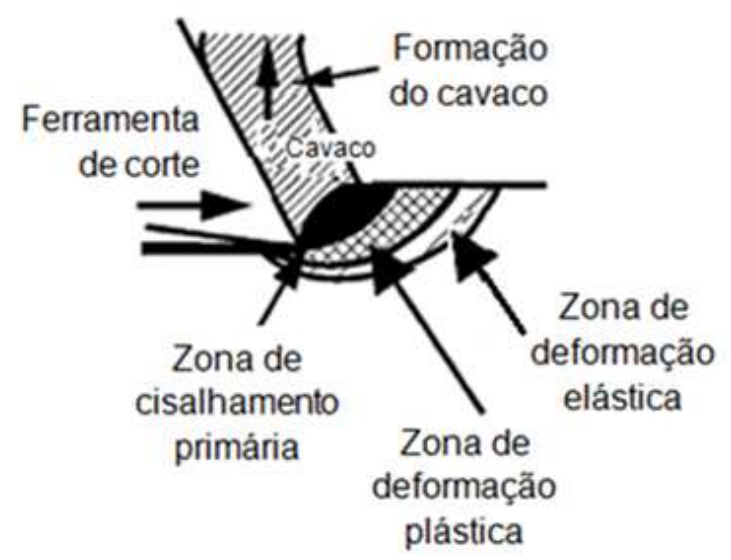

Figura 2.25 - Primeira etapa da formação da rebarba (HASHIMURA et al., 1999)

Na segunda etapa (Figura 2.26), conhecida como "pré-início", dá-se quando a ferramenta de corte passa pelo ponto $\mathbf{A}$ e o campo elástico a frente da região plástica da zona de cisalhamento primário atinge a borda de saída da peça. A borda da peça começa a ser envolvida pela deformação elástica, e o grau de evolução desse processo irá depender diretamente dos dados de corte utilizados na usinagem. 


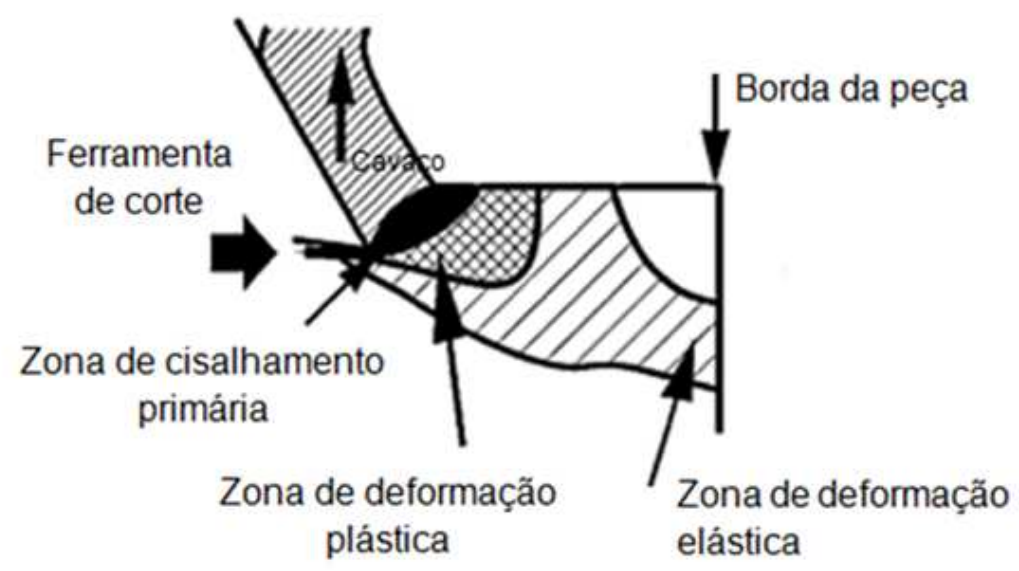

Figura 2.26 - Segunda etapa da formação da rebarba (HASHIMURA et al., 1999)

$\mathrm{Na}$ terceira etapa, chamada de "início da rebarba" (Figura 2.27), a deformação plástica passa a envolver a zona de cisalhamento primário, que ainda se expande na direção da aresta da peça, na extremidade da mesma. A borda na extremidade da peça sofre os efeitos da deformação plástica aparecendo um dobramento plástico.

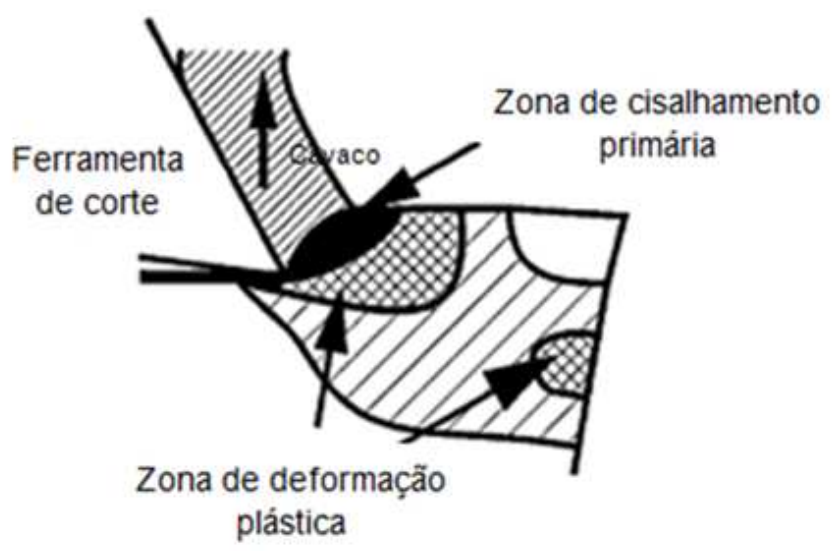

Figura 2.27 - Terceira etapa da formação da rebarba (HASHIMURA et al., 1999)

$\mathrm{Na}$ quarta etapa, conhecida como "pivotamento", fica visível a rotação da borda da peça em torno de um ponto chamado de "ponto de pivotamento", que aparece na superfície livre da peça. A zona de deformação plástica, além de envolver a zona de cisalhamento primária e secundária, irá atingir uma pequena região abaixo da aresta na extremidade da peça. A deformação plástica ao longo desta extremidade passa a ser visível, conforme mostra a Figura 2.28. 

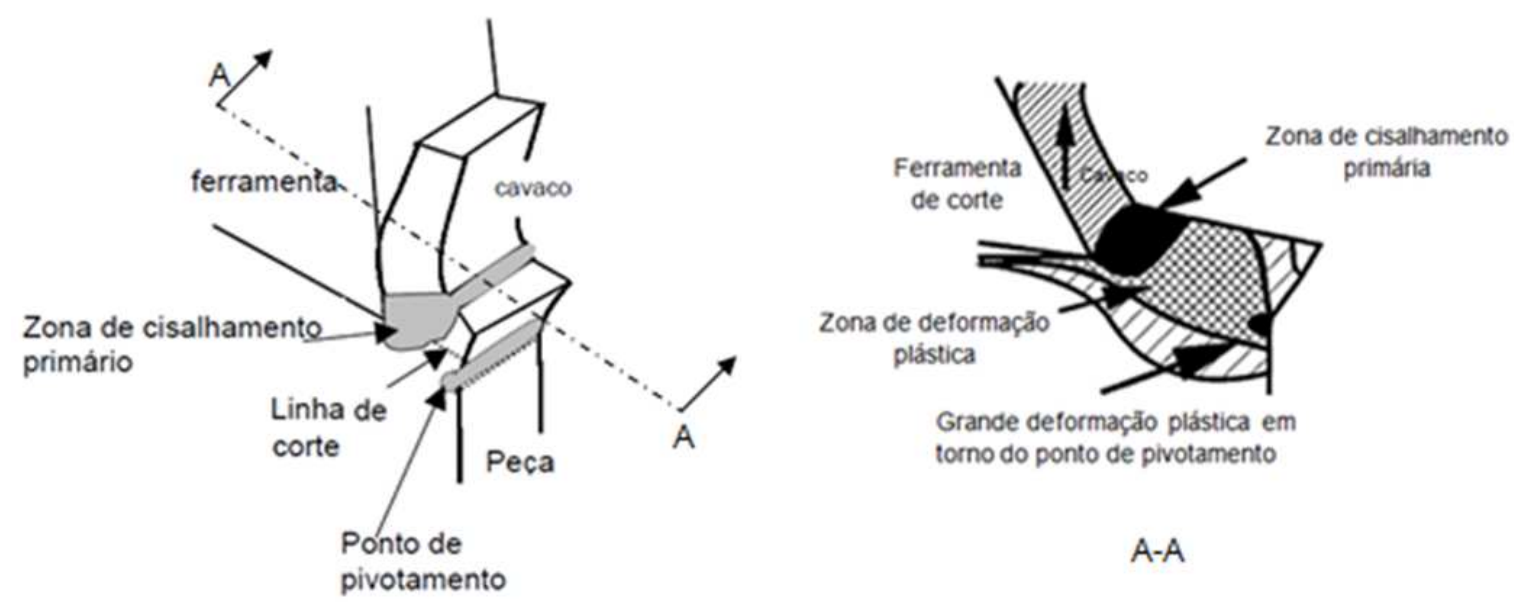

Figura 2.28 - Quarta etapa da formação da rebarba (HASHIMURA et al., 1999)

$\mathrm{Na}$ quinta etapa, chamada "desenvolvimento da rebarba" (Figura 2.29), ocorre o surgimento da zona de cisalhamento negativa. A medida que a ferramenta de corte desloca-se no sentido da borda da peça a deformação plástica se intensifica e envolve completamente o "ponto de pivotamento" se ligando a zona de cisalhamento primária.
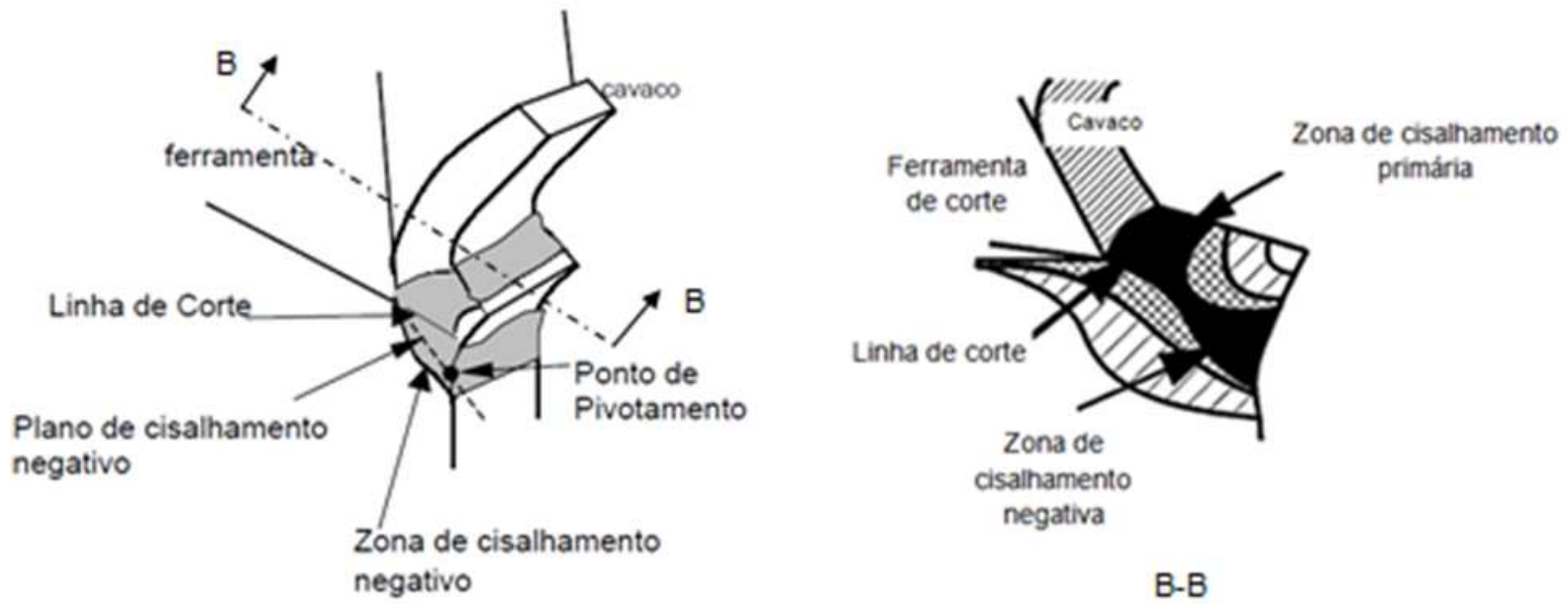

Figura 2.29 - Quinta etapa da formação da rebarba (HASHIMURA et al., 1999)

Nas etapas anteriores descreveu-se o desenvolvimento da rebarba apenas pela deformação plástica, sem considerar fratura. A partir desta etapa, Hashimura et al. (1999), classificaram as etapas conforme o material usinado: 


\section{A) Para materiais dúcteis}

A deformação crítica a fratura, $\varepsilon_{\text {f }}$, aparece no plano de cisalhamento primário, fazendo com que ocorra o início da trinca ao longo da linha de corte, na ponta da ferramenta de corte, conforme ilustra a Figura 2.30.
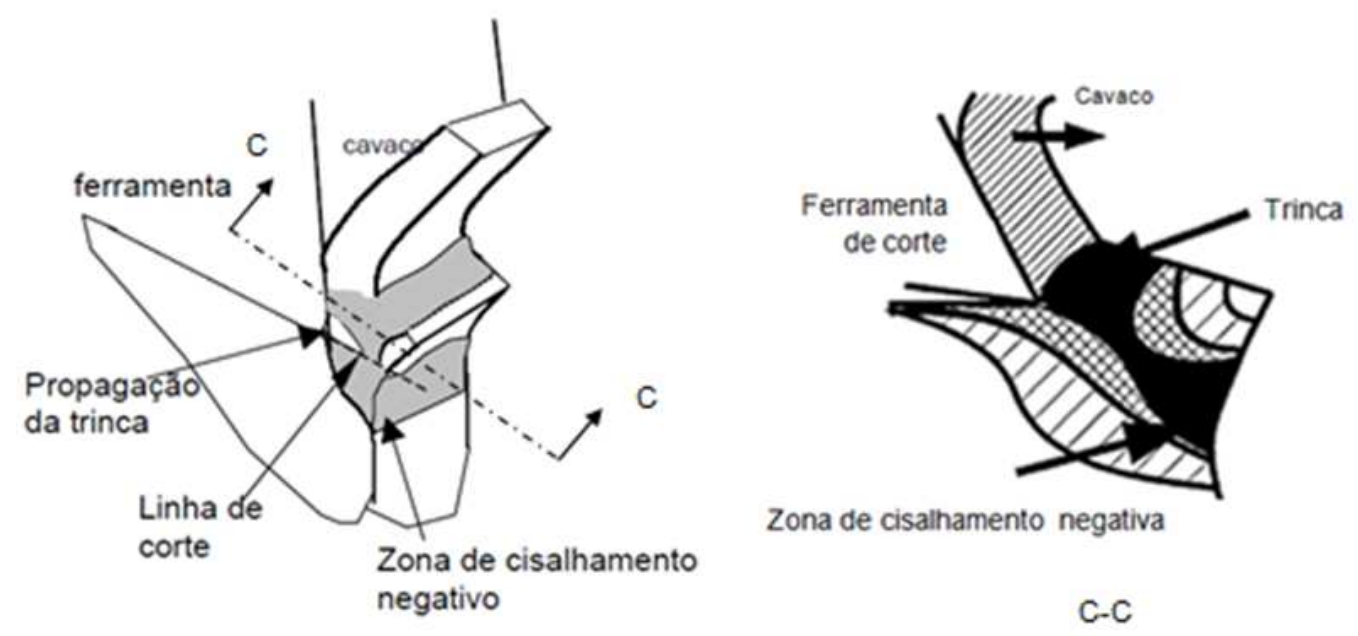

Figura 2.30 - Sexta etapa da formação da rebarba em materiais ducteis (HASHIMURA et al., 1999)

Nesta etapa ocorre o crescimento da trinca ao longo da linha de corte, conforme ilustra a Figura 2.31.

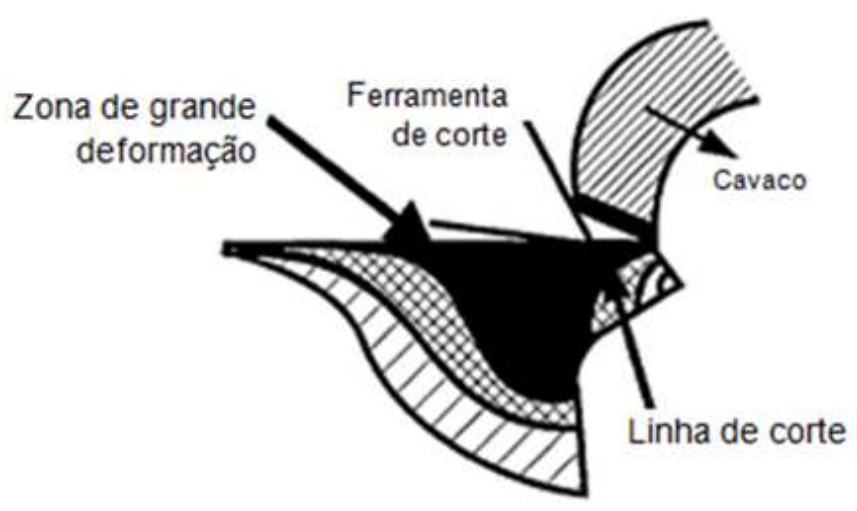

Figura 2.31 - Sétima etapa da formação da rebarba em materiais dúcteis (HASHIMURA et al., 1999)

Abaixo da linha de corte a deformação continua até a ferramenta de corte perder o contato com a peça. Nesta etapa ocorre a separação do cavaco ao longo da linha de corte, e o excesso de material retido na peça recebe o nome de rebarba positiva, conforme Figura 2.32. 

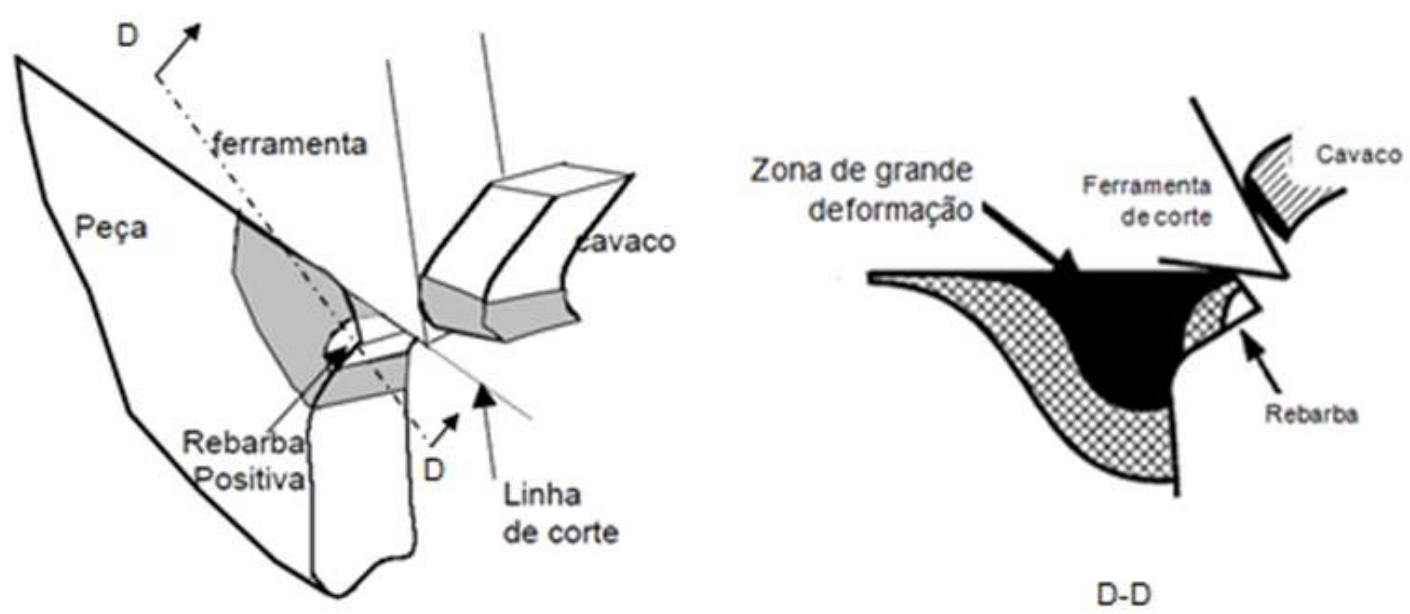

Figura 2.32 - Oitava etapa da formação da rebarba em materiais dúcteis (HASHIMURA et al., 1999)

\section{B) Para materiais frágeis}

Nesta etapa pode-se verificar que deformação crítica a fratura, $\varepsilon_{f}$ aparece no plano de cisalhamento negativo, ocorrendo o início da trinca ao longo da zona de cisalhamento negativa, conforme mostra a Figura 2.33.
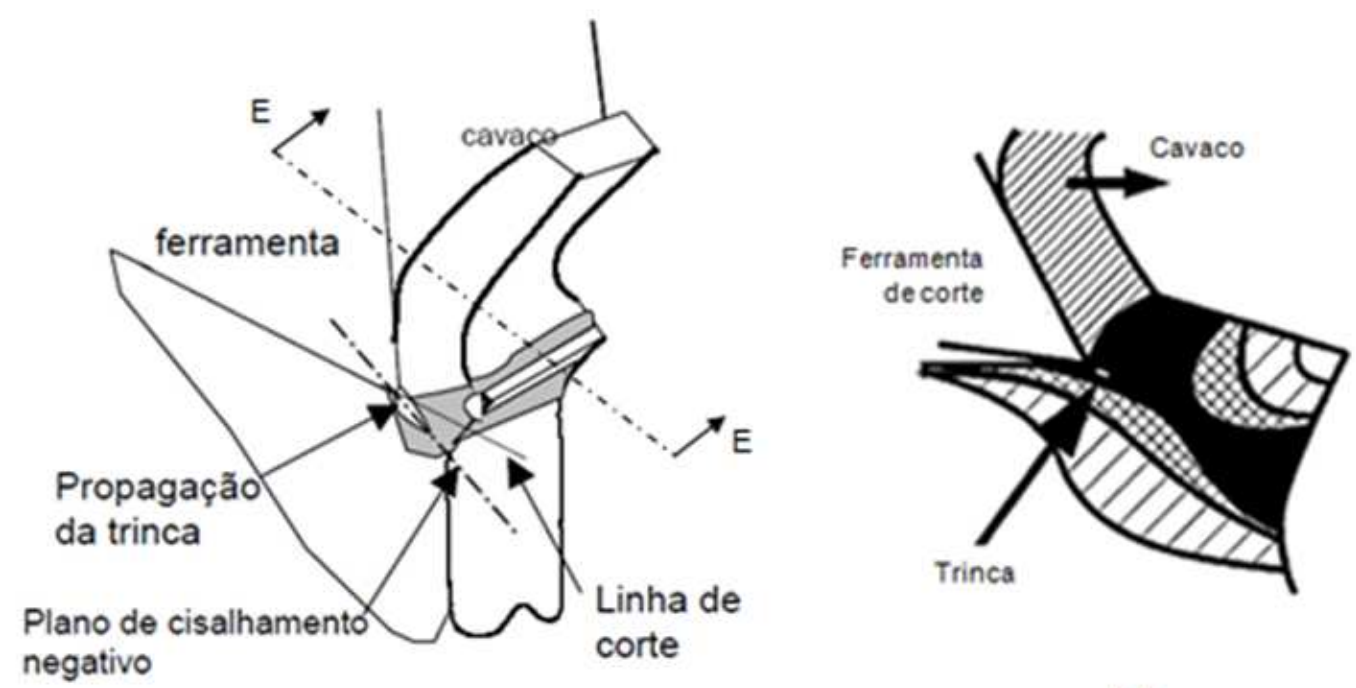

$$
\text { E-E }
$$

Figura 2.33 - Sexta etapa da formação da rebarba em materiais frágeis (HASHIMURA et al., 1999)

Nesta etapa ocorre o crescimento da trinca ao longo da zona de cisalhamento negativa, conforme Figura 2.34. 


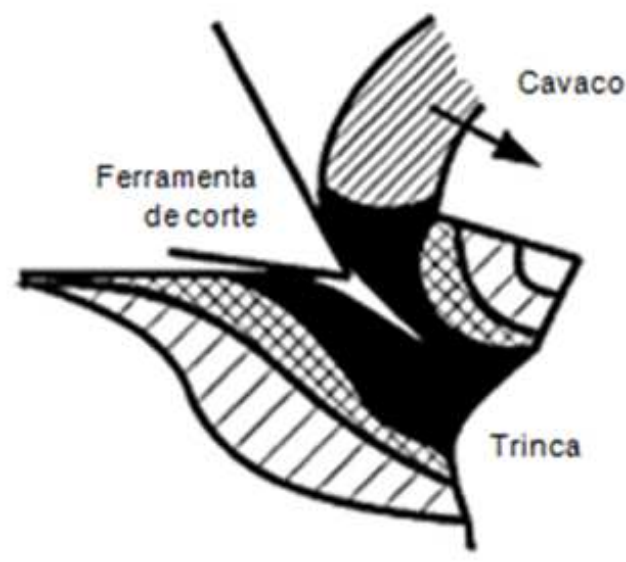

Figura 2.34 - Sétima etapa da formação da rebarba em materiais frágeis (HASHIMURA et al., 1999)

Assim, todo o material que se encontra sobre o plano de cisalhamento negativo será destacado da peça. Ao fenômeno que promove o destacamento deste material, é chamado de breakout, ou formação do pé (foot forming) conforme Pekelharing (1978). A borda da peça remanescente é chamada de rebarba negativa conforme Figura 2.35.
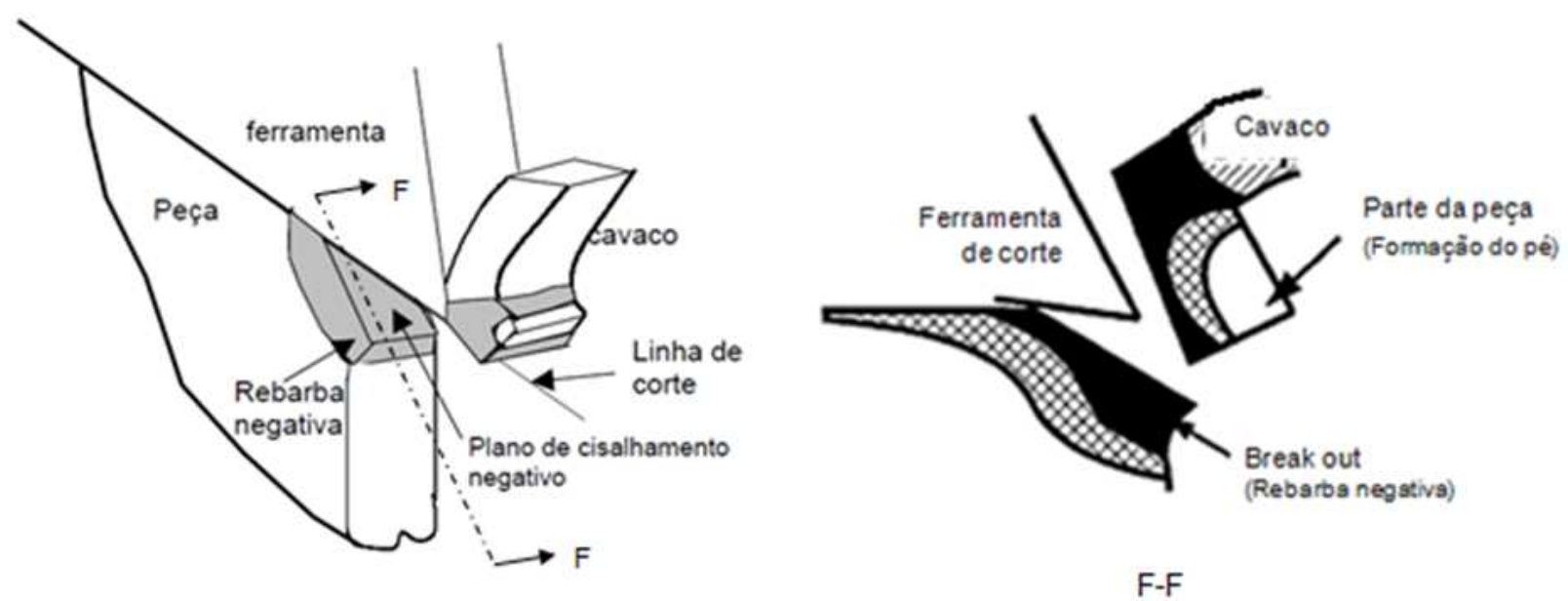

Figura 2.35 - Oitava etapa da formação da rebarba em materiais frágeis (HASHIMURA et al., 1999)

\subsubsection{Classificação das rebarbas}

A inexistência de uma classificação normalizada para as rebarbas levou cada um dos pesquisadores desse assunto a criar sua própria classificação. 
Critérios como a sua geometria, processos de fabricação, mecanismos de formação, morfologias e outros foram responsáveis pelo aparecimento de várias propostas de classificação para as rebarbas (DA SILVA, 2011). A seguir são descritas algumas formas de classificação das rebarbas.

Gillespie e Blotter (1976) pesquisaram a formação de rebarbas com o intuito de classificá-las e identificar os mecanismos de sua formação. Investigou a influência dos parâmetros de corte, da geometria da ferramenta e desgaste nas propriedades das rebarbas.

Eles identificaram quatro mecanismos básicos de formação das rebarbas: (1) a deformação plástica lateral envolvendo o fluxo do material para a superfície livre da peça, (2) dobramento e flexão do cavaco na mesma direção do corte quando a ferramenta chega ao final da peça, (3) ruptura por tração do material entre a peça e o cavaco e (4) a separação da peça do seu material antes da conclusão do corte.

As rebarbas geradas por estes mecanismos foram classificadas em quatro tipos diferentes: (a) do tipo Poisson (Figura 2.36), (b) do tipo Rollover (rebarba de encurvamento), conforme Figura 2.37, (c) do tipo Tear (rebarba de estiramento), como mostra a Figura 2.38 e (d) do tipo Cut-off (rebarba de ruptura) conforme Figura 2.39. Embora seja possível o aparecimento de mais de um mecanismo de formação de rebarba, a mesma ainda será classificada e descrita pelo mecanismo predominante.

- Rebarba do tipo Poisson

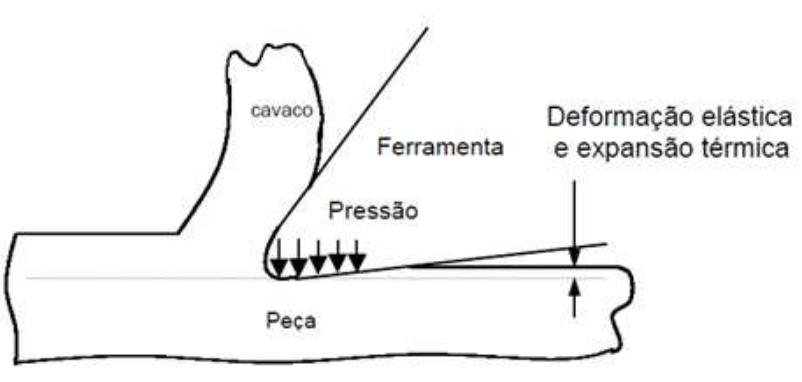

(a)

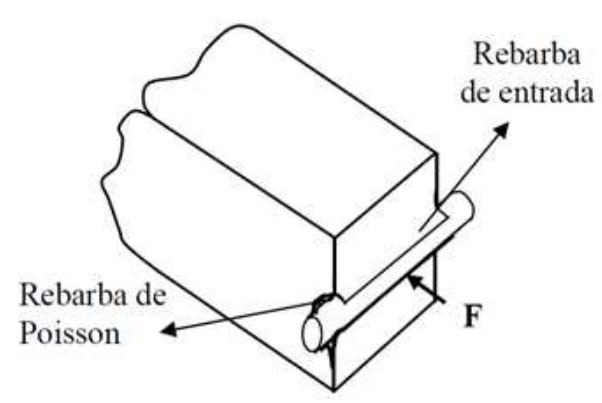

(b)

Figura 2.36 - (a) - Pressão da ferramenta sobre a superfície usinada, (b) - Penetração do cilindro (ferramenta de corte), (GILLESPIE e BLOTTER, 1976) 
- Rebarba do tipo Rollover (rebarba de encurvamento)

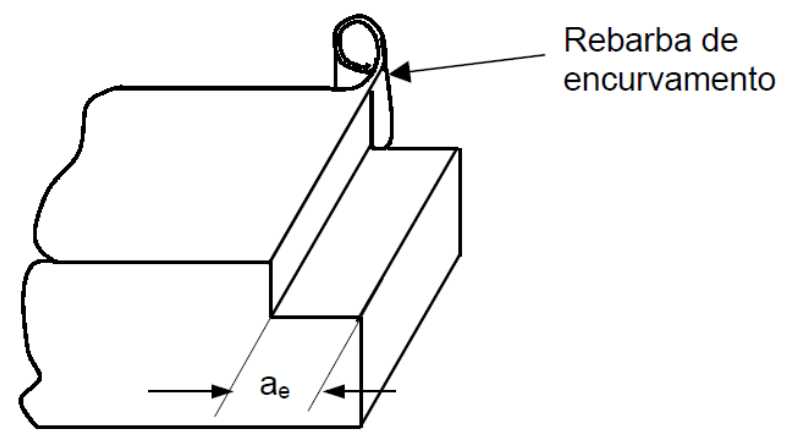

Figura 2.37 - Rebarba de encurvamento gerada no fresamento (GILLESPIE e BLOTTER, 1976)

- Rebarba do tipo Tear (rebarba de estiramento)

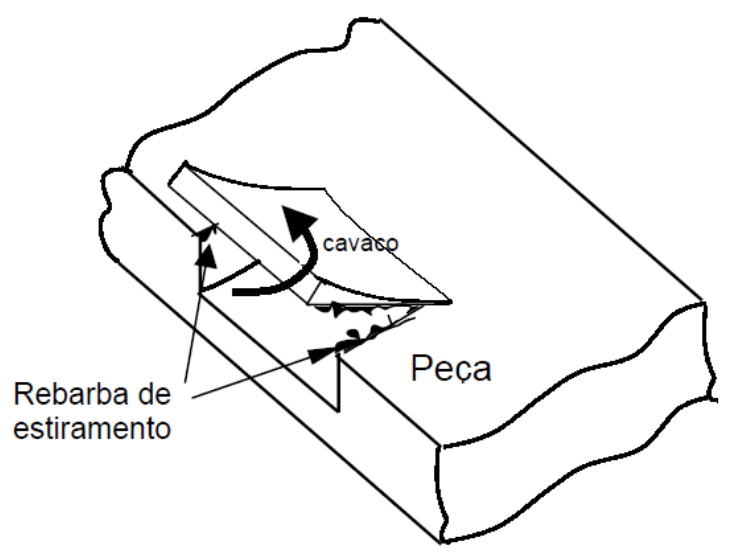

Figura 2.38 - Destacamento do cavaco e o surgimento da rebarba de estiramento, (GILLESPIE e BLOTTER, 1976)

- Rebarba do tipo Cut-off (rebarba de ruptura)

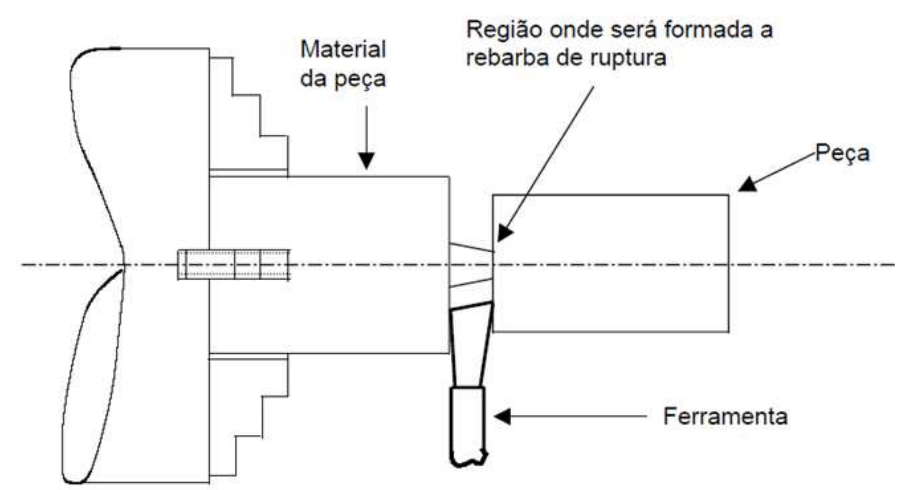

Figura 2.39 - Rebarba de Ruptura formada pela operação de corte no torneamento externo,

(GILLESPIE e BLOTTER, 1976) 


\subsubsection{Classificação das rebarbas formadas no processo de fresamento}

Gillespie (1999) investigou as rebarbas formadas nas bordas das peças usinadas pelo processo de fresamento e analisou a influência dos parâmetros de corte nas suas dimensões. Ele verificou que o avanço e a vida da ferramenta de corte são fatores de muita significância no tamanho das rebarbas. Foi proposta por ele a identificação das mesmas usando o seguinte critério: Rebarba $\mathbf{5}$ - rebarba de saída na direção do avanço (poderá terá mecanismos do tipo Tear ou Poisson dependendo da rotação da fresa), Rebarba 8 - rebarba de entrada na direção do corte (poderá terá mecanismos do tipo Tear ou Poisson dependendo da rotação da fresa), Rebarba 9 - rebarba lateral na direção do corte (poderá terá mecanismos do tipo Tear ou Poisson dependendo da rotação da fresa). As rebarbas que aparecem nas outras bordas são consideradas menos importantes para o desenvolvimento deste trabalho. A Figura 2.40 mostra as rebarbas e as suas identificações.

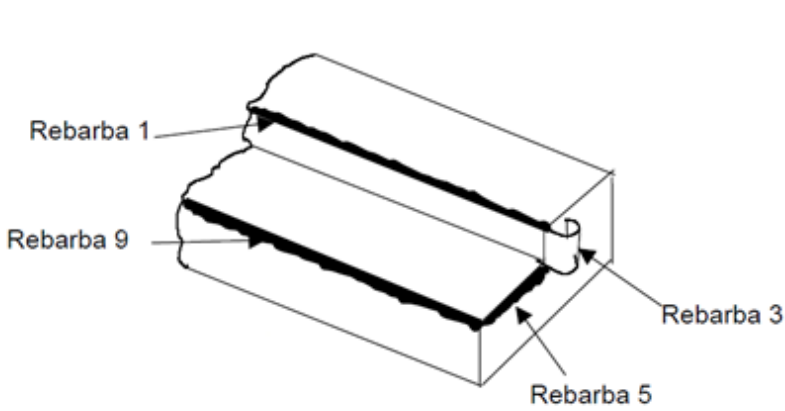

(a)

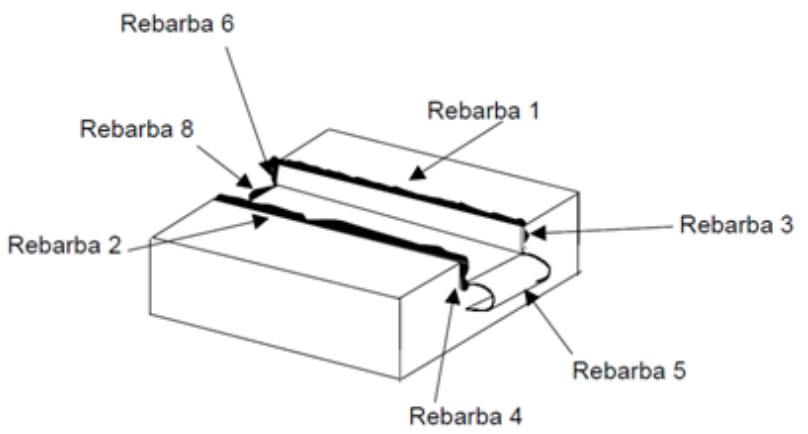

(b)

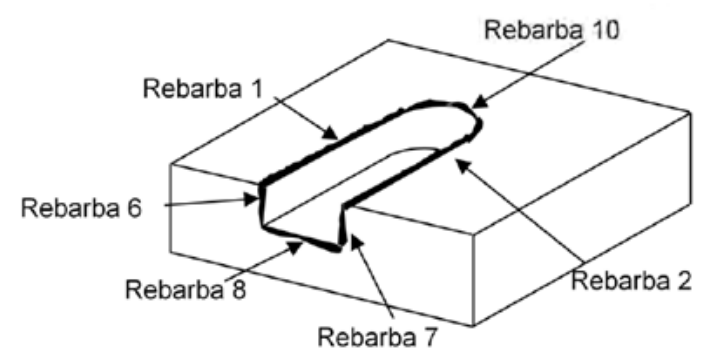

(c)

Figura 2.40 - Tipos de rebarbas formadas no fresamento. (a) - fresamento de faceamento, (b) fresamento tangencial discordante e (c) fresamento de topo (GILLESPIE, 1999) 
Kishimoto et al. (1981) investigaram a formação da rebarba formada na borda de saída da peça e introduziram os termos de rebarba primária e secundária para identificar as etapas da sua formação e dimensões, determinando as condições de corte para o aparecimento da mesma. A rebarba em questão é a mesma rebarba 5 ou 9 , da Figura 2.40a. A rebarba 9 terá altura constante em toda extensão da borda, pois o ângulo formado pela borda de saída e a direção da velocidade de corte não sofre alterações. Quanto a rebarba 5, essa tem altura variável, uma vez que o ângulo formado pela borda de saída e a direção da velocidade de corte é alterado desde a chegada da ferramenta de corte a borda da peça até a sua saída (DA SILVA, 2011).

A rebarba do tipo 9 é a mais difícil de ser removida devido ao seu comprimento longo e sua resistência (OLVERA e BARROW, 1998). Chern e Dornfeld (1996) observaram ainda três formas distintas da rebarba primária, sendo essas: rebarba tipo faca, rebarba tipo onda e rebarba tipo anelada.

A profundidade de corte, o ângulo de saída e o raio da ponta da ferramenta, são fatores determinantes na dimensão das rebarbas 5 e 9 (SOUZA JR 2001). Eles observaram que para um dado ângulo de saída da fresa, existe um determinado intervalo de profundidade de corte responsável pela transição da rebarba primária para secundária, chamado de profundidade de corte de transição $\left(a_{\mathrm{pt}}\right)$, conforme será possível observar no diagrama da Figura 2.41. Sendo h a altura da rebarba.

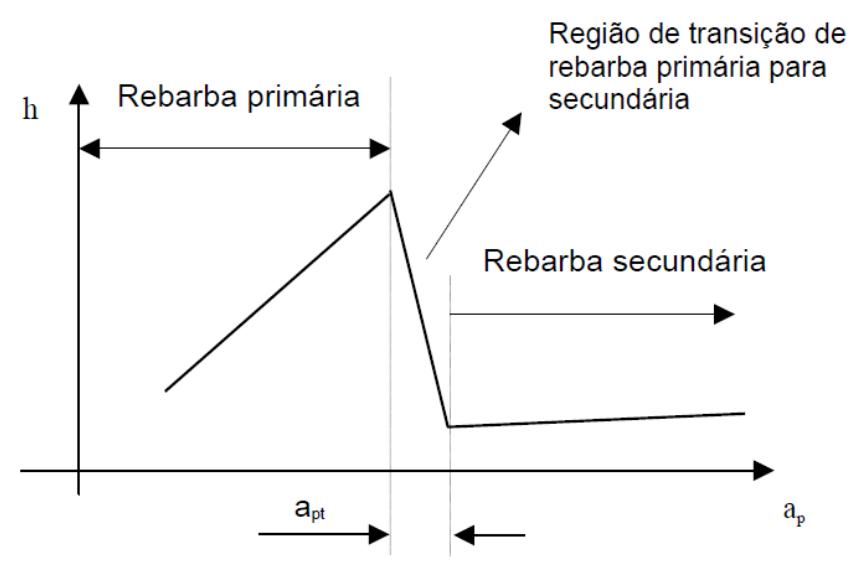

Figura 2.41 - Transição da rebarba primaria para rebarba secundaria. (DA SILVA, 2004)

Considerando-se 0 fresamento de faceamento, para pequenas profundidades, a ação do corte será formada principalmente pela aresta secundária 
da ferramenta de corte (Figura 2.42), gerando-se a rebarba primária. Na medida em que a profundidade de corte aumenta, a participação da aresta secundária de corte diminui (dividindo a função do corte com a aresta principal) gerando-se a rebarba de transição. A geração da rebarba secundária acontece quando a ação do corte ocorre principalmente pela aresta principal da ferramenta de corte (DA SILVA, 2004).

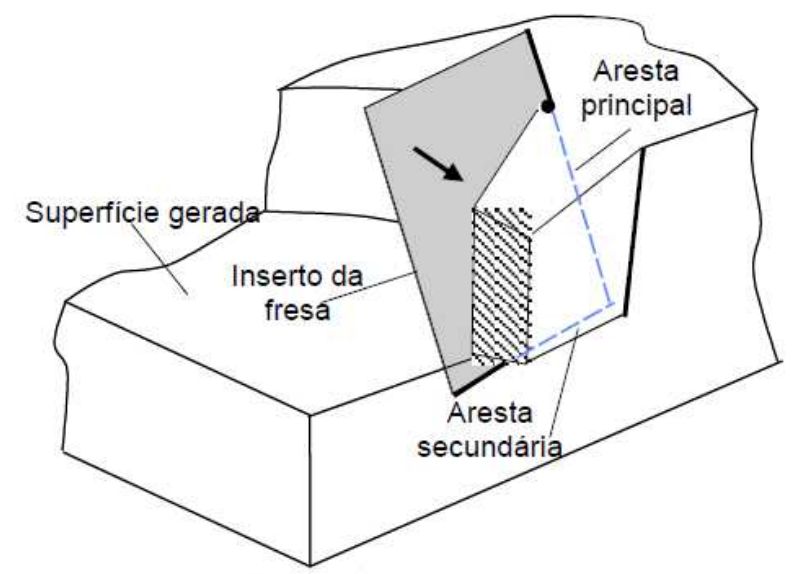

Figura 2.42 - Identificação das arestas principal e secundária no fresamento de faceamento (HASHIMURA et al., 1999)

Observa-se que a rebarba secundária tem altura bastante reduzida em relação à rebarba primária. Devido ao seu tamanho reduzido, Kishimoto et al. (1981), Olvera \& Barrow (1996) passaram a considerar as bordas formadas por rebarba secundária como regiões livres de rebarba.

Hashimura et al. (1999) descreveram e classificaram a formação da rebarba no fresamento de faceamento e verificaram que a ordem de saída da ferramenta de corte da peça tem efeito importante na formação da rebarba e influencia tanto a posição da rebarba quanto suas dimensões. Em função da localização na borda da peça as rebarbas são identificadas por rebarba de saída, rebarba lateral e rebarba de topo.

A identificação da rebarba em função da localização é completada a partir do envolvimento da aresta da ferramenta de corte na formação do cavaco. A ordem de saída da aresta de corte é de grande importância na classificação e na dimensão das rebarbas (DA SILVA, 2011). A Figura 2.43 mostra as duas ordens de saída da aresta e o local de formação da rebarba. 


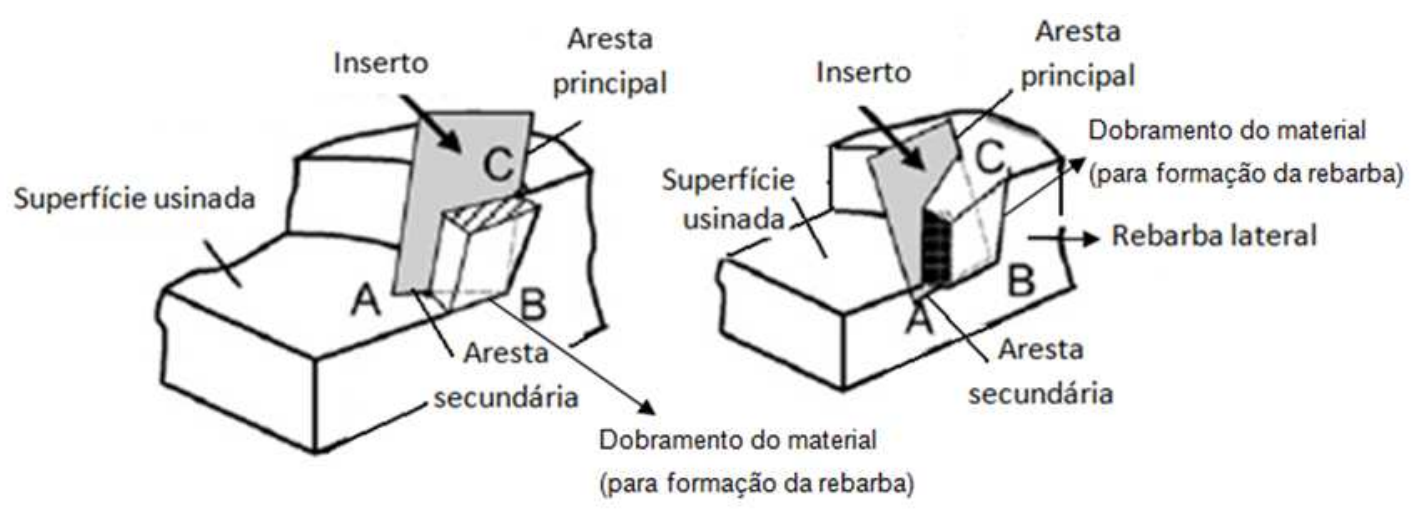

(a)

(b)

Figura 2.43 - Sequência de saída da ferramenta de corte influenciando na formação da rebarba. (a) Ordem de saída BCA, (b) Ordem de saída ABC (HASHIMURA et al., 1999)

Segundo Hashimura et al. (1999), as rebarbas foram denominadas da seguinte forma:

- Superior;

- Lateral de saída;

- Inferior de saída;

- Lateral de entrada;

- Inferior de entrada;

- Inferior.

Essas rebarbas podem ser observadas no processo de fresamento em cinco regiões distintas (HASHIMURA et al., 1999). Na borda entre a superfície usinada e a superfície de saída; entre a superfície de transição e a superfície de saída; entre a superfície superior e a superfície de transição; superfície usinada e a superfície de entrada; superfície de transição e a superfície de entrada conforme ilustra a Figura 2.44 . 


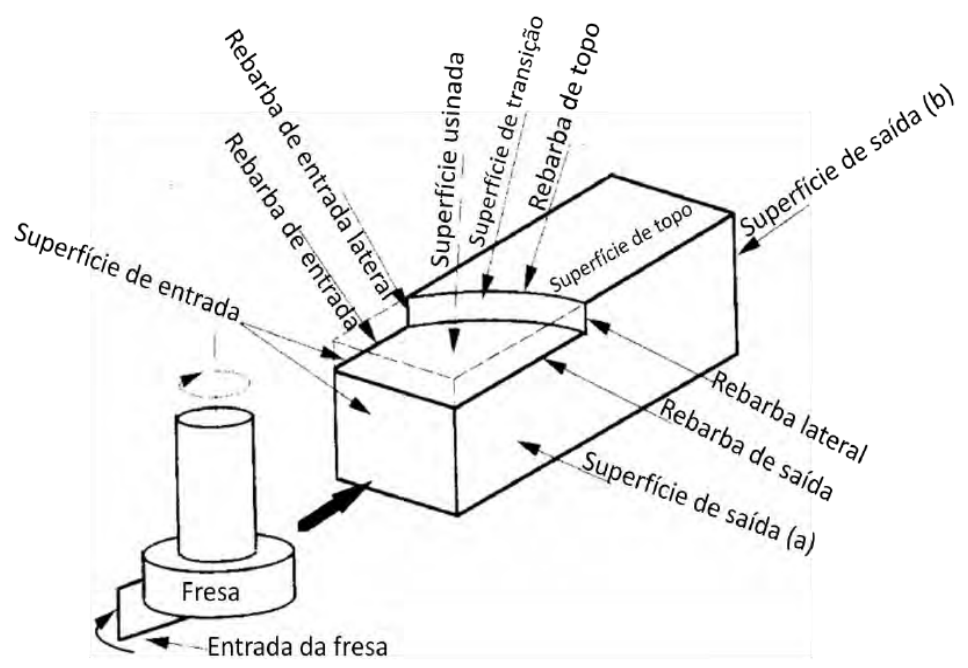

Figura 2.44 - Localização das rebarbas e superfícies utilizadas na classificação. (HASHIMURA et al., 1999)

Chern (1993) através de análises durante o fresamento de faceamento das ligas de alumínio AA 1100, AA 2024-T4 e AA 6061-T6, verificou o aparecimento de cinco tipos diferentes para as rebarbas, sendo elas (a) rebarba do tipo faca, (b) do tipo caracol, (c) do tipo onda, (d) do tipo breakout (em material frágil) e (e) do tipo secundário (participação da aresta secundária da ferramenta de corte), conforme verifica-se na Figura 2.45. Chern (1993) também verificou que estas morfologias das rebarbas são altamente dependentes do ângulo de borda de saída, ou ângulo formado entre a superfície de saída da ferramenta e a borda da peça.
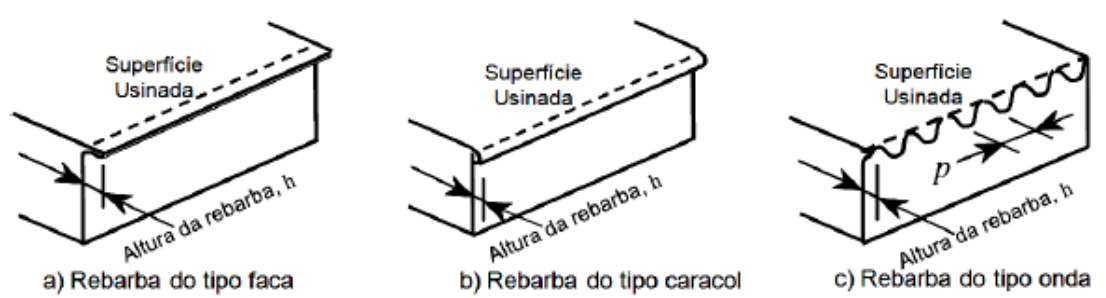

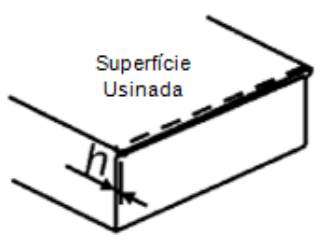

d) Rebarba do tipo secundário

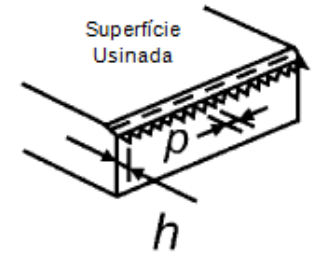

e) Rebarba do tipo Breakout

Figura 2.45 - Cinco morfologias de rebarbas observadas no processo de fresamento de faceamento. 
Lin (1999) após o fresamento de faceamento do aço inoxidável AISI 304 classificou as rebarbas em cinco tipos diferentes: (a) rebarba do tipo faca, (b) rebarba do tipo visível, (c) rebarba de ruptura, (d) rebarba do tipo caracol e (e) rebarba do tipo onda. A imagem de três destas morfologias de rebarbas aparecem nas imagens da Figura 2.46. A rebarba do tipo caracol, Figura 2.46a, ocorreu quando o ângulo de borda formado entre a superfície de saída da ferramenta com a borda da peça ficou entre $0^{\circ} \mathrm{e} 60^{\circ}$. A rebarba do ti po onda ocorreu para ângulos de borda de saída entre $60^{\circ}$ e $120^{\circ}$, conforme Figura 2. $46 \mathrm{~b}$ e a rebarba do tipo faca, conforme Figura $2.46 \mathrm{c}$, foram formadas para ângulos de borda de saída entre $120^{\circ} \mathrm{e}$ $180^{\circ}$.

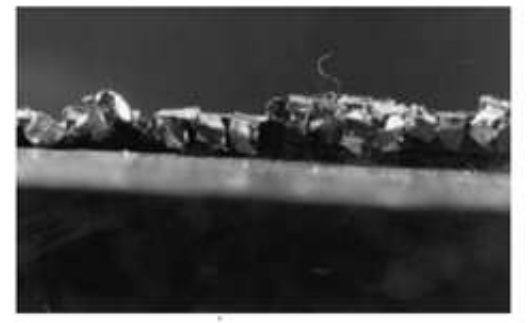

(a)

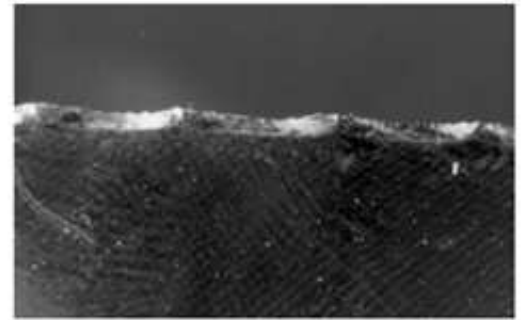

(b)

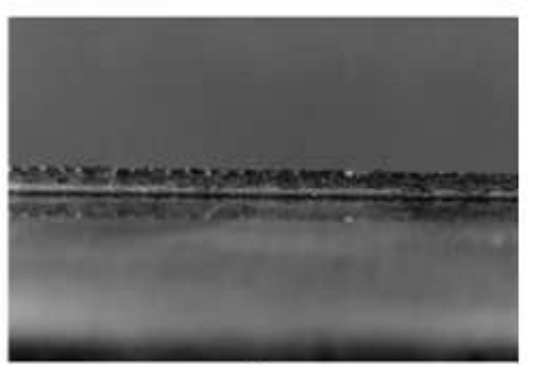

(c)

Figura 2.46 - Morfologias das rebarbas verificadas fresamento de faceamento do aço inoxidável AISI 304 (LIN, 1999)

\subsubsection{Influência dos parâmetros de usinagem na formação da rebarba}

Segundo Aurich (2009) é preciso diferenciar as investigações referentes ao processo de formação das rebarbas na usinagem das investigações sobre como minimizá-las. Gillespie e Blotter (1976) em seu trabalho, já havia observado que as 
rebarbas não podem ser evitadas alterando-se isoladamente parâmetros de usinagem como avanço, velocidade de corte ou geometria da ferramenta.

Essas variáveis de corte influenciam diretamente na formação das rebarbas e por isso devem ser levadas em conta na análise dos mecanismos de sua formação. Esses parâmetros estão em primeiro plano na influência sobre a formação de rebarbas $\mathrm{e}$ as suas dimensões podem ser minimizadas significativamente escolhendo-se dados de corte apropriados (AURICH et al, 2009).

A geometria da ferramenta também influencia as dimensões das rebarbas; o raio da aresta de corte e o raio de ponta da ferramenta possuem influência direta na espessura da raiz (HASHIMURA et al., 1999). O desgaste da ferramenta também está relacionado com as características da rebarba (entrada, saída lateral e inclinada) e também com suas dimensões geométricas (altura e espessura).

Olvera e Barrow (1996) encontraram pequenas diferenças nas dimensões das rebarbas em fresamento de faceamento produzidos por insertos com e sem cobertura e verificaram que insertos com raios nas pontas geram rebarbas maiores que insertos com arestas afiadas. Souza Jr (2001) revelou que ferramentas para fresamento com ângulo axial positivo e ângulo radial negativo resultam em um bom equilíbrio entre pequena altura de rebarba com boa qualidade superficial da peça.

Os efeitos de todos estes parâmetros sobre a formação da rebarba podem aparecer de forma isolada ou em conjunto. A seguir é apresentada uma abordagem da influência de alguns parâmetros de usinagem na formação da rebarba.

\subsubsection{Influência da velocidade de corte na formação da rebarba}

Olvera e Barrow (1996) verificaram em seu trabalho, no fresamento frontal do aço AISI 1040 (dureza de 180HB), a redução da altura da rebarba quando a velocidade de corte foi aumentada, já a espessura teve sua dimensão aumentada com o aumento da velocidade de corte. Observaram a redução de altura da rebarba em $50 \%$, quando a sua velocidade de corte foi dobrada.

Já Da Silva (2011), no fresamento de faceamento do aço inoxidável PH 13 $8 \mathrm{Mo}$, notou um pequeno aumento da altura da rebarba em relação ao aumento da 
velocidade de corte. E a velocidade demonstrou ter pouca significância na formação da rebarba em seu estudo, perante as outras variáveis estudadas.

\subsubsection{Influência do avanço na formação da rebarba}

Olvera e Barrow (1996) observaram uma diminuição da altura da rebarba em função do aumento do avanço, quando a mesma foi formada pela aresta principal de corte. Já quando a formação da rebarba se deu pela aresta secundária, notou-se o acentuado aumento de sua altura em função do avanço.

Da Silva (2004), na usinagem de blocos de motores em ferro fundido cinzento, observou que as rebarbas produzidas por ferramentas de cerâmicas são maiores que aquelas formadas por ferramentas de PCBN. Na Figura 2.47 pode-se observar também 0 decréscimo da altura da rebarba até 0 avanço de aproximadamente $0,06 \mathrm{~mm} /$ dente, para ferramenta de PCBN, aumentando ligeiramente, em seguida. Para a ferramenta de cerâmica, a altura da rebarba tem 0 mesmo comportamento no intervalo de $0,04 \mathrm{~mm} /$ dente até $0,10 \mathrm{~mm} /$ dente aproximadamente.

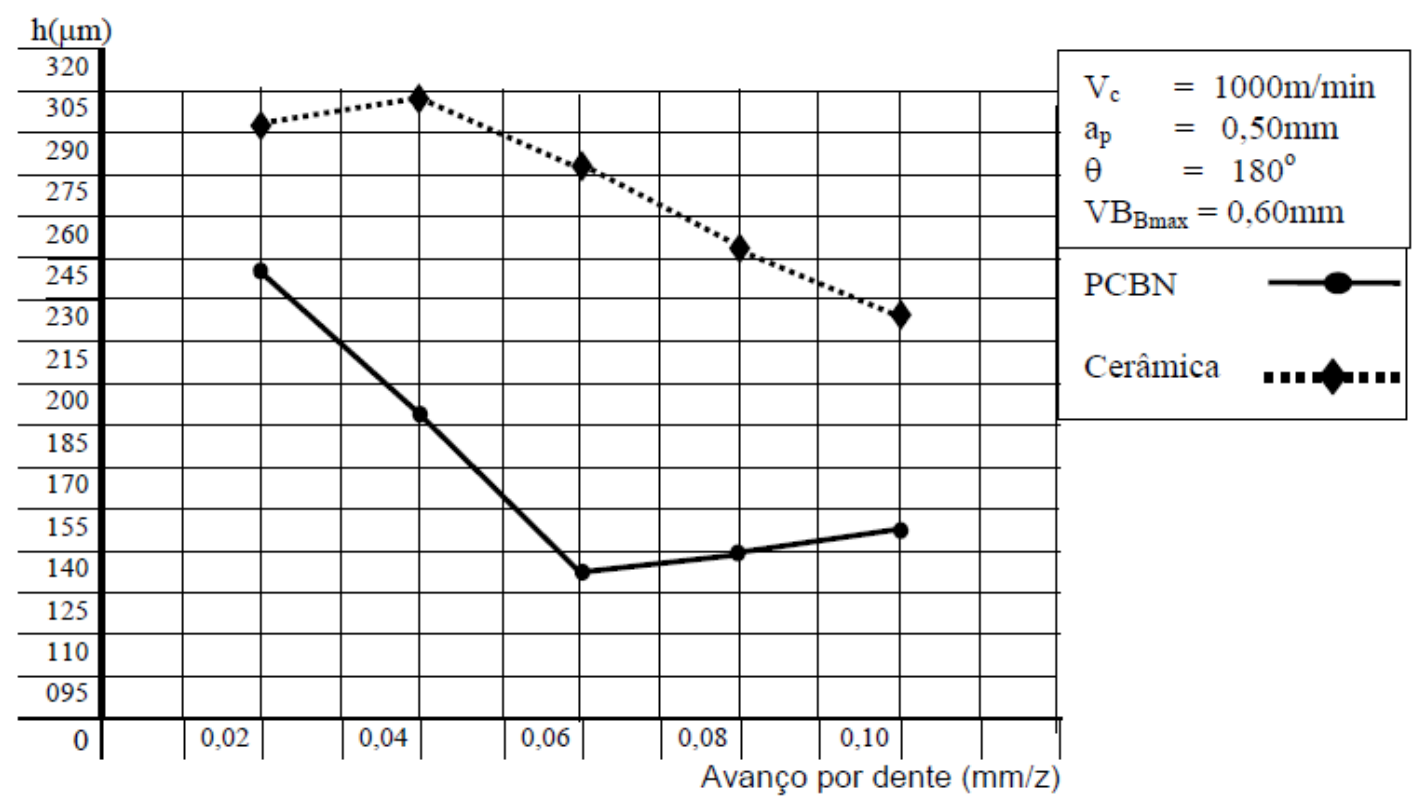

Figura 2.47 - Altura da rebarba em função do avanço por dente para ferramentas de PCBN e cerâmica, nas condições mostradas (DA SILVA, 2004) 
Da Silva (2004) conclui que a maior altura da rebarba para avanços menores ocorreu devido à alta taxa de deformação promovida pela ferramenta de corte nesta condição, devido à reduzida espessura do cavaco formado.

\subsubsection{Influência da profundidade de corte na formação da rebarba}

Em relação à profundidade de corte, Olvera e Barrow (1996) observaram que a rebarba do tipo Rollover (de encurvamento) teve altura correspondente à profundidade axial. Para outros tipos de rebarbas (aquelas geradas pela aresta principal) percebeu-se o crescimento da altura das mesmas em função do aumento da profundidade de corte em até $5 \mathrm{~mm}$ aproximadamente, já para a rebarba formada pela aresta secundária, sua altura manteve-se constante, principalmente para uma profundidade de corte acima de $0,5 \mathrm{~mm}$.

Da Silva (2004), verificou que para o ângulo de saída da peça de $180^{\circ}$, tanto utilizando-se insertos de cerâmica quanto insertos de PCBN, não ocorreu a presença de rebarba secundária. Portanto a rebarba formada tem seu comportamento crescente com o aumento da profundidade de corte, conforme é mostrado na Figura 2.48.

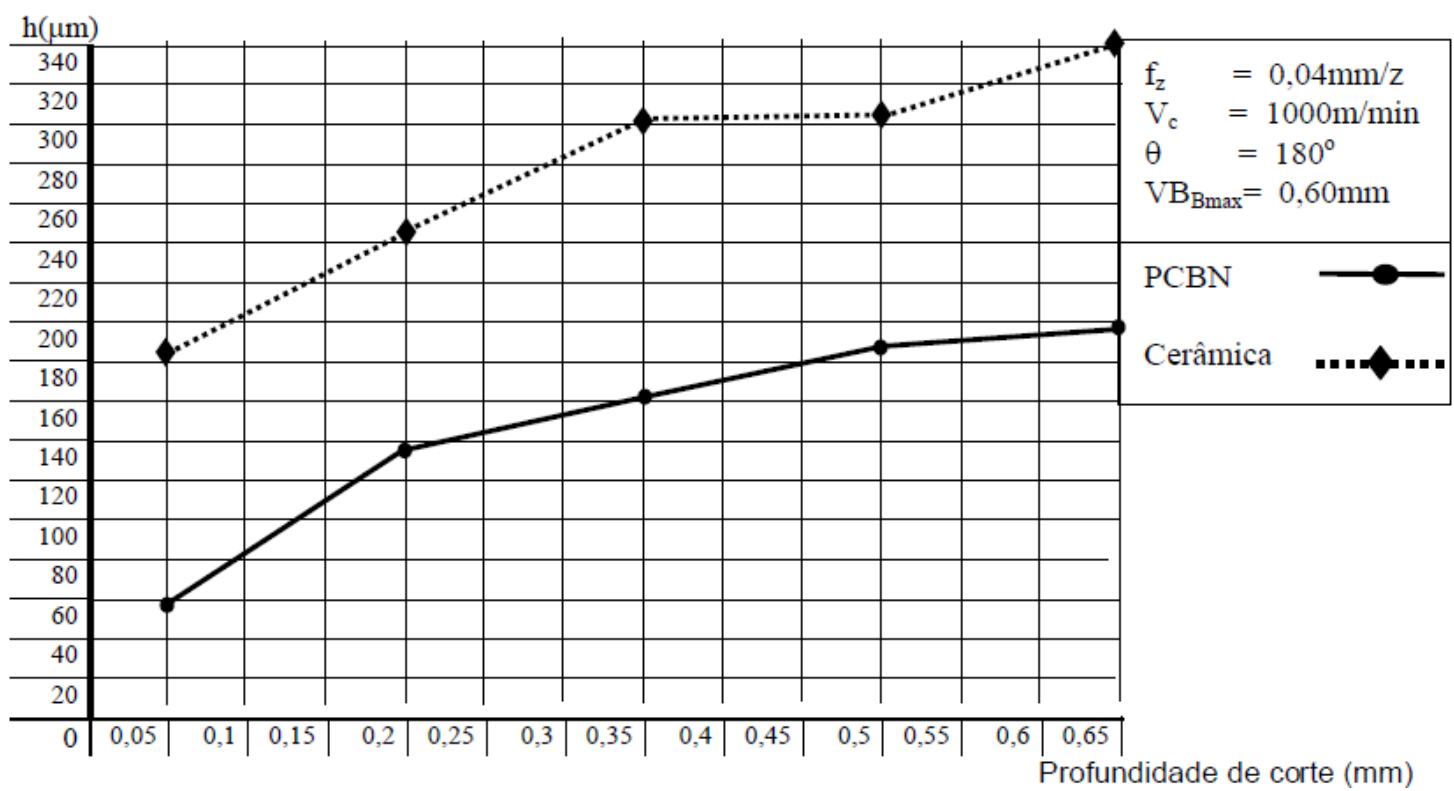

Figura 2.48 - Altura da rebarba em função do da profundidade de corte, para as condições mostradas (DA SILVA, 2004) 


\subsubsection{Influência dos ângulos de borda de entrada e de saída na formação da rebarba}

Conforme Da Silva (2004) em vários trabalhos de fresamento frontal, foi definido o ângulo de borda de saída ou ângulo de saída da ferramenta de corte da peça $(\theta)$, para também analisar a formação da rebarba de saída, uma vez que a mesma é altamente dependente do ângulo $(\theta)$. Aqui ele será definido como sendo o ângulo entre a tangente do vetor velocidade de corte, na saída, e a aresta da superfície livre da peça, medido no plano da superfície gerada pelo corte. Para a análise das rebarbas de entrada foi definido o ângulo de borda de entrada ou ângulo de entrada da ferramenta de corte na peça $(\psi)$ como sendo o ângulo entre a tangente do vetor velocidade de corte, na entrada, e a aresta da superfície livre da peça, medido no plano da superfície gerada pelo corte, conforme mostra a Figura 2.49 .

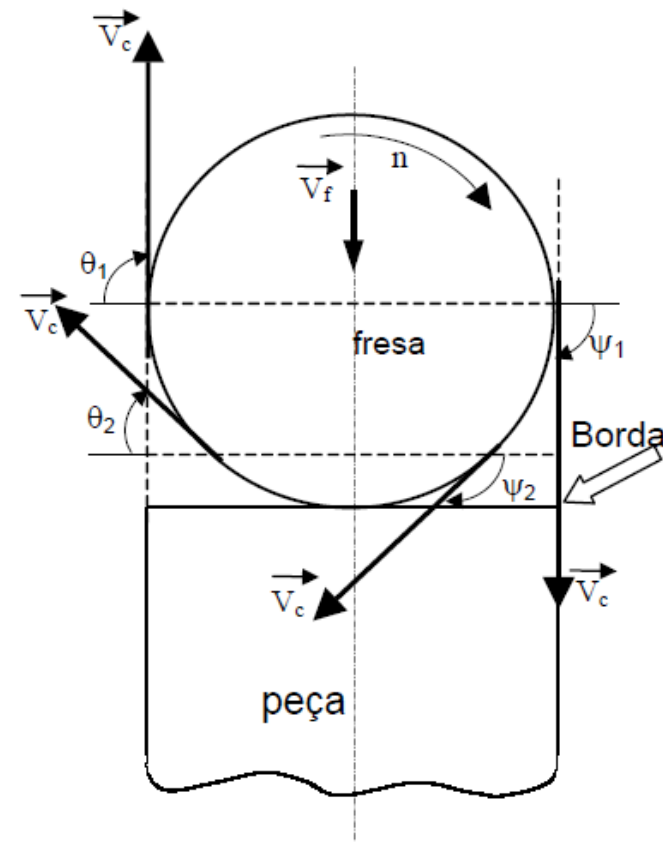

(a)

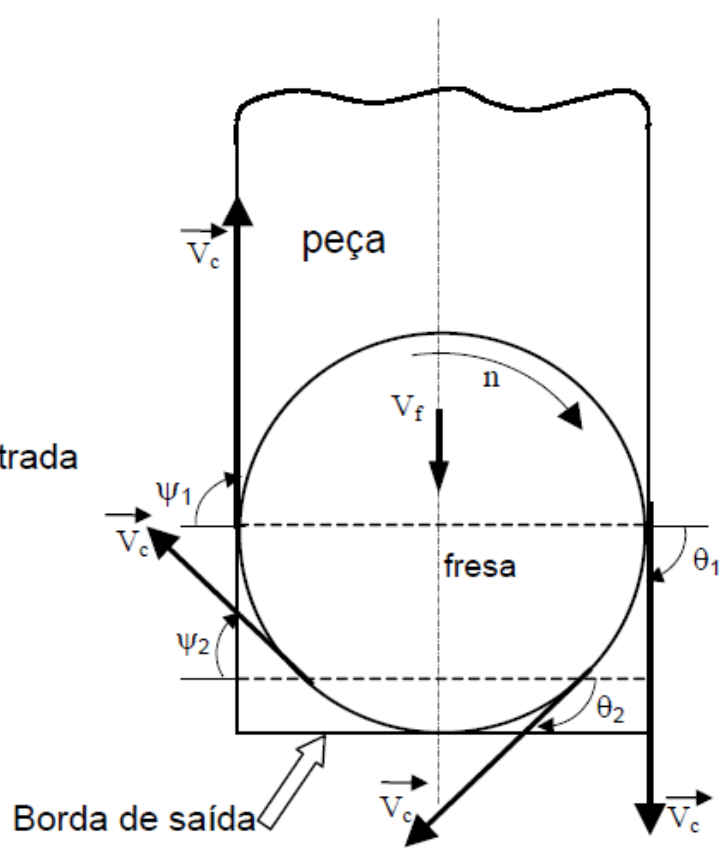

(b)

2.49 - Formação dos ângulos $\psi$ e $\theta$ na entrada e saída da fresa, (a) borda de entrada, (b) borda de saída (DA SILVA, 2004)

Olvera e Barrow (1996) verificaram que o ângulo de borda de saída , formado pela superfície de corte e a superfície de saída da ferramenta determina a 
altura da rebarba formada. $O$ tamanho da rebarba tende a diminuir com o aumento deste ângulo e, sobretudo para valores superiores a $150^{\circ}$.

Tripathi e Dornfeld (2004) observaram uma grande dependência das dimensões da rebarba em função do ângulo de saída/entrada da peça. Sua altura pode ser reduzida quando utilizado um ângulo com valores menores que o valor crítico de aproximadamente $120^{\circ}$, para uma dada condição de corte. Para ângulos menores que $30^{\circ}$ a dimensão da rebarba passa a ser desconsiderada.

Da Silva (2004), constatou em seu trabalho que as variáveis de maior influência na altura da rebarba foram o desgaste de flanco e o ângulo de saída de corte da ferramenta da peça.

\subsubsection{Formação do Breakout na usinagem dos metais}

No processo de usinagem, durante o corte contínuo, as tensões e deformações geradas concentram-se nas zonas de cisalhamento primárias e secundárias. À medida que a ferramenta de corte aproxima da borda da peça, as tensões e deformações estendem-se pela zona de cisalhamento negativa.

Dependendo das propriedades mecânicas do material que está sendo usinado, uma trinca que se inicia devido a ação da ponta da ferramenta poderá se propagar na direção do plano de cisalhamento e no sentido do ponto de pivotamento, promovendo a separação do material que está imediatamente acima do plano de cisalhamento negativo (Figura 2.50), formando o breakout (DA SILVA, 2004). 


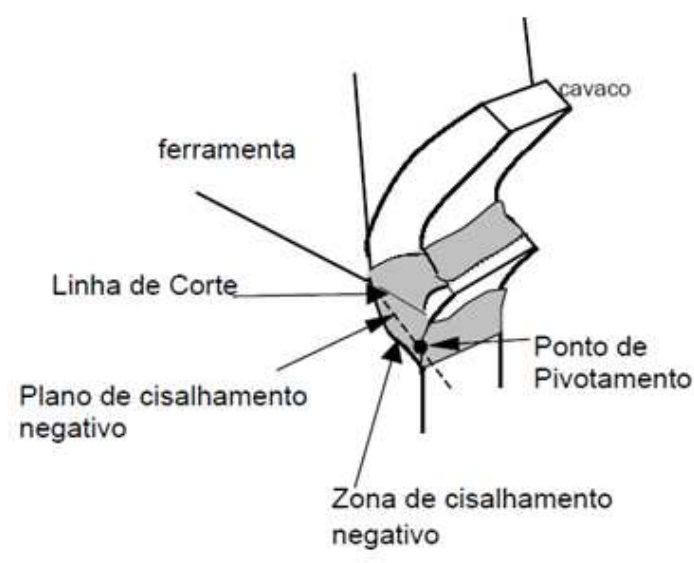

(a)

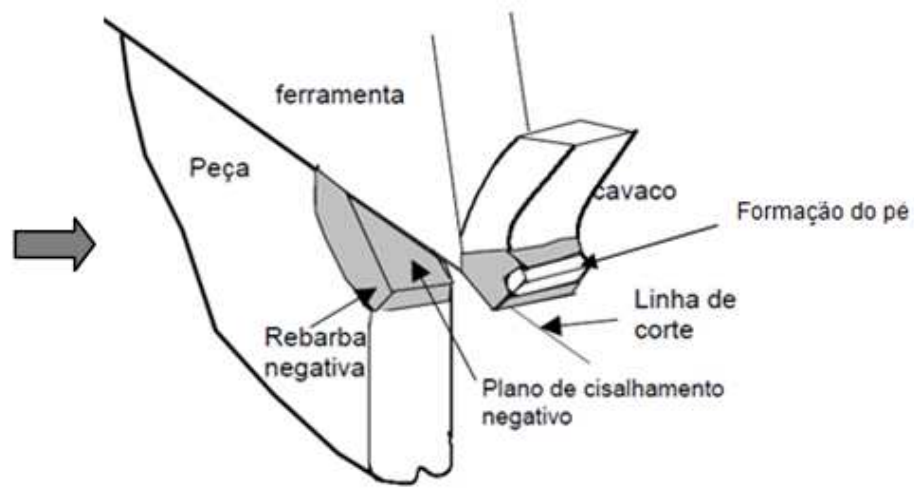

(b)

Figura 2.50 - (a) Plano de cisalhamento negativo ligando a ponta da ferramenta ao ponto de pivotamento, (b) Breakout formado na saída da ferramenta (HASHIMURA et al, 1999)

Da Silva (2004), durante o fresamento do ferro fundido cinzento do tipo GH190, verificou uma deformação plástica do material maior que a deformação crítica a fratura. A trinca iniciada na ponta da ferramenta de corte propagou-se na direção da zona de cisalhamento negativa, surgindo o breakout. Este fenômeno é bastante observado em materiais frágeis, e seu comportamento foi intensamente pesquisado por Pekelharing (1978), conforme mostrado na Figura 2.51.

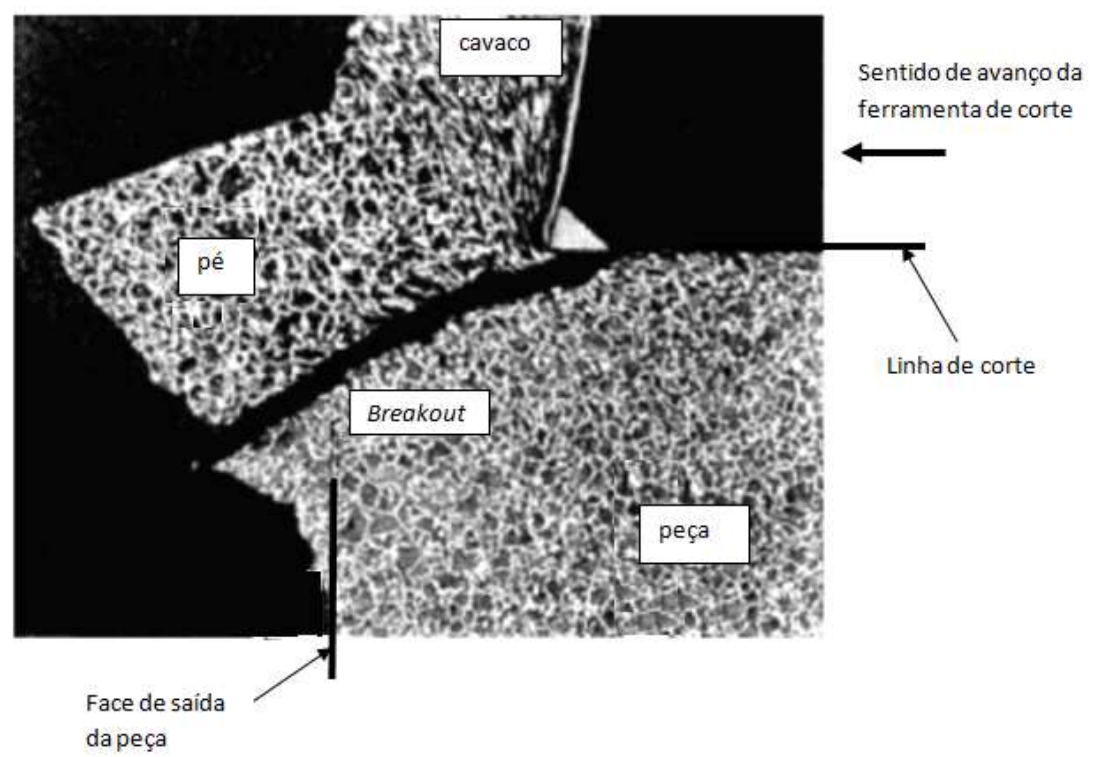

Figura 2.51 - Micrografia da raiz do cavaco mostrando a formação da rebarba negativa (PEKELHARING, 1978) 


\subsection{PLANEJAMENTO DE EXPERIMENTOS}

Bons resultados obtidos após operações de usinagem estão relacionados diretamente com a realização das medições das características desejadas, seleção de máquina, fixação e ferramentas de corte apropriadas vinculadas a condições de corte ideais. Estes são também elementos essenciais no processo de planejamento do processo de usinagem, pois suas características sofrem influência significativa dos diferentes parâmetros de usinagem. Porém, uma experimentação pode ser planejada e para isso existem técnicas de planejamento de experimentos que auxiliam nas investigações dessas interferências no processo.

O planejamento de experimento (Design Of Experiments - DOE) é uma metodologia muito utilizada em qualquer segmento que se pretende investigar a importância das variáveis envolvidas em determinado processo. A sua notabilidade pode ser melhor observada no desenvolvimento de experimentos em que a quantidade de variáveis é elevada, apesar de ser utilizada em situações que envolvam duas variáveis de entrada apenas.

Segundo Calado e Montgomery (2003) através do planejamento de experimentos pode-se determinar as variáveis que exercem maior influência em um processo utilizando-se dos seguintes resultados:

- Redução da variação do processo e melhor concordância entre os valores nominais obtidos e valores pretendidos;

- Redução do tempo do processo;

- Redução do custo operacional;

- Melhorias no rendimento do processo.

Conforme Da Silva (2011) dentre as diversas vantagens da aplicação do planejamento de experimento a influência das interações entre duas ou mais variáveis do processo podem ser claramente obtidas, desde que o tipo da técnica do planejamento de experimento seja corretamente selecionado. $O$ diagrama de bloco da Figura 2.52 identifica o processo de um sistema quando tratado por planejamento de experimentos. 


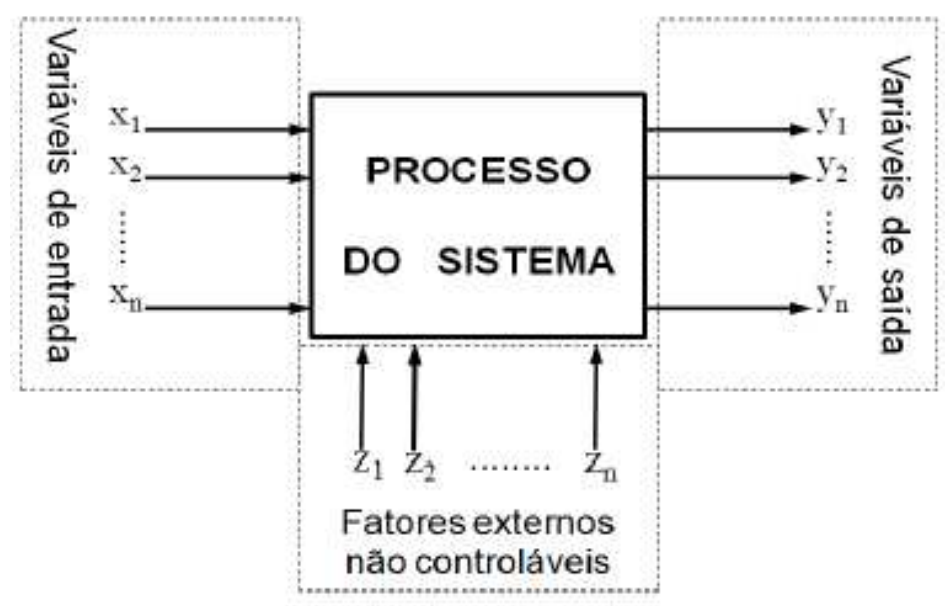

Figura 2.52 - Processo do sistema representado pelo planejamento de experimento (DA SILVA, 2011)

Ainda segundo Da Silva (2011) na Figura 2.52 identificam-se as variáveis de entrada como as variáveis que se pretende manipular ou controlar, também conhecidas como fatores, enquanto que as variáveis de saída são as respostas que se pretende obter. Os fatores externos não controláveis são perturbações ou ruídos indesejáveis que aparecem durante os ensaios e são característicos de cada processo.

Conforme Calado e Montgomery (2003) os três princípios básicos de um planejamento de experimentos ideal são a replicação, a aleatoriedade e a blocagem. Onde a replicação dos ensaios permite a obtenção de uma estimativa do erro experimental. A aleatoriedade dos experimentos permite independência das variáveis e erros durante sua análise. A blocagem tem a função de avaliar e controlar a presença de fatores externos não controláveis ou outros ruídos que possam perturbar o processo.

O planejamento experimental permite eficiência e economia no processo experimental e o uso de métodos estatísticos na análise dos dados obtidos resulta em objetividade científica nas conclusões.

\subsubsection{Planejamento Fatorial}

Dentre as técnicas de planejamento de experimentos o planejamento fatorial é o mais utilizado, pois trata de uma técnica capaz de analisar o comportamento de duas ou mais variáveis de entrada, denominadas por fatores, no processo. A sua 
importância é notada na medição das influências, denominadas de efeitos e dos fatores sobre as variáveis de saída. Portanto no planejamento fatorial devem-se conhecer inicialmente, quais fatores devem ser manipulados ou controlados e quais respostas são de maior interesse durante o processo.

Conforme Calado e Montgomery (2003) os planejamento fatoriais são frequentemente utilizados nos experimentos envolvendo vários fatores em que é necessário estudar o efeito conjunto dos fatores, denominados por efeitos de interação, sobre uma variável de resposta, sendo esta considerada a única maneira de obter as interações entre as diversas variáveis de entrada.

Segundo Da Silva (2011) dá-se o nome de níveis aos valores das variáveis de entrada, sendo estes fornecidos em intervalos ou valores discretos. No planejamento fatorial são utilizados dois ou três níveis para cada variável de entrada, podendo estes ser quantitativos ou qualitativos bem como alto e baixo ou valores máximo e mínimo. $O$ arranjo entre os níveis dos fatores permite a obtenção dos efeitos com uma menor quantidade de ensaios.

$\mathrm{Na}$ elaboração de planejamentos fatoriais alguns procedimentos devem ser verificados para sua exata aplicação:

- Escolha dos fatores;

- Seleção dos níveis;

- Escolha das variáveis de saída;

- Seleção do modelo de planejamento de experimento;

- Realização dos experimentos;

- Análise dos dados. 


\section{MATERIAIS E MÉTODOS}

Neste capítulo é apresentada a descrição dos materiais a serem usinados e os sistemas de medição e controle adotados, da metodologia aplicada na realização dos ensaios e os equipamentos e ferramentas utilizadas em todo o procedimento experimental.

\subsection{MATERIAIS}

A empresa TUPY Fundições situada na cidade de Joinville no estado de Santa Catarina realizou a fundição dos blanks de ferro fundido vermicular, classe FV 450, Norma ISO 16112/2006 JV450. Os blanks fundidos foram preparados com as dimensões de $450 \times 250 \times 35$ mm (Figura 3.1).
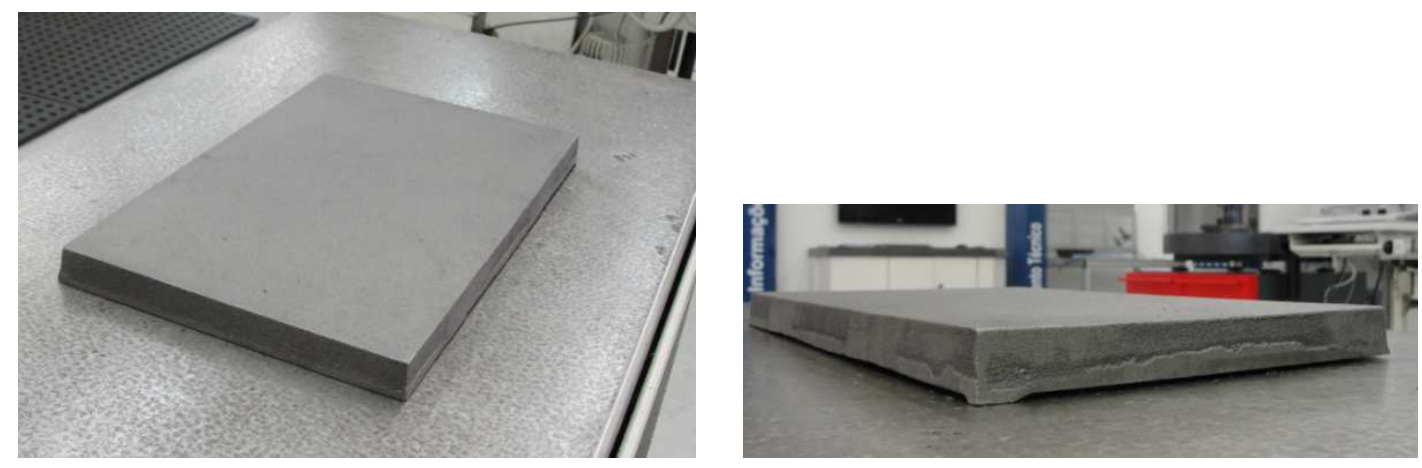

Figura 3.1 - Placas em ferro fundido vermicular fornecidas pela Tupy Fundições, para preparo dos corpos de prova

A preparação dos corpos de prova a partir dos blanks fundidos foi realizada no centro de treinamento da empresa B. GROB do Brasil situado na cidade de São Bernardo do Campo no estado de São Paulo. Os materiais foram preparados para simular a usinagem da face de fogo de um bloco de motor BigBore MAXXFORCE ${ }^{\mathrm{TM}}$ 11 , em escala reduzida de 4 vezes, com o apoio da empresa MWM International situada em Santo Amaro, São Paulo.

A Figura 3.2a mostra o bloco de motor BigBore MAXXFORCE ${ }^{\mathrm{TM}} 11$ fundido pela empresa TUPY Fundições e usinado na empresa MWM International. Na Figura 
3.2b é possível visualizar o modelo em 3D do projeto em escala da face de fogo do bloco de motor, e na Figura 3.2c, tem-se o corpo de prova pronto para os ensaios da segunda etapa.

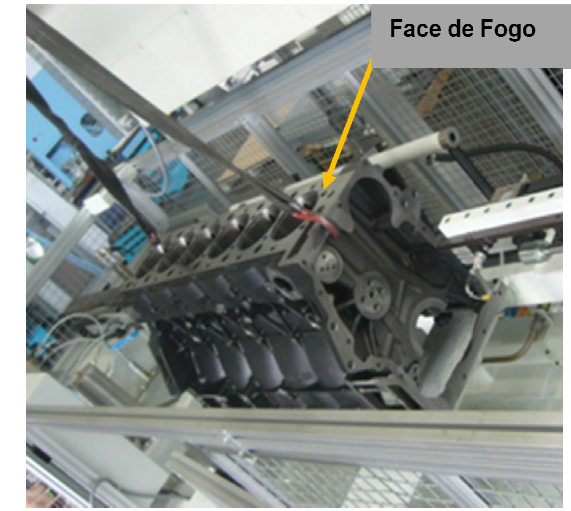

(a)

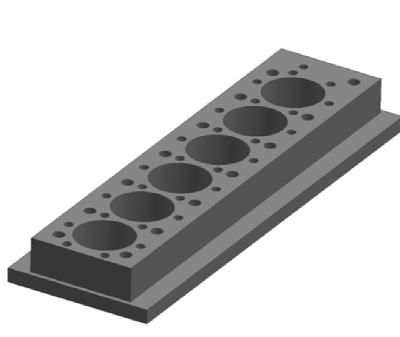

(b)

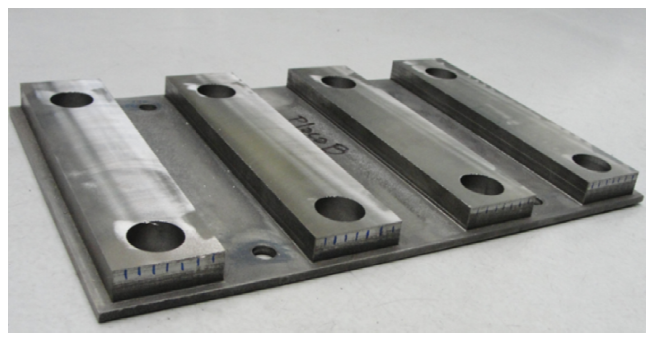

(c)

Figura 3.2 - (a) Bloco de motor MWM - BigBore MAXXFORCE ${ }^{\mathrm{TM}} 11$ em CGI; (b) Modelo em 3D do corpo de prova similar a face de fogo do bloco de motor; (c) Corpo de prova pronto para os ensaios

\subsection{PROPRIEDADES E MICROESTRUTURA}

O material usado neste trabalho é o ferro fundido vermicular, classe FV450 Norma ISO 16112/2006 JV450. A composição da liga é a mesma utilizada na fabricação de blocos de motores, estando dentro das faixas recomendadas pela literatura.

A análise química, metalográfica, de dureza e de propriedades mecânicas dos materiais dos corpos de prova foram fornecidos pela empresa TUPY Fundições. Os dados são apresentados nas Tabelas 3.1, 3.2, 3.3 e 3.4. Segundo a Empresa, as amostras fornecidas para análise, estão com propriedades e composições químicas iguais às dos blocos de motores utilizados como referência para este trabalho.

Tabela 3.1 - Composição química do ferro fundido vermicular utilizado para realização dos ensaios

\begin{tabular}{|c|c|c|c|}
\hline C (\%) & Si (\%) & Mn (\%) & S (\%) \\
\hline 3,58 & 2,22 & 0,31 & 0,005 \\
\hline
\end{tabular}


Tabela 3.2 - Dureza Brinell média dos corpos de prova

\begin{tabular}{|c|c|c|}
\hline & $\begin{array}{c}\text { Dureza } \\
\text { Superficial }\end{array}$ & $\begin{array}{c}\text { Dureza do } \\
\text { núcleo }\end{array}$ \\
\hline Dureza Média & $246 \mathrm{HB}$ & $241 \mathrm{HB}$ \\
\hline Desvio Padrão & 4 & 4 \\
\hline
\end{tabular}

Tabela 3.3 - Propriedades Mecânicas do material utilizado nos ensaios

\begin{tabular}{|c|c|c|}
\hline Propriedade & Média & Desvio \\
\hline$\sigma r[\mathrm{MPa}]$ & 431 & 5 \\
\hline$\sigma_{e}[\mathrm{MPa}]$ & 355 & 6 \\
\hline $\mathrm{A} \%$ & 0,4 & 4 \\
\hline
\end{tabular}

Tabela 3.4 - Porcentagem de Perlita, Forma da Grafita e Nodularidade na estrutura do material utilizado nos ensaios

\begin{tabular}{|c|c|c|}
\hline Matriz & Forma da Grafita & Nodularização \\
\hline $\begin{array}{c}\text { 1\% Ferrita } \\
99 \% \text { Perlita }\end{array}$ & III (85\%) & $7 \%$ \\
\hline
\end{tabular}

O laboratório de metalurgia do Instituto Mauá de Tecnologia realizou através de algumas amostras fornecidas dos corpos de provas, fotos com a micrografia mostrando a morfologia da grafita (Figura 3.3) e a micrografia mostrando a estrutura da matriz, conforme ilustra a Figura 3.4. 


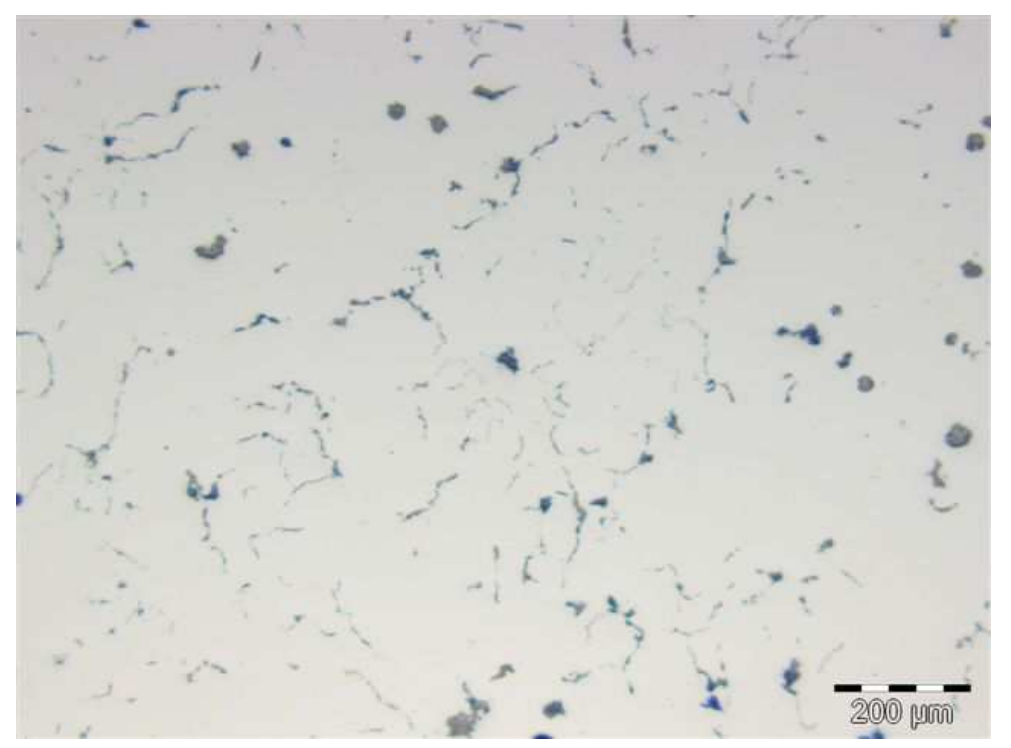

Figura 3.3 - Micrografias mostrando a morfologia da grafita - forma III $\approx 85 \%$ e forma $\mathrm{VI} \approx 15 \%$.

Sem ataque.

A caracterização da perlita é importante, visto estar diretamente ligada à quantidade de cementita $\left(\mathrm{Fe}_{3} \mathrm{C}\right)$ na estrutura do material, influenciando significativamente sua usinabilidade. Segundo a análise metalográrfica realizada, a estrutura metálica caracterizou-se por ausência de cementita livre e de carbonitreto de titânio. Visto que perlitas com maiores quantidades de cementita, também conhecida como perlita grosseira, ou seja, lamelas mais unidas e espessas tendem a ter pior usinabilidade (MOCELLIN, 2007).

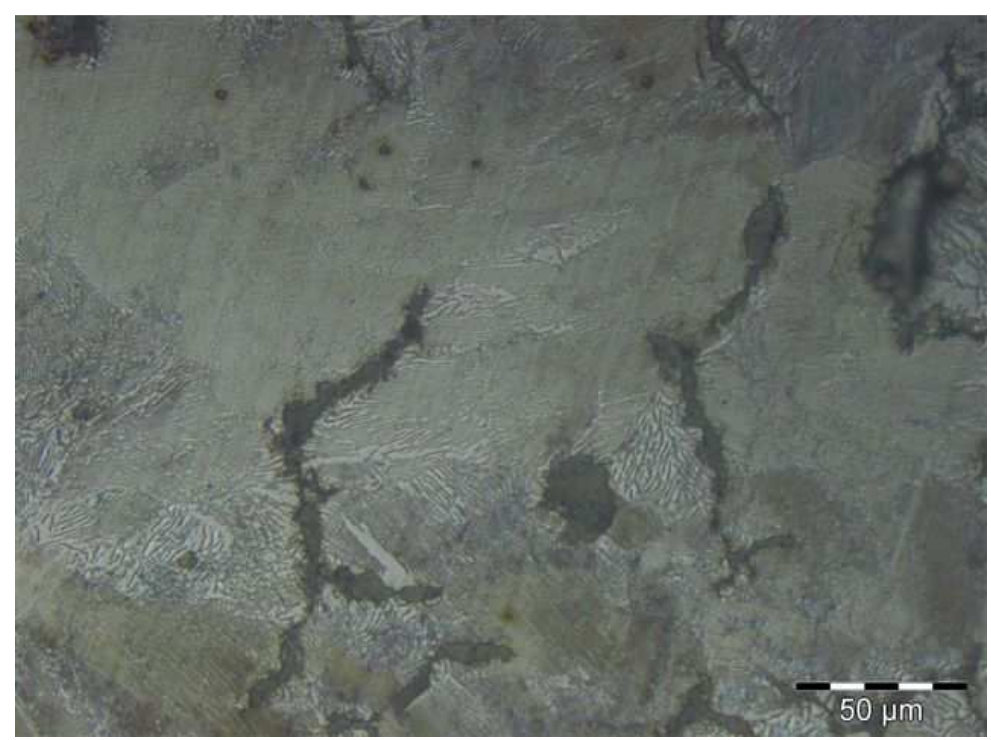

Figura 3.4 - Micrografias mostrando a estrutura da matriz metálica - matriz perlítica. Com ataque nital $3 \%$ 


\subsection{GEOMETRIA ENSAIADA}

O blank usinado a ser utilizado nos ensaios foi desenvolvido respeitando as características geométricas originais de um bloco de motor, principalmente 0 diâmetro do furo do cilindro, comprimento e a largura da face de fogo.

Para se aproximar das condições de usinagem, como por exemplo, choques mecânicos da aresta de corte com a peça e a conseqüente avaliação da formação da rebarba, na primeira etapa dos ensaios foram realizados todos os furos presentes na face de fogo do bloco de motor que serviu de referência para este trabalho, respeitando a escala imposta de 1/4, (Figura 3.5).
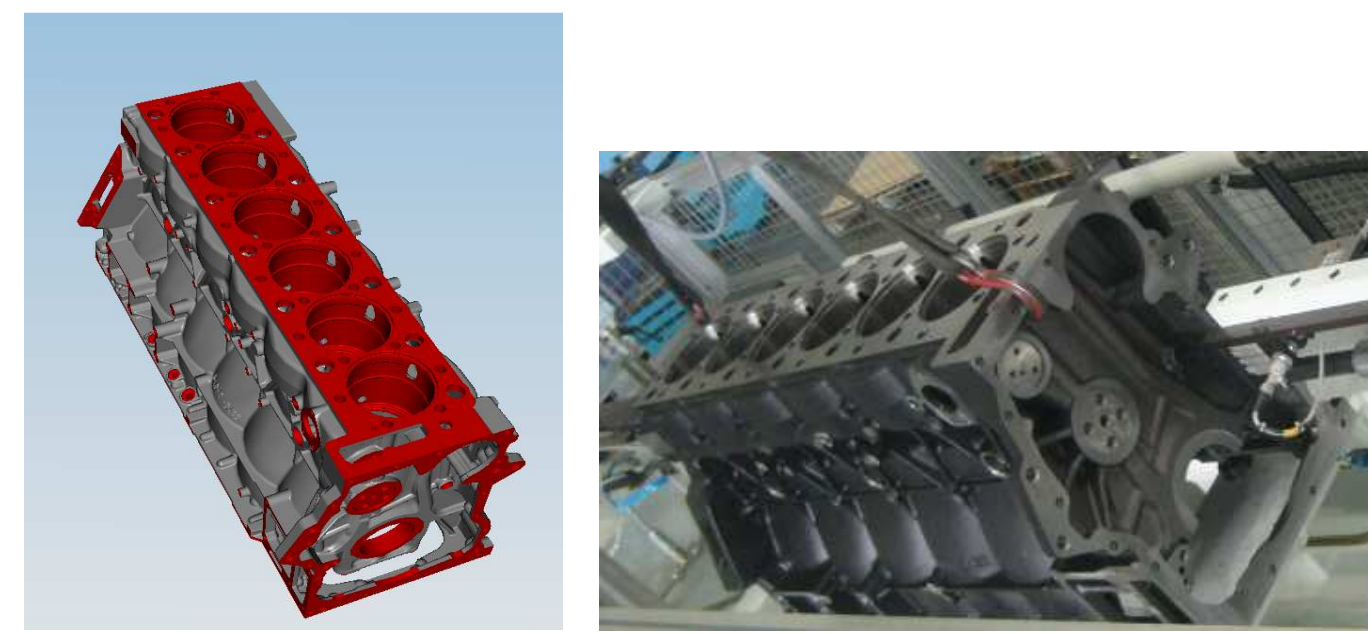

Figura 3.5 - (a) Modelo 3D do bloco de motor diesel referência para este projeto; (b) Bloco de motor MWM Big Bore MaxxForce (Fonte: B. GROB do Brasil)

O objetivo foi simular o contato entre peça e ferramenta nos furos das galerias de refrigeração do bloco do motor e nos furos roscados para a fixação do cabeçote no bloco e garantir nesta escala tanto da ferramenta de corte quanto da face usinada que os ângulos de entrada e de saída da ferramenta de corte na peça sejam os mesmos encontrados na usinagem do bloco de motor na linha de produção atual, conforme mostra a Figura 3.6. As coordenadas dos furos não serão divulgadas em comum acordo com a empresa que apóia este trabalho. 


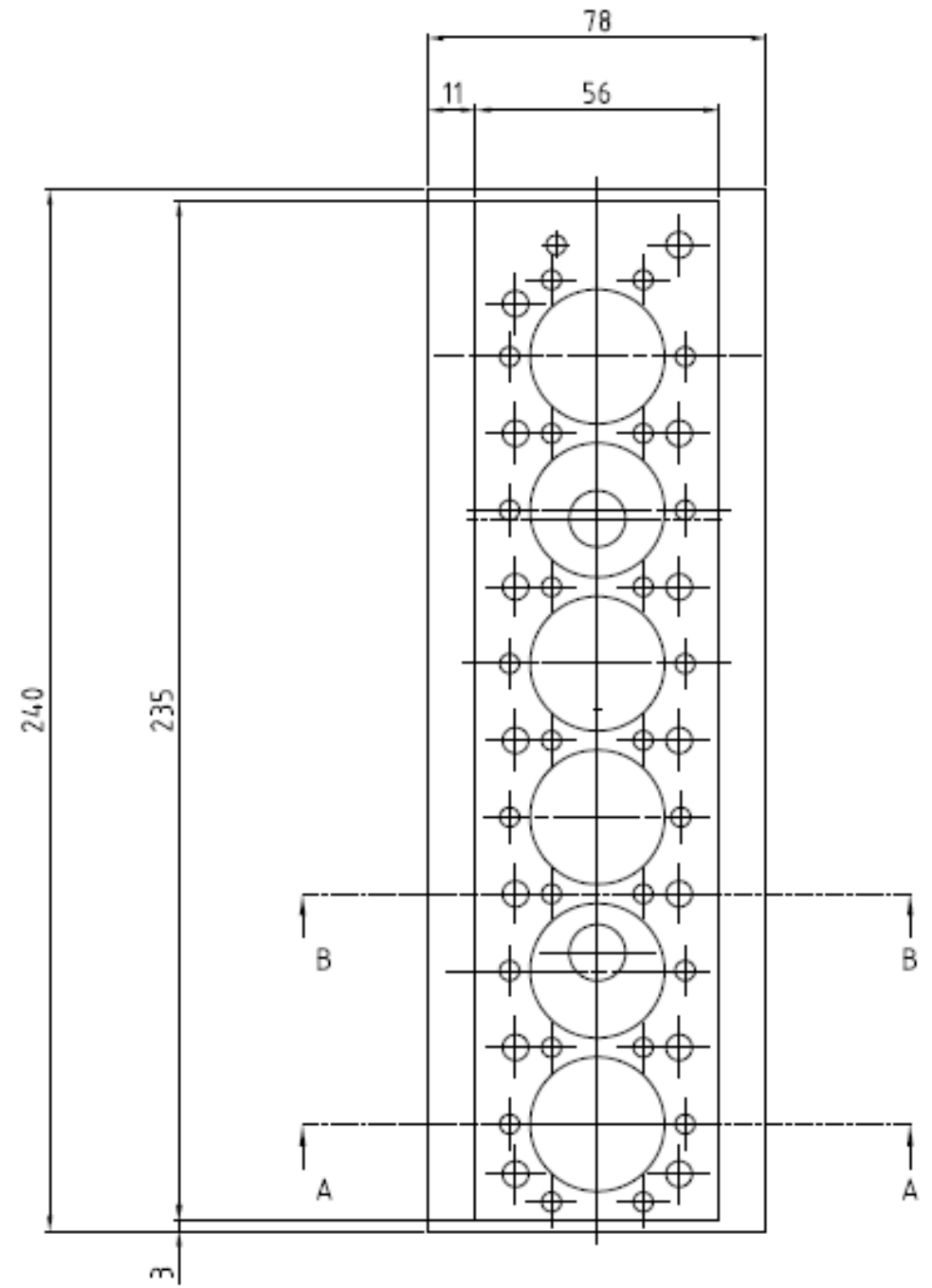

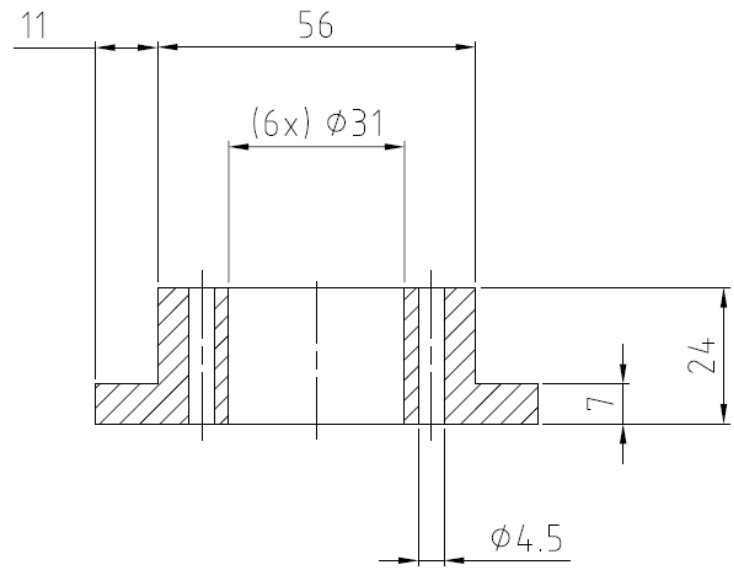

$A-A$

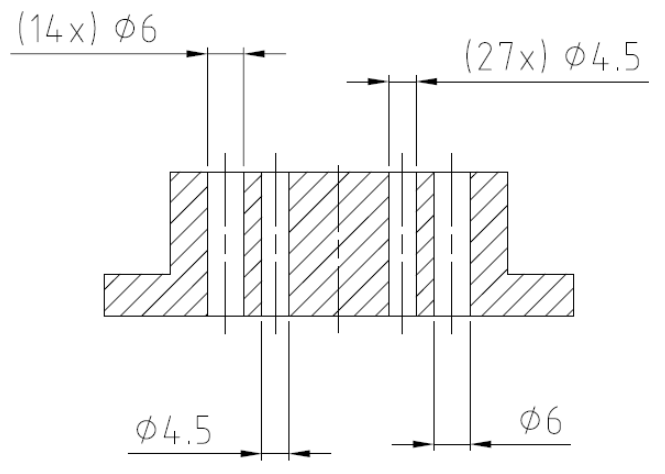

$B-B$

Figura 3.6 - Desenho do corpo de prova utilizados na primeira etapa dos ensaios. 
A Figura 3.7 mostra o blank usinado pronto para a realização dos ensaios da primeira etapa. Cada blank usinado é composto de uma superfície já desbastada com $240 \mathrm{~mm}$ lineares, $56 \mathrm{~mm}$ de largura e $14 \mathrm{~mm}$ de altura útil para a usinagem.
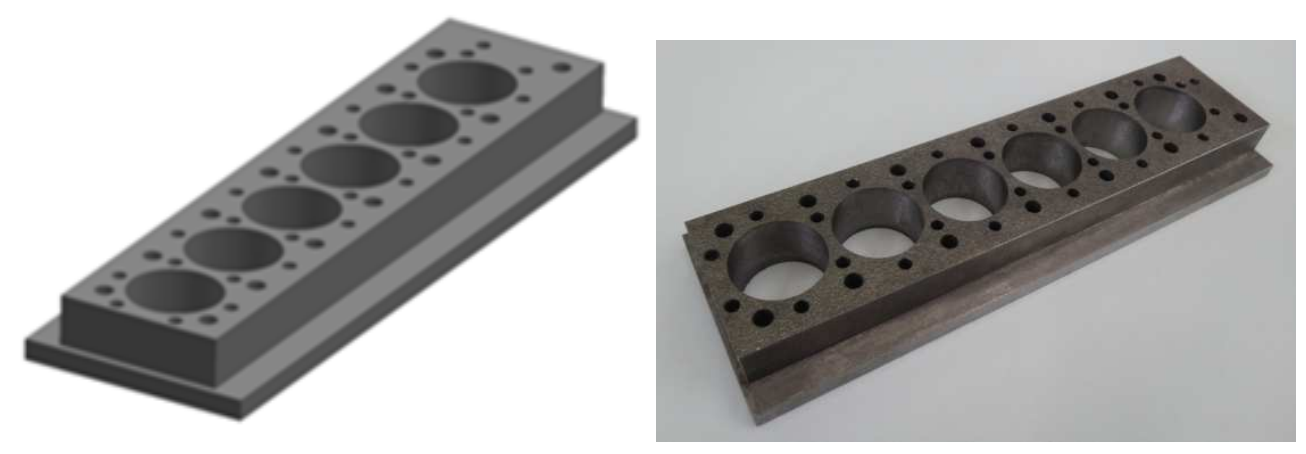

Figura 3.7 - (a) Modelos em 3D dos corpos de prova, (b) Corpos de prova prontos para realização dos ensaios de usinagem da primeira etapa.

Após a realização dos ensaios da primeira etapa, os corpos de prova da segunda etapa foram confeccionados guardando a mesma escala geométrica dos corpos de prova da primeira etapa, mas considerando apenas dois dos furos representativos dos cilindros usinados, pois o objetivo desta etapa foi avaliar principalmente a borda de saída da peça (Figura 3.8).
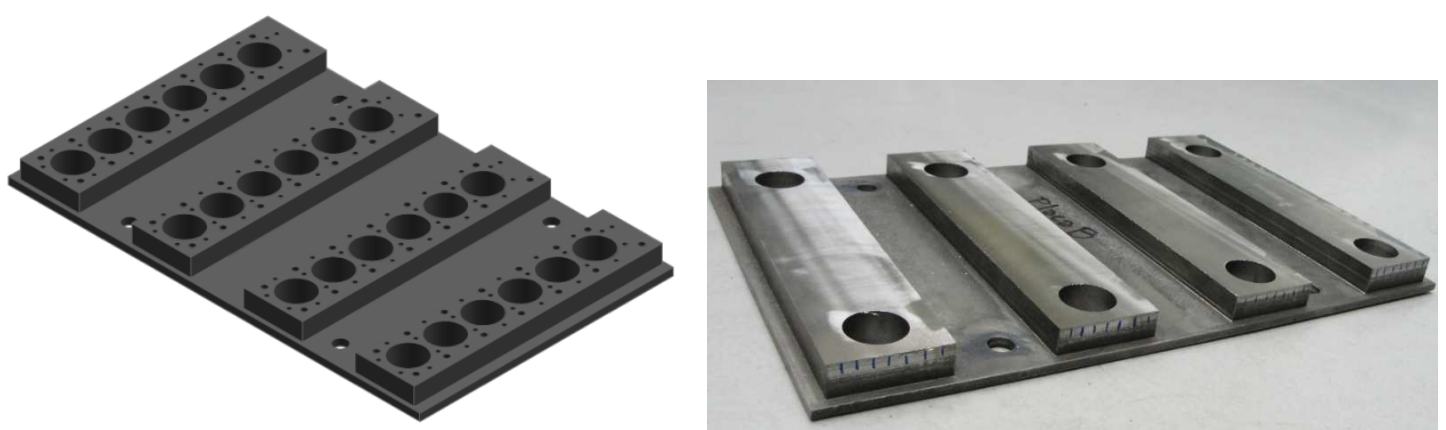

Figura 3.8. (a) Modelo 3D dos corpos de prova, (b) Corpo de prova preparado para a realização da segunda etapa dos ensaios de usinagem. 


\subsection{EQUIPAMENTOS}

\subsubsection{Máquina Ferramenta}

A máquina ferramenta (Figura 3.9) utilizada para a realização da primeira etapa dos ensaios, foi uma fresadora universal Romi U-30, cone ISO 40, com potência disponível de $6,0 \mathrm{cv}$, rotação máxima de $4.000 \mathrm{rpm}$. A fresadora está instalada na Escola Técnica da empresa B.GROB do Brasil.

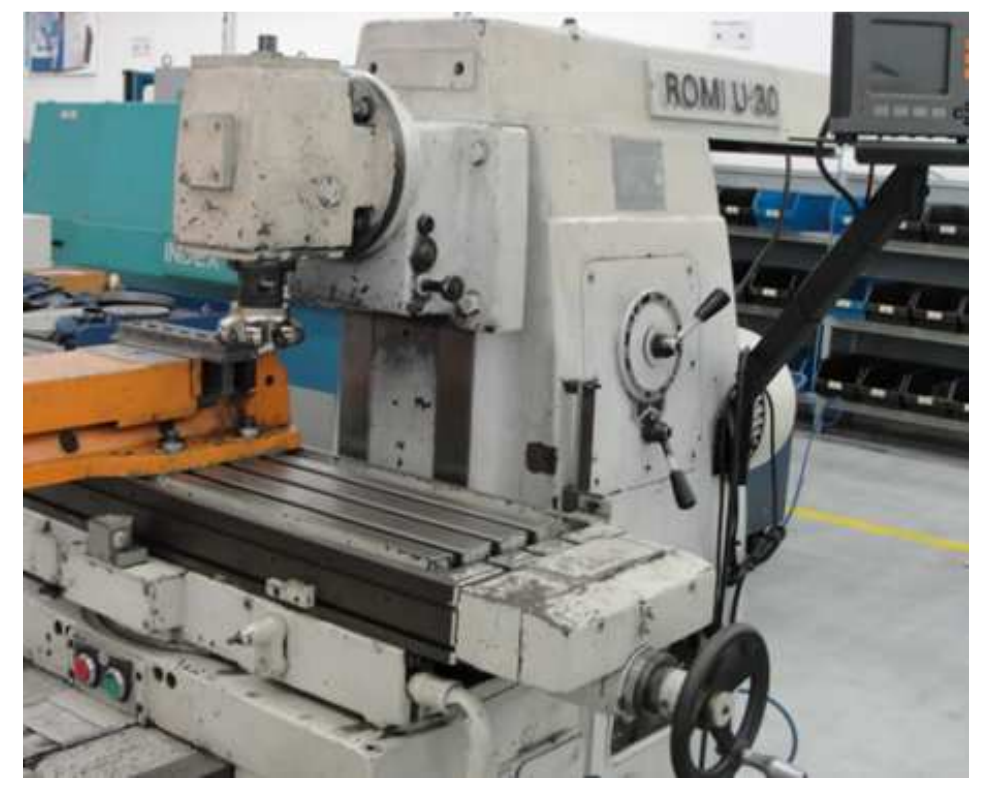

Figura 3.9 - Fresadora CNC utilizada para a realização dos ensaios da primeira etapa.

A máquina utilizada para a realização dos ensaios da segunda etapa, foi um centro de usinagem universal de 5 Eixos GROB, Módulo G550, com cone HSK63, rotação máxima de $12.000 \mathrm{rpm}$, potência $52 \mathrm{~kW}$ e torque 82,8 N.m. A máquina está instalada no Centro de Aplicação Tecnológica (CAT) da Empresa B. GROB do Brasil, conforme mostra a Figura 3.10. 


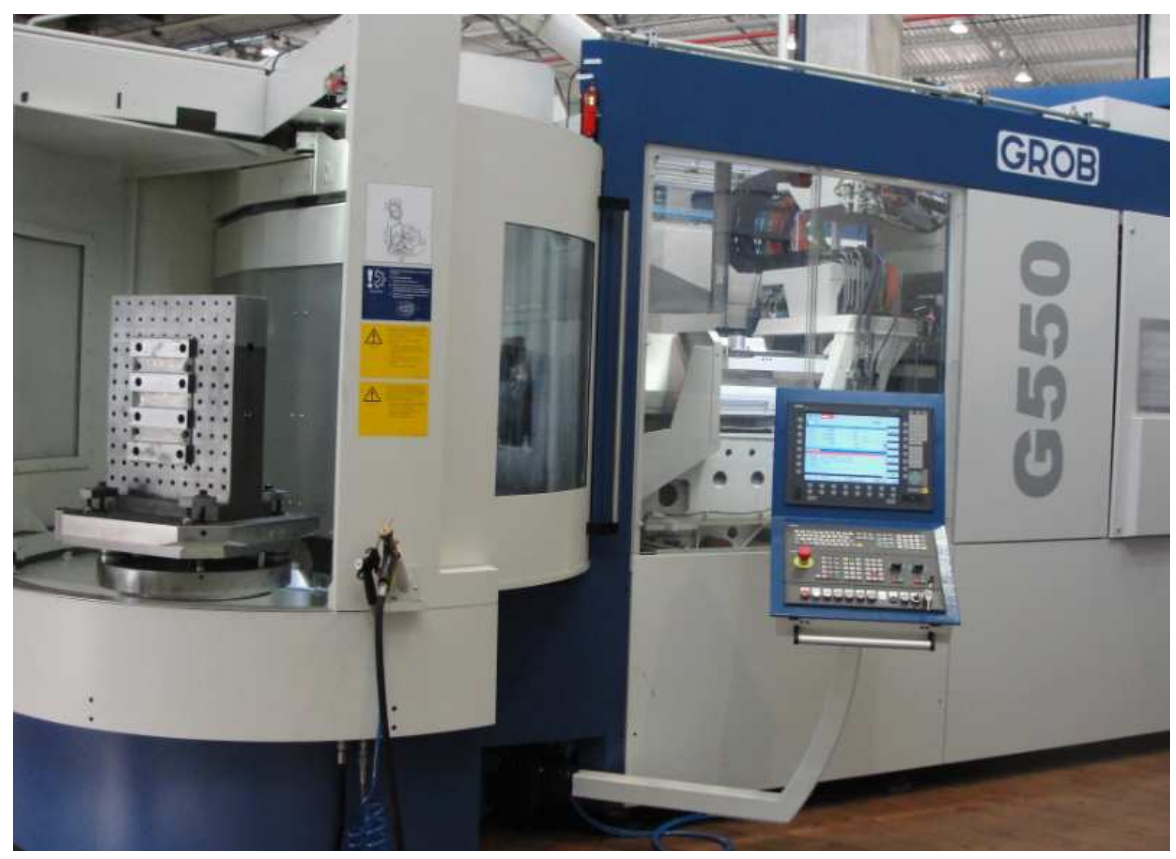

Figura 3.10 - Máquina utilizada para realização dos ensaios da segunda etapa.

A Figura 3.11 mostra a placa usinada pronta para a realização dos ensaios no centro de usinagem. Cada placa é composta de quatro superfícies pré usinadas com $240 \mathrm{~mm}$ lineares, $56 \mathrm{~mm}$ de largura e $14 \mathrm{~mm}$ de altura útil para a usinagem.

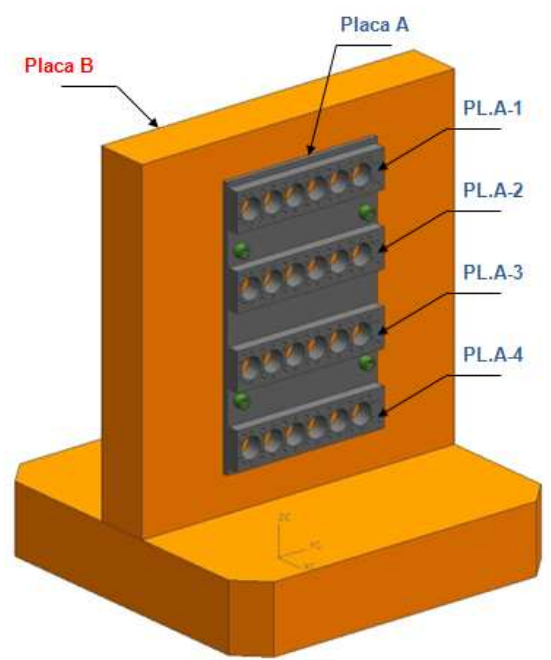

(a)

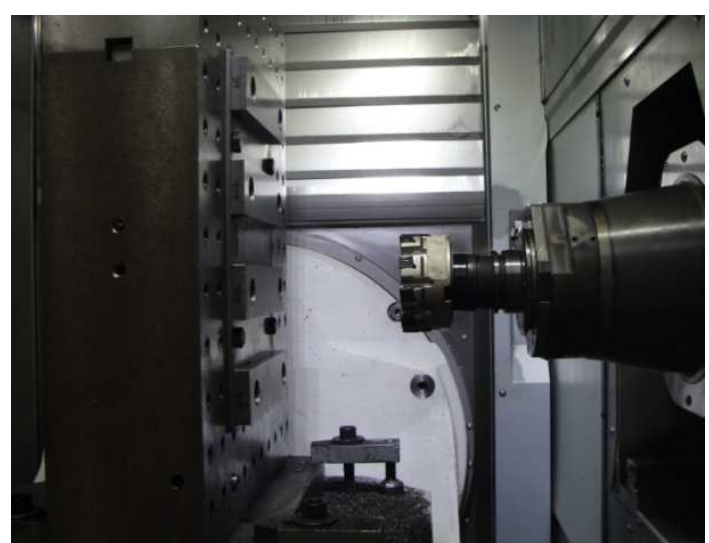

(b)

Figura 3.11 - (a) Modelo 3D esquematizando a fixação das placas na cantoneira. (b) Corpo de prova fixado na cantoneira sobre a mesa do centro de usinagem para a realização dos ensaios. 


\subsubsection{Ferramentas de corte}

Com o objetivo de avaliar a influência da geometria da ferramenta na altura da rebarba, foram avaliadas nos ensaios da primeira etapa três concepções diferentes de fresas conforme descrito a seguir.

Foi utilizada a mesma penetração de trabalho encontrada nas linhas de usinagem do bloco de motor que serviu de referencia para este trabalho, portanto foi utilizado para a realização dos ensaios fresas com diâmetro de $100 \mathrm{~mm}$, o que representa $56 \%$ de ocupação da fresa na usinagem da face em estudo.

\subsubsection{Ferramenta A}

A fresa/ferramenta A tem diâmetro nominal de $100 \mathrm{~mm}$, denominada VF2V 100R00, ângulo de posição $\chi_{r}: 88^{\circ}$ e geometria duplo positiva, fornecida pela Ingersoll Cutting Tools. É constituída de 10 alojamentos para insertos, onde 8 são para insertos com geometria para desbaste e os outros 2, com geometria alisadora conforme mostrado na Figura 312a. O inserto de metal duro de desbaste utilizado (Figura 3.12c) tem código NNE324-100 IN2004, e o alisador (Figura 3.12b) é do tipo YDA323L101 IN2010. Possuem método de deposição de Cobertura: PVD, com cobertura de TiAIN (Nitreto de Alumínio Titânio) e geometria positiva com preparação da aresta.

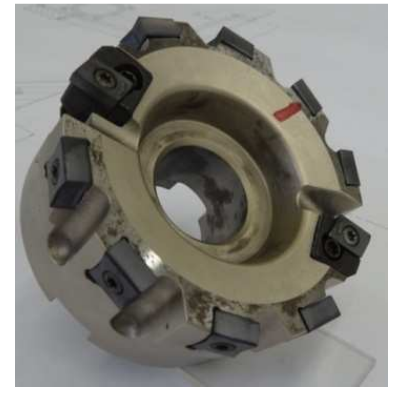

(a)

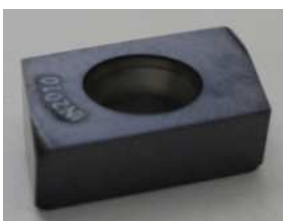

(b)

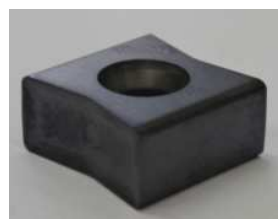

(c)

Figura 3.12 - (a) Ferramenta utilizada nos ensaios, (b) Inserto alisador YDA323L101 IN2010, (c) Inserto de desbaste NNE324-100 IN2004. 
Os alojamentos dos insertos alisadores possuem regulagem no sentido axial para garantir a planicidade entre eles e os insertos de desbaste e também garantir bom acabamento superficial. Através do ajuste lateral, feito por um parafuso de rosca fina, um calço logo abaixo do inserto produz um movimento no sentido axial, permitindo o deslocamento do mesmo. Os insertos alisadores são regulados com altura axial de $0,015 \mathrm{~mm}$ acima dos 8 insertos fixos de desbaste, enquanto que no sentido radial devem ficar afastados de $0,10 \mathrm{~mm}$. Esta regulagem não permite aos insertos alisadores a função básica de remoção de cavaco, mas sim de eliminar os picos deixados pelos fixos, conferindo melhor acabamento ao plano fresado.

\subsubsection{Ferramenta B}

A fresa/ferramenta $B$ tem diâmetro nominal de $100 \mathrm{~mm}$ denominada de Double Octomill, R220.48-0100-09-07SA fornecida pela SECO Tools do Brasil. É constituída de sete alojamentos para insertos, conforme ilustra a Figura 3.13a. Esta fresa possui ângulo de saída efetivo $\gamma_{0}:-11^{\circ}$ e ângulo de posição $x_{r}: 40^{\circ}$. Os insertos de metal duro têm código do fabricante ONMU090520ANTN - MK1500 e possui fase paralela $b_{s}=2,1 \mathrm{~mm}$. Possuem método de deposição de cobertura CVD, com cobertura de $\mathrm{Ti}(\mathrm{C}, \mathrm{N})+\mathrm{Al}_{2} \mathrm{O}_{3}$ (Carbonitreto de titânio e óxido de alumínio).

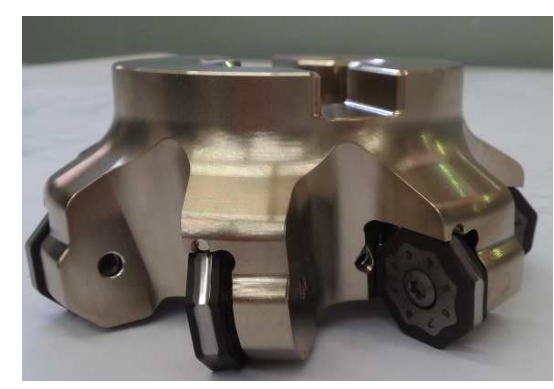

(a)

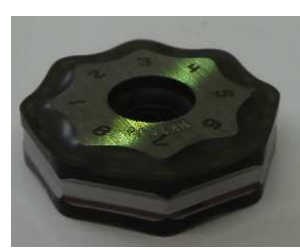

(b)

Figura 3.13 - (a) Ferramenta B utilizada nos ensaios, (b) Pastilha de corte ONMU090520ANTN - M14, MK1500 utilizada na ferramenta B. 


\subsubsection{Ferramenta C}

A fresa/ferramenta C tem diâmetro nominal de $100 \mathrm{~mm}$, código 100A08RS90ED14D, ângulo de posição $x_{r}$ de $90^{\circ}$ e geometria duplo positiva, fornecida pela Kennametal do Brasil. É constituída de 8 alojamentos para insertos, conforme mostrado na Figura 3.14a. Os insertos de metal duro (Figura 3.14b) têm código do fabricante EDPT140408PDERHD - KCK15 e possui ângulo de saída positivo de $\gamma=15^{\circ}$. Possui método de deposição de cobertura CVD, com cobertura de $\mathrm{Ti}(\mathrm{C}, \mathrm{N})+\mathrm{Al}_{2} \mathrm{O}_{3}$ (Carbonitreto de titânio e óxido de alumínio).

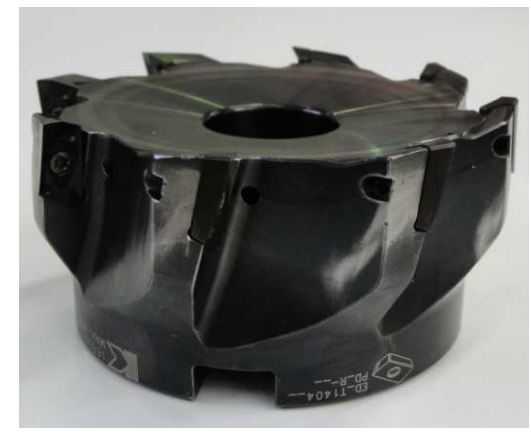

(a)

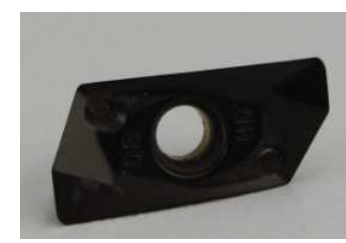

(b)

Figura 3.14. (a) Fresa utilizada nos ensaios 100A08RS90ED14D, (b) inserto de metal duro EDPT140408PDERHD - KCK15

\subsubsection{Controle Dimensional do Experimento}

O controle dimensional no processo envolve controle da dispersão de batimento, quando da realização do pre-set da fresa, a medição do desgaste de flanco e a medição da altura das rebarbas formadas após os ensaios. 


\subsubsection{Pre-set das ferramentas de corte}

Para o controle e medição do batimento foi utilizado um equipamento do fabricante Kelch $\mathrm{GmbH}$, modelo Kalimat A56-3/C e software EASY V4.4.0, instalado no departamento de controle de ferramental e pre-set da produção da empresa B.GROB do Brasil, conforme Figura 3.15.

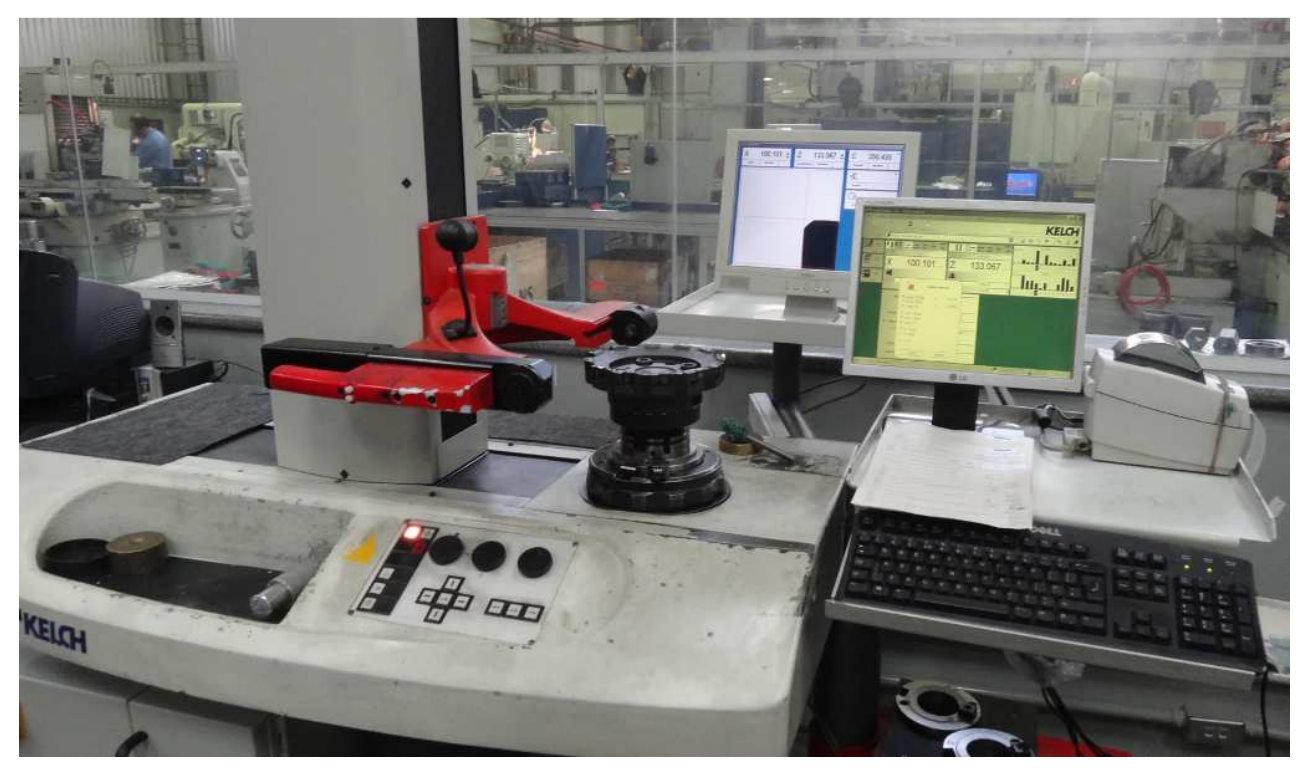

Figura 3.15 - Equipamento para pre-set das ferramentas de corte utilizadas nos ensaios.

\subsubsection{Medição do desgaste de flanco}

A medição do desgaste de flanco e o monitoramento das condições das pastilhas de corte utilizadas nos ensaios foram feitas no microscópio ferramenteiro, dotado de um parafuso micrométrico com resolução de $5 \mu \mathrm{m}$ e aumento de 100 vezes, interligado a um sistema de aquisição de imagens e um computador com software de aquisição de imagens com recurso de medição (Software Global Image). O microscópio, mostrado na Figura 3.16 pertence à Escola Técnica da B. GROB do Brasil. 

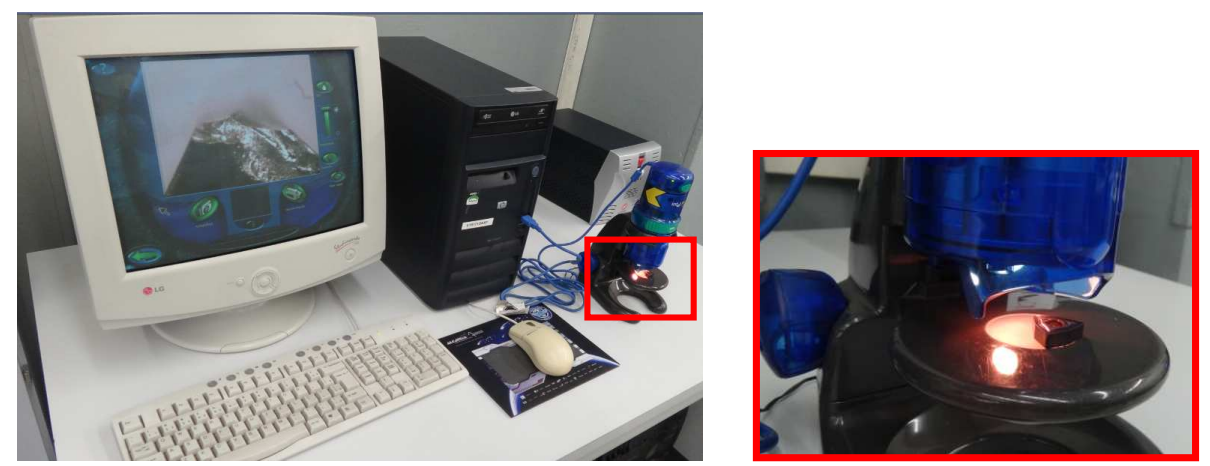

Figura 3.16 - Microscópio utilizado para inspecionar e medir o desgaste de flanco das pastilhas utilizadas nos ensaios.

\subsubsection{Medição da rebarba}

A altura da rebarba foi medida através do perfilometro do fabricante: Hommelwerke, modelo: Wave System WL-120, instalado no departamento de Metrologia da empresa B.GROB, conforme Figura 3.17.

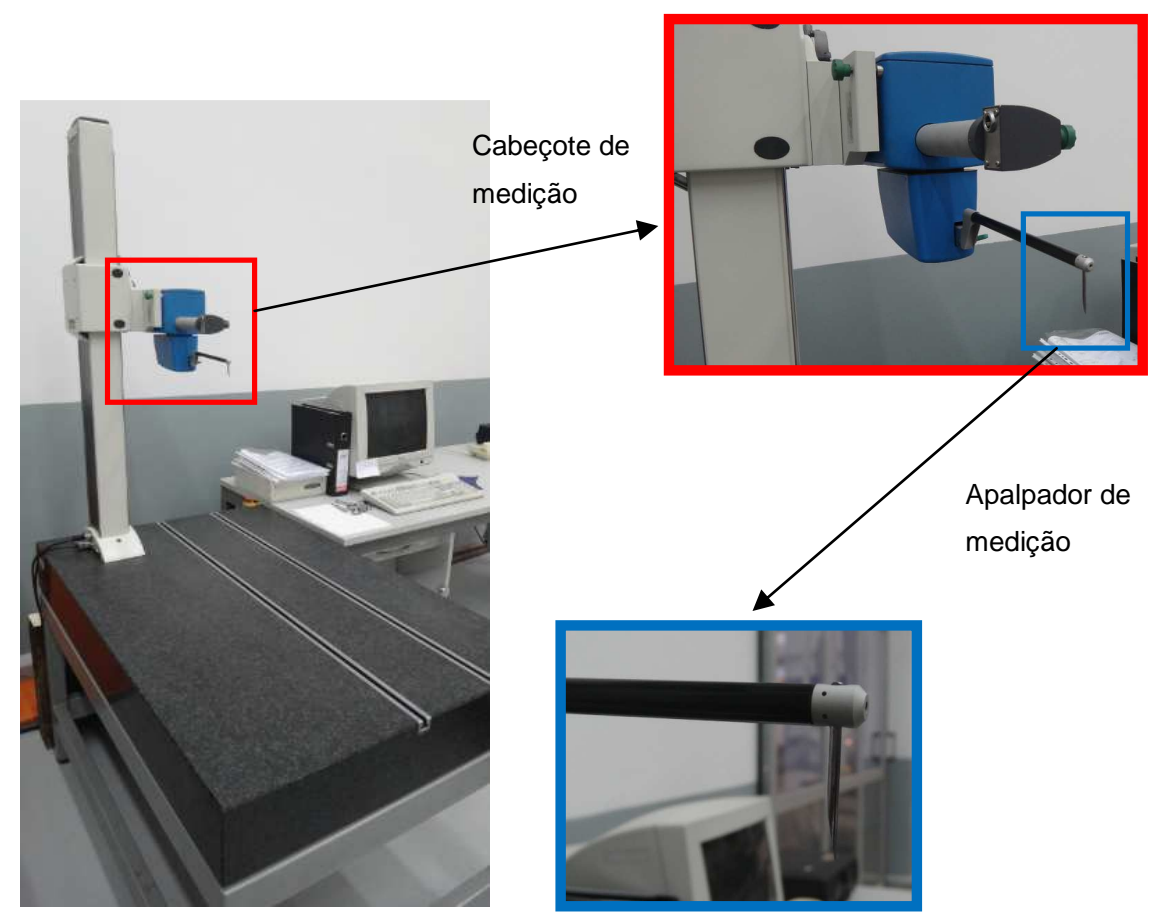

Figura 3.17 - Perfilometro utilizado para medição da altura da rebarba formada nos ensaios. 
Na Figura 3.18 pode-se verificar o procedimento para coleta do perfil da rebarba formada. Através do software que acompanha o equipamento é possível tratar a imagem do perfil da rebarba previamente medida e cotá-la, conforme ilustra a Figura 3.19.
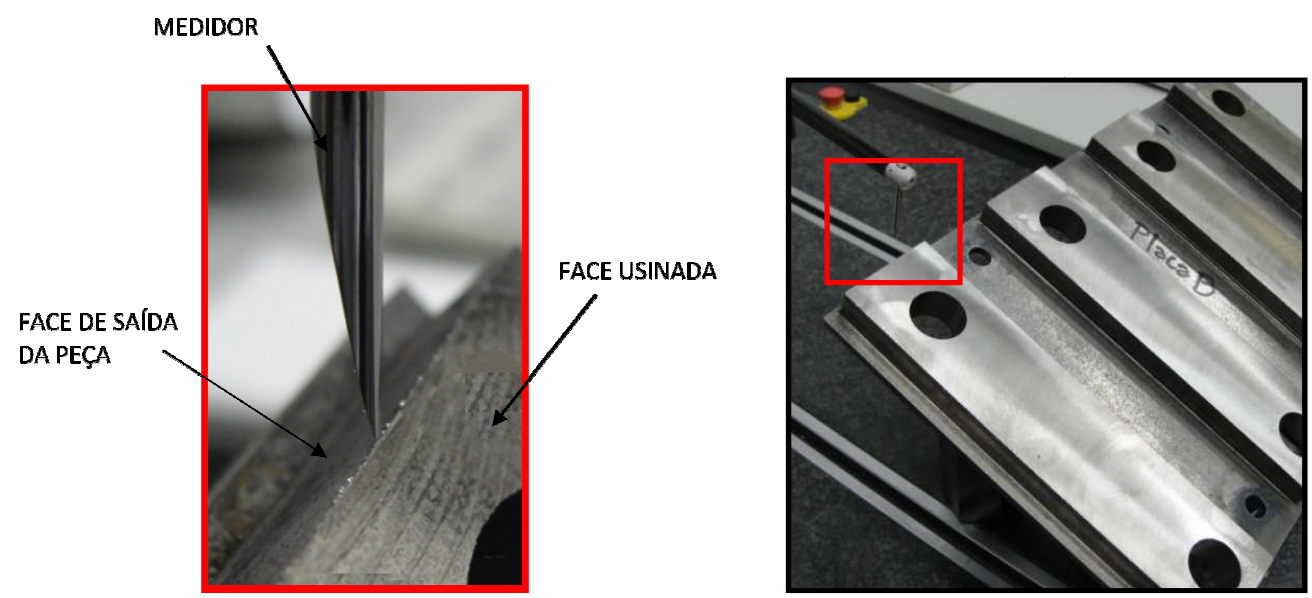

Figura 3.18 - Procedimento de medição da altura da rebarba após realização de cada ensaio.

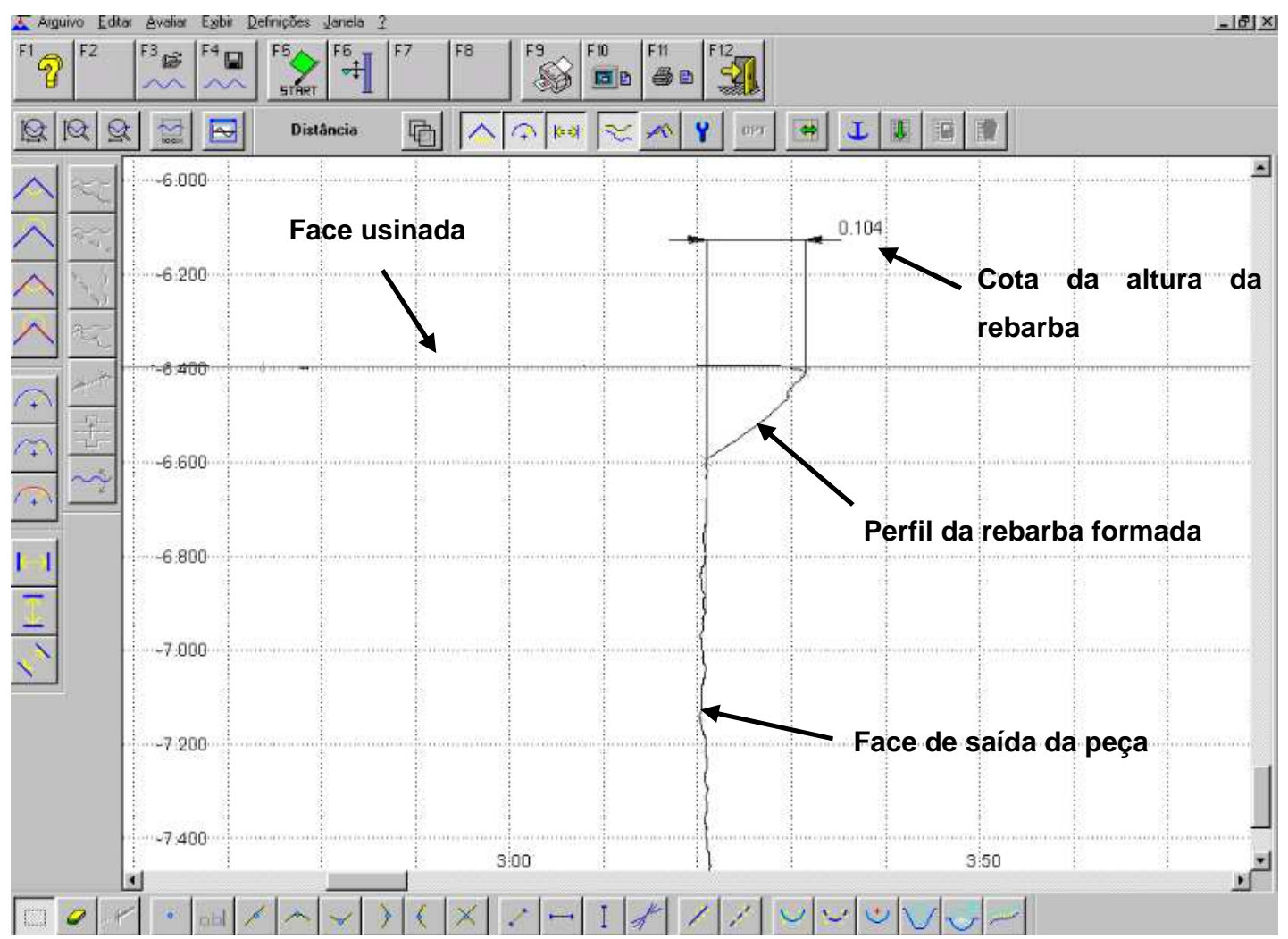

Figura 3.19 - Procedimento através do software Wave System WL-120 para aquisição da altura $h$ da rebarba $(\mathrm{mm})$. 


\subsection{METODOLOGIA DOS ENSAIOS}

Os ensaios de usinagem tiveram como objetivo a medição da rebarba gerada. Os mesmos consistem no fresamento de faceamento em acabamento de um corpo de prova com face similar a face de fogo de um bloco de motor em ferro fundido vermicular.

A realização dos ensaios foi dividida em duas etapas, sendo que na primeira foram investigadas as condições do processo com a utilização de três diferentes geometrias de ferramenta de corte. Foi verificada a influência das ferramentas na formação das rebarbas nas bordas de entrada, borda dos furos e na borda de saída da peça. Também foi verificada a condição de usinagem com e sem a retirada da rebarba remanescente. $O$ objetivo dos ensaios da primeira etapa foi de conhecer 0 comportamento das dimensões das rebarbas sob a atuação de diferentes geometrias de ferramenta e dados de corte. Conhecendo-se este comportamento, fixam-se as melhores condições para a realização dos ensaios da segunda etapa.

$\mathrm{Na}$ segunda etapa foram realizados ensaios que relacionam as principais variáveis dos processos de usinagem (profundidade de corte, avanço, velocidade de corte, desgaste de flanco e ângulo de borda de saída ou ângulo de saída da peça), com a altura da rebarba. A formação da rebarba na borda de saída da peça, durante o processo fresamento de faceamento é o principal objetivo desta etapa.

\subsubsection{Primeira etapa dos ensaios}

Nesta etapa analisou-se o comportamento da altura da rebarba com a utilização de três diferentes geometrias de ferramenta de corte. Foi verificada a influência das ferramentas na formação das rebarbas nas bordas de entrada, borda dos furos e na borda de saída da peça. Também foi verificada a condição de usinagem com e sem a retirada da rebarba remanescente. Em cada condição estudada foram realizadas réplicas suficientes para se obter uma tendência nas respostas dos ensaios. 
Os ensaios foram divididos em três partes, onde em cada parte foram realizados ensaios com um tipo de ferramenta. Foi realizada a medição da altura da rebarba (h) em vários ângulos de entrada da ferramenta de corte da peça $(\psi)$ ou ângulos de borda de entrada e vários ângulos de saída da ferramenta da peça $(\theta)$ ou ângulos de borda de saída. Também foi medida a altura da rebarba nas bordas dos furos de entrada e de saída da peça. O ponto de medição da altura da rebarba considerado para avaliação da rebarba remanescente condiz com o centro da peça, por onde passa o centro da ferramenta de corte.

Após a usinagem em cada condição de corte, mediu-se a altura das rebarbas na borda de entrada, na borda de saída e na borda de dois dos seus seis cilindros. Segue um resumo das etapas experimentais, com detalhamento apresentado na seqüência.

I - Operação do corte: Após a introdução dos dados $\left(v_{c}, f_{z}\right.$ e $\left.a_{p}\right)$ no CNC inicia-se a operação do fresamento frontal da superfície superior do corpo de prova, em apenas uma passada, conforme ilustra a Figura 3.20.

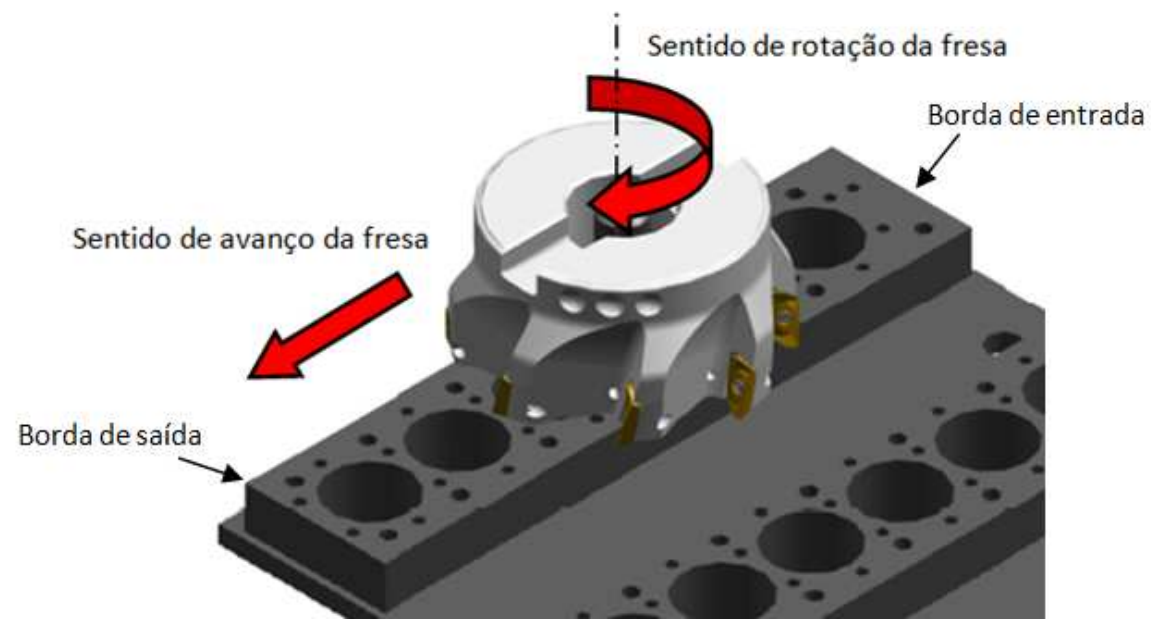

Figura 3.20 - Indicação do sentido do fresamento nos ensaios

II - Limpeza da superfície: Um jato de ar comprimido, com pressão de 6,0 Bar, foi direcionado às bordas em análise. Foi medida a altura da rebarba que permaneceu na borda, após este procedimento.

III - Medição das rebarbas na borda: Nesta etapa mede-se a rebarba gerada na borda de saída e na borda de entrada da peça. Para tanto as bordas analisadas foram divididas em sete segmentos chamados $\mathrm{Ae}, \mathrm{Be}, \mathrm{Ce}$, De, Ee, Fe e Ge para a 
borda de entrada da peça e As, Bs, Cs, Ds, Es, Fs e Gs para a borda de saída da da peça. A Figura 3.21 mostra as duas bordas e seus respectivos segmentos.

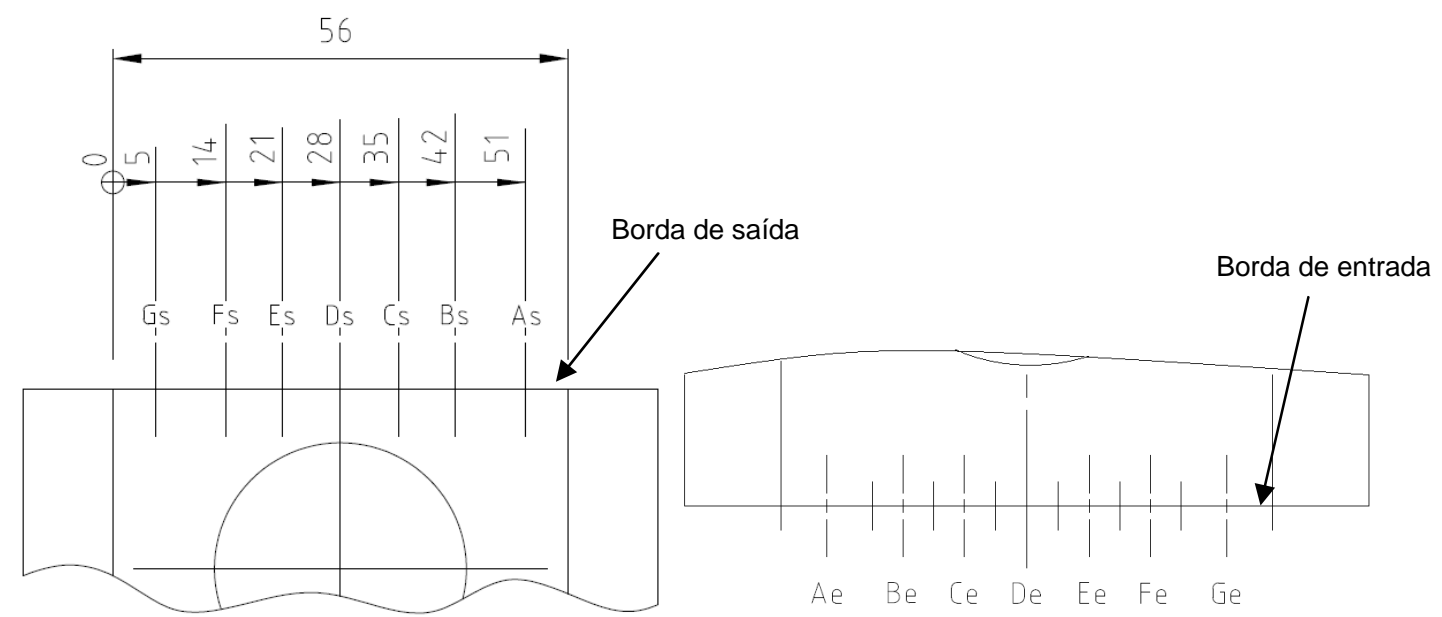

Figura 3.21 - Descritivo das divisões impostas nas bordas de saída (a) e borda de entrada da peça (b)

IV - Medição das rebarbas nos furos: Nos furos (ou cilindros) a rebarba foi medida em quatro pontos diferentes, sendo que cada ponto encontra-se $90^{\circ}$ distante do anterior. Considera-se o primeiro ponto o local onde a tangente, que passa pelo cilindro, for paralelo às bordas. Foram considerados os pontos 1, 2, 3 e 4 no cilindro de entrada (furo1), considerado conforme o sentido de avanço da ferramenta, e os pontos 5, 6, 7 e 8 no cilindro de saída (furo 2). A Figura 3.22 mostra os pontos de medições.
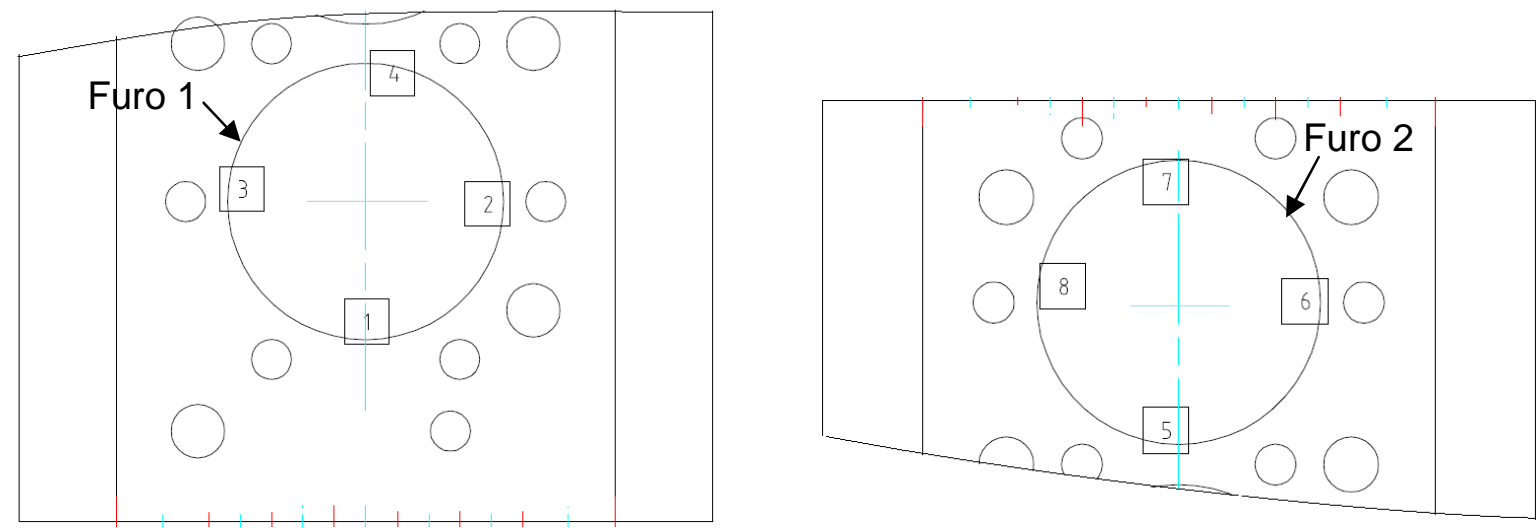

Figura 3.22 - Indicação dos pontos de medição da altura da rebarba nos furos de entrada (a) e de saída da ferramenta da peça (b) 
$V$ - Preparação da borda: Após a conclusão das medições da altura das rebarbas torna-se necessário a rebarbação das mesmas, pois a rebarba presente na borda poderá interferir na dimensão da rebarba formada pela passada seguinte. A rebarbação aconteceu de forma manual, utilizando-se uma espátula.

Conforme indicado na Figura 3.21 foi elaborado uma escala seccionando as bordas de entrada e de saída da peça. Para cada segmento foi associado um respectivo ângulo de borda de entrada e de borda de saída, ou ângulo de saída e de entrada da ferramenta de corte na borda peça. Assim pôde-se determinar o perfil da rebarba gerada nas bordas considerando seus ângulos de borda de entrada $(\psi)$ e os ângulos de borda de saída $(\theta)$. Este procedimento de determinação dos ângulos para cada segmento das bordas é demonstrado através da Figura 3.23a para a borda de saída e Figura 3.23b para a borda de entrada. Sendo cada ângulo formado entre a tangente do vetor velocidade de corte, na saída, e a aresta da superfície livre da peça.

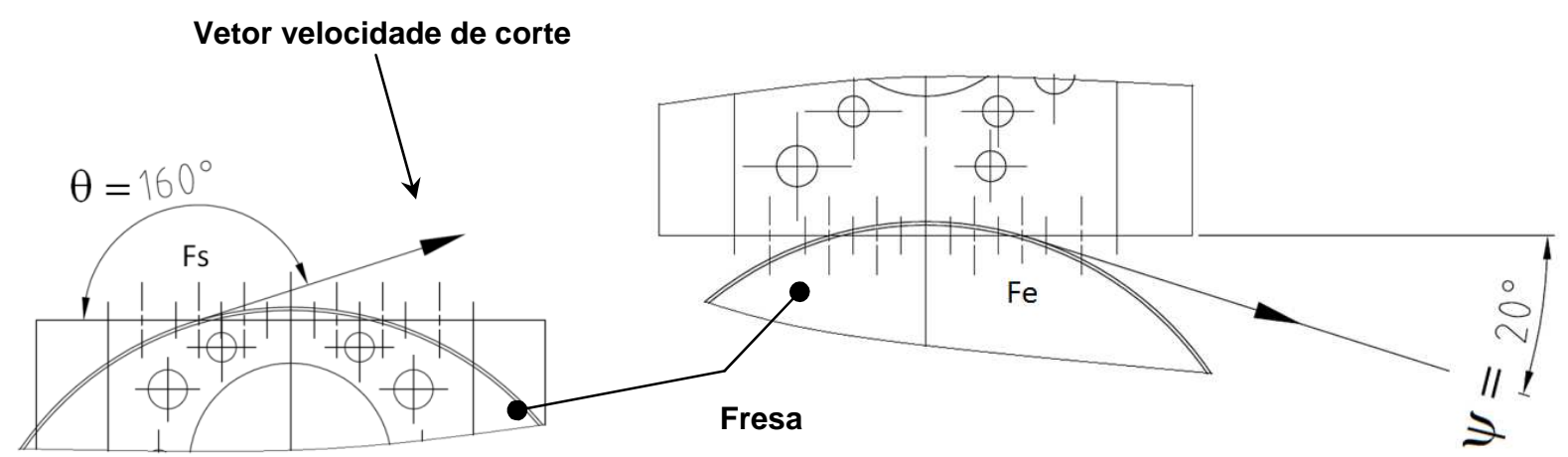

(a)

(b)

Figura 3.23 - Método de determinação dos ângulos de borda de entrada e de saída nas respectivas bordas da peça.

A variação dos segmentos nas bordas de entrada e de saída, e seus correspondentes ângulos de entrada e de saída podem ser verificados através da Tabela 3.5. $O$ ângulo de borda de saída $(\theta)$ e o ângulo de borda de entrada $(\psi)$ foram identificados pelo centro de cada segmento. Desta forma, na borda, seja ela de entrada ou saída, têm-se sete ângulos sendo três de entrada $(\psi)$ e quatro de saída $(\theta)$, bem definidos. Para cada ensaio realizado, pode se observar sete respostas (altura de rebarba) diferentes em cada borda. 
Tabela 3.5 - Valores dos ângulos com seus respectivos segmentos

\begin{tabular}{|c|c|c|c|c|c|}
\hline \multicolumn{2}{|c|}{ Borda de Entrada } & \multicolumn{3}{c|}{ Borda de Saída } \\
\hline \multirow{2}{*}{ Segmento } & \multicolumn{2}{|c|}{ Ângulo } & \multirow{2}{*}{ Segmento } & \multicolumn{2}{c|}{ Ângulo } \\
\cline { 2 - 4 } & $\psi$ & $\theta$ & & $\psi$ & $\theta$ \\
\hline \hline Ae & $150^{\circ}$ & - & As & $30^{\circ}$ & - \\
\hline Be & $160^{\circ}$ & - & Bs & $20^{\circ}$ & - \\
\hline Ce & $170^{\circ}$ & - & Cs & $10^{\circ}$ & - \\
\hline De & - & $0^{\circ}$ & Ds & - & $180^{\circ}$ \\
\hline Ee & - & $10^{\circ}$ & Es & - & $170^{\circ}$ \\
\hline Fe & - & $20^{\circ}$ & Fs & - & $160^{\circ}$ \\
\hline Ge & - & $30^{\circ}$ & Gs & - & $150^{\circ}$ \\
\hline
\end{tabular}

Com o auxilio das Figuras 3.20, 3.21 e 3.23, verifica-se que na borda de entrada os dentes da fresa entram na peça entre os segmentos Ae até o segmento De, à direita, e saem da peça da metade do segmento De até o final do segmento Ge. Na borda de saída os dentes da fresa saem da peça ao longo do início do segmento Gs até a metade do segmento Ds, à direita, e entram na borda da peça pelo segmento Ds, à esquerda, até o final do segmento As.

Assim, considerando a espessura de $56 \mathrm{~mm}$ das bordas de entrada e de saída da peça, e seus respectivos segmentos divisores, haverá a distinção nas bordas em entrada e saída dos dentes da fresa. Então, as rebarbas formadas pelos segmentos $\mathrm{Ae}$, Be e Ce na borda de entrada e os segmentos As, Bs e Cs na borda de saída serão consideradas rebarbas de entrada, enquanto as rebarbas formadas nos segmentos $\mathrm{De}$, Ee, Fe e Ge na borda de entrada e os segmentos Ds, Es, Fs e Gs na borda de saída serão tratadas como rebarbas de saída, conforme indica a Figura 3.5. Devido à elevada altura das rebarbas formadas nos segmentos De e Ds (intervalo de $28 \mathrm{~mm}$ da borda), as mesmas serão consideradas rebarbas de saída. Portanto tanto para a borda de entrada quanto para a borda de saída, existem rebarbas de entrada e rebarbas de saída. 


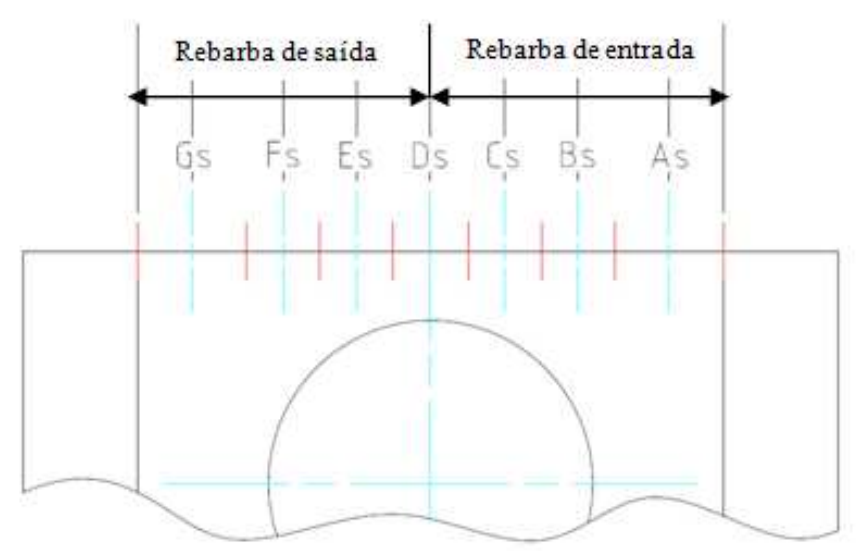

Figura 3.24 - Indicação da divisão entre rebarba de saída e rebarba de entrada na borda de saída da peça

Pela definição utilizada, o ângulo de borda de saída $(\theta)$ poderá variar entre $0^{\circ}<\theta<180^{\circ}$, sendo de $0^{\circ}<\theta<90^{\circ}$ na borda de entrada e de $90^{\circ}<\theta<180^{\circ}$ na borda de saída. $\mathrm{O}$ ângulo de borda de saída ou ângulo de saída da ferramenta da peça $(\theta)$ contempla as rebarbas de saída, ou seja, aquelas formadas pelos segmentos $\mathbf{D}, \mathbf{E}, \mathbf{F}$ e $\mathbf{G}$.

Da mesma forma o ângulo de borda de entrada $(\psi)$ poderá variar entre $0^{\circ}<$ $\psi<180^{\circ}$, sendo de $0^{\circ}<\psi<90^{\circ}$ para as rebarbas formadas na borda de saída e de $90^{\circ}<\psi<180^{\circ}$ para borda de entrada. $O$ ângulo de borda de entrada ou ângulo de entrada da ferramenta de corte na peça $(\psi)$ atende as rebarbas de entrada que são aquelas formadas nos dos segmentos A, B e C.

\subsubsection{Geometria da fresa}

Três fresas com geometrias diferentes foram testadas. Os parâmetros de corte e a dimensão do material foram os mesmos para as três ferramentas. O corte foi realizado a seco. No total foram realizados cinco ensaios, com mais três réplicas para cada ensaio, totalizando vinte experimentos para cada ferramenta.

Para cada ensaio foi analisada a altura da rebarba no ponto central da peça, na borda de saída, ponto correspondente ao ângulo $\theta=180^{\circ}$ da saída da ferramenta, ou segmento Ds. Os parâmetros de corte utilizados foram $a_{p}=0,5 \mathrm{~mm}, v_{c}=190$ $\mathrm{m} / \mathrm{min} ; \mathrm{f}_{\mathrm{z}}=0,08 \mathrm{~mm} /$ dente. 


\subsubsection{Dimensão da rebarba remanescente}

Foram avaliadas nesta etapa as três fresas, onde para cada ferramenta foram realizados seis ensaios (seis passadas), e as rebarbas formadas após os ensaios não foram retiradas. Para cada ensaio foi analisada a altura da rebarba no ponto central da peça, na borda de saída, ponto correspondente ao ângulo $\theta=180^{\circ}$ da saída da ferramenta, ou segmento Ds.

Os parâmetros de corte utilizados foram $a_{p}=0,5 \mathrm{~mm}, v_{c}=190 \mathrm{~m} / \mathrm{min} ; \mathrm{f}_{\mathrm{z}}=$ $0,08 \mathrm{~mm} /$ dente.

\subsubsection{Segunda etapa dos ensaios}

A partir dos ensaios e réplicas realizadas foi elaborado um planejamento fatorial completo (PFC) $2^{k}$ para analisar a significância de cada variável manipulada e a interação entre elas.

$\mathrm{Na}$ segunda etapa, foram realizadas medições da altura da rebarba apenas na borda de saída da peça, na qual foram obtidos os maiores valores de altura da rebarba nos ensaios da primeira etapa. Foram utilizadas as ferramentas A e C utilizadas na primeira etapa, ferramentas que obtiveram melhor resultado quando comparado à ferramenta $\mathrm{B}$.

Os quatro parâmetros controláveis: velocidade de corte, o avanço por dente, a profundidade de corte e o desgaste de flanco foram considerados variáveis de entrada, enquanto a altura da rebarba (h) é a variável de saída. A Tabela 3.6 mostra os quatro fatores com os seus respectivos níveis adotados no planejamento.

Tabela 3.6 - Variáveis utilizadas no planejamento fatorial e seus respectivos níveis.

\begin{tabular}{|c|c|c|c|c|}
\hline Fatores & $\begin{array}{c}\mathrm{v}_{\mathrm{c}} \\
\mathrm{m} / \mathrm{min}\end{array}$ & $\begin{array}{c}\mathrm{fz} \\
\mathrm{mm} / \text { dente }\end{array}$ & $\begin{array}{c}\mathrm{ap} \\
\mathrm{mm}\end{array}$ & $\begin{array}{c}\mathrm{V}_{\mathrm{Bmax}} \\
\mathrm{mm}\end{array}$ \\
\hline Nível 1 (min.) & 130 & 0,05 & 0,30 & 0,00 \\
\hline Nível 2 (max.) & 190 & 0,10 & 0,70 & 0,30 \\
\hline
\end{tabular}


O número de ensaios foi determinado através do Planejamento Fatorial Completo $2^{k}=2^{4}=16$ ensaios. Em um único ensaio obtêm-se duas respostas (h), uma para cada nível do ângulo de saída da ferramenta de corte da peça, sendo $\theta_{\text {mín }}$ $=160^{\circ}$ e $\theta_{\text {máx }}=180^{\circ}$. Portanto, no planejamento, foram obtidos trinta e duas respostas $(h)$. Foram realizadas três réplicas para cada ensaio, totalizando $2^{4}+3 \times 16$ $=64$ ensaios e 128 respostas para cada uma das duas ferramentas utilizadas na segunda etapa.

A Figura 3.25 mostra os dois segmentos medidos na borda de saída na segunda etapa dos ensaios.

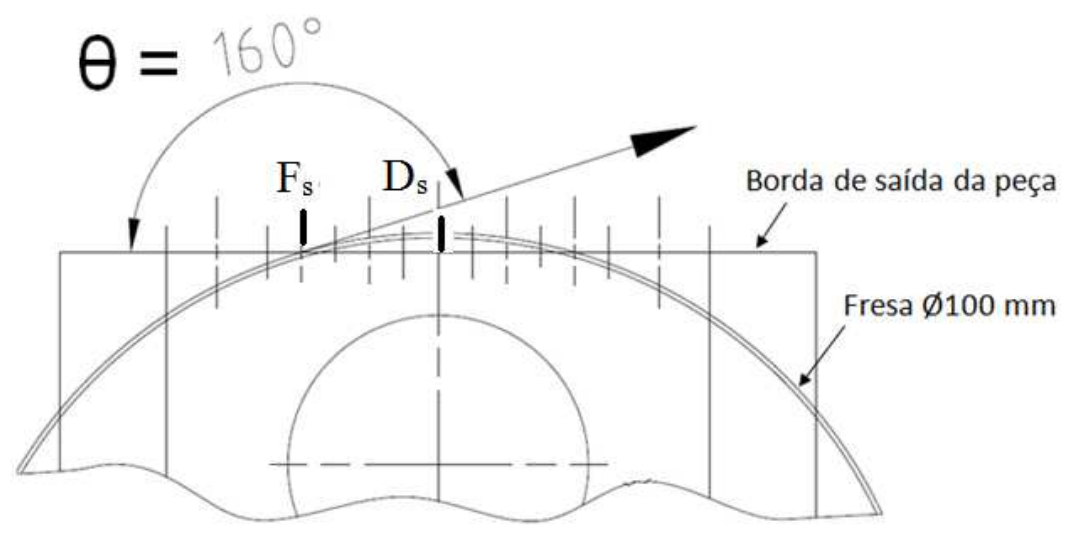

Figura 3.25 - Descritivo dos pontos Ds e Fs, onde foram realizadas as medições de altura da rebarba na segunda etapa dos ensaios

As Tabelas 3.7, 3.8, 3.9 e 3.10 indicam a seqüência e a numeração dos ensaios realizados. Contemplam também os níveis utilizados para as variáveis de entrada: velocidade de corte, avanço por dente, profundidade de corte e desgaste da ferramenta de corte.

As Tabelas 3.7 e 3.8 ilustram as condições de corte para os ensaios realizados com a ferramenta $A$, e as Tabelas 3.9 e 3.10 mostram as condições aplicadas à ferramenta $\mathrm{C}$, para todos os ensaios realizados e suas réplicas. 
Tabela 3.7 - Sequência dos ensaios realizados com a Ferramenta A para um desgaste de flanco de $\mathrm{V}_{\mathrm{Bmax}}=0,00 \mathrm{~mm}$

\begin{tabular}{|c|c|c|c|c||c|}
\hline $\begin{array}{c}\mathrm{V}_{\mathrm{c}} \\
\mathrm{m} / \mathrm{min}\end{array}$ & $\begin{array}{c}\mathrm{f}_{\mathrm{z}} \\
\mathrm{mm} / \mathrm{dente}\end{array}$ & $\begin{array}{c}\mathrm{a}_{\mathrm{p}} \\
\mathrm{mm}\end{array}$ & $\begin{array}{c}\mathrm{V}_{\mathrm{Bmax}} \\
\mathrm{mm}\end{array}$ & $\begin{array}{c}\mathrm{N}^{\circ} \\
\text { ensaio }\end{array}$ & $\begin{array}{c}\text { Ferramenta } \\
\mathrm{A}\end{array}$ \\
\hline \hline 130 & 0,05 & 0,30 & 0,00 & 1 & Ensaio \\
\hline 190 & 0,05 & 0,30 & 0,00 & 2 & Ensaio \\
\hline 130 & 0,10 & 0,30 & 0,00 & 3 & Ensaio \\
\hline 190 & 0,10 & 0,30 & 0,00 & 4 & Ensaio \\
\hline 130 & 0,05 & 0,70 & 0,00 & 5 & Ensaio \\
\hline 190 & 0,05 & 0,70 & 0,00 & 6 & Ensaio \\
\hline 130 & 0,10 & 0,70 & 0,00 & 7 & Ensaio \\
\hline 190 & 0,10 & 0,70 & 0,00 & 8 & Ensaio \\
\hline 130 & 0,05 & 0,30 & 0,00 & 9 & 1a Réplica \\
\hline 190 & 0,05 & 0,30 & 0,00 & 10 & 1a Réplica \\
\hline 130 & 0,10 & 0,30 & 0,00 & 11 & 1a Réplica \\
\hline 190 & 0,10 & 0,30 & 0,00 & 12 & 1a Réplica \\
\hline 130 & 0,05 & 0,70 & 0,00 & 13 & 1a Réplica \\
\hline 190 & 0,05 & 0,70 & 0,00 & 14 & 1a Réplica \\
\hline 130 & 0,10 & 0,70 & 0,00 & 15 & 1a Réplica \\
\hline 190 & 0,10 & 0,70 & 0,00 & 16 & 1a Réplica \\
\hline 130 & 0,05 & 0,30 & 0,00 & 17 & 2a Réplica \\
\hline 190 & 0,05 & 0,30 & 0,00 & 18 & 2a Réplica \\
\hline 130 & 0,10 & 0,30 & 0,00 & 19 & 2a Réplica \\
\hline 190 & 0,10 & 0,30 & 0,00 & 20 & 2a Réplica \\
\hline 130 & 0,05 & 0,70 & 0,00 & 21 & 2a Réplica \\
\hline 190 & 0,05 & 0,70 & 0,00 & 22 & 2a Réplica \\
\hline 130 & 0,10 & 0,70 & 0,00 & 23 & 2a Réplica \\
\hline 190 & 0,10 & 0,70 & 0,00 & 24 & 2a Réplica \\
\hline 130 & 0,05 & 0,30 & 0,00 & 25 & 3a Réplica \\
\hline 190 & 0,05 & 0,30 & 0,00 & 26 & 3a Réplica \\
\hline 130 & 0,10 & 0,30 & 0,00 & 27 & 3a Réplica \\
\hline 190 & 0,10 & 0,30 & 0,00 & 28 & 3a Réplica \\
\hline 130 & 0,05 & 0,70 & 0,00 & 29 & 3a Réplica \\
\hline 190 & 0,05 & 0,70 & 0,00 & 30 & 3a Réplica \\
\hline 130 & 0,10 & 0,70 & 0,00 & 31 & 3a Réplica \\
\hline 190 & 0,10 & 0,70 & 0,00 & 32 & 3a Réplica \\
\hline
\end{tabular}


Tabela 3.8 - Sequência dos ensaios realizados com a Ferramenta A para um desgaste de flanco de $V_{B \max }=0,30 \mathrm{~mm}$

\begin{tabular}{|c|c|c|c|c||c|}
\hline $\begin{array}{c}\mathrm{Vc}_{\mathrm{c}} \\
\mathrm{m} / \mathrm{min}\end{array}$ & \begin{tabular}{c}
$\mathrm{f}_{\mathrm{z}} \mathrm{mm} / \mathrm{dente}$ \\
\hline 130
\end{tabular} & $\begin{array}{c}\mathrm{a}_{\mathrm{p}} \\
\mathrm{mm}\end{array}$ & $\begin{array}{c}\mathrm{V}_{\mathrm{Bmax}} \\
\mathrm{mm}\end{array}$ & $\begin{array}{c}\mathrm{N}^{\circ} \\
\text { ensaio }\end{array}$ & $\begin{array}{c}\text { Ferramenta } \\
\text { A }\end{array}$ \\
\hline \hline 190 & 0,05 & 0,30 & 0,30 & 33 & Ensaio \\
\hline 130 & 0,10 & 0,30 & 0,30 & 34 & Ensaio \\
\hline 190 & 0,10 & 0,30 & 0,30 & 35 & Ensaio \\
\hline 130 & 0,05 & 0,70 & 0,30 & 36 & Ensaio \\
\hline 190 & 0,05 & 0,70 & 0,30 & 38 & Ensaio \\
\hline 130 & 0,10 & 0,70 & 0,30 & 39 & Ensaio \\
\hline 190 & 0,10 & 0,70 & 0,30 & 40 & Ensaio \\
\hline 130 & 0,05 & 0,30 & 0,30 & 41 & Ensaio \\
\hline 190 & 0,05 & 0,30 & 0,30 & 42 & 1a Réplica \\
\hline 130 & 0,10 & 0,30 & 0,30 & 43 & 1a Réplica \\
\hline 190 & 0,10 & 0,30 & 0,30 & 44 & 1a Réplica \\
\hline 130 & 0,05 & 0,70 & 0,30 & 45 & 1a Réplica \\
\hline 190 & 0,05 & 0,70 & 0,30 & 46 & 1a Réplica \\
\hline 130 & 0,10 & 0,70 & 0,30 & 47 & 1a Réplica \\
\hline 190 & 0,10 & 0,70 & 0,30 & 48 & 1a Réplica \\
\hline 130 & 0,05 & 0,30 & 0,30 & 49 & 2a Réplica \\
\hline 190 & 0,05 & 0,30 & 0,30 & 50 & 2a Réplica \\
\hline 130 & 0,10 & 0,30 & 0,30 & 51 & 2a Réplica \\
\hline 190 & 0,10 & 0,30 & 0,30 & 52 & 2a Réplica \\
\hline 130 & 0,05 & 0,70 & 0,30 & 53 & 2a Réplica \\
\hline 190 & 0,05 & 0,70 & 0,30 & 54 & 2a Réplica \\
\hline 130 & 0,10 & 0,70 & 0,30 & 55 & 2a Réplica \\
\hline 190 & 0,10 & 0,70 & 0,30 & 56 & 2a Réplica \\
\hline 130 & 0,05 & 0,30 & 0,30 & 57 & 3a Réplica \\
\hline 190 & 0,05 & 0,30 & 0,30 & 58 & 3a Réplica \\
\hline 130 & 0,10 & 0,30 & 0,30 & 59 & 3a Réplica \\
\hline 190 & 0,10 & 0,30 & 0,30 & 60 & 3a Réplica \\
\hline 130 & 0,05 & 0,70 & 0,30 & 61 & 3a Réplica \\
\hline 190 & 0,05 & 0,70 & 0,30 & 62 & 3a Réplica \\
\hline 130 & 0,10 & 0,70 & 0,30 & 63 & 3a Réplica \\
\hline 190 & 0,10 & 0,70 & 0,30 & 64 & 3a Réplica \\
\hline
\end{tabular}


Tabela 3.9 - Sequência dos ensaios realizados com a Ferramenta $C$ para um desgaste de flanco de $\mathrm{V}_{\mathrm{Bmax}}=0,00 \mathrm{~mm}$

\begin{tabular}{|c|c|c|c|c|c|}
\hline $\begin{array}{c}\mathrm{Vc} \\
\mathrm{m} / \mathrm{min}\end{array}$ & $\begin{array}{c}\mathbf{f}_{\mathbf{z}} \\
\mathrm{mm} / \text { dente }\end{array}$ & $\begin{array}{c}a_{p} \\
m m\end{array}$ & $\begin{array}{c}\mathrm{V}_{\mathrm{Bmax}} \\
\mathrm{mm}\end{array}$ & $\begin{array}{c}\mathbf{N}^{\circ} \\
\text { ensaio }\end{array}$ & $\begin{array}{c}\text { Ferramenta } \\
\text { C }\end{array}$ \\
\hline 130 & 0,05 & 0,3 & 0,00 & 65 & Ensaio \\
\hline 190 & 0,05 & 0,3 & 0,00 & 66 & Ensaio \\
\hline 130 & 0,1 & 0,3 & 0,00 & 67 & Ensaio \\
\hline 190 & 0,1 & 0,3 & 0,00 & 68 & Ensaio \\
\hline 130 & 0,05 & 0,7 & 0,00 & 69 & Ensaio \\
\hline 190 & 0,05 & 0,7 & 0,00 & 70 & Ensaio \\
\hline 130 & 0,1 & 0,7 & 0,00 & 71 & Ensaio \\
\hline 190 & 0,1 & 0,7 & 0,00 & 72 & Ensaio \\
\hline 130 & 0,05 & 0,3 & 0,00 & 73 & 1a Réplica \\
\hline 190 & 0,05 & 0,3 & 0,00 & 74 & 1a Réplica \\
\hline 130 & 0,1 & 0,3 & 0,00 & 75 & 1a Réplica \\
\hline 190 & 0,1 & 0,3 & 0,00 & 76 & 1a Réplica \\
\hline 130 & 0,05 & 0,7 & 0,00 & 77 & 1a Réplica \\
\hline 190 & 0,05 & 0,7 & 0,00 & 78 & 1a Réplica \\
\hline 130 & 0,1 & 0,7 & 0,00 & 79 & 1a Réplica \\
\hline 190 & 0,1 & 0,7 & 0,00 & 80 & 1a Réplica \\
\hline 130 & 0,05 & 0,3 & 0,00 & 81 & 2a Réplica \\
\hline 190 & 0,05 & 0,3 & 0,00 & 82 & 2a Réplica \\
\hline 130 & 0,1 & 0,3 & 0,00 & 83 & 2a Réplica \\
\hline 190 & 0,1 & 0,3 & 0,00 & 84 & 2a Réplica \\
\hline 130 & 0,05 & 0,7 & 0,00 & 85 & 2a Réplica \\
\hline 190 & 0,05 & 0,7 & 0,00 & 86 & 2a Réplica \\
\hline 130 & 0,1 & 0,7 & 0,00 & 87 & 2a Réplica \\
\hline 190 & 0,1 & 0,7 & 0,00 & 88 & 2a Réplica \\
\hline 130 & 0,05 & 0,3 & 0,00 & 89 & 3a Réplica \\
\hline 190 & 0,05 & 0,3 & 0,00 & 90 & 3a Réplica \\
\hline 130 & 0,1 & 0,3 & 0,00 & 91 & 3a Réplica \\
\hline 190 & 0,1 & 0,3 & 0,00 & 92 & 3a Réplica \\
\hline 130 & 0,05 & 0,7 & 0,00 & 93 & 3a Réplica \\
\hline 190 & 0,05 & 0,7 & 0,00 & 94 & 3a Réplica \\
\hline 130 & 0,1 & 0,7 & 0,00 & 95 & 3a Réplica \\
\hline 190 & 0,1 & 0,7 & 0,00 & 96 & 3a Réplica \\
\hline
\end{tabular}


Tabela 3.10 - Sequência dos ensaios realizados com a Ferramenta $C$ para um desgaste de flanco de VBmax $=0,30 \mathrm{~mm}$

\begin{tabular}{|c|c|c|c|c||c|}
\hline $\begin{array}{c}\mathrm{V}_{\mathrm{c}} \\
\mathrm{m} / \mathrm{min}\end{array}$ & $\begin{array}{c}\mathrm{f}_{\mathrm{z}} \\
\mathrm{mm} / \mathrm{dente}\end{array}$ & $\begin{array}{c}\mathrm{a}_{\mathrm{p}} \\
\mathrm{mm}\end{array}$ & $\begin{array}{c}\mathrm{V}_{\mathrm{Bmax}} \\
\mathrm{mm}\end{array}$ & $\begin{array}{c}\mathrm{N}^{\circ} \\
\text { ensaio }\end{array}$ & $\begin{array}{c}\text { Ferramenta } \\
\mathrm{C}\end{array}$ \\
\hline \hline 130 & 0,05 & 0,3 & 0,30 & 97 & Ensaio \\
\hline 190 & 0,05 & 0,3 & 0,30 & 98 & Ensaio \\
\hline 130 & 0,1 & 0,3 & 0,30 & 99 & Ensaio \\
\hline 190 & 0,1 & 0,3 & 0,30 & 100 & Ensaio \\
\hline 130 & 0,05 & 0,7 & 0,30 & 101 & Ensaio \\
\hline 190 & 0,05 & 0,7 & 0,30 & 102 & Ensaio \\
\hline 130 & 0,1 & 0,7 & 0,30 & 103 & Ensaio \\
\hline 190 & 0,1 & 0,7 & 0,30 & 104 & Ensaio \\
\hline 130 & 0,05 & 0,3 & 0,30 & 105 & 1a Réplica \\
\hline 190 & 0,05 & 0,3 & 0,30 & 106 & 1a Réplica \\
\hline 130 & 0,1 & 0,3 & 0,30 & 107 & 1a Réplica \\
\hline 190 & 0,1 & 0,3 & 0,30 & 108 & 1a Réplica \\
\hline 130 & 0,05 & 0,7 & 0,30 & 109 & 1a Réplica \\
\hline 190 & 0,05 & 0,7 & 0,30 & 110 & 1a Réplica \\
\hline 130 & 0,1 & 0,7 & 0,30 & 111 & 1a Réplica \\
\hline 190 & 0,1 & 0,7 & 0,30 & 112 & 1a Réplica \\
\hline 130 & 0,05 & 0,3 & 0,30 & 113 & 2a Réplica \\
\hline 190 & 0,05 & 0,3 & 0,30 & 114 & 2a Réplica \\
\hline 130 & 0,1 & 0,3 & 0,30 & 115 & 2a Réplica \\
\hline 190 & 0,1 & 0,3 & 0,30 & 116 & 2a Réplica \\
\hline 130 & 0,05 & 0,7 & 0,30 & 117 & 2a Réplica \\
\hline 190 & 0,05 & 0,7 & 0,30 & 118 & 2a Réplica \\
\hline 130 & 0,1 & 0,7 & 0,30 & 119 & 2a Réplica \\
\hline 190 & 0,1 & 0,7 & 0,30 & 120 & 2a Réplica \\
\hline 130 & 0,05 & 0,3 & 0,30 & 121 & 3a Réplica \\
\hline 190 & 0,05 & 0,3 & 0,30 & 122 & 3a Réplica \\
\hline 130 & 0,1 & 0,3 & 0,30 & 123 & 3a Réplica \\
\hline 190 & 0,1 & 0,3 & 0,30 & 124 & 3a Réplica \\
\hline 130 & 0,05 & 0,7 & 0,30 & 125 & 3a Réplica \\
\hline 190 & 0,05 & 0,7 & 0,30 & 126 & 3a Réplica \\
\hline 130 & 0,1 & 0,7 & 0,30 & 127 & 3a Réplica \\
\hline 190 & 0,1 & 0,7 & 0,30 & 128 & 3a Réplica \\
\hline
\end{tabular}




\section{RESULTADOS E DISCUSSÕES}

A discussão dos resultados será apresentada em duas partes. A primeira trata da análise da formação da rebarba nas características que descrevem os ensaios da primeira etapa, onde foram avaliadas a formação da rebarba remanescente e as dimensões das rebarbas formadas na borda de entrada, na borda de saída e na borda de dois dos seis furos do cilindro na face do corpo de prova. Na segunda parte, uma análise dos resultados a partir da significância dos parâmetros e um modelo empírico para prever a altura da rebarba são apresentados.

\subsection{PRIMEIRA ETAPA DOS ENSAIOS}

Os ensaios propostos para a realização da primeira etapa envolveram a variação da geometria da fresa/ferramenta e a análise da formação da rebarba remanescente. Esta etapa também visou caracterizar as rebarbas formadas na borda de entrada, na borda de saída e nas bordas dos furos e, assim identificar os resultados mais relevantes e as melhores condições para minimização da rebarba, e posterior utilização destes resultados nos ensaios da segunda etapa.

\subsubsection{Dimensão da rebarba remanescente}

Poucos trabalhos retratam este assunto. Nos processos de usinagem em geral não existe nenhuma preocupação com a rebarba formada durante os passes intermediários, apesar do provável desgaste de entalhe que ela pode causar na ferramenta de corte (DA SILVA, 2011). Cabe lembrar também que, a formação da rebarba é uma característica das bordas de acabamento, ou seja, o último passe.

Devido à difícil usinabilidade do ferro fundido vermicular, dando destaque ao precipitado desgaste das ferramentas de corte e a tolerância "apertada" de forma e 
posição exigidas, o processo de fresamento da face de fogo do bloco de motor, nos processos industriais, acabam exigindo três etapas ou passes para o acabamento desta face. Ou seja, uma operação em desbaste, com retirada de aproximadamente $6 \mathrm{~mm}$ ou mais, uma operação de semi-acabamento, com profundidade de $0,7 \mathrm{~mm}$ e o último passe de acabamento com profundidade de 0,3 $\mathrm{mm}$. Onde normalmente as etapas de semi e de acabamento são realizadas em uma máquina dedicada, para que o processo possa garantir as tolerâncias do produto. Isso faz com que a rebarba gerada no processo de acabamento sofra influência da rebarba gerada na etapa de semi acabamento.

Para relacionar a altura da rebarba formada pelo acúmulo de passes, que caracterizam a rebarba remanescente, e aquela formada na borda livre de rebarba remanescente, foram realizados cinco ensaios. Para cada ensaio, ou passe, foram realizados três réplicas. Os ensaios foram repetidos para cada uma das três ferramentas, com o objetivo de se avaliar também a influência das diferentes geometrias na formação da rebarba remanescente.

Pode-se verificar os resultados obtidos para os ensaios utilizando-se a Ferramenta A na Tabela 4.1.

Tabela 4.1 - Altura da rebarba posterior, sem a retirada da rebarba remanescente e com a retirada da rebarba remanescente, para a Ferramenta $A$, segmento Ds.

\begin{tabular}{|c|c|c|c|c|c|c|c|c|c|}
\hline \multicolumn{10}{|c|}{ Sem retirada da rebarba anterior } \\
\hline $\begin{array}{l}\text { Ensaio } \\
\text { (passe) }\end{array}$ & $\begin{array}{c}\mathbf{h} \\
-\mathbf{m m}-\end{array}$ & $\begin{array}{c}1 \mathrm{a} \\
\text { Réplica }\end{array}$ & $\begin{array}{c}\mathrm{h} \\
-\mathrm{mm}-\end{array}$ & $\begin{array}{c}2 \mathrm{a} \\
\text { Réplica }\end{array}$ & $\begin{array}{c}\mathrm{h} \\
-\mathrm{mm}-\end{array}$ & $\begin{array}{c}\text { 3a } \\
\text { Réplica }\end{array}$ & $\begin{array}{c}\mathbf{h} \\
-\mathbf{m m}-\end{array}$ & $\begin{array}{c}\text { Média h } \\
\text {-mm- }\end{array}$ & $\begin{array}{l}\text { Desv. } \\
\text { Pad h } \\
\text {-mm- }\end{array}$ \\
\hline 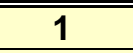 & 0,0562 & 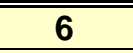 & 0,0483 & 11 & 0,0367 & 16 & 0,0580 & 0,0498 & 0,0097 \\
\hline 2 & 0,0682 & 7 & 0,0541 & 12 & 0,0350 & 17 & 0,0712 & 0,0571 & 0,0165 \\
\hline 3 & 0,0696 & 8 & 0,0620 & 13 & 0,0405 & 18 & 0,0725 & 0,0612 & 0,0145 \\
\hline 4 & 0,0716 & 9 & 0,0736 & 14 & 0,0640 & 19 & 0,0857 & 0,0737 & 0,0090 \\
\hline 5 & 0,0836 & 10 & 0,0830 & 15 & 0,0735 & 20 & 0,0880 & 0,0820 & 0,0061 \\
\hline \multicolumn{10}{|c|}{ Com retirada da rebarba anterior } \\
\hline Ensaio & $\begin{array}{c}\mathbf{h} \\
-\mathbf{m m}\end{array}$ & $\begin{array}{c}1 a \\
\text { Réplica }\end{array}$ & $\begin{array}{c}\mathrm{h} \\
-\mathrm{mm}-\end{array}$ & $\begin{array}{c}2 a \\
\text { Réplica }\end{array}$ & $\begin{array}{c}\mathrm{h} \\
-\mathrm{mm}-\end{array}$ & $\begin{array}{c}\text { 3a } \\
\text { Réplica }\end{array}$ & $\begin{array}{c}\mathrm{h} \\
-\mathrm{mm}\end{array}$ & $\begin{array}{c}\text { Média h } \\
\text {-mm- }\end{array}$ & $\begin{array}{l}\text { Desv. } \\
\text { Pad h } \\
\text {-mm- }\end{array}$ \\
\hline 1 & 0,0486 & 6 & 0,0387 & 11 & 0,0523 & 16 & 0,0423 & 0,0455 & 0,0061 \\
\hline 2 & 0,0487 & 7 & 0,0420 & 12 & 0,0492 & 17 & 0,0567 & 0,0492 & 0,0060 \\
\hline 3 & 0,0390 & 8 & 0,0581 & 13 & 0,0386 & 18 & 0,0329 & 0,0422 & 0,0110 \\
\hline 4 & 0,0420 & 9 & 0,0487 & 14 & 0,0514 & 19 & 0,0441 & 0,0466 & 0,0043 \\
\hline 5 & 0,0396 & 10 & 0,0242 & 15 & 0,0429 & 20 & 0,0329 & 0,0349 & 0,0083 \\
\hline
\end{tabular}


Utilizando os dados da Tabela 4.1 obteve-se o gráfico da Figura 4.1. Observa-se neste gráfico o aumento proporcional da altura da rebarba em função do número de passes. O que não ocorreu para os ensaios que tiveram a rebarba remanescente retirada.

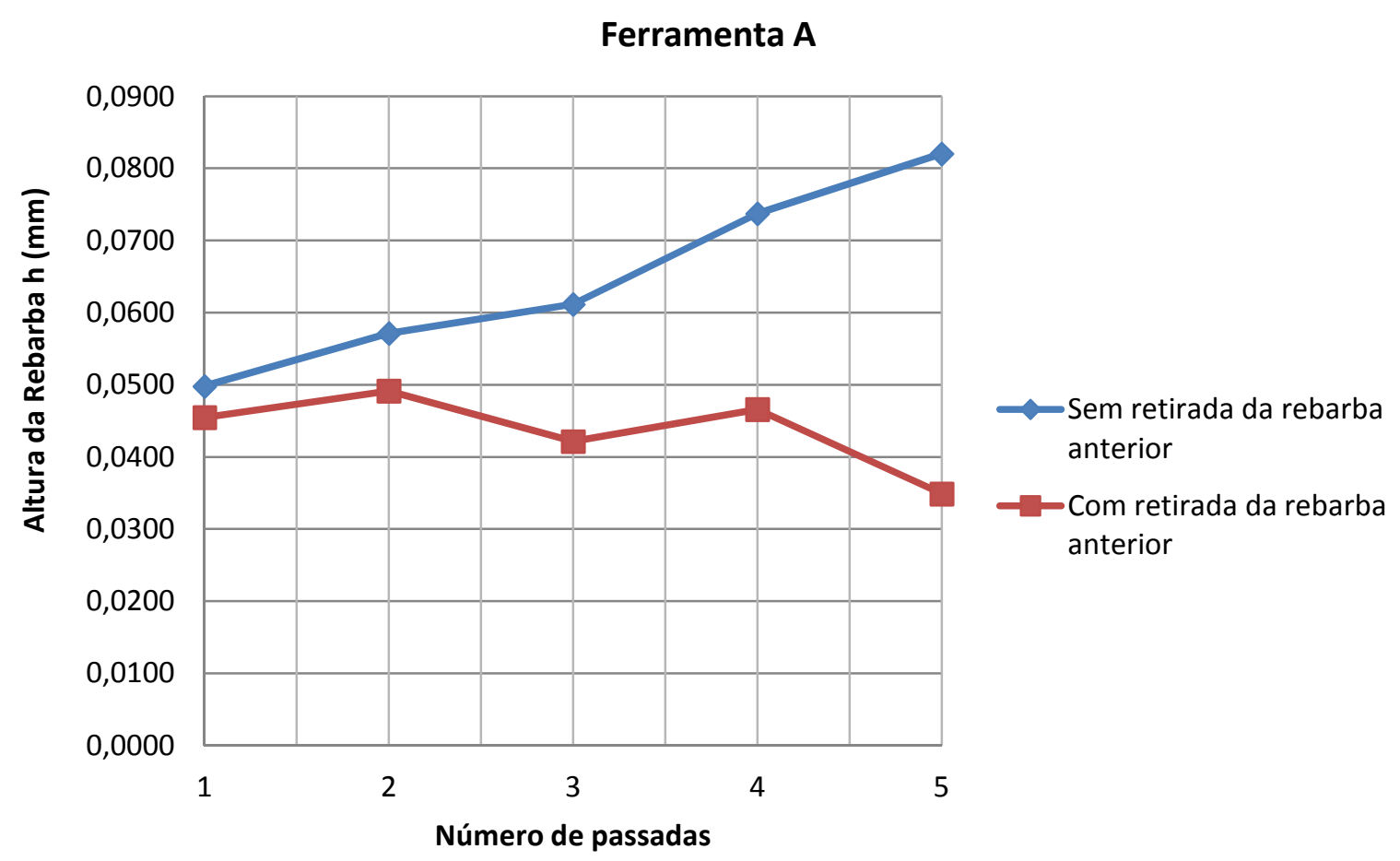

Figura 4.1 - Altura média da rebarba em relação ao número de passadas para retirada da rebarba remanescente e com a rebarba remanescente para a ferramenta $A$.

Observou-se uma influência média de $13 \%$ de aumento na altura da rebarba formada em cada novo passe sem a retirada da rebarba anterior. Partindo de uma altura de $\mathrm{h}=0,0498 \mathrm{~mm}$ no primeiro passe, sem a rebarba remanescente, $\mathrm{e}$ chegando em $\mathrm{h}=0,0820 \mathrm{~mm}$ no quinto passe seguido sem retirada da rebarba remanescente.

A Tabela 4.2 mostra os resultados das medições de altura da rebarba utilizando-se a Ferramenta B. 
Tabela 4.2 - Altura da rebarba posterior, sem a retirada da rebarba remanescente e com a retirada da rebarba remanescente, para a Ferramenta B, segmento Ds.

\begin{tabular}{|c|c|c|c|c|c|c|c|c|c|}
\hline \multicolumn{10}{|c|}{ Sem retirada da rebarba anterior } \\
\hline $\begin{array}{l}\text { Ensaio } \\
\text { (passe) }\end{array}$ & $\begin{array}{c}\mathbf{h} \\
-\mathrm{mm}-\end{array}$ & $\begin{array}{c}1 \mathrm{a} \\
\text { Réplica }\end{array}$ & $\begin{array}{c}\mathbf{h} \\
-\mathbf{m m}-\end{array}$ & $\begin{array}{c}2 \mathrm{a} \\
\text { Réplica }\end{array}$ & $\begin{array}{c}\mathbf{h} \\
-\mathbf{m m}-\end{array}$ & $\begin{array}{c}3 a \\
\text { Réplica }\end{array}$ & $\underset{-m m-}{\mathbf{h}}$ & $\begin{array}{c}\text { Média } \mathrm{h} \\
\text {-mm- }\end{array}$ & $\begin{array}{l}\text { Desv. } \\
\text { Pad h } \\
\text {-mm- }\end{array}$ \\
\hline 1 & 0,2783 & 6 & 0,2496 & 11 & 0,2631 & 16 & 0,2726 & 0,2659 & 0,0125 \\
\hline 2 & 0,3287 & 7 & 0,3617 & 12 & 0,3492 & 17 & 0,3587 & 0,3496 & 0,0149 \\
\hline 3 & 0,3941 & 8 & 0,4009 & 13 & 0,4121 & 18 & 0,4216 & 0,4072 & 0,0122 \\
\hline 4 & 0,4181 & 9 & 0,4125 & 14 & 0,4512 & 19 & 0,4607 & 0,4356 & 0,0239 \\
\hline 5 & 0,4411 & 10 & 0,4617 & 15 & 0,4837 & 20 & 0,4839 & 0,4676 & 0,0205 \\
\hline \multicolumn{10}{|c|}{ Com retirada da rebarba anterior } \\
\hline Ensaio & $\begin{array}{c}\mathbf{h} \\
-\mathrm{mm}\end{array}$ & $\begin{array}{c}1 \mathrm{a} \\
\text { Réplica }\end{array}$ & $\begin{array}{c}\mathbf{h} \\
-\mathrm{mm}-\end{array}$ & $\begin{array}{c}2 \mathrm{a} \\
\text { Réplica }\end{array}$ & $\underset{-m m}{h}$ & $\begin{array}{c}3 a \\
\text { Réplica }\end{array}$ & $\underset{-\mathbf{m m}}{\mathbf{h}}$ & $\begin{array}{c}\text { Média h } \\
- \text { mm- }\end{array}$ & $\begin{array}{l}\text { Desv. } \\
\text { Pad h } \\
\text {-mm- }\end{array}$ \\
\hline$\overline{1}$ & 0,2581 & 6 & 0,2831 & 11 & 0,2439 & $\overline{16}$ & 0,2377 & 0,2557 & 0,0202 \\
\hline 2 & 0,2486 & 7 & 0,2638 & 12 & 0,2792 & 17 & 0,2605 & 0,2630 & 0,0126 \\
\hline 3 & 0,2631 & 8 & 0,2681 & 13 & 0,2395 & 18 & 0,2456 & 0,2541 & 0,0137 \\
\hline 4 & 0,2496 & 9 & 0,2493 & 14 & 0,2783 & 19 & 0,2631 & 0,2601 & 0,0137 \\
\hline 5 & 0,2689 & 10 & 0,2672 & 15 & 0,2581 & 20 & 0,2539 & 0,2620 & 0,0072 \\
\hline
\end{tabular}

Através dos dados da Tabela 4.2 obteve-se o gráfico da Figura 4.2. Assim como ocorreu com a ferramenta $A$, também verifica-se o aumento proporcional da altura da rebarba em função do número de passes seguidos sem a retirada da rebarba anterior.

\section{Ferramenta B}

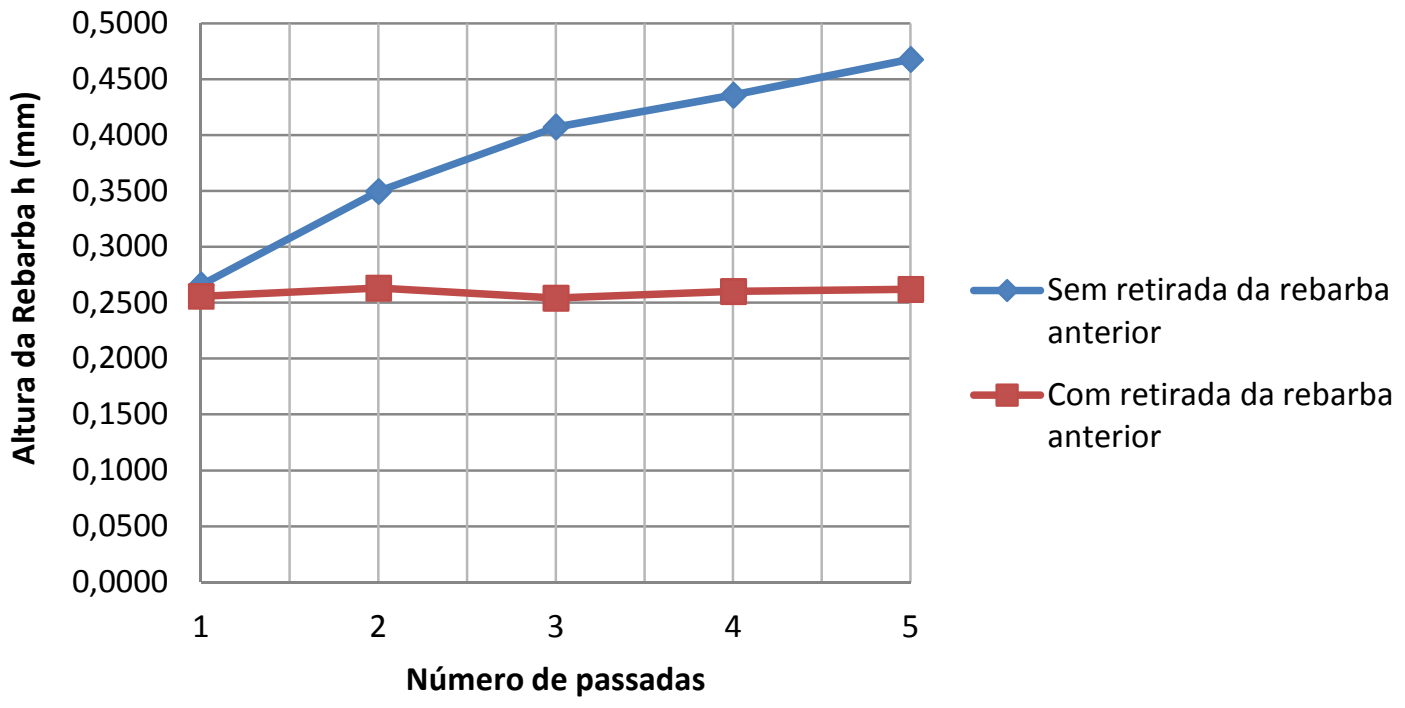

Figura 4.2 - Altura média da rebarba em relação ao número de passadas para retirada da rebarba remanescente e com a rebarba remanescente para a ferramenta $B$. 
Com a ferramenta $B$, verificou-se também a influência da rebarba remanescente. Onde observou-se uma média de $12 \%$ de aumento na altura da rebarba formada em cada novo passe sem a retirada da rebarba anterior. Partindo de uma altura de $\mathrm{h}=0,2659 \mathrm{~mm}$ no primeiro passe, sem rebarba remanescente, chegando em $\mathrm{h}=0,4676 \mathrm{~mm}$ no quinto passe seguido sem retirada da rebarba remanescente.

Os mesmos ensaios também foram realizados com a Ferramenta $\mathrm{C}$ e podem ser vistos na Tabela 4.3.

Tabela 4.3 - Altura da rebarba posterior, sem a retirada da rebarba remanescente e com a retirada da rebarba remanescente, para a Ferramenta C, segmento Ds.

\begin{tabular}{|c|c|c|c|c|c|c|c|c|c|}
\hline \multicolumn{10}{|c|}{ Sem retirada da rebarba anterior } \\
\hline Ensaio & $\begin{array}{c}\mathrm{h} \\
-\mathrm{mm}\end{array}$ & $\begin{array}{c}\text { 1a } \\
\text { Réplica }\end{array}$ & $\begin{array}{c}\mathrm{h} \\
-\mathrm{mm}-\end{array}$ & $\begin{array}{c}2 a \\
\text { Réplica }\end{array}$ & $\begin{array}{c}\mathbf{h} \\
-\mathrm{mm}-\end{array}$ & $\begin{array}{c}\text { 3a } \\
\text { Réplica }\end{array}$ & $\begin{array}{c}\mathbf{h} \\
-\mathbf{m m}-\end{array}$ & $\begin{array}{c}\text { Média h } \\
- \text {-mm- }\end{array}$ & $\begin{array}{l}\text { Desv. } \\
\text { Pad h } \\
\text {-mm- }\end{array}$ \\
\hline 1 & 0,1156 & 6 & 0,1189 & 11 & 0,1291 & 16 & 0,1203 & 0,1210 & 0,0058 \\
\hline 2 & 0,1276 & 7 & 0,1417 & 12 & 0,1387 & 17 & 0,1359 & 0,1360 & 0,0061 \\
\hline 3 & 0,1438 & 8 & 0,1374 & 13 & 0,1388 & 18 & 0,1372 & 0,1393 & 0,0031 \\
\hline 4 & 0,1458 & 9 & 0,1682 & 14 & 0,1572 & 19 & 0,1504 & 0,1554 & 0,0097 \\
\hline 5 & 0,1872 & 10 & 0,1789 & 15 & 0,1667 & 20 & 0,1578 & 0,1727 & 0,0130 \\
\hline \multicolumn{10}{|c|}{ Com retirada da rebarba anterior } \\
\hline Ensaio & $\begin{array}{c}\mathbf{h} \\
-\mathrm{mm}-\end{array}$ & $\begin{array}{c}\text { 1a } \\
\text { Réplica }\end{array}$ & $\begin{array}{c}\mathrm{h} \\
-\mathrm{mm}-\end{array}$ & $\begin{array}{c}2 \mathrm{a} \\
\text { Réplica }\end{array}$ & $\begin{array}{c}\mathrm{h} \\
-\mathrm{mm}-\end{array}$ & $\begin{array}{c}\text { 3a } \\
\text { Réplica }\end{array}$ & 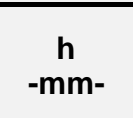 & $\begin{array}{c}\text { Média h } \\
- \text {-mm- }\end{array}$ & $\begin{array}{l}\text { Desv. } \\
\text { Pad } h \\
\text {-mm- }\end{array}$ \\
\hline 1 & 0.1173 & 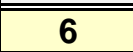 & 0,1284 & $\overline{111}$ & 0,1322 & 16 & 0,0962 & 0,1189 & 0,0198 \\
\hline 2 & 0,1156 & 7 & 0,1472 & 12 & 0,1382 & 17 & 0,1103 & 0,1278 & 0,0177 \\
\hline 3 & 0,0993 & 8 & 0,1473 & 13 & 0,1245 & 18 & 0,1291 & 0,1251 & 0,0198 \\
\hline 4 & 0,1278 & 9 & 0,0980 & 14 & 0,0982 & 19 & 0,1426 & 0,1167 & 0,0223 \\
\hline 5 & 0,1221 & 10 & 0,1287 & 15 & 0,1359 & 20 & 0,1203 & 0,1268 & 0,0071 \\
\hline
\end{tabular}

No gráfico da Figura 4.3 pode-se observar o aumento proporcional da altura da rebarba em função do número de passes, assim como verificado para as ferramentas A e B anteriormente. 


\section{Ferramenta C}

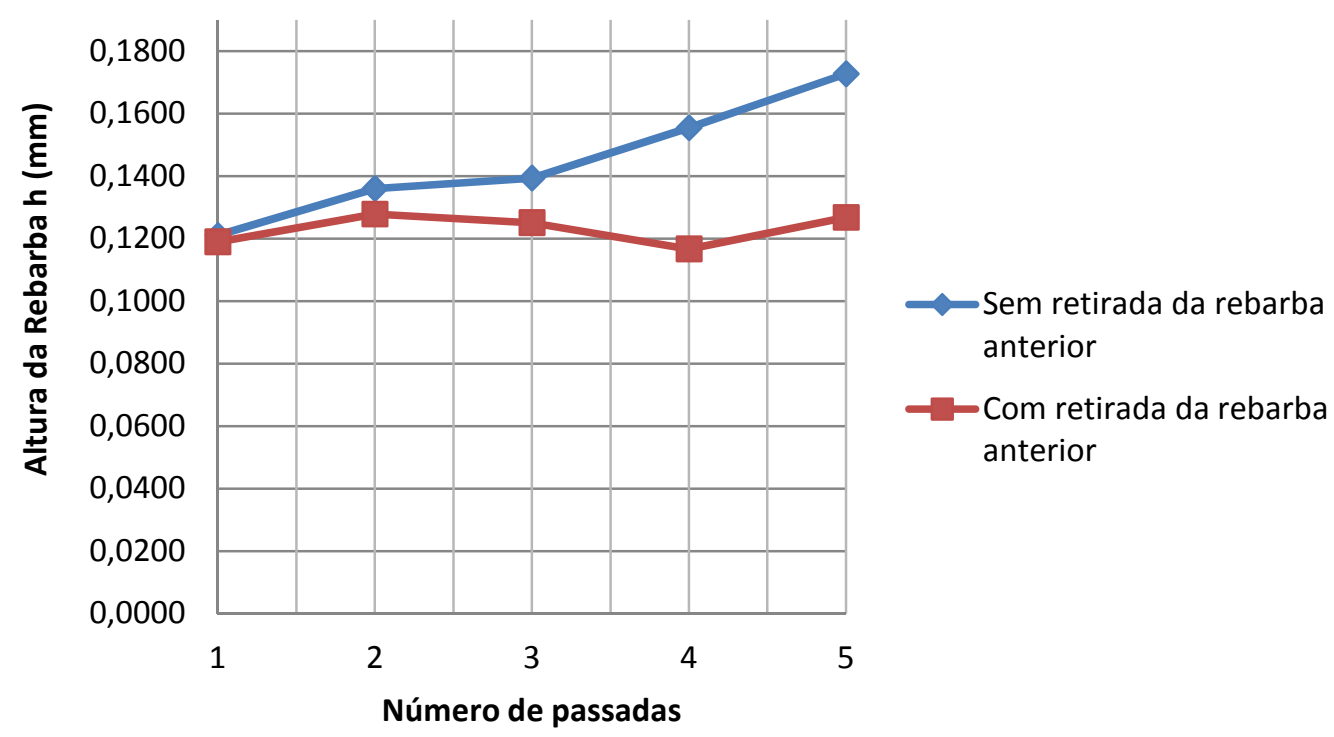

Figura 4.3 - Altura média da rebarba em relação ao número de passadas para retirada da rebarba remanescente e com a rebarba remanescente para a ferramenta C.

Através dos ensaios utilizando-se a ferramenta $\mathrm{C}$, obteve-se uma média de $11 \%$ de aumento na altura da rebarba formada em cada novo passe sem a retirada da rebarba remanescente. Partindo de uma altura de $h=0,1210 \mathrm{~mm}$ no primeiro passe, sem rebarba remanescente, chegando em $\mathrm{h}=0,1727 \mathrm{~mm}$ no quinto passe seguido sem retirada da rebarba remanescente.

Verificou-se uma tendência muito próxima das três ferramentas no comportamento da rebarba remanescente. Ficando a porcentagem de aumento da rebarba em torno de $10 \%$ da rebarba formada no passe sem a retirada da rebarba remanescente. Também se observou um comportamento irregular da rebarba formada nesta condição. Assim como em Da Silva (2011), observou-se uma altura diferente da real, proporcionada pelo acúmulo de material da rebarba remanescente.

Este acontecimento pode ser responsabilizado pelo acúmulo de material deixado na borda da peça, em forma de rebarba, após cada passe. Onde nota-se que após certo número de passes a rebarba tem perfil irregular. O mesmo não ocorre com as curvas identificadas como "com retirada", pois neste caso não foi permitido o acúmulo de material na borda da peça, e a rebarba teve seu comportamento praticamente uniforme e constante. 


\subsubsection{Geometria da fresa}

Com o objetivo de avaliar a participação da geometria da fresa na formação da rebarba, foram testadas três diferentes tipos de ferramenta, sendo elas a ferramenta A, ferramenta B e ferramenta $C$, conforme descrito no item 3.5.2.

Os parâmetros de corte utilizados foram $a_{p}=0,5 \mathrm{~mm}, v_{c}=190 \mathrm{~m} / \mathrm{min} ; \mathrm{f}_{\mathrm{z}}=$ $0,08 \mathrm{~mm} /$ dente na condição de ferramenta nova. As medições foram realizadas no segmento Ds, correspondente ao ângulo de $\theta=180^{\circ}$ na borda de saída da peça, e os resultados são mostrados na Tabela 4.4 .

Tabela 4.4 - Altura da rebarba formada com a retirada da rebarba remanescente, para as

Ferramentas A, B e C medidas no segmento Ds.

\begin{tabular}{|c|c|c|c|c|c|c|c|c|c|}
\hline \multicolumn{10}{|c|}{ Análise Ferramenta A } \\
\hline Ensaio & $\begin{array}{c}\mathbf{h} \\
-\mathbf{m m}-\end{array}$ & $\begin{array}{c}1 a \\
\text { Réplica }\end{array}$ & $\begin{array}{c}\mathbf{h} \\
-\mathbf{m m}-\end{array}$ & $\begin{array}{c}2 \mathrm{a} \\
\text { Réplica }\end{array}$ & $\begin{array}{c}\mathbf{h} \\
-\mathbf{m m}-\end{array}$ & $\begin{array}{c}\text { 3a } \\
\text { Réplica }\end{array}$ & $\begin{array}{c}\mathbf{h} \\
-\mathbf{m m}-\end{array}$ & $\begin{array}{l}\text { Média h } \\
\text {-mm- }\end{array}$ & $\begin{array}{c}\text { Desv. Pad } \\
\text { h -mm- }\end{array}$ \\
\hline$\overline{11}$ & 0,0486 & 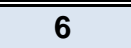 & 0,0387 & 11 & 0,0523 & 16 & 0,0423 & 0,0455 & 0,0061 \\
\hline 2 & 0,0487 & 7 & 0,0420 & 12 & 0,0492 & 17 & 0,0567 & 0,0492 & 0,0060 \\
\hline 3 & 0,0390 & 8 & 0,0581 & 13 & 0,0386 & 18 & 0,0329 & 0,0422 & 0,0110 \\
\hline 4 & 0,0420 & 9 & 0,0487 & 14 & 0,0514 & 19 & 0,0441 & 0,0466 & 0,0043 \\
\hline 5 & 0,0396 & 10 & 0,0242 & 15 & 0,0429 & 20 & 0,0329 & 0,0349 & 0,0083 \\
\hline \multicolumn{10}{|c|}{ Análise Ferramenta B } \\
\hline Ensaio & $\begin{array}{c}\mathrm{h} \\
-\mathrm{mm}-\end{array}$ & $\begin{array}{c}1 \mathrm{a} \\
\text { Réplica }\end{array}$ & $\begin{array}{c}\mathrm{h} \\
-\mathrm{mm}-\end{array}$ & $\begin{array}{c}2 \mathrm{a} \\
\text { Réplica }\end{array}$ & $\begin{array}{c}\mathrm{h} \\
-\mathbf{m m}-\end{array}$ & $\begin{array}{c}3 a \\
\text { Réplica }\end{array}$ & $\begin{array}{c}\mathrm{h} \\
-\mathrm{mm}-\end{array}$ & $\begin{array}{c}\text { Média h } \\
\text {-mm- }\end{array}$ & $\begin{array}{c}\text { Desv. Pad } \\
\text { h -mm- }\end{array}$ \\
\hline 1 & 0,2581 & 6 & 0,2831 & 11 & 0,2439 & 16 & 0,2377 & 0,2557 & 0,0202 \\
\hline 2 & 0,2486 & 7 & 0,2638 & 12 & 0,2792 & 17 & 0,2605 & 0,2630 & 0,0126 \\
\hline 3 & 0,2631 & 8 & 0,2681 & 13 & 0,2395 & 18 & 0,2456 & 0,2541 & 0,0137 \\
\hline 4 & 0,2496 & 9 & 0,2493 & 14 & 0,2783 & 19 & 0,2631 & 0,2601 & 0,0137 \\
\hline 5 & 0,2689 & 10 & 0,2672 & 15 & 0,2581 & 20 & 0,2539 & 0,2620 & 0,0072 \\
\hline \multicolumn{10}{|c|}{ Análise Ferramenta C } \\
\hline Ensaio & $\begin{array}{c}\mathrm{h} \\
-\mathrm{mm}-\end{array}$ & $\begin{array}{c}1 a \\
\text { Réplica }\end{array}$ & $\begin{array}{c}\mathrm{h} \\
-\mathrm{mm}-\end{array}$ & $\begin{array}{c}2 a \\
\text { Réplica }\end{array}$ & $\begin{array}{c}\mathrm{h} \\
-\mathbf{m m}-\end{array}$ & $\begin{array}{c}3 a \\
\text { Réplica }\end{array}$ & $\begin{array}{c}\mathrm{h} \\
-\mathrm{mm}-\end{array}$ & $\begin{array}{l}\text { Média h } \\
\text {-mm- }\end{array}$ & $\begin{array}{l}\text { Desv. Pad } \\
\text { h -mm- }\end{array}$ \\
\hline 1 & 0.1173 & 6 & 0,1284 & 11 & 0,1322 & 16 & 0,0962 & 0,1189 & 0,0198 \\
\hline 2 & 0,1156 & 7 & 0,1472 & 12 & 0,1382 & 17 & 0,1103 & 0,1278 & 0,0177 \\
\hline 3 & 0,0993 & 8 & 0,1473 & 13 & 0,1245 & 18 & 0,1291 & 0,1251 & 0,0198 \\
\hline 4 & 0,1278 & 9 & 0,0980 & 14 & 0,0982 & 19 & 0,1426 & 0,1167 & 0,0223 \\
\hline 5 & 0,1221 & 10 & 0,1287 & 15 & 0,1359 & 20 & 0,1203 & 0,1268 & 0,0071 \\
\hline
\end{tabular}

Os valores médios da altura da rebarba para os três diferentes tipos de ferramenta estão ilustrados no gráfico da Figura 4.4. 


\section{Comparativo das ferramentas}

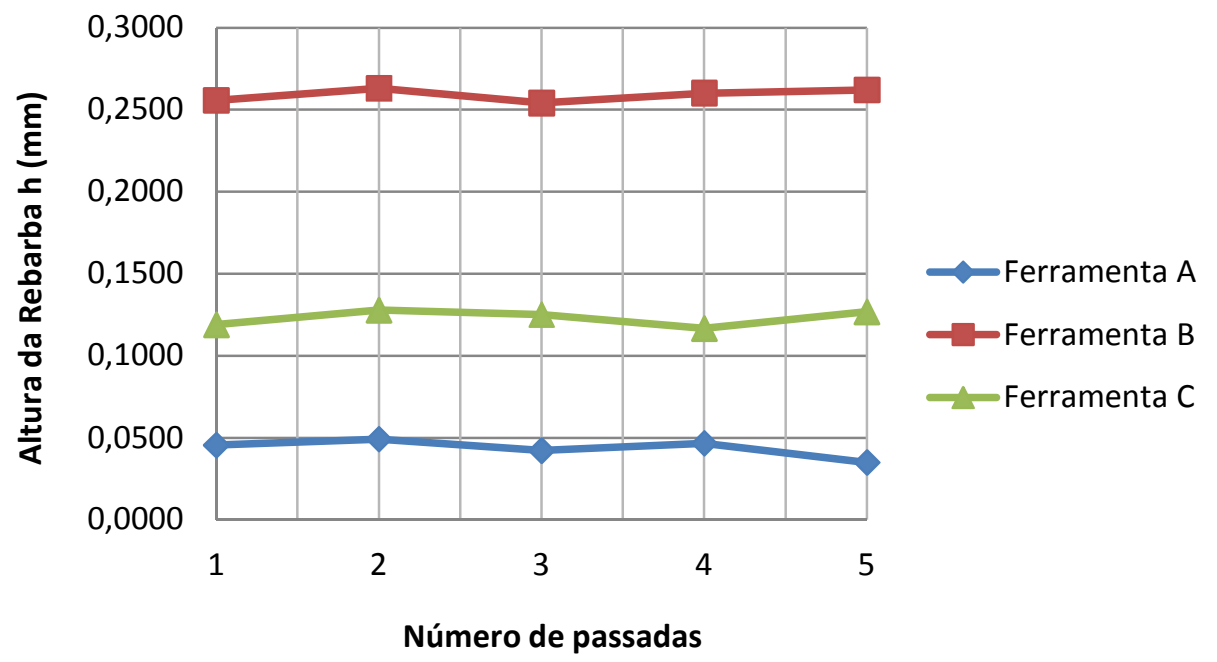

Figura 4.4 - Comparativo da altura da rebarba para as ferramentas A, B e C. Medição considerada no segmento Ds, na borda de saída da peça

Após analisar a Figura 4.4, torna-se claro a maior altura da rebarba formada pela usinagem com a Ferramenta $B$, com altura média em torno de $h=0,2601 \mathrm{~mm}$, enquanto a dimensão da rebarba formada com a ferramenta $C$, teve altura média de $\mathrm{h}=0,1251 \mathrm{~mm}$, e a ferramenta A obteve o melhor desempenho dentre elas com altura média de $\mathrm{h}=0,0455 \mathrm{~mm}$. Portanto conclui-se que os ensaios com a ferramenta $A$, com face alisadora, geometria positiva e ângulo de posição $\chi_{r}=88^{\circ}$ obtiveram uma redução de $64 \%$ na altura da rebarba quando comparada com a ferramenta $C$, ferramenta esta com ângulo de saída positivo e ângulo de posição de $\chi_{\mathrm{r}}=90^{\circ}$, mas sem face alisadora e uma redução de $83 \%$ quando comparada a Ferramenta $A$ com a Ferramenta $B$, que possui geometria negativa e ângulo de posição de $\chi_{r}=40^{\circ}$.

Segundo Diniz, Marcondes e Coppini, 2010 o corte dos metais envolve o cisalhamento ao longo do plano de cisalhamento primário, e o ângulo entre o plano de cisalhamento e a direção de corte é chamado de ângulo de cisalhamento $(\varphi)$. Quanto menor o ângulo de saída da ferramenta $\left(\gamma_{0}\right)$, menor será o ângulo de cisalhamento e maior a deformação plástica. Conseqüentemente, maior será o grau de recalque (razão espessura do cavaco depois de formado/espessura do cavaco antes de formado), aumentando o atrito ferramenta/cavaco e a temperatura de corte. Fatores que favorecem a formação de rebarbas maiores. Mas deve ser salientado 
que geometrias negativas são normalmente empregadas no corte de materiais de difícil usinabilidade e em cortes interrompidos, por garantir maior resistência à cunha de corte e melhores índices de vida da ferramenta de corte (MACHADO et. al, 2009).

Uma justificativa para a ferramenta $B$ obter o pior desempenho dentre as três ferramentas, deve-se ao fato da pastilha ter chanfro com fase paralela, $b_{s}=2,1 \mathrm{~mm}$, gerando um contato intenso da aresta da ferramenta de corte com o material da peça, pois o ângulo de folga entre a aresta secundária e a superfície usinada é nulo. Fazendo com que o calor gerado seja maior devido ao atrito, e conseqüentemente proporcionando uma elevada deformação plástica, favorecendo a formação de rebarbas com dimensões maiores.

Outra desvantagem no aspecto da formação da rebarba da ferramenta B é o menor ângulo de posição $\chi_{r}=40^{\circ}$, que para o mesmo avanço e a mesma profundidade de corte, acarreta uma diminuição da espessura de corte, e ao mesmo tempo, um aumento da largura de corte, favorecendo o dobramento do cavaco e maior deformação plástica. O fato de possuir uma geometria negativa também favorece o aumento na dimensão da rebarba, pois o ângulo de saída menor promove maior atrito ferramenta/cavaco e temperatura de corte. Fatores que favorecem a formação de rebarbas maiores. Por outro lado, segundo Machado et al. (2009) este ângulo de posição permite maior vida da ferramenta, pois resulta em uma melhor distribuição da temperatura de corte.

O mesmo não ocorre com as ferramentas $A$ e $C$, que não possuem a fase paralela e o contato da aresta da ferramenta com a peça é pequeno, sendo o suficiente para o corte. O ângulo de posição de ambas é alto, $\chi_{r}=88^{\circ}$ e $\chi_{r}=90^{\circ}$ respectivamente e possuem geometria positiva, que já demonstram ser uma vantagem em relação à ferramenta $B$, pois proporciona uma espessura do cavaco maior, conseqüentemente um plano de cisalhamento primário maior o que favorece o cisalhamento com menor deformação plástica, formando rebarbas menores. Conforme Kim et al. (2000), a formação da rebarba é influenciada de forma mais significativa pelas forças de corte, que dependem diretamente da espessura do cavaco.

A vantagem da ferramenta $A$ em relação a $C$ pode ser justificada pela utilização de pastilhas alisadoras. Segundo Dornfeld et al (1999) as pastilhas alisadoras, promovem o fluxo do material que está sendo usinado, ou seja, o fluxo 
de cavaco se processa de forma gradativa, evitando o dobramento do metal e consequentemente diminuindo a zona de deformação plástica na borda da peça.

Da Silva, (2004) verificou em seu trabalho que o aumento do ângulo de cisalhamento, promovido pelo aumento do ângulo de folga da ferramenta, proporcionou uma redução no grau de recalque e uma menor deformação plástica no plano de cisalhamento primário favorecendo a formação de rebarbas com dimensões reduzidas.

\subsubsection{Aspectos gerais sobre a rebarba formada}

Com o objetivo de avaliar os aspectos gerais da rebarba formada nos ensaios da primeira etapa, medições da altura da rebarba foram realizadas nas bordas de entrada e de saída da peça e nas bordas de dois dos seis furos (cilindros). Os parâmetros de corte utilizados foram $a_{p}=0,7 \mathrm{~mm}, v c=130 \mathrm{~m} / \mathrm{min} ; \mathrm{f}_{z}$ $=0,05 \mathrm{~mm} /$ dente, e os ensaios foram realizados com a Ferramenta $A$ com $V_{B \max }=$ $0,00 \mathrm{~mm}$.

O que pode ser observado nestes primeiros ensaios, coincide com a literatura, para a qual as dimensões da rebarba na borda de entrada são mais uniformes e menores do que as rebarbas formadas na borda de saída. Verificou-se também uma dimensão pequena e uniforme para as rebarbas formadas na borda do cilindro.

Durante a realização dos ensaios foi observado o surgimento de rebarbas em, praticamente, toda superfície usinada inclusive nas bordas dos furos. Nota se uma grande variação na altura das mesmas. Em uma mesma borda pode-se perceber rebarbas bem menores, com altura de apenas 0,008 mm, e outras consideradas maiores, atingindo $0,0324 \mathrm{~mm}$, como é o caso da borda de entrada do ensaio $\mathrm{N}^{\circ} 03$, mostrado na Tabela 4.6. 


\subsubsection{Rebarbas formadas nas bordas dos furos (cilindros)}

O mecanismo de formação da rebarba nos cilindros aproxima-se da rebarba tipo Poisson, indicada por Gillespie e Blotter (1976) e predominantemente do tipo faca conforme Chern e Dornfeld (1996). Ainda sim, não se percebeu rebarbas formadas nos furos, com dimensões que venham despertar maiores interesses, conforme Figura 4.5 .

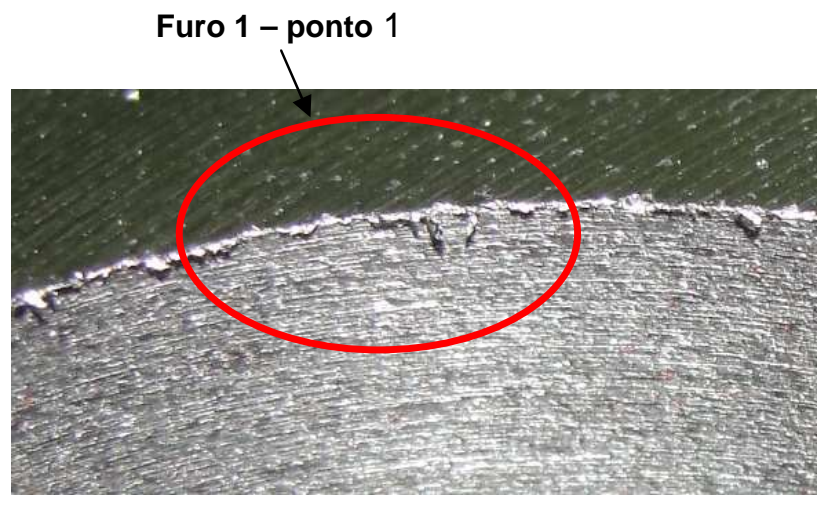

4.5 - Aspecto da rebarba formada na borda do furo do cilindro de entrada. Ensaio 3

A Tabela 4.5 mostra os resultados obtidos pela medição da rebarba formada nos furos de entrada e de saída, em quatro pontos.

Tabela 4.5 - Tabela de resultados da altura da rebarba na borda dos furos - Ferramenta A

\begin{tabular}{|c|c|c|c|c|c|c|c|c|c|}
\hline \multicolumn{10}{|c|}{ Borda dos Furos (Cilindros) } \\
\hline \multirow{2}{*}{\multicolumn{2}{|c|}{$\begin{array}{c}\text { Classificação } \\
\text { Divisão dos } \\
\text { segmentos na borda }\end{array}$}} & \multicolumn{4}{|c|}{ Furo 1 (Cilindro de entrada) } & \multicolumn{4}{|c|}{ Furo 2 (Cilindro de saída) } \\
\hline & & Ponto 1 & Ponto 2 & Ponto 3 & Ponto 4 & Ponto 5 & Ponto 6 & Ponto 7 & Ponto 8 \\
\hline \multicolumn{2}{|c|}{ Divisão angular } & $0^{\circ}$ & $90^{\circ}$ & $180^{\circ}$ & $270^{\circ}$ & $0^{\circ}$ & $90^{\circ}$ & $180^{\circ}$ & $270^{\circ}$ \\
\hline \multicolumn{2}{|c|}{ Altura da rebarba } & \multicolumn{8}{|c|}{$\mathrm{h}(\mathrm{mm})$} \\
\hline Ensaio & 1 & 0,0121 & 0,0135 & 0,0084 & 0,0072 & 0,0089 & 0,0135 & 0,0062 & 0,0134 \\
\hline 1a Réplica & 2 & 0,0156 & 0,0134 & 0,0062 & 0,0079 & 0,0136 & 0,0083 & 0,0071 & 0,0098 \\
\hline 2a Réplica & 3 & 0,0138 & 0,0083 & 0,0073 & 0,0118 & 0,0092 & 0,0094 & 0,0084 & 0,0052 \\
\hline 3a Réplica & 4 & 0,0137 & 0,0097 & 0,0137 & 0,0092 & 0,0184 & 0,0152 & 0,0062 & 0,0079 \\
\hline \multicolumn{2}{|c|}{ Média h (mm) } & 0,0138 & 0,0112 & 0,0089 & 0,0090 & 0,0125 & 0,0116 & 0,0070 & 0,0091 \\
\hline \multicolumn{2}{|c|}{ Desv.Pad. (mm) } & 0,0014 & 0,0026 & 0,0033 & 0,0020 & 0,0045 & 0,0033 & 0,0010 & 0,0034 \\
\hline
\end{tabular}


Os valores médios das alturas das rebarbas formadas nos furos não passaram de $0,014 \mathrm{~mm}$, sem distinção entre o furo de entrada e o furo de saída. 0 ponto correspondente a $0^{\circ}$ apresentou uma dimensão da rebarba ligeiramente maior, possivelmente isso se deve ao fato da deformação plástica ocorrer para fora da borda neste ponto, mecanismo este semelhante ao formador da rebarba na borda de saída, classificado por Gillespie e Blotter(1976) como rebarba do tipo Rollover.

Segundo observado por Da Silva (2004), o perfil cilíndrico da borda dos furos dificulta a expansão além da borda do material deformado plasticamente durante o processo de usinagem, tornando assim, pequenas as rebarbas formadas nessas bordas.

\subsubsection{Rebarba na borda de entrada versus Rebarba na borda de saída}

Para avaliação inicial das rebarbas formadas na borda de entrada e na borda de saída foram realizados quatro experimentos, sendo um ensaio e três réplicas. Onde foram medidas a altura da rebarba em todos os sete segmentos nas bordas de entrada e de saída do corpo de prova. Os parâmetros de corte utilizados foram $a_{p}=0,7 \mathrm{~mm}, v_{c}=130 \mathrm{~m} / \mathrm{min} ; \mathrm{f}_{\mathrm{z}}=0,05 \mathrm{~mm} /$ dente, utilizando a Ferramenta $A$ com $\mathrm{V}_{\mathrm{Bmax}}=0,00 \mathrm{~mm}$.

As bordas de entrada e de saída analisadas encontram-se perpendicular a direção de avanço da ferramenta de corte. O ângulo de saída da ferramenta da peça $(\theta)$ será dado pelo intervalo entre $0^{\circ}<\theta<90^{\circ}$ na borda de entrada e $90^{\circ}<\theta<180^{\circ}$ na borda de saída. O ângulo de entrada da ferramenta da peça $(\psi)$ estará dentro do intervalo $90^{\circ}<\psi<180^{\circ}$ na borda de entrada e $0^{\circ}<\psi<90^{\circ}$ na borda de saída.

Conforme pode ser observado nas Tabelas 4.6 e 4.7, as rebarbas formadas nas bordas de entrada são bem menores, com sua altura ficando em torno de $34 \%$ da altura da rebarba formada na borda de saída, e possuem mecanismos de formação diferentes. Tanto na borda de entrada quanto na borda de saída, considerou-se no intervalo de 0 até $28 \mathrm{~mm}$ (local onde passa o centro da fresa) a formação da rebarba do tipo de entrada (segmento A até D) e de 28 até 56 formouse a rebarba do tipo de saída (do segmento $D$ até $G$ ), conforme classificação de Da Silva (2004). 
Apesar das dimensões reduzidas das rebarbas formadas na borda de entrada, ainda é possível verificar que as rebarbas do tipo de entrada possuem alturas menores do que as rebarbas do tipo de saída. O mesmo pode ser observado na formação da rebarba na borda de saída. Em geral as rebarbas formadas no intervalo de 0 até próximo de $28 \mathrm{~mm}$, em quase todos os ensaios, tem o mecanismo de formação classificado por Gillespie e Blotter (1976) como sendo a rebarba do tipo Poisson. Narayanaswami e Dornfeld (1997) consideraram as bordas dentro deste intervalo, como sendo regiões livres de rebarbas.

Tabela 4.6 - Tabela de resultados da altura da rebarba na borda de entrada - Ferramenta A

\begin{tabular}{|c|c|c|c|c|c|c|c|c|}
\hline \multicolumn{9}{|c|}{ Borda de entrada } \\
\hline \multirow{2}{*}{\multicolumn{2}{|c|}{$\begin{array}{c}\text { Tipo de rebarba } \\
\text { Divisão dos } \\
\text { segmentos na borda }\end{array}$}} & \multicolumn{3}{|c|}{ Rebarba de entrada } & \multicolumn{4}{|c|}{ Rebarba de saída } \\
\hline & & $\begin{array}{c}\mathrm{Ae} \\
\left(\psi=150^{\circ}\right)\end{array}$ & $\begin{array}{c}\mathrm{Be} \\
\left(\psi=160^{\circ}\right)\end{array}$ & $\begin{array}{c}\mathrm{Ce} \\
\left(\psi=170^{\circ}\right)\end{array}$ & $\begin{array}{c}\mathrm{De} \\
(\theta=09)\end{array}$ & $\begin{array}{c}\mathrm{Ee} \\
(\theta=109)\end{array}$ & $\begin{array}{c}\mathrm{Fe} \\
(\theta=20)\end{array}$ & $\begin{array}{c}\mathrm{Ge} \\
(\theta=309)\end{array}$ \\
\hline \multicolumn{2}{|c|}{ Divisão da borda (mm) } & 5 & 14 & 21 & 28 & 35 & 42 & 51 \\
\hline \multicolumn{2}{|c|}{ Altura da rebarba } & \multicolumn{7}{|c|}{$h(\mathrm{~mm})$} \\
\hline Ensaio & 1 & 0,0091 & 0,0135 & 0,0156 & 0,0213 & 0,0192 & 0,0148 & 0,0121 \\
\hline 1a Réplica & 2 & 0,0086 & 0,0119 & 0,0163 & 0,0267 & 0,0183 & 0,0150 & 0,0098 \\
\hline 2a Réplica & 3 & 0,0080 & 0,0129 & 0,0172 & 0,0324 & 0,0193 & 0,0164 & 0,0113 \\
\hline 3a Réplica & 4 & 0,0100 & 0,0145 & 0,0158 & 0,0213 & 0,0187 & 0,0167 & 0,0092 \\
\hline \multicolumn{2}{|c|}{ Média h (mm) } & 0,0089 & 0,0132 & 0,0162 & 0,0254 & 0,0189 & 0,0157 & 0,0106 \\
\hline \multicolumn{2}{|c|}{ Desv.Pad. (mm) } & 0,0008 & 0,0011 & 0,0007 & 0,0053 & 0,0005 & 0,0010 & 0,0013 \\
\hline
\end{tabular}

Tabela 4.7 - Tabela de resultados da altura da rebarba na borda de saída - Ferramenta A

\begin{tabular}{|c|c|c|c|c|c|c|c|c|}
\hline \multicolumn{9}{|c|}{ Borda de saída } \\
\hline \multirow{2}{*}{\multicolumn{2}{|c|}{$\begin{array}{c}\text { Tipo de rebarba } \\
\text { Divisão dos } \\
\text { segmentos na borda }\end{array}$}} & \multicolumn{3}{|c|}{ Rebarba de entrada } & \multicolumn{4}{|c|}{ Rebarba de saída } \\
\hline & & $\begin{array}{c}\text { As } \\
\left(\psi=30^{\circ}\right)\end{array}$ & $\begin{array}{c}\text { Bs } \\
\left(\psi=20^{\circ}\right)\end{array}$ & $\begin{array}{c}\text { Cs } \\
\left(\psi=10^{\circ}\right)\end{array}$ & $\begin{array}{c}\text { Ds } \\
(\theta=1809)\end{array}$ & $\begin{array}{c}\text { Es } \\
(\theta=1709)\end{array}$ & $\begin{array}{c}\text { Fs } \\
(\theta=1609)\end{array}$ & $\begin{array}{c}\text { Gs } \\
(\theta=1509)\end{array}$ \\
\hline \multicolumn{2}{|c|}{ Divisão da borda (mm) } & 5 & 14 & 21 & 28 & 35 & 42 & 51 \\
\hline \multicolumn{2}{|c|}{ Altura da rebarba } & \multicolumn{7}{|c|}{$\mathrm{h}(\mathrm{mm})$} \\
\hline Ensaio & 1 & 0,0482 & 0,0400 & 0,0571 & 0,0543 & 0,0482 & 0,0319 & 0,0234 \\
\hline 1a Réplica & 2 & 0,0337 & 0,0493 & 0,0502 & 0,0510 & 0,0740 & 0,0693 & 0,0610 \\
\hline 2a Réplica & 3 & 0,0547 & 0,0478 & 0,0592 & 0,1035 & 0,0742 & 0,0830 & 0,0670 \\
\hline 3a Réplica & 4 & 0,0490 & 0,0610 & 0,0470 & 0,0880 & 0,0789 & 0,0470 & 0,0580 \\
\hline \multicolumn{2}{|c|}{ Média $\mathrm{h}(\mathrm{mm})$} & 0,0464 & 0,0495 & 0,0534 & 0,0742 & 0,0688 & 0,0578 & 0,0524 \\
\hline \multicolumn{2}{|c|}{ Desv.Pad. (mm) } & 0,0090 & 0,0087 & 0,0057 & 0,0257 & 0,0139 & 0,0228 & 0,0197 \\
\hline
\end{tabular}


Através da Tabela 4.6 notou-se a presença de rebarba na borda de entrada com uma dimensão muito pequena. Essa rebarba possui perfil uniforme, do tipo faca, conforme classificação dada por Chern (2006) e Lin (1999). A sua altura é aproximadamente constante e pode ser observada através da Figura 4.6, para o ensaio $\mathrm{N}^{\circ} 3$, indicado no segmento De.

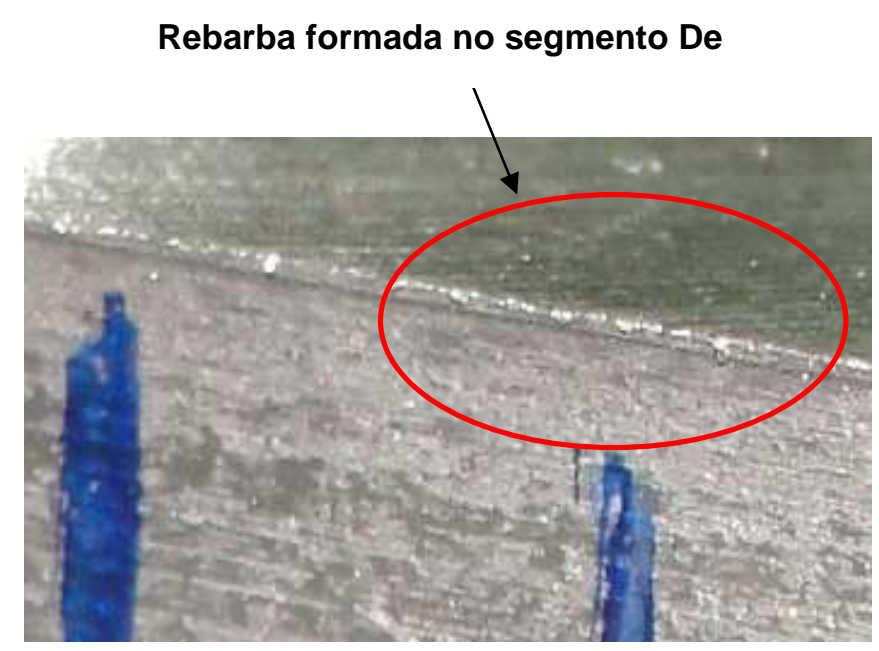

Figura 4.6 - Rebarba do tipo faca, formada na borda de entrada da peça, e observada em praticamente todos os ensaios realizados, com a ferramenta $\mathrm{A}$.

Conforme pode ser observado na Tabela 4.6, as rebarbas formadas nas bordas de saída são, indiscutivelmente, maiores que as formadas nas bordas de entrada. A Figura 4.7 mostra o segmento Ds da borda de saída do ensaio $N^{\circ} 4$.

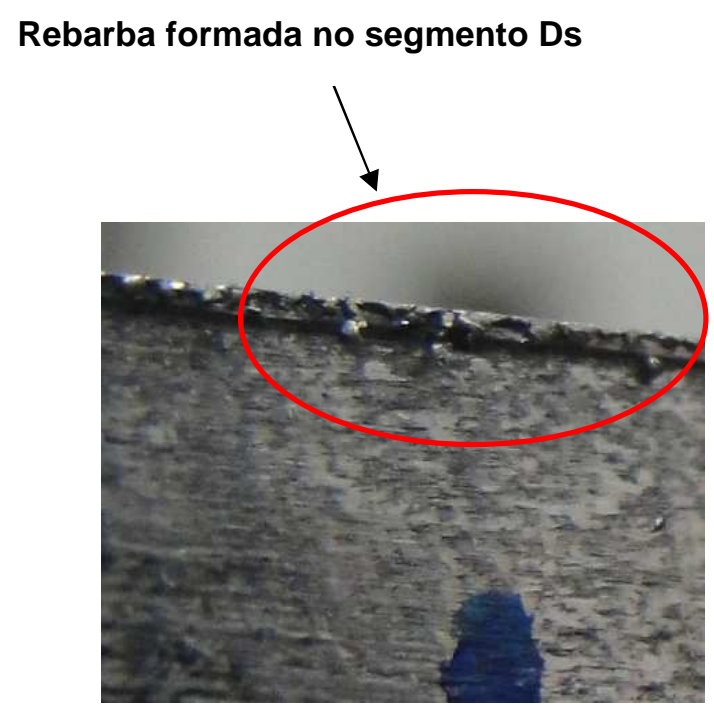

Figura 4.7 - Rebarba do tipo Rollover (em conjunto com Tear), formada na borda de saída da peça, e observada em boa parte dos ensaios realizados, com a ferramenta $A$. 
O deslocamento da fresa sobre a borda de entrada proporciona uma deformação no material, e de acordo com Da Silva (2004), grande parte desta deformação será distribuída sobre a própria peça, não permitindo a expansão da mesma, tornando a dimensão da rebarba formada menor. O mesmo não ocorre na borda de saída, pois a deformação do material estender-se-á além da peça, formando uma rebarba muito maior.

Através do gráfico da Figura 4.8 pode-se verificar o comportamento médio das alturas das rebarbas formadas em toda a extensão da borda de entrada e na borda de saída para cada segmento medido.

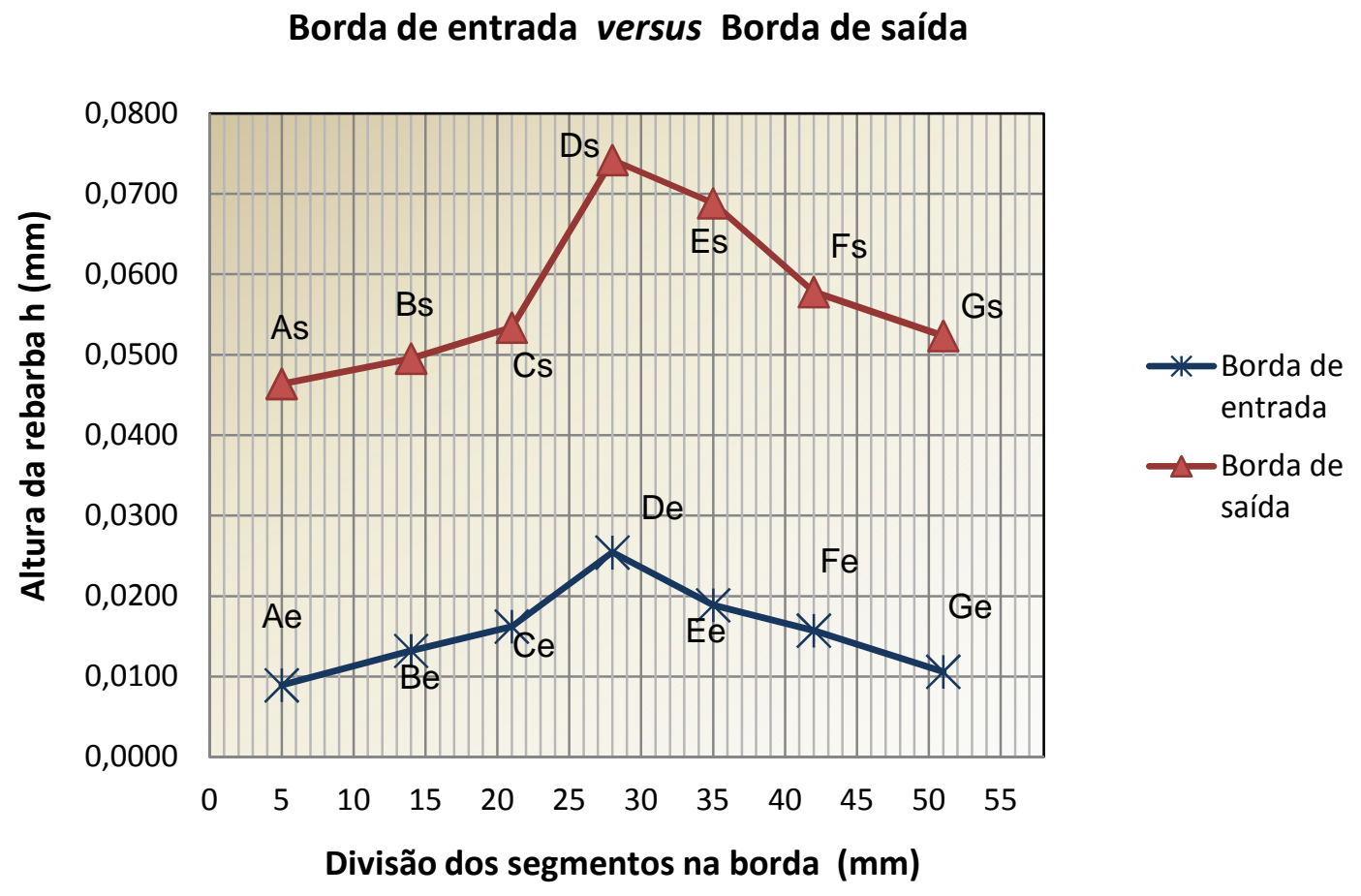

Figura 4.8 - Variação da altura da rebarba em todo o comprimento da borda de entrada e da borda de saída utilizando os valores médios - Ferramenta A.

Pode-se afirmar que a altura da rebarba tem comportamento ascendente até o centro da borda, no segmento $\mathbf{D}$, que corresponde a medida de $28 \mathrm{~mm}$. A partir deste segmento a altura da rebarba começa a decrescer podendo desaparecer totalmente como no caso da borda de entrada, ou ficar com dimensões muito pequenas, como as encontradas da borda de saída. Cada segmento corresponde a um ângulo de saída da ferramenta da peça $(\theta)$ ou ângulo de entrada da ferramenta 
na peça $(\psi)$, a rebarba tem altura diferente para cada um deles, conforme verifica-se na Tabela 4.6 para a borda de entrada e na Tabela 4.7 para a borda de saída.

As rebarbas que aparecem no intervalo entre $90^{\circ}<\theta<180^{\circ}$ têm 0 mecanismo de formação classificado por Gillespie e Blotter (1976) como sendo rebarba de encurvamento (Rollover) em conjunto com a rebarba de estiramento (Tear), e são rebarbas do tipo de saída. O mecanismo de Poisson atua nas rebarbas formadas no intervalo de $0^{\circ}<\psi<90^{\circ}$, sendo estas rebarbas do tipo de entrada.

A Tabela 4.8 demonstra os resultados da altura da rebarba na borda de saída com a Ferramenta $A$ em condição de desgaste máximo admitido neste trabalho, $\mathrm{V}_{\mathrm{Bmax}}=0,3 \mathrm{~mm}$. Trata-se de uma etapa inicial, apenas para fornecer dados para avaliar o comportamento da rebarba na condição de desgaste de flanco máximo. Os parâmetros de corte utilizados foram $a_{p}=0,7 \mathrm{~mm}, v_{c}=130 \mathrm{~m} / \mathrm{min} ; f_{z}=$ $0,05 \mathrm{~mm} /$ dente, utilizando somente a Ferramenta $A$.

Tabela 4.8 - Resultados da altura da rebarba na borda de saída - Ferramenta $\mathrm{A}, \mathrm{V}_{\mathrm{Bmax}}=0,3 \mathrm{~mm}$

\begin{tabular}{|c|c|c|c|c|c|c|c|c|}
\hline \multicolumn{9}{|c|}{ Borda de saída } \\
\hline \multicolumn{9}{|c|}{ VBmax $=0,30 \mathrm{~mm}$} \\
\hline \multicolumn{2}{|c|}{ Tipo de rebarba } & \multicolumn{3}{|c|}{ Rebarba de entrada } & \multicolumn{4}{|c|}{ Rebarba de saída } \\
\hline \multicolumn{2}{|c|}{$\begin{array}{c}\text { Divisão dos segmentos } \\
\text { na borda }\end{array}$} & $\begin{array}{c}\text { As } \\
\left(\psi=30^{\circ}\right)\end{array}$ & $\begin{array}{c}\text { Bs } \\
\left(\psi=20^{\circ}\right)\end{array}$ & $\begin{array}{c}\text { Cs } \\
\left(\psi=10^{\circ}\right)\end{array}$ & $\begin{array}{c}\text { Ds } \\
(\theta=1809)\end{array}$ & $\begin{array}{c}\text { Es } \\
(\theta=1709)\end{array}$ & $\begin{array}{c}\text { Fs } \\
(\theta=1609)\end{array}$ & $\begin{array}{c}\text { Gs } \\
(\theta=1509)\end{array}$ \\
\hline \multicolumn{2}{|c|}{ Divisão da borda (mm) } & 5 & 14 & 21 & 28 & 35 & 42 & 51 \\
\hline \multicolumn{2}{|c|}{ Altura da rebarba } & \multicolumn{7}{|c|}{$h(\mathrm{~mm})$} \\
\hline Ensaio & 1 & 0,0440 & 0,0570 & 0,0982 & 0,1023 & 0,1072 & 0,0930 & 0,0681 \\
\hline 1a Réplica & 2 & 0,0472 & 0,0610 & 0,0710 & 0,1231 & 0,0873 & 0,0824 & 0,0521 \\
\hline 2a Réplica & 3 & 0,0589 & 0,0620 & 0,0840 & 0,1248 & 0,0924 & 0,0874 & 0,0623 \\
\hline 3a Réplica & 4 & 0,0582 & 0,0724 & 0,1130 & 0,1105 & 0,1082 & 0,0724 & 0,0484 \\
\hline \multicolumn{2}{|c|}{ Média h (mm) } & 0,0521 & 0,0631 & 0,0916 & 0,1152 & 0,0988 & 0,0838 & 0,0577 \\
\hline \multicolumn{2}{|c|}{ Desv.Pad. (mm) } & 0,0076 & 0,0066 & 0,0181 & 0,0107 & 0,0105 & 0,0087 & 0,0091 \\
\hline
\end{tabular}

Através dos ensaios realizados, principalmente em condições de maior desgaste da ferramenta, notou se a presença de rebarba com duas morfologias diferentes, sendo elas: do tipo caracol e do tipo faca (Figura 4.9), muitas vezes ocorrendo as duas morfologias na mesma borda. Variáveis como o ângulo de saída da peça, e o próprio desgaste da ferramenta de corte, dentre outras menos influentes, definem o tipo da morfologia gerada na borda da peça. Observou-se 
ainda que a forma é característica da rebarba de estiramento (tear), de acordo com a classificação oferecida por Gillespie e Blotter (1976).

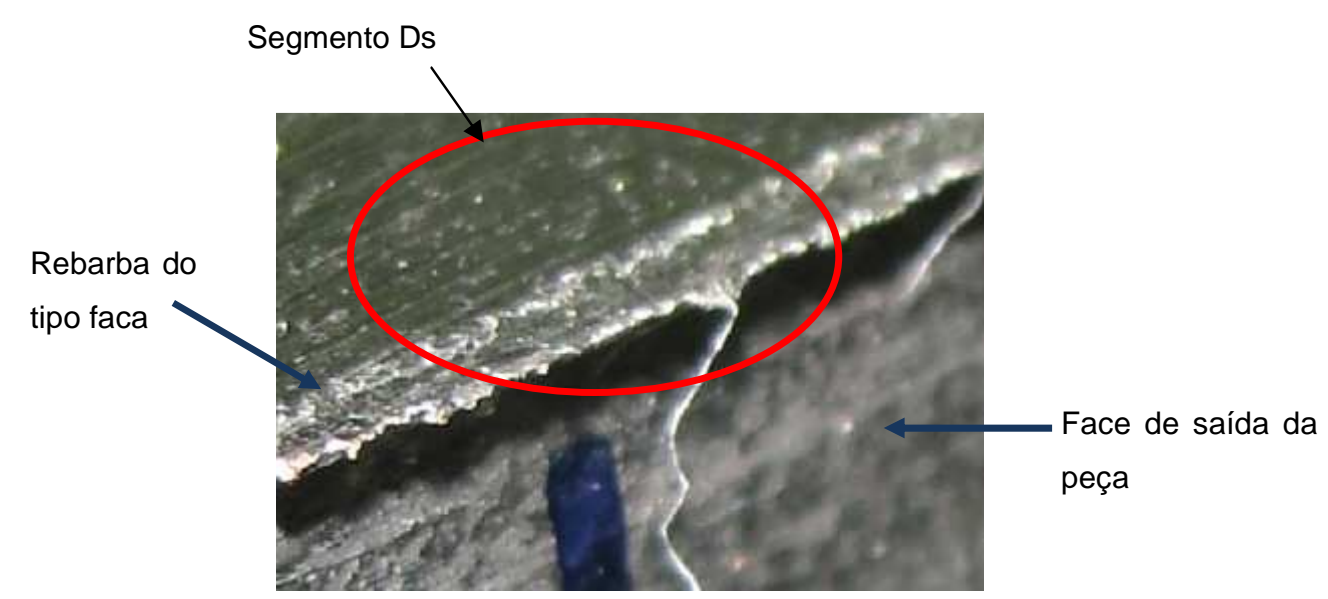

Figura 4.9 - Análise da rebarba formada durante o ensaio N2, para $\mathrm{V}_{\mathrm{Bmáx}}=0,3 \mathrm{~mm}$.

Mesmo nos ensaios realizados com ferramenta em fim de vida não se observou a formação do breakout em nenhuma borda. Acredita-se que possíveis deformações que tenham ocorrido na direção do plano de cisalhamento negativo durante os testes não atingiram a deformação crítica, prevalecendo a deformação crítica a fratura. Além disso, diferentemente do ferro fundido cinzento, o ferro fundido vermicular possui propriedades dúcteis mais elevadas, estando portanto esta constatação de acordo com o esperado pela literatura.

\subsection{SEGUNDA ETAPA DOS ENSAIOS}

Após análise da revisão bibliográfica no capítulo dois observou-se a influência dos parâmetros de corte nas dimensões e na morfologia da rebarba formada após a usinagem. Deste modo justifica-se a segunda etapa dos ensaios, através do qual será possível avaliar a influência dos principais parâmetros de corte: velocidade de corte, profundidade de corte, avanço, desgaste da ferramenta de corte e ângulo de saída da peça na dimensão da rebarba formada após o fresamento através do planejamento de experimentos DOE.

Os resultados dos ensaios da primeira etapa que determinaram as melhores condições para os ensaios da segunda etapa foram: 
- Usinagem com retirada da rebarba remanescente, pois esta influenciou de forma significativa a formação da rebarba seguinte.

- Os ensaios realizados com a ferramenta B apresentaram rebarbas com altura significativamente maiores do que as rebarbas formadas com as ferramentas $\mathrm{A}$ e $\mathrm{C}$. Portanto foram utilizadas somente as ferramentas $\mathrm{A}$ e $C$ para a realização dos ensaios da segunda etapa.

- A rebarba formada na borda de saída teve altura maior do que a formada nas bordas de entrada e nas bordas dos furos. Assim a borda de saída foi o objeto de estudo para a segunda etapa.

O planejamento proposto neste trabalho prevê a análise da significância das variáveis envolvidas e de suas interações. Ainda permite a criação de um modelo empírico capaz de predizer a altura da rebarba. Para tanto foi necessária a replicação de forma aleatória dos ensaios, para se ter a estimativa do erro experimental, e com a variância verificou-se as dimensões dos resíduos.

O planejamento que envolve cinco variáveis de entrada e uma variável de saída é esquematizado através do diagrama de bloco da Figura 4.10.

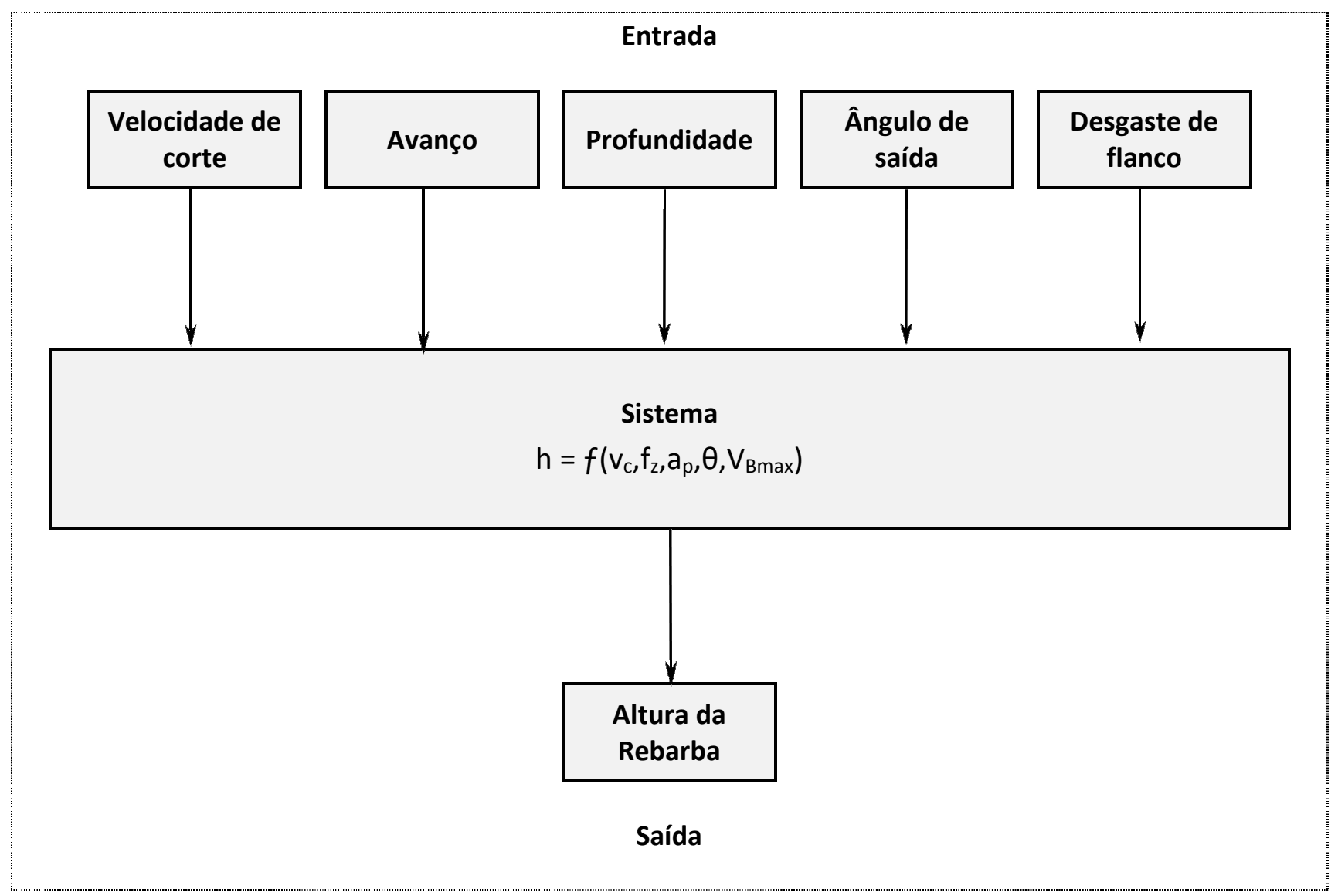

Figura 4.10 - Diagrama de bloco com a identificação das variáveis de entrada e de saída aplicadas no planejamento de experimentos - DOE 


\subsubsection{Análise de significância entre os efeitos}

Utilizando-se o software dedicado à estatística, chamado STATISTICA 8.0, foram obtidos os valores dos efeitos principais e de interações, juntamente com 0 intervalo de confiança e o erro padrão dos mesmos através de um planejamento fatorial completo. Foram analisados os resultados obtidos com a ferramenta $A$ e com a ferramenta $\mathrm{C}$, as quais demonstraram um melhor desempenho na primeira etapa dos ensaios. Os valores das alturas das rebarbas formadas nesta etapa para as ferramentas $A$ e $C$ podem ser encontrados nos Apêndices $A$ e $B$ respectivamente.

Através do Planejamento de Experimentos aplicado aos ensaios foi possível indicar os parâmetros influentes na altura média das rebarbas, na qual utilizou-se um índice de confiança igual a 95\%.

A Figura 4.11 mostra o diagrama de Pareto dos efeitos principais e das interações sobre a altura da rebarba para os ensaios realizados com a ferramenta $A$.

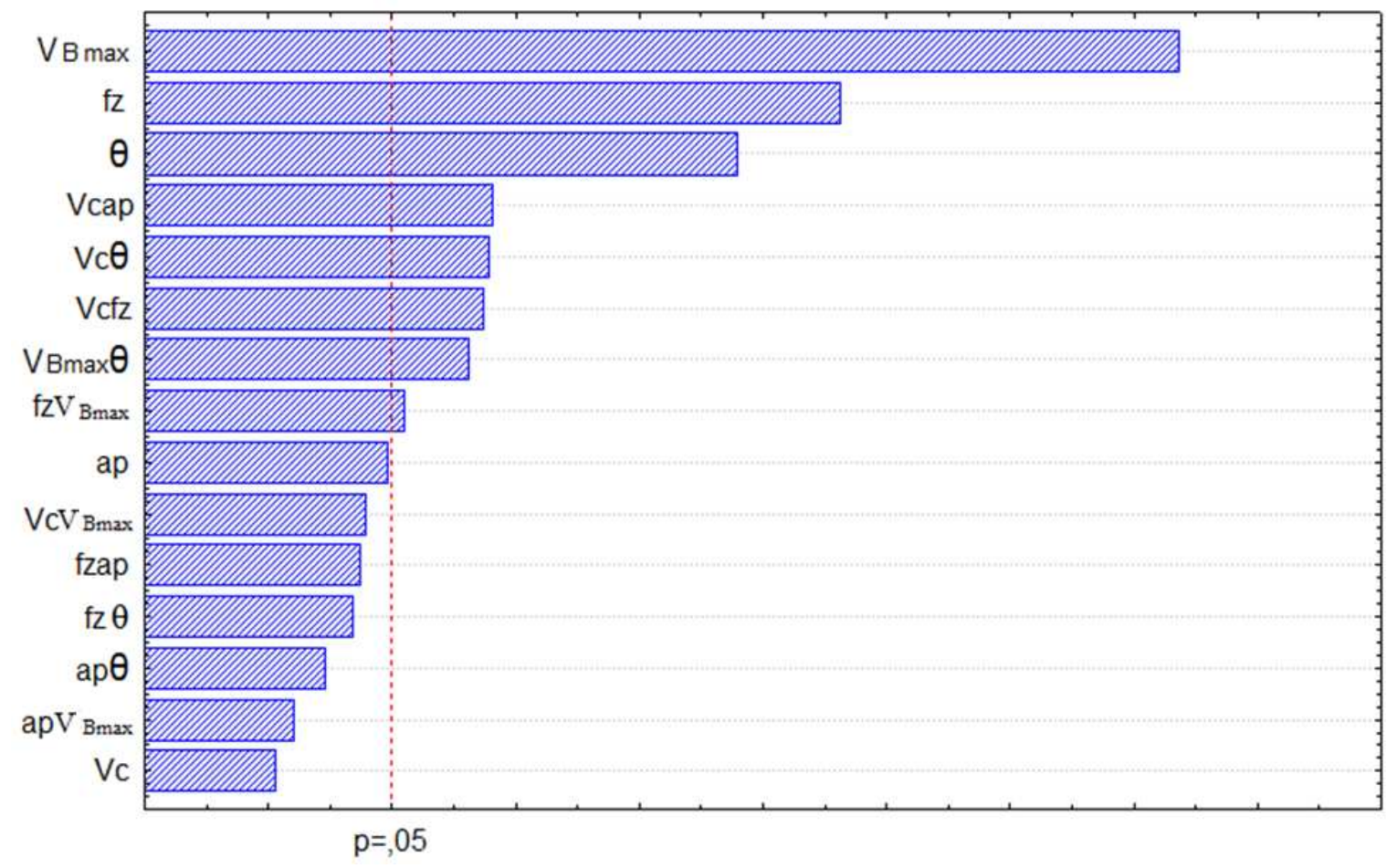

Figura 4.11 - Diagrama de Pareto para os efeitos principais e interações sobre a altura da rebarba $\mathrm{h}$ Ferramenta A

Percebeu-se no gráfico da Figura 4.11 que os efeitos significativos dentro do intervalo de confiança proposto foram o desgaste da ferramenta, o avanço e o 
ângulo de saída da peça, enquanto as interações mais significantes foram velocidade de corte com a profundidade de corte, ângulo de borda de saída e avanço, sendo estas interações influenciadas em menor escala pela velocidade de corte, que como já observado, possui pouca influencia linear sobre a formação da rebarba. Sendo então o desgaste o parâmetro mais importante na formação da rebarba, seguido do avanço e do ângulo de saída da ferramenta da peça.

Resultados um pouco diferentes são ilustrados na Figura 4.12 que mostra o diagrama de Pareto dos efeitos principais e das interações sobre a altura da rebarba para os ensaios realizados com a Ferramenta $C$.

Através da Figura 4.12 observou-se que os efeitos significantes dentro do intervalo de confiança de 95\% foram o desgaste da ferramenta, o ângulo de borda de saída, o avanço, e a profundidade de corte enquanto as interações mais significantes foram velocidade de corte com o desgaste da ferramenta, ângulo de saída com avanço, e velocidade de corte com ângulo de borda de saída, sendo esta interação influenciada em menor escala pela velocidade de corte, que possui pouca influência linear sobre a formação da rebarba.

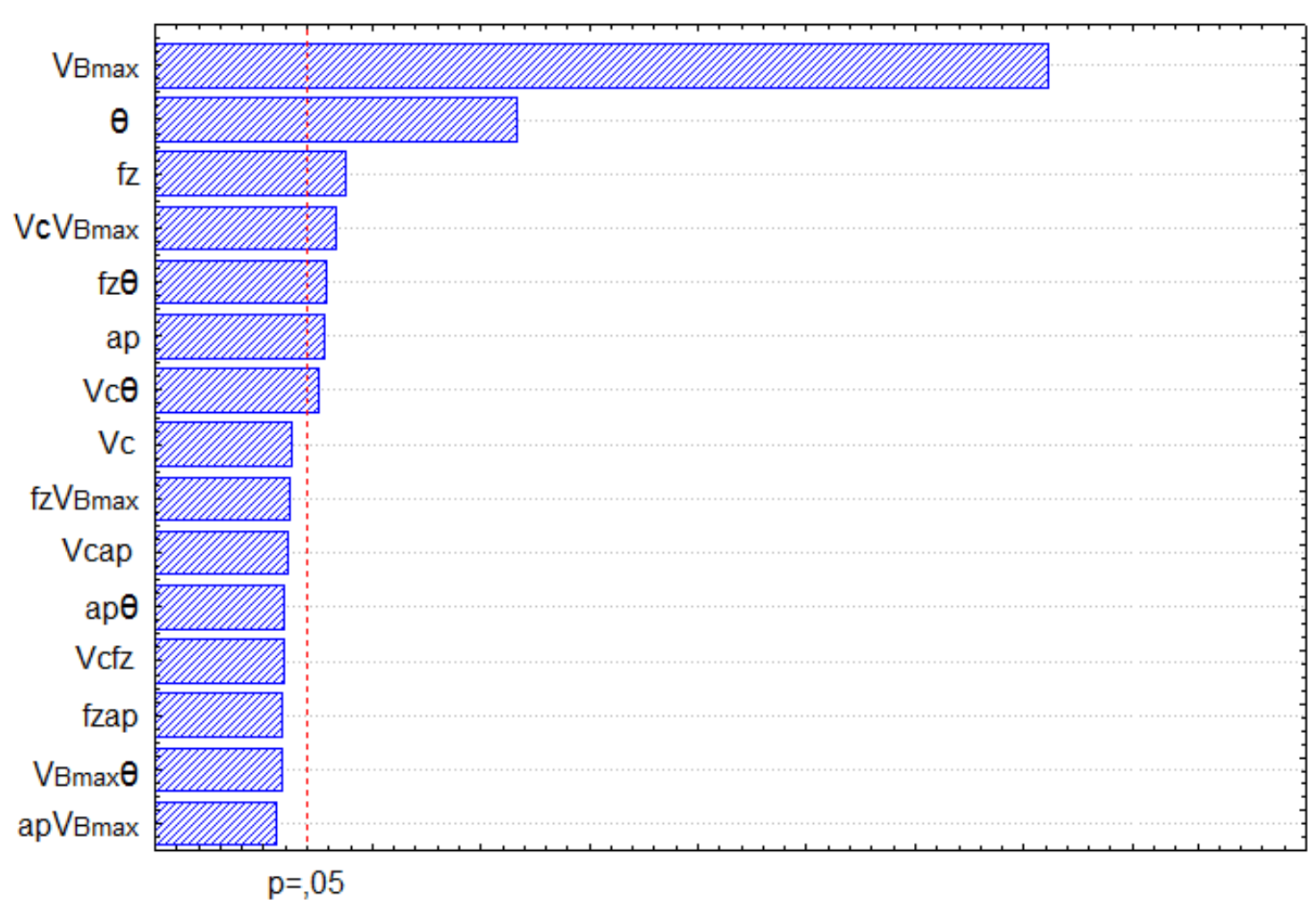

Figura 4.12. Diagrama de Pareto para os efeitos principais e interações sobre a altura da rebarba $\mathrm{h}-$ Ferramenta C. 
Notou-se que para as duas ferramentas analisadas a velocidade de corte não teve significância, sendo portanto a variável dentre a estudadas que menor influência teve na altura da rebarba. Nos dois casos estudados verificou-se também que a variável que foi mais determinante na variação da dimensão da rebarba foi o desgaste da ferramenta. Condição esta que também foi observado em Da Silva (2004 e 2011).

Considerando os resultados obtidos, conforme Figuras 4.11 e 4.12, as cinco variáveis de entrada do experimento terão seus comportamentos discutidos a seguir, independente da significância, pois conforme Da Silva (2011), a notabilidade destas variáveis recebe destaque não só na formação da rebarba no fresamento, mas também em outros processos de usinagem.

\subsubsection{Desgaste da ferramenta}

O desgaste da ferramenta de corte foi a variável que teve a maior influência na altura da rebarba. $O$ gráfico da Figura 4.13 analisa as 128 respostas para a ferramenta $A$, e verifica-se que a altura média da rebarba para a ferramenta nova passou de aproximadamente 0,055 $\mathrm{mm}$ para uma média acima de 0,105 mm quando tratava-se da ferramenta com desgaste de flanco de 0,3 $\mathrm{mm}$.

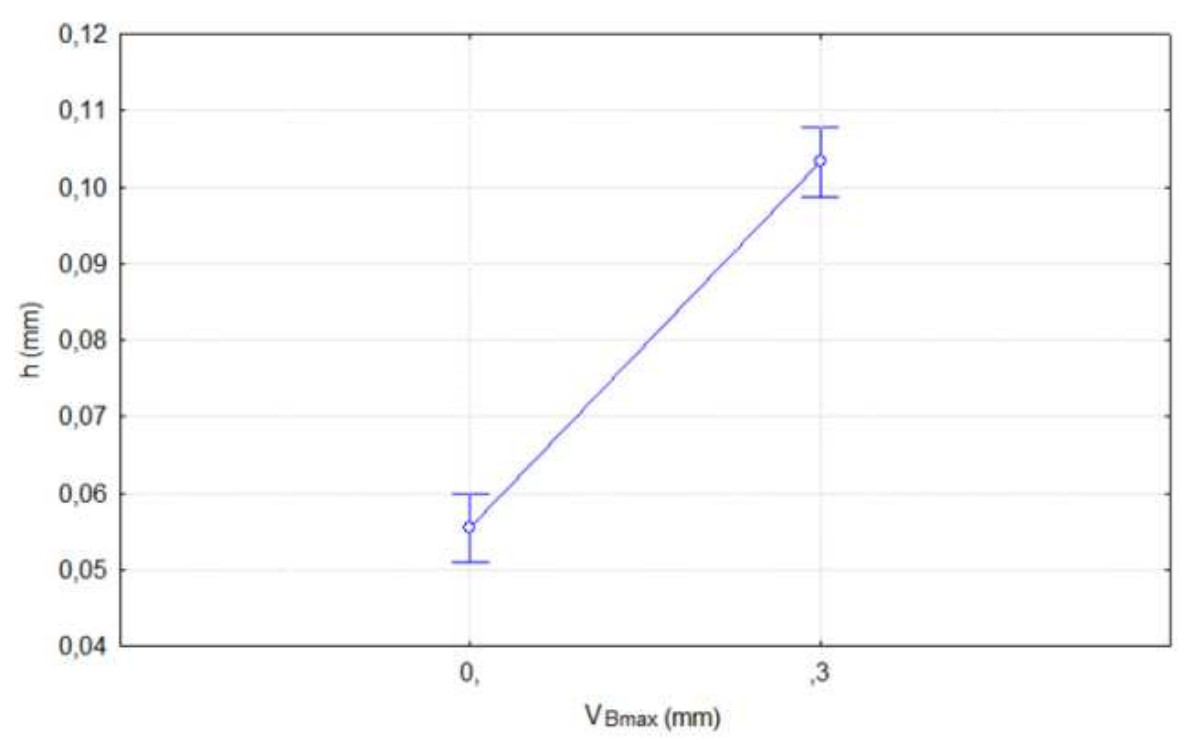

Figura 4.13 - llustra os efeitos das médias do fator $V_{B m a ́ x}$ sobre a altura da rebarba $h$ - Ferramenta $A$. 
No planejamento experimental deste trabalho, o desgaste da ferramenta B também foi a variável que teve a maior influência na altura da rebarba. $O$ gráfico da Figura 4.14 ilustra os resultados para as 128 respostas, e verifica-se que altura média da rebarba para a ferramenta nova passou de $0,130 \mathrm{~mm}$ para uma média acima de $0,275 \mathrm{~mm}$ quando tratava-se da ferramenta com o desgaste máximo admitido neste trabalho.

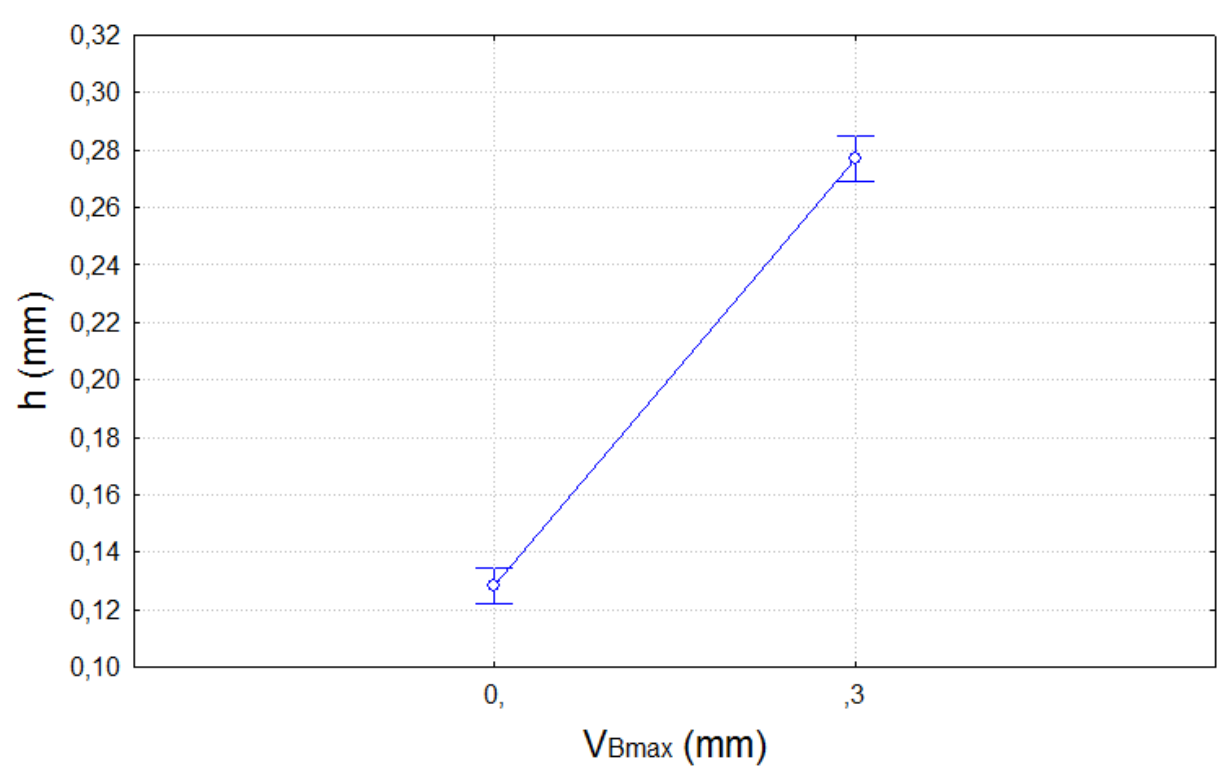

Figura 4.14 - llustra os efeitos das médias do fator $V_{B \text { máx }}$ sobre a altura da rebarba $\mathrm{h}$ - Ferramenta $\mathrm{C}$

Durante a usinagem do ferro fundido cinzento Souza Jr. (2001) e Da Silva (2004) também observaram que o desgaste da ferramenta de corte foi a variável que mais modificou a altura da rebarba, e verificaram em seus estudos que na medida em que o desgaste da ferramenta de corte evoluía, a altura da rebarba aumentava.

Lin (1999), durante o fresamento do aço inoxidável, verificou que não só no fresamento frontal, mas em quase todos os processos de usinagem, as dimensões das rebarbas dependem do nível de desgaste da ferramenta, pois o desgaste altera a geometria original da ferramenta de corte, alterando a área de contato na interface cavaco-ferramenta. Como conseqüência ocorre o aumento na geração do calor, aumento das forças de corte, e a elevação da deformação plástica, fatores estes que podem promover a alteração dimensional da rebarba (DA SILVA, 2011).

A alteração na geometria original da ferramenta ocasionada pelo desgaste promove maiores comprimentos de contatos na interface cavaco ferramenta o que causam aumentos nos esforços de usinagem, na potência consumida e na 
temperatura de corte, o que consequentemente facilita a deformação do material sem que o mesmo destaque-se da borda da peça, formando rebarbas com dimensões maiores que as encontradas no fresamento com ferramentas novas.

\subsubsection{Velocidade de corte}

O gráfico da Figura 4.15 mostra a tendência média da relação entre a altura da rebarba e a variação da velocidade para as 128 respostas utilizando-se a ferramenta A. No mesmo observa-se pequena redução da altura da rebarba em relação ao crescimento da velocidade, em torno da altura média de $0,0786 \mathrm{~mm}$. Conforme observado na Figura 4.11 a velocidade de corte não teve significância neste experimento e isto se justifica agora pela elevada dispersão da altura da rebarba verificada na Figura 4.15.

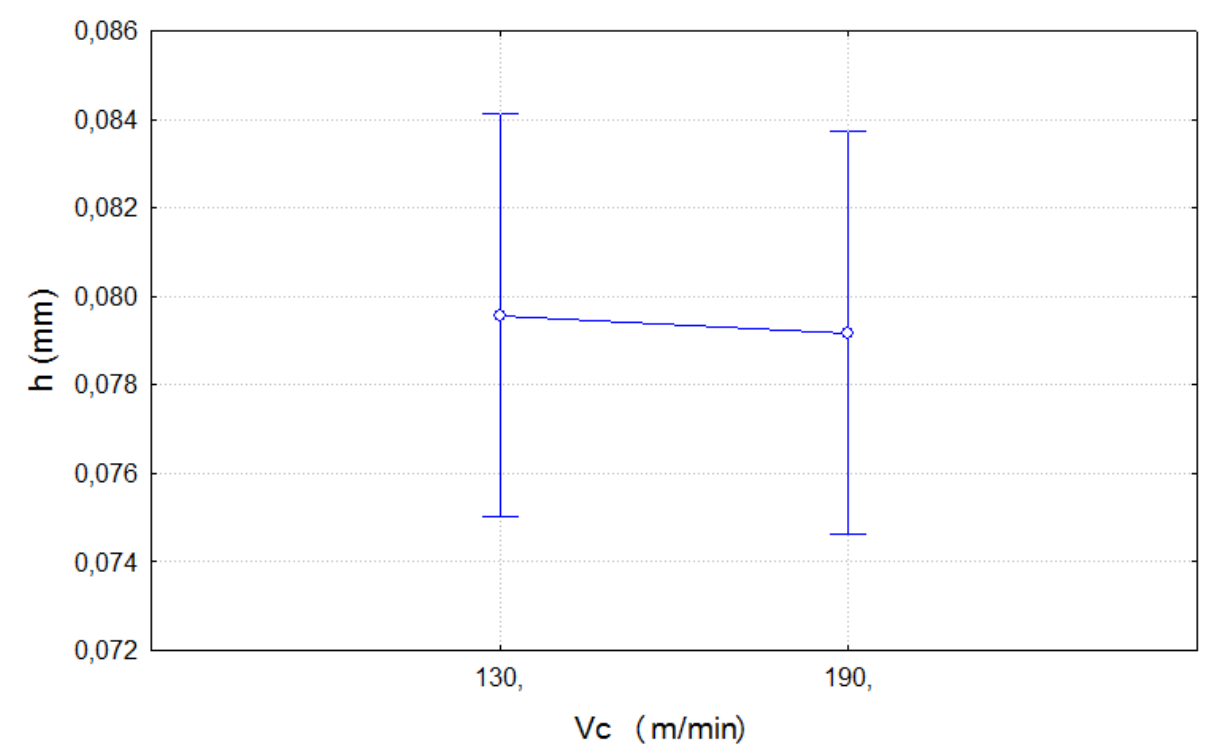

Figura 4.15 - Ilustra os efeitos das médias do fator $\mathrm{v}_{\mathrm{C}}$ sobre a altura da rebarba $\mathrm{h}$ - Ferramenta $\mathrm{A}$

O gráfico da Figura 4.16 ilustra a tendência média da relação entre a altura da rebarba e a variação da velocidade para a ferramenta $\mathrm{C}$. O valor médio da altura da rebarba para a velocidade de $160 \mathrm{~m} / \mathrm{min}$ é de aproximadamente $0,205 \mathrm{~mm}$, enquanto que para a velocidade de $190 \mathrm{~m} / \mathrm{min}$ mede aproximadamente $0,200 \mathrm{~mm}$. Observa-se uma pequena redução da altura da rebarba em relação ao aumento da 
velocidade, mas que torna-se não significativo perante a elevada dispersão observada nas 128 respostas de altura de rebarbas medidas.

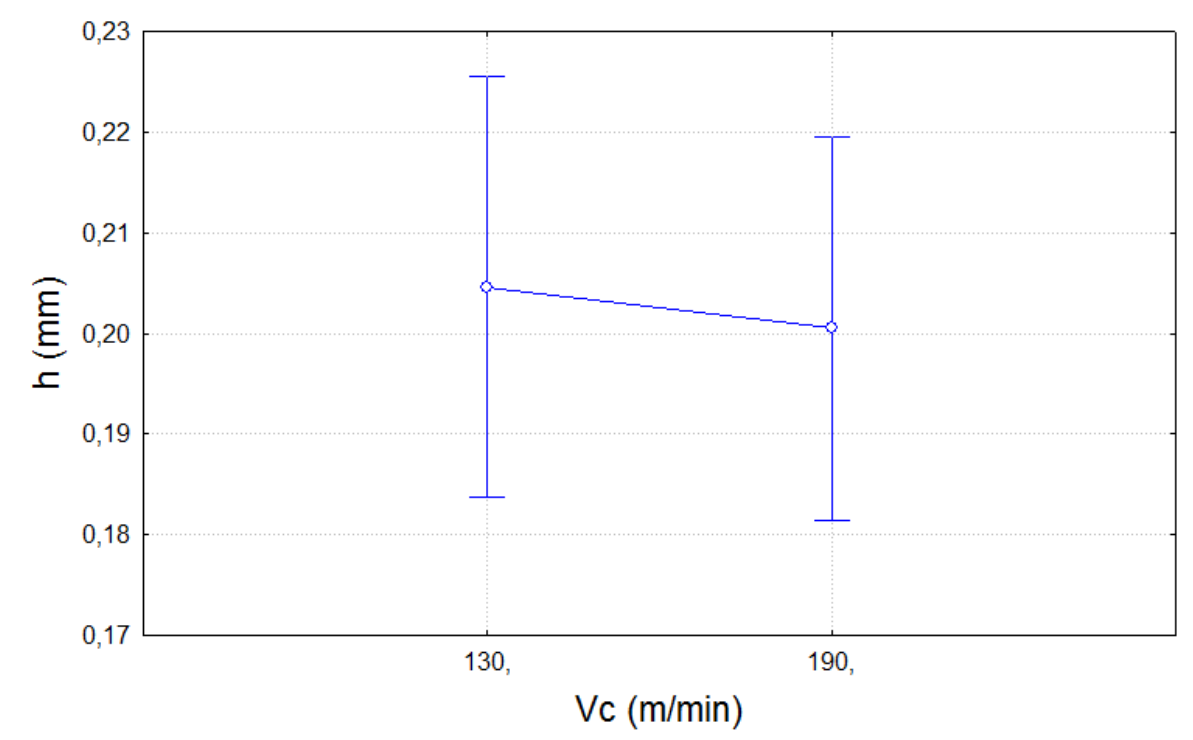

Figura 4.16 - Ilustra os efeitos das médias do fator $\mathrm{v}_{\mathrm{C}}$ sobre a altura da rebarba $\mathrm{h}$ - Ferramenta $\mathrm{C}$

Não foram notadas alterações significativas nas dimensões das rebarbas com a variação da velocidade de corte. Nos ensaios realizados com a ferramenta $A$, dentro da faixa de velocidade de corte estudada, observa-se uma diferença da maior altura para a menor de apenas $0,0011 \mathrm{~mm}$ enquanto que para a ferramenta $C$ essa diferença foi de $0,005 \mathrm{~mm}$. Valores muito pequenos quando comparados com as respectivas dispersões.

É sabido que o aumento da velocidade de corte irá proporcionar a redução do comprimento de contato cavaco ferramenta na interface. Um correspondente aumento no ângulo de cisalhamento, devido a redução do contato, acontecerá e, portanto um menor grau de recalque, (MACHADO et al 2009). Tudo isso são fatores que indicam uma menor deformação na zona de cisalhamento primária e como conseqüência a formação de rebarbas com dimensões reduzidas.

No fresamento frontal do aço médio carbono AISI 1040 (dureza de 180HB) Olvera e Barrow (1998) observaram a diminuição da altura da rebarba em 50\%, enquanto a sua velocidade de corte foi dobrada, enquanto Da Silva (2004), no fresamento do FoFo Cinzento, observou apenas oscilações das dimensões das rebarbas, não sendo nítidas a sua redução com o aumento da velocidade de corte. 
O aumento da velocidade de corte reduz o atrito na interface cavaco ferramenta. A redução desse atrito proporciona da mesma forma, um correspondente aumento do ângulo de cisalhamento primário, reduzindo o grau de recalque e consequentemente a deformação plástica no plano de cisalhamento primário. Por outro lado, o aumento da velocidade de corte promove a elevação da temperatura, tornando-se a deformação plástica do material da peça maior. Da Silva (2011), no fresamento do aço inoxidável PH 13 8Mo, apesar não ter significância, notou um pequeno aumento da altura da rebarba em relação ao crescimento da velocidade.

Neste trabalho, as outras variáveis envolvidas no planejamento do experimento tiveram uma influência muito maior que a velocidade de corte, tornando o efeito da velocidade de corte praticamente desprezível.

\subsubsection{Avanço por dente}

O gráfico da Figura 4.17 relaciona a altura da rebarba com o avanço, para os 32 ensaios mais suas três réplicas totalizando 64 ensaios e 128 respostas para a ferramenta A. No mesmo observa-se uma altura média da rebarba de aproximadamente $0,095 \mathrm{~mm}$ para um avanço de $0,05 \mathrm{~mm}$ por dente. Aumentando o avanço para $0,1 \mathrm{~mm}$ por dente, verifica-se a redução da altura média da rebarba para $0,065 \mathrm{~mm}$.

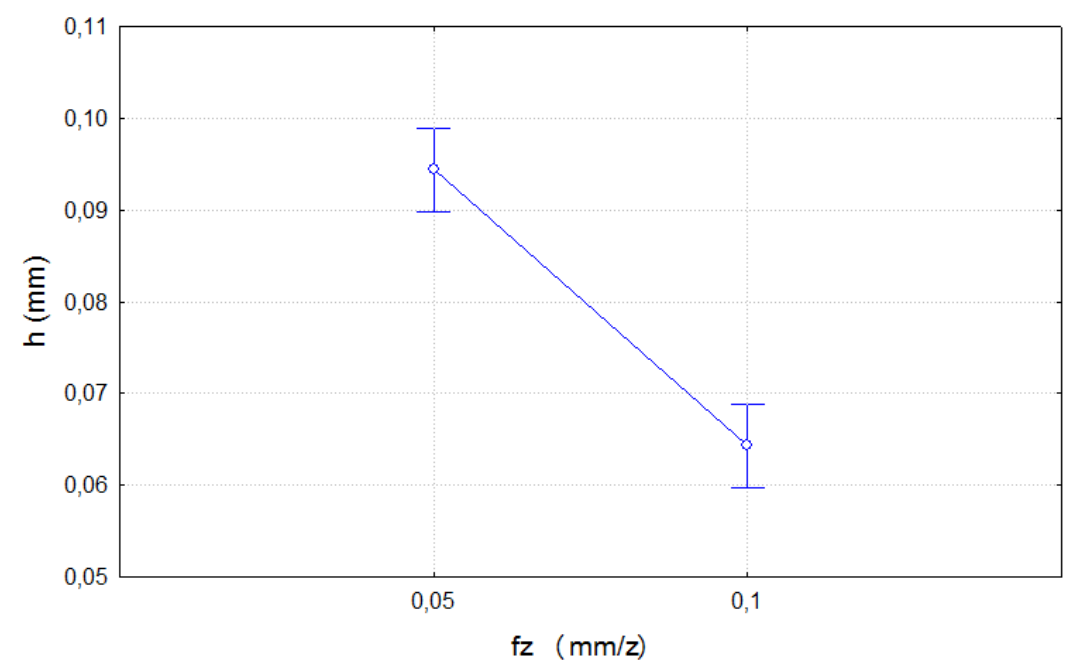

Figura 4.17 - Ilustra os efeitos das médias do fator $f_{Z}$ sobre a altura da rebarba $h$ - Ferramenta $A$ 
O gráfico da Figura 4.18 analisa a altura média da rebarba com a variação do avanço nas 128 respostas para a ferramenta $\mathrm{C}$. Observa-se uma altura média da rebarba de aproximadamente $0,208 \mathrm{~mm}$ para um avanço de $0,05 \mathrm{~mm}$ por dente. Aumentando o avanço para $0,1 \mathrm{~mm}$ por dente, a altura média da rebarba cai para aproximadamente $0,197 \mathrm{~mm}$.

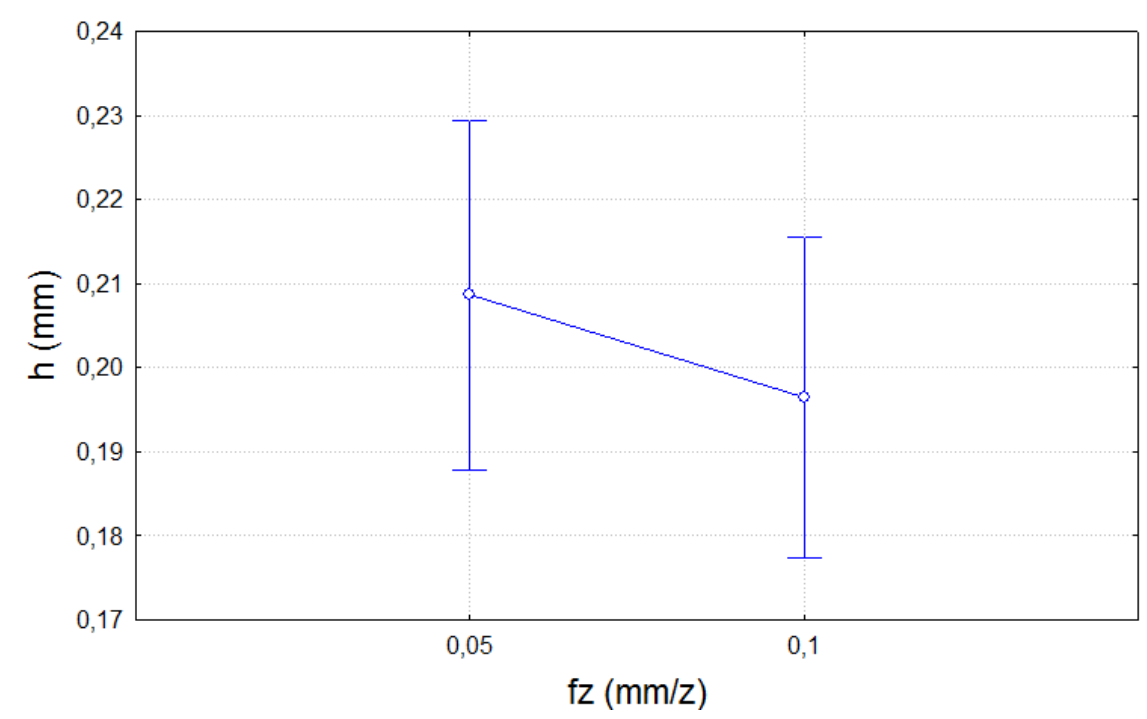

Figura 4.18 - llustra os efeitos das médias do fator $\mathrm{f}_{\mathrm{z}}$ sobre a altura da rebarba $\mathrm{h}$ - Ferramenta $\mathrm{C}$

Hashimura et al (1999) apresentaram um modelo matemático desenvolvido em elementos finitos e resolvido por métodos computacionais, verificando a relação entre a quantidade de material usinado e as dimensões das regiões deformadas plasticamente e por fim no comprimento e largura da rebarba. Eles relacionaram o avanço para quantificar a área da seção de corte. Eles concluíram que o aumento do avanço promove a elevação das regiões deformadas plasticamente e também das dimensões da rebarba (principalmente o comprimento e a espessura).

Neste trabalho notou-se que o aumento do avanço promoveu a redução nas dimensões das rebarbas, o que contradiz os resultados obtidos por Hashimura et al (1999). A redução da rebarba ocorreu com o aumento do avanço, para ambas as ferramentas, ocorrendo em escala um pouco maior para a ferramenta C. Porém o aumento do avanço promove a elevação da força de corte e a redução da qualidade superficial da superfície usinada, portanto o aumento do avanço deve ocorrer de forma criteriosa avaliando outros impactos que não foram o objeto de estudo desta pesquisa. 
Em avanços menores o material da peça é comprimido pelas arestas da ferramenta de corte. Essa compressão irá gerar uma grande deformação plástica do material, que proporciona o aumento da altura da rebarba, e que tem o mecanismo de formação do tipo Poisson. Conforme o avanço aumenta, observa-se o cisalhamento do material da peça e a formação do cavaco, proporcionando a redução da deformação plástica, como conseqüência a redução da altura da rebarba. O mecanismo de formação dessa rebarba é do tipo Tear. Na medida em que o avanço aumenta, torna-se nítido o aumento da espessura do cavaco cisalhado, proporcionando a redução da deformação plástica, e em consequência a altura da rebarba.

Quando o fresamento ocorre com avanços menores, o cavaco tem espessura reduzida. A aresta da ferramenta toca a peça (superfície encruada devido ao corte anterior), gerando atrito em excesso, elevada temperatura e, em conseqüência, alta deformação plástica, portanto não ocorrendo o corte, Da Silva (2011). Esta deformação promove o deslocamento do material, sendo este fenômeno denominado de sulcamento (ploughing). Confome Olvera e Barrow, (1995), na medida em que a espessura no material aumenta, isso devido ao aumento do avanço, a pressão da aresta de corte atinge o valor acima da tensão de ruptura e a aresta da ferramenta penetra no material, iniciando a formação do cavaco.

A significância elevada do avanço na altura da rebarba e a redução desta com o aumento do avanço também foi observado por Da Silva (2004) no fresamento do ferro fundido cinzento e por Da Silva (2011) na usinagem do aço inoxidável PH $138 \mathrm{Mo}$.

\subsubsection{Profundidade de Corte}

Pode-se observar no gráfico da Figura 4.19 uma rebarba de altura média de $0,0765 \mathrm{~mm}$ para a profundidade de corte de $0,3 \mathrm{~mm}$, enquanto que para uma profundidade de corte de $0,7 \mathrm{~mm}$ a altura média aumentou para $0,0835 \mathrm{~mm}$ com a ferramenta A. 


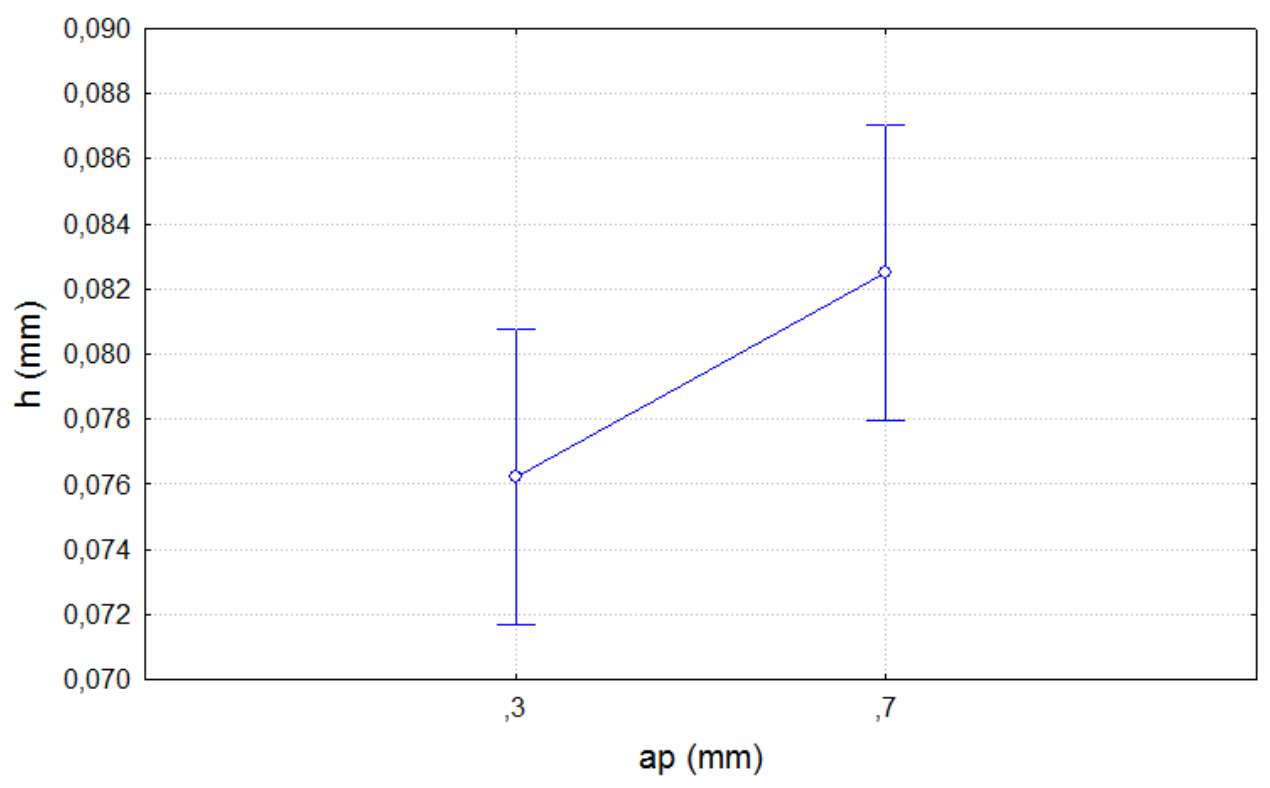

Figura 4.19 - llustra os efeitos das médias do fator $a_{p}$ sobre a altura da rebarba $h$ - Ferramenta $A$.

O gráfico da Figura 4.20 mostra com a utilização da ferramenta $C$, uma rebarba de altura média de 0,198 $\mathrm{mm}$ para a profundidade de corte de 0,3 $\mathrm{mm}$, enquanto que para uma profundidade de corte de $0,7 \mathrm{~mm}$ a altura média aumentou para $0,208 \mathrm{~mm}$.

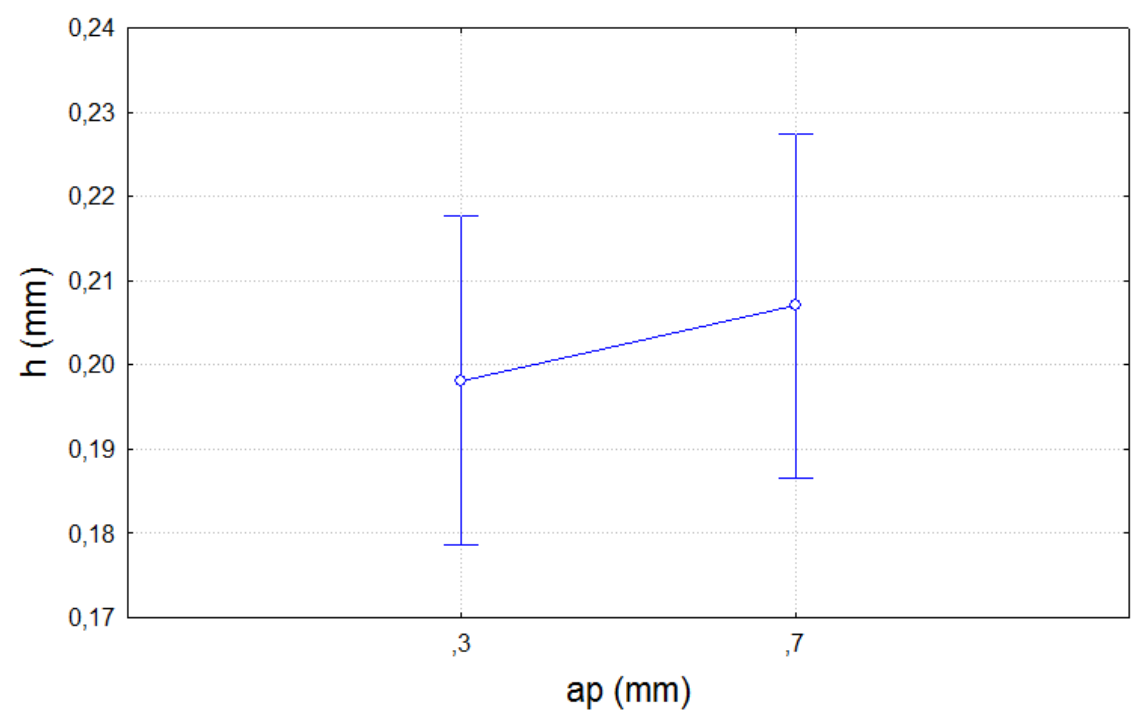

Figura 4.20 - Ilustra os efeitos das médias do fator $a_{p}$ sobre a altura da rebarba $h$ - Ferramenta $C$

No fresamento a profundidade de corte influencia diretamente na área da seção de corte e acredita-se que ela apresente influência similar à do avanço (DINIZ et al 2010). Mas isto não ocorreu, pois o aumento do avanço promove o aumento na espessura do cavaco, fato que facilita o cisalhamento deste, e gera 
conseqüentemente menor deformação plástica na borda da peça. Já a profundidade de corte atua na largura do cavaco, e seu aumento propicia o dobramento do cavaco e conseqüente maior deformação plástica, acarretando na formação de rebarbas maiores. A formação da rebarba ocorre após a deformação plástica do material formador do cavaco, quando a ferramenta de corte aproxima-se da borda da peça, tornando desta forma a altura da rebarba primária diretamente proporcional a profundidade de corte.

Verifica-se que para pequenas profundidades de corte, como no caso deste trabalho, a ação do corte ocorre principalmente pela aresta secundaria da ferramenta de corte, gerando então a rebarba primaria, rebarba está que possui um aumento de dimensão proporcional a profundidade de corte até um limite de transição. O limite de transição da rebarba primária para a rebarba secundária não foi observado dentro os parâmetros avaliados neste experimento.

Quando a profundidade de corte aumenta, a participação da aresta secundária de corte é reduzida formando a rebarba de transição. O surgimento da rebarba secundária ocorre quando a ação do corte ocorre principalmente pela aresta principal da ferramenta de corte. As rebarbas formadas durante os ensaios são caracterizadas por rebarbas primárias.

Segundo Da Silva (2011), a transformação da rebarba primária para secundária é de responsabilidade, principalmente, da profundidade de corte para um dado ângulo de borda de saída e um dado raio de arredondamento da ferramenta. Isto porque, em pequenas profundidades de corte a aresta secundária da ferramenta de corte participa de forma efetiva na formação da rebarba primária. À medida que a profundidade de corte aumenta a participação da aresta principal de corte cresce, aparecendo a formação da rebarba primária.

Pequena largura do cavaco, devido à baixa profundidade de corte, causa o dobramento do cavaco na borda de saída da peça, formando a rebarba. Os mecanismos de formação desta rebarba são principalmente do tipo Poisson e do tipo Tear. Essa rebarba tem sua altura crescente de forma proporcional à profundidade de corte, até a profundidade de transição. A partir de então, o aumento da profundidade de corte, que promoverá o aumento da largura do cavaco, que terá o seu dobramento não mais na borda de saída da peça, mas sim na borda transiente transversal de saída. Essa borda, juntamente com a sua rebarba, é temporária, uma 
vez que será removida a cada nova passada. O mecanismo de formação dessa rebarba é do tipo Rollover, e sua altura é aproximadamente igual à profundidade de corte.

Em situações onde a profundidade de corte atinge valores acima da profundidade de transição, a aresta principal da ferramenta de corte tem a sua participação aumentada na formação do cavaco, pois a largura do cavaco aumenta em relação a sua espessura. O cavaco é então, conduzido para a borda de transição transversal da peça, onde permanece fixo, formando uma rebarba de transição. No avanço seguinte da ferramenta, o novo volume de cavaco, mais uma vez, será conduzido pela aresta principal de corte para a borda de transição transversal, gerando o acúmulo de material.

A manipulação da profundidade de corte é um procedimento que garante o sucesso no controle da altura da rebarba. A sua redução leva a redução da rebarba primária enquanto o seu aumento proporciona a formação da rebarba secundária, sendo esta última a ideal, pois possui altura reduzida. O problema neste aspecto decorre do fato de o limitador da profundidade de corte ser o próprio processo de usinagem, que depende diretamente das tolerâncias de forma e posição do produto. Não sendo muitas vezes possibilitada a variação da profundidade de corte, principalmente em operações de acabamento. Também deve ser observado, conforme Gabaldo (2009) o alto consumo de torque da máquina na usinagem do CGI, consumo este que é elevado com o aumento do avanço, e pode ser outro limitador para a manipulação do avanço.

No fresamento do aço AISI 1040, Olvera e Barrow (1996) observaram o aumento proporcional da altura da rebarba primária em relação a progressão da profundidade de corte. Nesta investigação foi analisada a rebarba 9, conforme Gillespie (1976). O mesmo foi observado por Chern (2006) durante o fresamento das ligas de Al 2024-T4 e Al 6061-T6. Em seu trabalho foi utilizado diferentes ângulos de saída da peça e a rebarba primária foi formada na borda de saída da peça.

\subsubsection{5 Ângulo de borda de saída}

O ângulo de borda de saída teve elevada significância dentre as variáveis analisadas neste trabalho. Para a ferramenta $A$ notou-se um considerável aumento 
da altura da rebarba conforme pode ser visto no gráfico da Figura 4.21. Para o ângulo de $160^{\circ}$ a altura média da rebarba é de aproximadamente $0,068 \mathrm{~mm}$, enquanto para o ângulo de $180^{\circ}$ a altura média da rebarba vale $0,093 \mathrm{~mm}$.

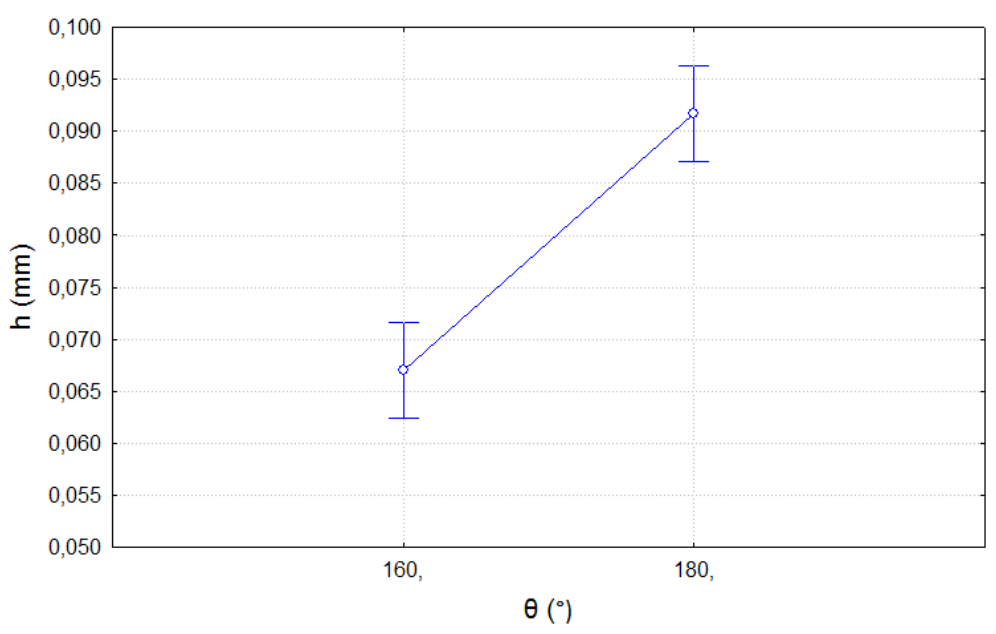

Figura 4.21 - llustra os efeitos das médias do fator $\theta$ sobre a altura da rebarba $\mathrm{h}$ - Ferramenta $A$

Quando foi utilizada a ferramenta C notou-se um considerável aumento da altura da rebarba conforme pode ser visto no gráfico da Figura 4.22. Para o ângulo de $180^{\circ}$ a altura média da rebarba é de aproximadamente $0,185 \mathrm{~mm}$, enquanto para o ângulo de $160^{\circ}$ a altura média da rebarba vale $0,221 \mathrm{~mm}$.

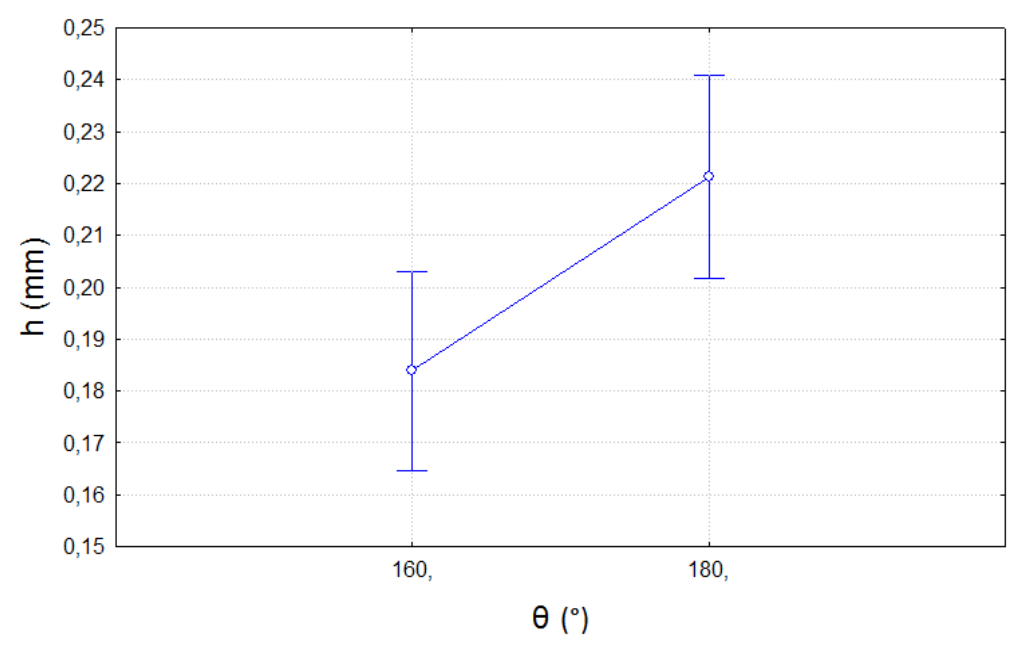

Figura 4.22 - llustra os efeitos das médias do fator $\theta$ sobre a altura da rebarba $\mathrm{h}$ - Ferramenta $\mathrm{C}$

As análises dos resultados confirmam que geralmente, o segmento $D_{S}$ com ângulo de borda de saída igual a $180^{\circ}$, apresenta va lores de rebarbas maiores que os outros segmentos ( $A_{S}$ à $G_{S}$ ) o que confirma os resultados encontrados por Souza 
Jr. (2001) e Da Silva (2004), no fresamento do bloco de motor em ferro fundido vermicular, que definiu a região $D_{S}$ como o ponto crítico da borda de saída do bloco de motor.

Chern e Dornfeld (1996) justificam o crescimento da altura da rebarba nesse ponto, devido à gradual aproximação da ferramenta ao final do corte, então a borda da peça sofre uma deformação plástica maior quando nela atua a força de corte, causando a redução da espessura de corte e consequentemente o dobramento do cavaco.

Conforme se prevê em varias literaturas, (Tripathi; Dornfeld, 2004) há uma considerável dependência das dimensões da rebarba com o ângulo de borda de saída da peça, uma vez que utilizado um ângulo de saída $(\theta)$ menor que $30^{\circ}$, a dimensão da rebarba passa a ser desconsiderada. No fresamento das ligas Al 2024T4 e Al 6061-T6, Chern (2006) verificou a elevação da altura da rebarba de saída, em relação ao aumento do ângulo de saída da peça $(\theta)$.

$O$ efeito do deslocamento da fresa quando na região de entrada, seja na borda de entrada ou borda de saída da peça, proporciona uma elevada deformação plástica no material que será distribuída sobre a própria peça, não permitindo a expansão do mesmo, o que tornará a dimensão da rebarba menor. O mesmo não ocorre quando a fresa está na região de saída, pois a deformação do material estender-se-á além da borda da peça, formando uma rebarba maior.

\subsubsection{Efeito das interações}

Apesar da reduzida influência da velocidade de corte, esta deve ser manipulada no controle dimensional da rebarba, visto que neste experimento, teve grande participação nas interações com o desgaste da ferramenta, o ângulo de saída, o avanço e a profundidade de corte com a ferramenta A.

Através do gráfico de superfície de resposta, mostrada na Figura 4.23, podese notar a grande dependência da altura da rebarba em função da interação do ângulo de borda de saída, com a velocidade de corte proporcionando um aumento na altura da rebarba. Grande efeito também pode ser observado pela interação entre o avanço e a velocidade de corte, com esta acarretando ao aumento da altura da 
rebarba. Já a interação entre a velocidade de corte e a profundidade de usinagem promoveu uma diminuição na altura da rebarba.
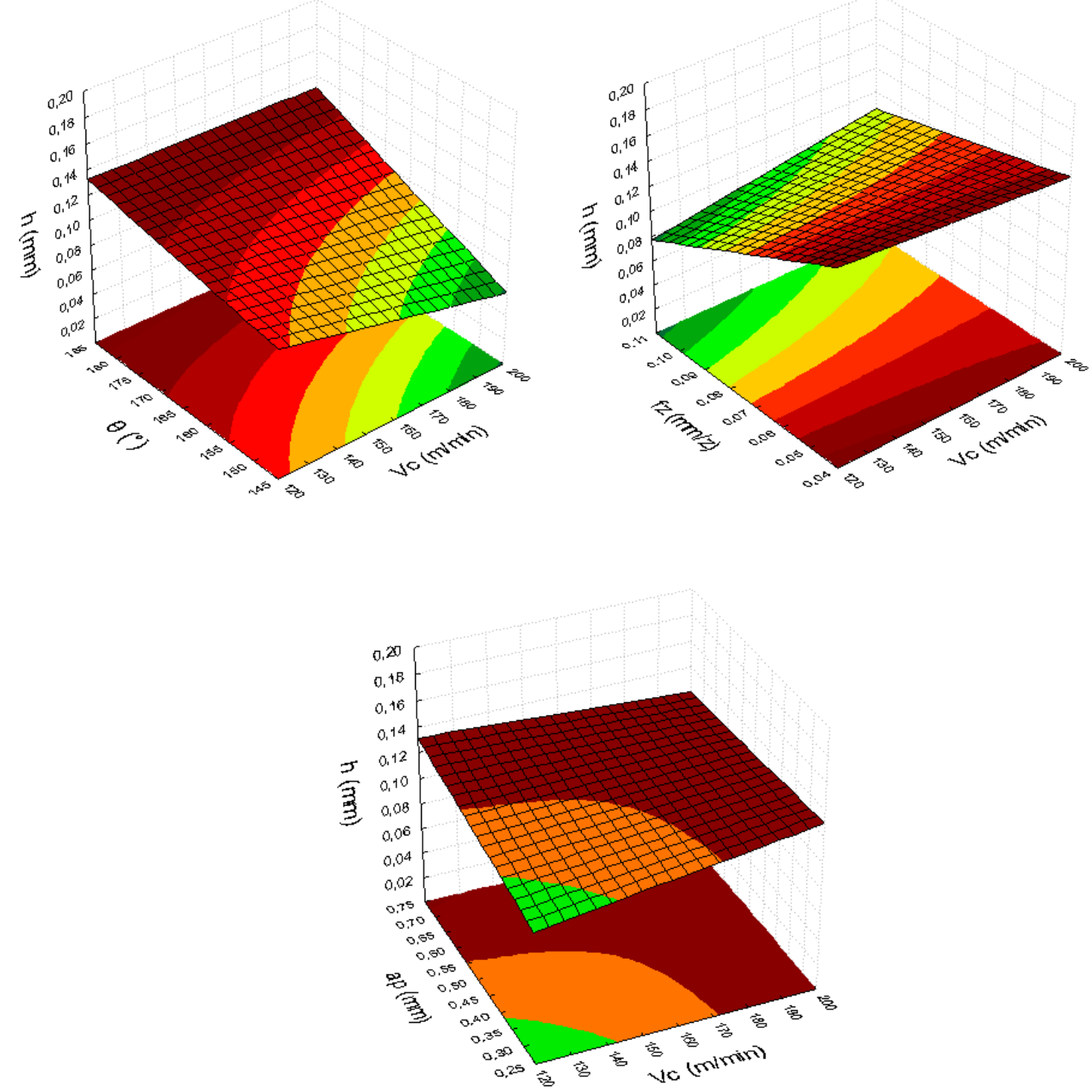

Figura 4.23 - Gráficos de superfície de resposta utilizando ferramentas com profundidade de corte $=0,7 \mathrm{~mm}$ e avanço $=0,05 \mathrm{~mm} /$ dente - Superfície com Confiança de $95 \%$ ( $p$-value $=0,05)$ Ferramenta A

A velocidade de corte também foi significativa para a ferramenta $C$ nas interações com o desgaste da ferramenta e o ângulo de saída. Através do gráfico de superfície resposta, mostrada na Figura 4.24, pode-se notar a grande dependência da altura da rebarba em função da interação do desgaste da ferramenta e do ângulo de saída com a velocidade de corte. Com relação às interações entre as variáveis, a combinação de velocidade de corte e desgaste da ferramenta foi a mais significativa 
promovendo uma redução na altura da rebarba enquanto que, com a combinação de velocidade de corte e ângulo de saída da ferramenta da peça obteve-se um aumento na altura da rebarba.
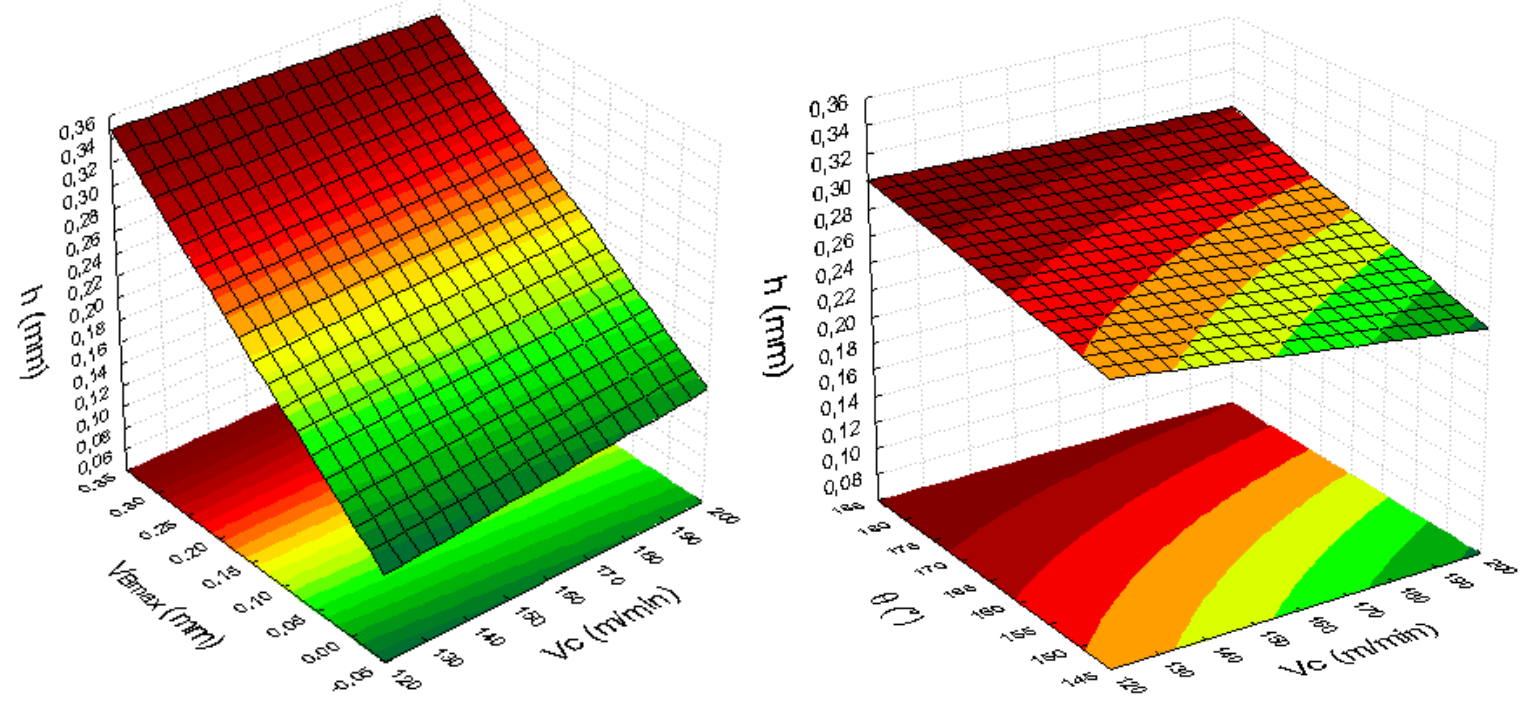

Figura 4.24 - Gráficos de superfície de resposta utilizando ferramentas com profundidade de corte $=0,7 \mathrm{~mm}$ e avanço $=0,05 \mathrm{~mm} /$ dente - Superfície com Confiança de $95 \%$ ( $p$-value $=0,05)-$ Ferramenta C

Deve ser levado em consideração o fato de a redução na velocidade de corte gerar redução da produtividade, pois diminui o tempo de usinagem. Porém, nesta condição a ferramenta estará exposta a menores temperaturas de usinagem, promovendo assim maior vida às ferramentas de corte.

Quando se pretende manipular os dados de corte para se minimizar a altura da rebarba considerando interações entre os dados deve-se atentar a alguns pontos importantes. O desgaste da ferramenta, por exemplo, é influenciado principalmente pela velocidade de corte, depois pelo avanço e, por último, pela profundidade de usinagem (DINIZ et al, 2010). A velocidade de corte é o parâmetro mais influente, pois quanto maior, mais aumenta o calor que é imputado ao processo. Além disso, existem outras limitações a este procedimento: a diminuição da velocidade de corte não pode ser tal que ultrapasse o valor da velocidade crítica e comece a produzir aresta postiça de corte (APC) e conseqüentemente maior desgaste da ferramenta.

Ao se aumentar o avanço para obter uma altura da rebarba menor deve-se levar dois pontos importantes em consideração: o desgaste da ferramenta e o acabamento da superfície usinada. Visto que o avanço influencia mais no desgaste 
do que a profundidade de corte, e o desgaste será ainda maior se este aumento for acompanhado pelo aumento da velocidade de corte. O aumento do avanço contribui também para a piora da rugosidade superficial da peça, parâmetro crítico em operações de acabamento.

\subsubsection{Modelo empírico para predição da altura da rebarba}

O planejamento de experimentos utilizado permitiu a elaboração de um modelo empírico capaz de estimar a altura da rebarba, dentro do intervalo das variáveis proposto neste trabalho. A qualidade dos modelos dados pelas Equações (1) e (2) serão discutidos no item 4.2.1.

\subsubsection{Ferramenta A}

$\mathrm{Na}$ construção do modelo empírico, onde a altura da rebarba é função de cinco variáveis, sendo $h=f\left(v_{c}, f_{z}, a_{p}, V_{B m a x}, \theta\right)$, o modelo que melhor prevê a altura da rebarba em função das variáveis analisadas, com o coeficiente de erro padrão avaliado em $\pm 0,001625$, pode ser estimado pela Eq. (5):

$$
\begin{aligned}
& \hat{h}=(0,07937)+(-0,015052) f z+(0,023929) V_{B \max }+(0,012342) \theta+(0,005630) V c f z+ \\
& +(-0,005870) V c a_{p}+(0,005806) V c \theta+(-0,003590) f z V_{B \max }+(0,005253) V_{B \max } \theta
\end{aligned}
$$

\subsubsection{Ferramenta C}

Através dos ensaios utilizando-se a Ferramenta C, o modelo que melhor prevê a altura da rebarba em função das variáveis analisadas, com o coeficiente de erro padrão avaliado em $\pm 0,001603$, pode ser estimado pela Eq. (6):

$$
\begin{aligned}
& \hat{h}=0,202568+(-0,006058) f z+(0,004433) a_{p}+(0,074341) V_{B \max }++(0,018717) \theta+ \\
& +(-0,005369) V c V_{B \max }+(0,004029) V c \theta+(-0,004573) f z \theta
\end{aligned}
$$




\subsubsection{Influência dos efeitos principais e interações}

Serão discutidos inicialmente os percentuais de influência dos efeitos principais e das interações sobre a altura da rebarba para cada ferramenta. Deve-se observar, que se um parâmetro ou interações de dois parâmetros são influentes, tem-se que saber se esta influência contribui para o aumento ou para a diminuição da rebarba, e isto pode ser observado através das Tabelas 4.8 e 4.9 para os efeitos principais e das Tabelas 4.10 e 4.11 para os efeitos das interações, analisando os resultados dados pelas Ferramentas $\mathrm{A}$ e $\mathrm{C}$ respectivamente.

Os percentuais que relacionam os efeitos principais e as interações das variáveis sobre a altura da rebarba foram calculados tendo como referência a média geral dos resultados dos ensaios, à qual foi atribuído um percentual de $100 \%$. As células em vermelho na tabela destacam os efeitos que foram significativos para confiabilidade de $95 \%$.

Tabela 4.9 - Efeitos Principais da mudança de níveis das variáveis nos valores da altura da rebarba Ferramenta A.

\begin{tabular}{|c||c|c|c|}
\cline { 2 - 4 } \multicolumn{1}{c|}{} & Variável & Efeito $\mathbf{h}(\mu \mathrm{m})$ & $\begin{array}{c}\text { Percentual } \\
\text { de variação } \\
(\%)\end{array}$ \\
\hline \multirow{4}{*}{ Principais } & Média Geral & 79,37 & $100 \%$ \\
\cline { 2 - 4 } & $\mathbf{v}_{\mathbf{c}}$ & $-0,4$ & $-0,50 \%$ \\
\cline { 2 - 4 } & $\mathbf{f}_{\mathrm{z}}$ & $-30,11$ & $-37,90 \%$ \\
\cline { 2 - 4 } & $\mathrm{a}_{\mathrm{p}}$ & 6,27 & $7,90 \%$ \\
\cline { 2 - 4 } & $\mathbf{V}_{\mathrm{Bmax}}$ & 47,86 & $60,30 \%$ \\
\cline { 2 - 4 } & $\boldsymbol{\theta}$ & 24,69 & $31,10 \%$ \\
\hline
\end{tabular}

Através da Tabela 4.9 observa-se que com o aumento do avanço por dente a rebarba diminuiu $30,11 \mu \mathrm{m}(37,9 \%)$, o desgaste da ferramenta provocou um efeito médio muito mais pronunciado aumentando em $60 \%$ a altura da rebarba, enquanto 0 ângulo de saída da ferramenta da peça promoveu um aumento de 24,69 $\mu \mathrm{m}(31 \%)$. Apesar de não significativo, o aumento da profundidade de corte aumentou em 7,9\% a altura da rebarba. 
Tabela 4.10. Efeitos Principais da mudança de níveis das variáveis nos valores da altura da rebarba Ferramenta C.

\begin{tabular}{|c|c|c|c|}
\cline { 2 - 4 } \multicolumn{1}{c|}{} & Variável & $\begin{array}{c}\text { Efeito } \\
(\mu \mathrm{m})\end{array}$ & $\begin{array}{c}\text { Percentual } \\
\text { de } \\
\text { variação } \\
(\%)\end{array}$ \\
\hline \multirow{4}{*}{ Principais } & $\begin{array}{c}\text { Média } \\
\text { Geral }\end{array}$ & 202,57 & $100 \%$ \\
\cline { 2 - 4 } & $\mathbf{v}_{\mathbf{c}}$ & $-4,13$ & $-2,00 \%$ \\
\cline { 2 - 4 } & $\mathbf{f}_{\mathbf{z}}$ & $-12,12$ & $-6,00 \%$ \\
\cline { 2 - 4 } & $\mathbf{a}_{\mathrm{p}}$ & 8,87 & $4,40 \%$ \\
\cline { 2 - 4 } & $\mathbf{V}_{\mathrm{Bmax}}$ & 148,68 & $73,40 \%$ \\
\cline { 2 - 4 } & $\boldsymbol{\theta}$ & 37,43 & $18,50 \%$ \\
\hline \hline
\end{tabular}

Considerando o intervalo de variáveis proposto neste trabalho, observa-se na Tabela 4.10 que com o aumento do avanço por faca a rebarba diminuiu $12,12 \mu \mathrm{m}$ (6\%), o aumento da profundidade de corte gerou um aumento de $8,87 \mu \mathrm{m}(4,5 \%)$. $\mathrm{O}$ desgaste da ferramenta provocou um efeito médio muito mais pronunciado aumentando em $73 \%$ a altura da rebarba, enquanto o ângulo de saída da ferramenta da peça promoveu um aumento de $18,5 \%$. Apesar de não significativo a velocidade de corte reduziu em $2 \%$ a altura da rebarba.

Tabela 4.11 - Efeitos das Interações da mudança de níveis das variáveis nos valores da altura da rebarba - Ferramenta A.

\begin{tabular}{|c|c|c|c|}
\hline & Variável & $\begin{array}{c}\text { Efeito } h \\
\quad(\mu \mathrm{m})\end{array}$ & $\begin{array}{c}\text { Percentual } \\
\text { de variação } \\
(\%)\end{array}$ \\
\hline \multirow{11}{*}{ Interações } & Média Geral & 79,37 & $100 \%$ \\
\hline & $\mathbf{v}_{\mathrm{c}} \mathbf{f}_{\mathrm{z}}$ & 11,26 & $14,20 \%$ \\
\hline & $\mathbf{v}_{c} a_{p}$ & $-11,74$ & $-14,80 \%$ \\
\hline & $\mathbf{V}_{\mathrm{c}} \mathbf{V}_{\mathrm{Bmax}}$ & $-5,07$ & $-6,40 \%$ \\
\hline & $\mathbf{v}_{\mathrm{c}} \boldsymbol{\theta}$ & 11,61 & $14,60 \%$ \\
\hline & $f_{z} a_{p}$ & $-4,82$ & $-6,10 \%$ \\
\hline & $f_{z} V_{B \text { max }}$ & $-7,18$ & $-9,00 \%$ \\
\hline & $f_{z} \theta$ & $-4,47$ & $-5,60 \%$ \\
\hline & $a_{p} V_{\text {Bmax }}$ & $-1,3$ & $-1,60 \%$ \\
\hline & $a_{p} \theta$ & 2,95 & $3,70 \%$ \\
\hline & $\mathrm{V}_{\mathrm{Bmax}} \boldsymbol{\theta}$ & 10,51 & $13,20 \%$ \\
\hline
\end{tabular}


A Tabela 4.11 mostra que a combinação de velocidade de corte e profundidade de usinagem foi a mais significativa promovendo uma redução de 14,8\% na altura da rebarba. Já a interação entre a velocidade de corte e o avanço propiciou um aumento de $14 \%$ enquanto que, com a combinação avanço e desgaste de flanco obteve-se uma redução de $9 \%$ na altura da rebarba.

Tabela 4.12. Efeitos das Interações da mudança de níveis das variáveis nos valores da altura da rebarba - Ferramenta C

\begin{tabular}{|c|c|c|c|}
\hline & Variável & $\begin{array}{c}\text { Efeito } \\
\text { ( } \mu \mathrm{m})\end{array}$ & \begin{tabular}{|c} 
Percentual \\
de \\
variação \\
$(\%)$ \\
\end{tabular} \\
\hline \multirow{10}{*}{ Interações } & $\mathbf{v}_{\mathrm{c}} \mathbf{f}_{\mathrm{z}}$ & 3,1 & $1,50 \%$ \\
\hline & $\mathbf{v}_{\mathrm{c}} \mathbf{a}_{\mathrm{p}}$ & 3,46 & $1,70 \%$ \\
\hline & $\mathbf{v}_{\mathbf{c}} \mathbf{V}_{\text {Bmax }}$ & $-10,74$ & $-5,30 \%$ \\
\hline & $\mathbf{v}_{\mathrm{c}} \boldsymbol{\theta}$ & 8,06 & $4,00 \%$ \\
\hline & $f_{z} a_{p}$ & 2,61 & $1,30 \%$ \\
\hline & $\mathbf{f}_{\mathrm{Z}} \mathbf{V}_{\mathrm{Bmax}}$ & $-3,79$ & $-1,90 \%$ \\
\hline & $\mathbf{f}_{\mathbf{z}} \boldsymbol{\theta}$ & $-9,15$ & $-4,50 \%$ \\
\hline & $a_{p} V_{B \max }$ & 1,88 & $0,90 \%$ \\
\hline & $a_{p} \theta$ & 3,11 & $1,50 \%$ \\
\hline & $V_{B \max } \theta$ & 2,61 & $1,30 \%$ \\
\hline
\end{tabular}

Com relação às interações entre as variáveis, a Tabela 4.12 mostra que a combinação de velocidade de corte e desgaste da ferramenta foi a mais significativa promovendo uma redução de $5 \%$ enquanto que, com a combinação de velocidade de corte e ângulo de saída da ferramenta da peça obteve-se um aumento de $4 \%$ na altura da rebarba.

\subsubsection{Análise de variância do modelo}

A análise de variância (ANOVA) é um modelo bastante prático para avaliar a qualidade do modelo, examinar o resíduo causado pelo erro experimental e medir as 
distorções entre o resultado proposto e o observado. A análise de variância será realizada para a ferramenta $A$, através do quadro de ANOVA da Tabela 4.13 e para a ferramenta $C$ através do quadro de ANOVA da Tabela 4.14.

A Tabela 4.13 representa o quadro de ANOVA, que juntamente com o gráfico de distribuição normal dos resíduos, na Figura 4.25, são suficientes para as considerações sobre o modelo empírico que prevê a altura da rebarba formada com a ferramenta $\mathrm{A}$.

Tabela 4.13. Análise de variância para ajuste do modelo - Ferramenta A.

\begin{tabular}{|c|c|c|c||c|}
\hline $\begin{array}{c}\text { Fonte de } \\
\text { Variação }\end{array}$ & $\begin{array}{c}\text { Soma dos } \\
\text { Quadrados }\end{array}$ & $\begin{array}{c}\text { Grau de } \\
\text { Liberdade }\end{array}$ & \multicolumn{2}{|c|}{$\begin{array}{c}\text { Média } \\
\text { Quadrática }\end{array}$} \\
\hline \hline $\begin{array}{c}\text { Regressão } \\
\text { (SQR) }\end{array}$ & 0,14356 & 15 & SQMR & 0,0095705 \\
\hline $\begin{array}{c}\text { Resíduo } \\
\text { (SQr) }\end{array}$ & 0,03286 & 112 & SQMr & 0,0002934 \\
\hline $\begin{array}{c}\text { Total } \\
\text { (SQT) }\end{array}$ & 0,17641 & 127 & \\
\hline
\end{tabular}

A qualidade do mesmo poderá ser notada através de um teste de

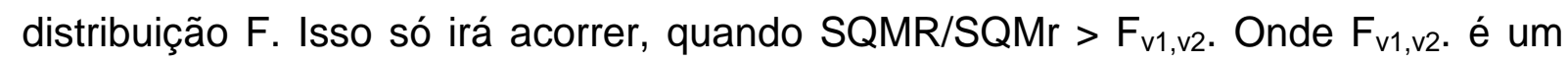
valor que pode ser encontrado em tabelas de estatística quando for conhecido o grau de liberdade de SQR e de SQr. Sendo $F_{15,112}$ igual a 1,82 para $\alpha$ de 0,05 , com $95 \%$ de confiança, tem se:

$$
\begin{aligned}
& \frac{S Q M R}{S Q M r}=\frac{0,009570}{0,000293}=32,62 \\
& F_{15,127}=\underset{\alpha \Rightarrow 0,05}{1,82}
\end{aligned}
$$

Portanto:

$$
\begin{aligned}
& \frac{S Q M R}{S Q M r}>\mathrm{F}_{15,127} \\
& R^{2}=\frac{S Q R}{S Q T}=\frac{0,143557}{0,176415}=0,81
\end{aligned}
$$


O coeficiente de correlação apresenta resultado satisfatório para o modelo, $R^{2}=0,81$, significando que $81 \%$ da variação total em torno da média é explicada pela regressão, ficando para os resíduos $19 \%$.

Resumidamente, os resíduos entre os valores medidos e os estimados podem ser analisados através dos gráficos da Figura 4.25. Os resíduos deixados pelos ensaios distribuem de forma normal e aleatória, conforme nota-se na Figura 4.25a. O valor do resíduo para os ensaios encontram-se representados na Figura $4.25 b$.

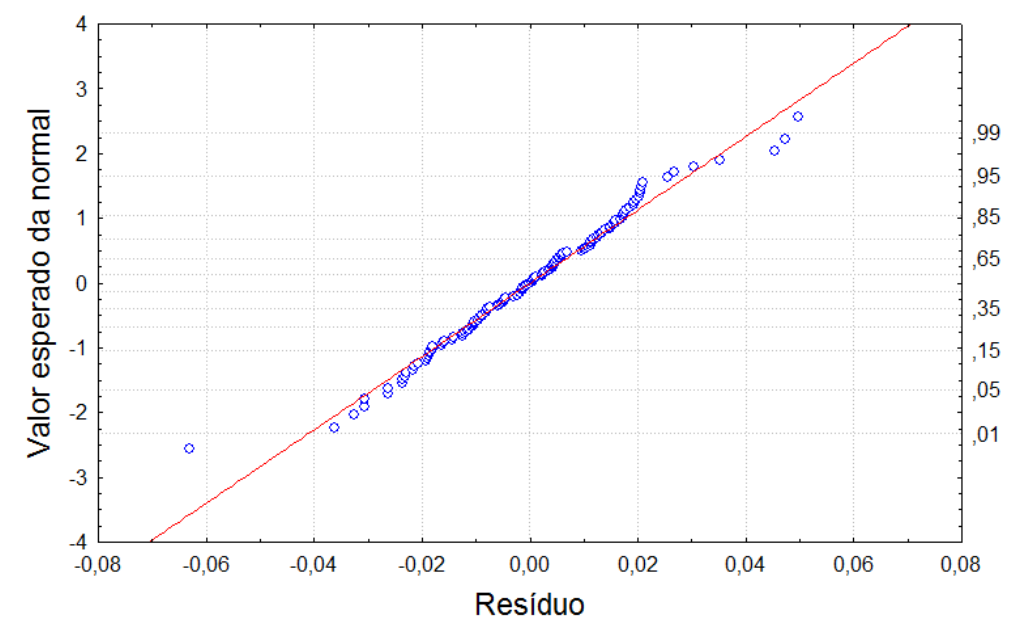

(a)

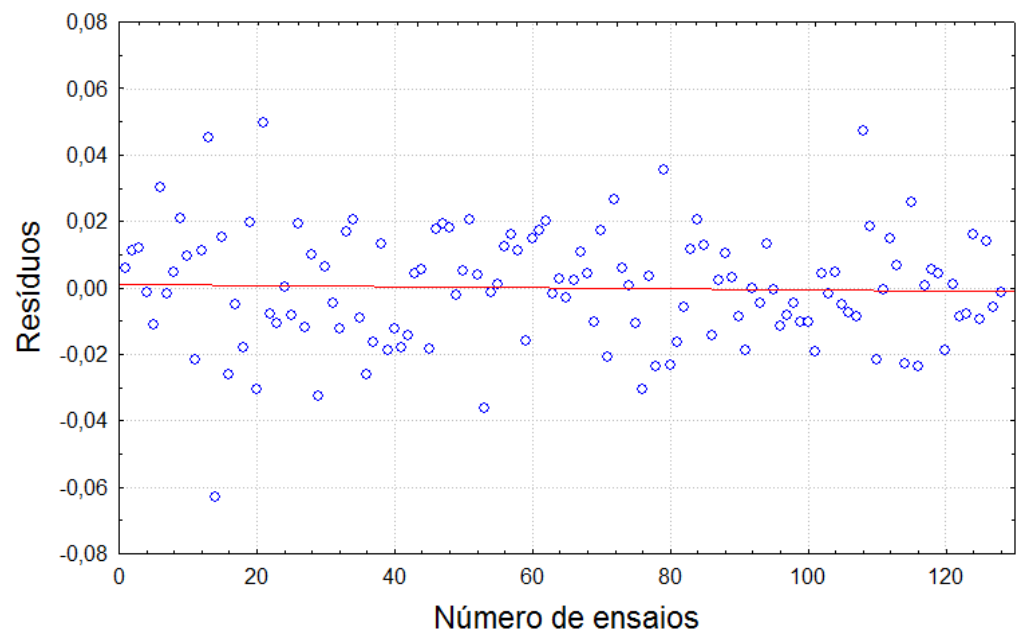

(b)

Figura 4.25 - Resíduo entre os valores medidos e estimados. a) - Distribuição normal do resíduo, b) Valor do resíduo para as 128 respostas - Ferramenta A 
A Tabela 4.14 representa o quadro de ANOVA, que juntamente com o gráfico de distribuição normal dos resíduos, na Figura 4.26, são suficientes para as considerações sobre o modelo empírico que prevê a altura da rebarba formada com a ferramenta C.

Tabela 4.14. Análise de variância para ajuste do modelo - Ferramenta C.

\begin{tabular}{|c|c|c|c||c|}
\hline $\begin{array}{c}\text { Fonte de } \\
\text { Variação }\end{array}$ & $\begin{array}{c}\text { Soma dos } \\
\text { Quadrados }\end{array}$ & $\begin{array}{c}\text { Grau de } \\
\text { Liberdade }\end{array}$ & \multicolumn{2}{|c|}{ Média Quadrática } \\
\hline \hline $\begin{array}{c}\text { Regressão } \\
\text { (SQR) }\end{array}$ & 0,770461 & 15 & SQMR & 0,051364 \\
\hline Resíduo (SQr) & 0,036828481 & 112 & SQMr & 0,000329 \\
\hline Total (SQT) & 0,80728945 & 127 & & \\
\hline
\end{tabular}

A qualidade do mesmo poderá ser notada através de um teste de

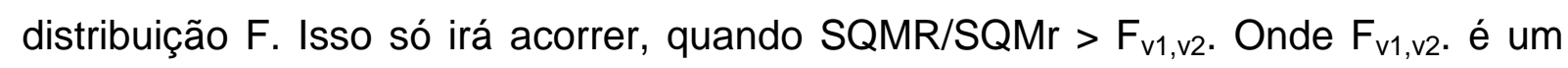
valor que pode ser encontrado em tabelas de estatística quando for conhecido 0 grau de liberdade de SQR e de $S Q$. Sendo $F_{15,112}$ igual a 1,82 para $\alpha$ de 0,05, com 95\% de confiança, tem se:

$$
\begin{aligned}
& \frac{S Q M R}{S Q M r}=\frac{0,051364}{0,000329}=156,20 \\
& F_{15,127}=\underset{\alpha \Rightarrow 0,05}{1,82}
\end{aligned}
$$

Portanto:

$$
\frac{S Q M R}{S Q M r}>\mathrm{F}_{15,112}
$$

O coeficiente de correlação apresenta um resultado ótimo para o modelo, $\mathrm{R}^{2}=0,95$, significando que $95 \%$ da variação total em torno da média é explicada pela regressão, ficando para os resíduos apenas $5 \%$.

$$
R^{2}=\frac{S Q R}{S Q T}=\frac{0,77046}{0,80729}=0,95
$$


Resumidamente, os resíduos entre os valores medidos e os estimados podem ser analisados através dos gráficos da Figura 4.26. Os resíduos deixados pelos ensaios distribuem de forma normal e aleatória, conforme nota-se na Figura 4.26a. O valor do resíduo para os ensaios encontram-se representados na Figura $4.26 \mathrm{~b}$.

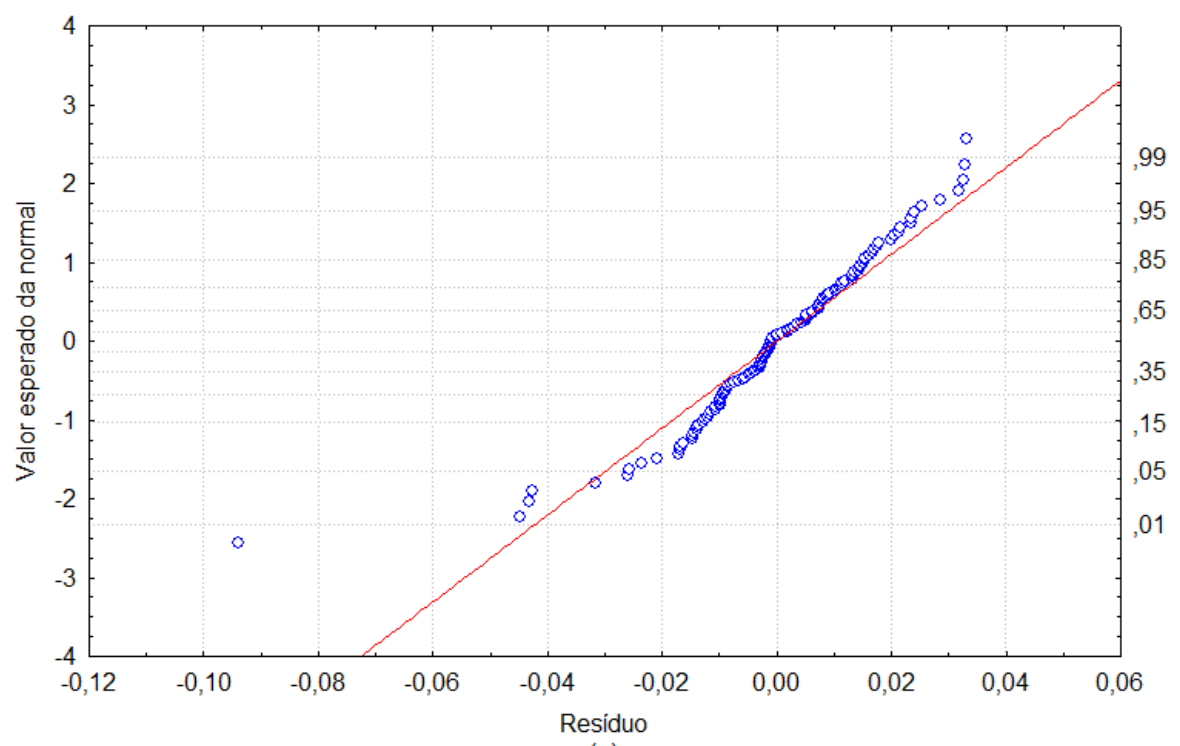

(a)

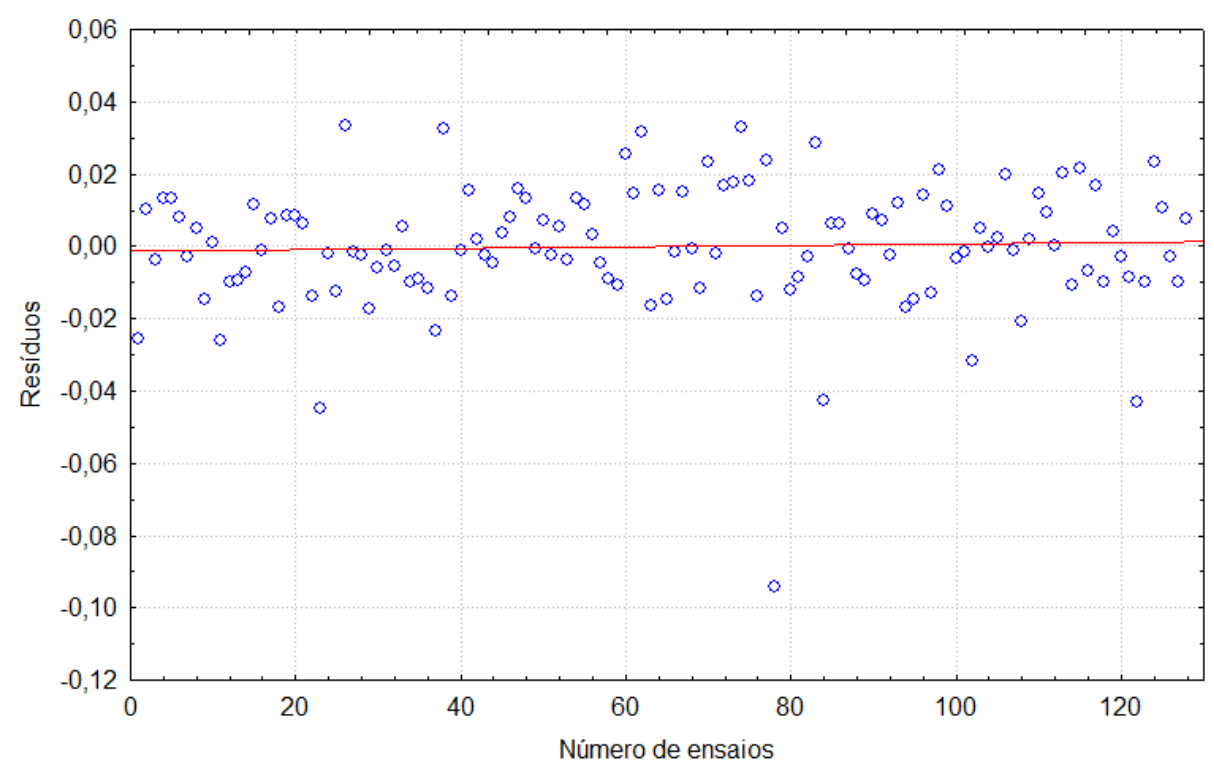

(b)

Figura 4.26. Resíduo entre os valores medidos e estimados. (a) - Distribuição normal do resíduo, (b) - Valor do resíduo para as 128 respostas - Ferramenta C 


\section{CONCLUSÕES}

O presente trabalho possibilitou as seguintes conclusões:

- A não retirada da rebarba remanescente proporcionou um aumento linear da rebarba a cada nova passada.

- O ângulo de posição maior e a geometria positiva da ferramenta propiciou a formação de rebarbas com dimensões menores.

- As rebarbas formadas nas bordas dos furos possuem dimensões uniformes e menores que as rebarbas formadas nas bordas.

- A borda de saída apresenta rebarbas bem maiores do que a borda de entrada.

- No geral, nas condições de corte investigadas, o aumento da velocidade de corte $\left(v_{c}\right)$, o aumento do avanço por dente $\left(f_{z}\right)$ e a redução na profundidade de corte $\left(a_{p}\right)$ proporcionam a diminuição da altura $(h)$ da rebarba.

- As rebarbas têm suas alturas crescentes no sentido da extremidade da borda para o centro da mesma.

- As rebarbas de saída possuem dimensões maiores do que as rebarbas de entrada.

- A velocidade de corte apresentou-se menos influente nas dimensões da rebarba em relação às demais variáveis examinadas.

- O desgaste da ferramenta de corte proporciona rebarbas maiores que aquelas apresentadas por ferramentas novas. 


\section{SUGESTÕES PARA TRABALHOS FUTUROS}

- Análise da formação da rebarba secundária, para diferentes níveis de profundidade de corte e avanço.

- Análise da variação da altura da rebarba em diferentes tipos de processos de usinagem utilizando-se MQL (Mínima Quantidade de Lubrificação).

- Determinação de um modelo empírico capaz de relacionar a menor altura da rebarba para diferentes valores de dados de corte com um nível mínimo de desgaste da ferramenta de corte.

- Verificação da influência de outras penetrações de trabalho na formação da rebarba no ferro fundido vermicular

- Verificação da relação entre o cavaco e rebarba formada no processo de fresamento do ferro fundido vermicular. 


\section{REFERÊNCIAS}

ABNT - ASSOCIAÇÃO BRASILEIRA DE NORMAS TÉCNICAS. NBR-6162. Conceitos da técnica de usinagem, movimentos e relações geométricas. $17 \mathrm{p}$., 1989.

ABNT - ASSOCIAÇÃO BRASILEIRA DE NORMAS TÉCNICAS. NBR-6163: Geometria de cunha de corte. 45p., 1971.

ABNT - ASSOCIAÇÃO BRASILEIRA DE NORMAS TÉCNICAS. NBR-6175: Processos Mecânicos de Usinagem. 19p., 1971.

AURICH, J. C.; DORNFELD, D.; ARRAZOLA, P. J.; FRANKE, V.; LEITZ, L.; MIN, S. Burrs-Analysis, Control and Removal. Proceedings of the CIRP - International Conference on Burrs (CIRP Annals) - Manufacturing Technology, v. 58, p. 519 542, 2009.

ASM Handbook. Machining. V.16, p. $681-707,1997$.

BAGETTI, J. H. Análise da usinabilidade, deformação e temperatura no fresamento dos ferros fundidos vermicular e cinzento. 2009. 136p. Dissertação (Mestrado) - Universidade Federal de Santa Catarina. Florianópolis - SC, 2009.

BOFF, C. R. Metodologia de análise de blocos de motores - Aplicação a blocos de motores diesel em ferro fundido vermicular. 2003. 101p. Dissertação (Mestrado) - Universidade Federal de Santa Catarina. Florianópolis - SC, 2003.

BOGUE, R. Finishing robots: a review of technologies and applications. Industrial Robot: An International Journal, v. 1, p. 6-12, 2009.

CALADO, V.; MONTGOMERY, D. C., 2003. Planejamento de Experimento Usando a Estatística. Rio de Janeiro - RJ: E - papers Serviços Editoriais Ltda, 260p.

CHERN, G. L. Analysis of Burr Formation and Breakout in Metal Cutting. 1993. 236p. Ph.D. (Thesis) - University of California. Berkeley, CA - EUA. 1993.

CHERN, G. L.; DORNFELD, D. A. Burr/Breakout Model Development and Experimental Verification. Journal of Engineering Materials and Technology. $v$. 118, p. $201-206,1996$. 
CHERN, G. L. Experimental Observation and Analysis of Burr Formation Mechanisms in Face Milling of Aluminum Alloys. International Journal of Machine Tools \& Manufacture, v. 46, p. $1417-1525,2006$.

CONAMA - Conselho Nacional do Meio Ambiente. Ministério do Meio Ambiente Resolução n̊.315, de 29 de outubro de 2002.

CORRÊA, D. C. Usinabilidade de mancais bimetálicos: Influência do avanço nos mecanismos de desgaste e na formação de rebarbas. Dissertação (Mestrado) - Pontifícia Universidade Católica de Minas Gerais. Belo Horizonte - MG, 2002.

DA SILVA, L. C. Estudo da Rebarba no Fresamento de Faceamento em Blocos de Motores de Ferro Fundido Cinzento Utilizando Inserto de Cerâmica e PCBN. 2004. 184p. Dissertação (Mestrado) - Universidade Federal de Uberlândia. Uberlândia - MG, 2004.

DA SILVA, L. C. Comportamento da Rebarba no Fresamento de Faceamento do Aço Inoxidável PH 13 8Mo. 2011. 190p. Tese (Doutorado) - Universidade Federal de Uberlândia. Uberlândia - MG, 2011.

DAWSON, S. Practical applications for compacted graphite iron. In: Compacted graphite iron. Journal of Manufacturing Science and Engineering, v. 53, p. $25-32$, 2002.

DAWSON, S. Compacted graphite iron - A material solution for modern engine cylinder blocks and heads. Sweden, China Foundry, v.6, p. 241 - 246, Aug. 2009.

DIN 6784, 1982. Bordas das peças, conceitos e indicações.

DINIZ, A. E., MARCONDES, F. C., COPPINI, N. L. Tecnologia da Usinagem dos Materiais. $7^{a}$ Ed., São Paulo: Artliber, 268 p., 2010.

DORÉ, C. Influência da variação da nodularidade na usinabilidade do ferro fundido vermicular. 2007. 131p. Dissertação (Mestrado) - Universidade Federal de Santa Catarina. Florianópolis - SC, 2007.

DORNFELD, D. A., CHANG, Y. P., HASHIMURA, M. Analysis of Burr Formation Mechanism in Orthogonal Cutting. Journal of Manufacturing Science and Engineering, v. 121, p. 1-7,1999. 
GABALDO, S. Uma contribuição à melhoria do processo de fresamento de ferro fundido vermicular - CGI. 2009. 136p. Dissertação (Mestrado) - Faculdade de Engenharia Mecânica - Universidade Estadual de Campinas. Campinas - SP, 2009.

GEIER, G. F.; BAUER, W.; SCHUMACHER, P. A produção do GJV por tratamento com magnésio cério ou lantânio. Fundição e Serviços, p. 72 - 81, Ago. 2011.

GILLESPIE, L. K. Deburring and edge finishing handbook. American Society Mechanical Engineers New York EUA: SME - Society of Manufacturing Engineering, 400p., 1999.

GILLESPIE, L. K.; BLOTTER, P. T. The formation and properties of machining burrs. Journal of Engineering for Industry, v. 128, p. 66 - 74, 1976.

GODINHO, A. F. C. E. Análise do mandrilamento de cilindros de blocos de motores em ferro fundido vermicular com diferentes concepções de ferramentas. 2007. 129p. Dissertação (Mestrado) - Universidade Federal de Santa Catarina. Florianópolis - SC, 2007.

GUESSER, W. L. Ferro fundido com grafita compactada. Metalurgia \& Materiais Publicação Técnica, Jun. 2002.

GUESSER, W. L. Propriedades mecânicas dos ferros fundidos. São Paulo: Ed. Blucher, 336p, 2009.

HASHIMURA, M.; HASSAMONTH, J.; DORNFELD, D. A., CHANG, Y. P. Effect of in-plane exit angle and rake angles on burr height and thickness in face milling operation. Journal of Manufacturing Science and Engineering, v.121, p. $13-19$, Feb. 1999.

HASHIMURA, M.; DORNFELD, D. A. Analysis of Three Dimensional Burr Formation in Oblique Cutting. Annals of the CIRP. v. 44, p. $27-30,1995$.

HASHIMURA, M., CHANG, Y. P. Analysis of Burr Formation Mechanism in Orthogonal Cutting Using Micro Machining and FEM. International Journal of Machine Tools and Manufacture, v. 38, p. $73-81,1994$

ISO 13715, 2000. Desenhos Técnicos - Arestas Sem Forma Definida - Vocabulário e Indicações, v.2, 13p., 2000. 
KAMINISE, A. K.; DA SILVA, M. B.; JORGE, G. J. A. R.; GOLÇALVES, R. A. Estudo sobre a formação de rebarbas no torneamento do aço ABNT 1045. XVI COBEM 2001, Nov. 2001.

KIM, J., MIN, S., DORNFELD, A. D. Optimization and Control of Drilling Burr Formation of AISI 304L and AISI 4118 Based on Drilling Burr Control Charts. International Journal of Machine Tools \& Manufacture, v. 12, p.23 - 29, 2000.

KISHIMOTO, W.; MIYAKE, T.; YAMAMOTO, A.; YAMANAKA, K. Study of burr formation in face Milling. Journal of Materials Processing Technology, v.15, p. 51 54, 1981.

KO, S. L.; DORNFELD, D. A. A study on burr formation mechanism. Journal of Engineering Materials and Technology, v. 113, p. 75 -79, Jan. 1991.

KO, S. L.; DORNFELD, D. A. Analysis of Fracture in Burr Formation at the Exit Stage of Metal Cutting. Journal of Materials Processing Technology, v.58, p. 189 200, 1996.

LIN, T. R. Experimental Study of Formation and Tool Chipping in the Face Milling of Stainless Steel. Journal of Materials Processing Technology, v. 108, p. $12-20,1999$.

MACHADO, A. R.; ABRÃO, A. M.; COELHO, R. T.; DA SILVA, M. B. Teoria da Usinagem dos Materiais. São Paulo: Edgard Blücher Ltda, 371p. 2009.

MIURA, S. I. Para alcançar maior usinabilidade. Publicação técnica: O mundo da Usinagem, p. 12-21, ago. 2011.

MOCELLIN, F. Desenvolvimento de tecnologia para brunimento de cilindros de blocos de motores em ferro fundido vermicular. 2007. 264p. Tese (Doutorado) Universidade Federal de Santa Catarina. Florianópolis - SC, 2007.

MONTGOMERY, C. D.; RUNGER, G. C. Estatística Aplicada e Probabilidade para Engenheiros. São Paulo: LTC, 2003.

NAKAYAMA, K.; ARAI, M. Burr formation in metal cutting. Journal of Manufacturing Systems, v. 36, p. $33-36,1987$.

NARAYANASWAMI, R.; DORNFELD, D.A. Burr Minimization in Face Milling: A Geometric Approach. Journal of Manufacturing Science and Engineering, 119, p. $170-177,1997$. 
OLVERA, O.; BARROW, G. An Experimental Study of Burr Formation in Square Shoulder Face Milling. International Journal of Machining Tools and Manufacturing, p. $1005-1020,1996$.

OLVERA, O.; BARROW, G. Influence of Exit Angle and Tool Nose Geometric on Burr Formation in Milling Operations. Proc. Inst. Mech. Engrs., v.212, part b, p. 59 $-72,1998$.

PALMAN, S.; MÜLLER, S.; BECHLER, M. Marktübersicht Entgrattechnik für Werkstücke im Automobil Powertrain Bereich. 2011. 52p. Projektarbeit Hochschule Kempten - University of Applied Sciences, 2011.

PEKELHARING, A. J. The exit failure in interrupted cutting. Annals of the CIRP, v. 27, p. $5-10,1978$.

REFERENCE GUIDE MWM Motors, 2010.

SCHÄFER, F. Product Design Influences on Deburring. SME Paper MR75, v. 12, p. $47-55,1978$

SHÖNFELD, F. Gusseisenwerkstoffe für Wirtschaftlichkeit und Zuverlässigkeit von NFZ-Dieselmotoren. Giesserei-Praxis, v.6, p. 270 - 274, 2003.

SECO TOOLS. Fresamento. Catálogo de Ferramentas, 2009.

SOUZA JR., A. M. Estudo da utilização de PCBN e Cerâmica Mista no fresamento de blocos de motores de ferro fundido cinzento. 2001. 141p. Dissertação (Mestrado) - Pontifícia Universidade Católica de Minas Gerais. Belo Horizonte - MG, 2001.

TRIPATHI, S.; DORNFELD, D. A. Review of Geometric Solutions for Milling Burr Prediction and Minimization. VII International Conference on Deburring and Surface Finishing. University of California at Berkeley, EUA, 2004.

WEBER, R.; GORTZ, W. O uso de ferro fundido na produção de blocos de motores modernos. 2011. São Paulo, Fundição e Serviços, p. 16 - 25, Out. 2011.

XAVIER, F. A. Aspectos tecnológicos do torneamento do ferro fundido vermicular com ferramentas de metal duro, cerâmica e CBN. 2003. 146p. Dissertação (Mestrado) - Universidade Federal de Santa Catarina. Florianópolis SC, 2003. 


\section{APÊNDICE A}

Seqüência e numeração dos ensaios realizados com a Ferramenta A para a segunda etapa.

\begin{tabular}{|c|c|c|c|c|c|c|c|}
\hline $\begin{array}{l}\text { Vc } \\
\mathrm{m} / \mathrm{min}\end{array}$ & $\begin{array}{c}\mathrm{fz} \\
\mathrm{mm} / \text { dente }\end{array}$ & $\underset{\mathrm{mm}}{\mathrm{ap}}$ & $\begin{array}{c}\text { VBmax } \\
\mathrm{mm}\end{array}$ & $\begin{array}{c}\text { No } \\
\text { ensaio }\end{array}$ & $\begin{array}{c}\text { Ferramenta } \\
\text { A }\end{array}$ & $\begin{array}{c}\text { Ds } \\
\theta=180^{\circ} \\
\mathrm{h}(\mathrm{mm})\end{array}$ & $\begin{array}{c}\text { Fs } \\
\theta=160^{\circ} \\
h(\mathrm{~mm})\end{array}$ \\
\hline 130 & 0,05 & 0,30 & 0,00 & 1 & Ensaio & 0,0550 & 0,0620 \\
\hline 190 & 0,05 & 0,30 & 0,00 & 2 & Ensaio & 0,0590 & 0,0610 \\
\hline 130 & 0,10 & 0,30 & 0,00 & 3 & Ensaio & 0,0460 & 0,0430 \\
\hline 190 & 0,10 & 0,30 & 0,00 & 4 & Ensaio & 0,0350 & 0,0460 \\
\hline 130 & 0,05 & 0,70 & 0,00 & 5 & Ensaio & 0,1370 & 0,0660 \\
\hline 190 & 0,05 & 0,70 & 0,00 & 6 & Ensaio & 0,0727 & 0,0777 \\
\hline 130 & 0,10 & 0,70 & 0,00 & 7 & Ensaio & 0,0333 & 0,0410 \\
\hline 190 & 0,10 & 0,70 & 0,00 & 8 & Ensaio & 0,0600 & 0,0400 \\
\hline 130 & 0,05 & 0,30 & 0,00 & 9 & 1a Réplica & 0,0580 & 0,0730 \\
\hline 190 & 0,05 & 0,30 & 0,00 & 10 & 1a Réplica & 0,0820 & 0,0700 \\
\hline 130 & 0,10 & 0,30 & 0,00 & 11 & 1a Réplica & 0,0470 & 0,0220 \\
\hline 190 & 0,10 & 0,30 & 0,00 & 12 & 1a Réplica & 0,0693 & 0,0210 \\
\hline 130 & 0,05 & 0,70 & 0,00 & 13 & 1a Réplica & 0,0510 & 0,0610 \\
\hline 190 & 0,05 & 0,70 & 0,00 & 14 & 1a Réplica & 0,0793 & 0,0607 \\
\hline 130 & 0,10 & 0,70 & 0,00 & 15 & 1a Réplica & 0,0450 & 0,0240 \\
\hline 190 & 0,10 & 0,70 & 0,00 & 16 & 1a Réplica & 0,0720 & 0,0230 \\
\hline 130 & 0,05 & 0,30 & 0,00 & 17 & 2a Réplica & 0,0440 & 0,0530 \\
\hline 190 & 0,05 & 0,30 & 0,00 & 18 & 2a Réplica & 0,0710 & 0,0520 \\
\hline 130 & 0,10 & 0,30 & 0,00 & 19 & 2a Réplica & 0,0380 & 0,0420 \\
\hline 190 & 0,10 & 0,30 & 0,00 & 20 & 2a Réplica & 0,0860 & 0,0517 \\
\hline 130 & 0,05 & 0,70 & 0,00 & 21 & 2a Réplica & 0,1000 & 0,0670 \\
\hline 190 & 0,05 & 0,70 & 0,00 & 22 & 2a Réplica & 0,0663 & 0,0646 \\
\hline 130 & 0,10 & 0,70 & 0,00 & 23 & 2a Réplica & 0,0460 & 0,0220 \\
\hline 190 & 0,10 & 0,70 & 0,00 & 24 & 2a Réplica & 0,0700 & 0,0620 \\
\hline 130 & 0,05 & 0,30 & 0,00 & 25 & 3a Réplica & 0,0670 & 0,0480 \\
\hline 190 & 0,05 & 0,30 & 0,00 & 26 & 3a Réplica & 0,0540 & 0,0450 \\
\hline 130 & 0,10 & 0,30 & 0,00 & 27 & 3a Réplica & 0,0520 & 0,0210 \\
\hline 190 & 0,10 & 0,30 & 0,00 & 28 & 3a Réplica & 0,0420 & 0,0370 \\
\hline 130 & 0,05 & 0,70 & 0,00 & 29 & 3a Réplica & 0,0880 & 0,0580 \\
\hline 190 & 0,05 & 0,70 & 0,00 & 30 & 3a Réplica & 0,0860 & 0,0517 \\
\hline 130 & 0,10 & 0,70 & 0,00 & 31 & 3a Réplica & 0,0480 & 0,0410 \\
\hline 190 & 0,10 & 0,70 & 0,00 & 32 & 3a Réplica & 0,0410 & 0,0400 \\
\hline
\end{tabular}




\begin{tabular}{|c|c|c|c|c|c|c|c|}
\hline $\begin{array}{c}\text { Vc } \\
\mathrm{m} / \mathrm{min}\end{array}$ & $\begin{array}{c}\mathrm{fz} \\
\mathrm{mm} / \text { dente }\end{array}$ & $\begin{array}{l}\text { ap } \\
\mathrm{mm}\end{array}$ & $\begin{array}{c}\text { VBmax } \\
\text { mm }\end{array}$ & $\begin{array}{c}\text { No } \\
\text { ensaio }\end{array}$ & $\begin{array}{c}\text { Ferramenta } \\
\text { A }\end{array}$ & $\begin{array}{c}\text { Ds } \\
\theta=180^{\circ} \\
\mathrm{h}(\mathrm{mm})\end{array}$ & $\begin{array}{c}\text { Fs } \\
\theta=160^{\circ} \\
h(\mathrm{~mm})\end{array}$ \\
\hline 130 & 0,05 & 0,30 & 0,30 & 33 & Ensaio & 0,1240 & 0,1280 \\
\hline 190 & 0,05 & 0,30 & 0,30 & 34 & Ensaio & 0,1580 & 0,1000 \\
\hline 130 & 0,10 & 0,30 & 0,30 & 35 & Ensaio & 0,0720 & 0,0460 \\
\hline 190 & 0,10 & 0,30 & 0,30 & 36 & Ensaio & 0,1230 & 0,0850 \\
\hline 130 & 0,05 & 0,70 & 0,30 & 37 & Ensaio & 0,1240 & 0,1710 \\
\hline 190 & 0,05 & 0,70 & 0,30 & 38 & Ensaio & 0,1460 & 0,0225 \\
\hline 130 & 0,10 & 0,70 & 0,30 & 39 & Ensaio & 0,0940 & 0,0920 \\
\hline 190 & 0,10 & 0,70 & 0,30 & 40 & Ensaio & 0,0920 & 0,0330 \\
\hline 130 & 0,05 & 0,30 & 0,30 & 41 & 1a Réplica & 0,1480 & 0,0890 \\
\hline 190 & 0,05 & 0,30 & 0,30 & 42 & 1a Réplica & 0,1500 & 0,0760 \\
\hline 130 & 0,10 & 0,30 & 0,30 & 43 & 1a Réplica & 0,0680 & 0,0720 \\
\hline 190 & 0,10 & 0,30 & 0,30 & 44 & 1a Réplica & 0,1280 & 0,0790 \\
\hline 130 & 0,05 & 0,70 & 0,30 & 45 & 1a Réplica & 0,1740 & 0,1070 \\
\hline 190 & 0,05 & 0,70 & 0,30 & 46 & 1a Réplica & 0,1600 & 0,1030 \\
\hline 130 & 0,10 & 0,70 & 0,30 & 47 & 1a Réplica & 0,0970 & 0,0960 \\
\hline 190 & 0,10 & 0,70 & 0,30 & 48 & 1a Réplica & 0,1070 & 0,0770 \\
\hline 130 & 0,05 & 0,30 & 0,30 & 49 & 2a Réplica & 0,1350 & 0,1130 \\
\hline 190 & 0,05 & 0,30 & 0,30 & 50 & 2a Réplica & 0,1300 & 0,0910 \\
\hline 130 & 0,10 & 0,30 & 0,30 & 51 & 2a Réplica & 0,0650 & 0,0570 \\
\hline 190 & 0,10 & 0,30 & 0,30 & 52 & 2a Réplica & 0,1130 & 0,0430 \\
\hline 130 & 0,05 & 0,70 & 0,30 & 53 & 2a Réplica & 0,1520 & 0,1290 \\
\hline 190 & 0,05 & 0,70 & 0,30 & 54 & 2a Réplica & 0,1530 & 0,0620 \\
\hline 130 & 0,10 & 0,70 & 0,30 & 55 & 2a Réplica & 0,0980 & 0,1120 \\
\hline 190 & 0,10 & 0,70 & 0,30 & 56 & 2a Réplica & 0,0930 & 0,0360 \\
\hline 130 & 0,05 & 0,30 & 0,30 & 57 & 3a Réplica & 0,1330 & 0,1020 \\
\hline 190 & 0,05 & 0,30 & 0,30 & 58 & 3a Réplica & 0,1300 & 0,0830 \\
\hline 130 & 0,10 & 0,30 & 0,30 & 59 & 3a Réplica & 0,0760 & 0,0590 \\
\hline 190 & 0,10 & 0,30 & 0,30 & 60 & 3a Réplica & 0,1290 & 0,1210 \\
\hline 130 & 0,05 & 0,70 & 0,30 & 61 & 3a Réplica & 0,1470 & 0,1440 \\
\hline 190 & 0,05 & 0,70 & 0,30 & 62 & 3a Réplica & 0,1536 & 0,0640 \\
\hline 130 & 0,10 & 0,70 & 0,30 & 63 & 3a Réplica & 0,0930 & 0,0760 \\
\hline 190 & 0,10 & 0,70 & 0,30 & 64 & 3a Réplica & 0,1030 & 0,0740 \\
\hline
\end{tabular}




\section{APÊNDICE B}

Seqüência e numeração dos ensaios realizados com a Ferramenta C para a segunda etapa.

\begin{tabular}{|c|c|c|c|c|c|c|c|}
\hline $\begin{array}{l}\mathrm{Vc} \\
\mathrm{m} / \mathrm{min}\end{array}$ & $\begin{array}{c}\text { fz } \\
\mathrm{mm} / \text { dente }\end{array}$ & $\underset{\mathrm{mm}}{\mathrm{app}}$ & $\begin{array}{c}\text { VBmax } \\
\text { mm }\end{array}$ & $\begin{array}{c}\text { No } \\
\text { ensaio }\end{array}$ & $\begin{array}{c}\text { Ferramenta } \\
\text { C }\end{array}$ & $\begin{array}{c}\text { Ds } \\
\theta=180^{\circ} \\
h(\mathrm{~mm})\end{array}$ & $\begin{array}{c}\text { Fs } \\
\theta=160^{\circ} \\
h(\mathrm{~mm})\end{array}$ \\
\hline 130 & 0,05 & 0,3 & 0,00 & 65 & Ensaio & 0,1540 & 0,0880 \\
\hline 190 & 0,05 & 0,3 & 0,00 & 66 & Ensaio & 0,1430 & 0,1160 \\
\hline 130 & 0,1 & 0,3 & 0,00 & 67 & Ensaio & 0,1540 & 0,1050 \\
\hline 190 & 0,1 & 0,3 & 0,00 & 68 & Ensaio & 0,1440 & 0,1205 \\
\hline 130 & 0,05 & 0,7 & 0,00 & 69 & Ensaio & 0,1270 & 0,1250 \\
\hline 190 & 0,05 & 0,7 & 0,00 & 70 & Ensaio & 0,1443 & 0,1185 \\
\hline 130 & 0,1 & 0,7 & 0,00 & 71 & Ensaio & 0,0600 & 0,1090 \\
\hline 190 & 0,1 & 0,7 & 0,00 & 72 & Ensaio & 0,1720 & 0,1220 \\
\hline 130 & 0,05 & 0,3 & 0,00 & 73 & 1a Réplica & 0,1460 & 0,1190 \\
\hline 190 & 0,05 & 0,3 & 0,00 & 74 & 1a Réplica & 0,1620 & 0,0960 \\
\hline 130 & 0,1 & 0,3 & 0,00 & 75 & 1a Réplica & 0,1210 & 0,1000 \\
\hline 190 & 0,1 & 0,3 & 0,00 & 76 & 1a Réplica & 0,1430 & 0,0954 \\
\hline 130 & 0,05 & 0,7 & 0,00 & 77 & 1a Réplica & 0,1470 & 0,0880 \\
\hline 190 & 0,05 & 0,7 & 0,00 & 78 & 1a Réplica & 0,1790 & 0,1430 \\
\hline 130 & 0,1 & 0,7 & 0,00 & 79 & 1a Réplica & 0,1440 & 0,0980 \\
\hline 190 & 0,1 & 0,7 & 0,00 & 80 & 1a Réplica & 0,1570 & 0,1160 \\
\hline 130 & 0,05 & 0,3 & 0,00 & 81 & 2a Réplica & 0,1380 & 0,0990 \\
\hline 190 & 0,05 & 0,3 & 0,00 & 82 & 2a Réplica & 0,1520 & 0,1044 \\
\hline 130 & 0,1 & 0,3 & 0,00 & 83 & 2a Réplica & 0,1520 & 0,1240 \\
\hline 190 & 0,1 & 0,3 & 0,00 & 84 & 2a Réplica & 0,0950 & 0,1062 \\
\hline 130 & 0,05 & 0,7 & 0,00 & 85 & 2a Réplica & 0,1570 & 0,1000 \\
\hline 190 & 0,05 & 0,7 & 0,00 & 86 & 2a Réplica & 0,1720 & 0.1340 \\
\hline 130 & 0,1 & 0,7 & 0,00 & 87 & 2a Réplica & 0,1320 & 0,1100 \\
\hline 190 & 0,1 & 0,7 & 0,00 & 88 & 2a Réplica & 0,1460 & 0,1340 \\
\hline 130 & 0,05 & 0,3 & 0,00 & 89 & 3a Réplica & 0,1670 & 0,1010 \\
\hline 190 & 0,05 & 0,3 & 0,00 & 90 & 3a Réplica & 0,1440 & 0,1270 \\
\hline 130 & 0,1 & 0,3 & 0,00 & 91 & 3a Réplica & 0,1450 & 0,1200 \\
\hline 190 & 0,1 & 0,3 & 0,00 & 92 & 3a Réplica & 0,1310 & 0,1040 \\
\hline 130 & 0,05 & 0,7 & 0,00 & 93 & 3a Réplica & 0,1675 & 0,1100 \\
\hline 190 & 0,05 & 0,7 & 0,00 & 94 & 3a Réplica & 0,1560 & 0,0790 \\
\hline 130 & 0,1 & 0,7 & 0,00 & 95 & 3a Réplica & 0,1370 & 0,1170 \\
\hline 190 & 0,1 & 0,7 & 0,00 & 96 & 3a Réplica & 0,1510 & 0,1170 \\
\hline
\end{tabular}




\begin{tabular}{|c|c|c|c|c|c|c|c|}
\hline $\begin{array}{l}\text { Vc } \\
\mathrm{m} / \mathrm{min}\end{array}$ & $\begin{array}{c}\mathrm{fz} \\
\mathrm{mm} / \text { dente }\end{array}$ & $\underset{\mathrm{mm}}{\mathrm{ap}}$ & $\begin{array}{c}\text { VBmax } \\
\mathrm{mm}\end{array}$ & $\begin{array}{c}\text { No } \\
\text { ensaio }\end{array}$ & $\begin{array}{c}\text { Ferramenta } \\
\text { C }\end{array}$ & $\begin{array}{c}\text { Ds } \\
\theta=180^{\circ} \\
h(\mathrm{~mm})\end{array}$ & $\begin{array}{c}\text { Fs } \\
\theta=160^{\circ} \\
h(\mathrm{~mm})\end{array}$ \\
\hline 130 & 0,05 & 0,3 & 0,30 & 97 & Ensaio & 0,2980 & 0,2580 \\
\hline 190 & 0,05 & 0,3 & 0,30 & 98 & Ensaio & 0,2770 & 0,2440 \\
\hline 130 & 0,1 & 0,3 & 0,30 & 99 & Ensaio & 0,2980 & 0,2340 \\
\hline 190 & 0,1 & 0,3 & 0,30 & 100 & Ensaio & 0,2740 & 0,2270 \\
\hline 130 & 0,05 & 0,7 & 0,30 & 101 & Ensaio & 0,2540 & 0,2647 \\
\hline 190 & 0,05 & 0,7 & 0,30 & 102 & Ensaio & 0,2870 & 0,2442 \\
\hline 130 & 0,1 & 0,7 & 0,30 & 103 & Ensaio & 0,2916 & 0,2782 \\
\hline 190 & 0,1 & 0,7 & 0,30 & 104 & Ensaio & 0,3420 & 0,2494 \\
\hline 130 & 0,05 & 0,3 & 0,30 & 105 & 1a Réplica & 0,3060 & 0,2880 \\
\hline 190 & 0,05 & 0,3 & 0,30 & 106 & 1a Réplica & 0,2880 & 0,2450 \\
\hline 130 & 0,1 & 0,3 & 0,30 & 107 & 1a Réplica & 0,2690 & 0,2577 \\
\hline 190 & 0,1 & 0,3 & 0,30 & 108 & 1a Réplica & 0,2980 & 0,2320 \\
\hline 130 & 0,05 & 0,7 & 0,30 & 109 & 1a Réplica & 0,3330 & 0,2778 \\
\hline 190 & 0,05 & 0,7 & 0,30 & 110 & 1a Réplica & 0,3437 & 0,2596 \\
\hline 130 & 0,1 & 0,7 & 0,30 & 111 & 1a Réplica & 0,2764 & 0,2829 \\
\hline 190 & 0,1 & 0,7 & 0,30 & 112 & 1a Réplica & 0,3080 & 0,2636 \\
\hline 130 & 0,05 & 0,3 & 0,30 & 113 & 2a Réplica & 0,3012 & 0,2900 \\
\hline 190 & 0,05 & 0,3 & 0,30 & 114 & 2a Réplica & 0,3060 & 0,2760 \\
\hline 130 & 0,1 & 0,3 & 0,30 & 115 & 2a Réplica & 0,2870 & 0,2780 \\
\hline 190 & 0,1 & 0,3 & 0,30 & 116 & 2a Réplica & 0,2700 & 0,2230 \\
\hline 130 & 0,05 & 0,7 & 0,30 & 117 & 2a Réplica & 0,3304 & 0,2980 \\
\hline 190 & 0,05 & 0,7 & 0,30 & 118 & 2a Réplica & 0,2950 & 0,1575 \\
\hline 130 & 0,1 & 0,7 & 0,30 & 119 & 2a Réplica & 0,2780 & 0,2720 \\
\hline 190 & 0,1 & 0,7 & 0,30 & 120 & 2a Réplica & 0,3069 & 0,2384 \\
\hline 130 & 0,05 & 0,3 & 0,30 & 121 & 3a Réplica & 0,3020 & 0,2750 \\
\hline 190 & 0,05 & 0,3 & 0,30 & 122 & 3a Réplica & 0,2540 & 0,2630 \\
\hline 130 & 0,1 & 0,3 & 0,30 & 123 & 3a Réplica & 0,2700 & 0,2589 \\
\hline 190 & 0,1 & 0,3 & 0,30 & 124 & 3a Réplica & 0,2960 & 0,2160 \\
\hline 130 & 0,05 & 0,7 & 0,30 & 125 & 3a Réplica & 0,3290 & 0,2760 \\
\hline 190 & 0,05 & 0,7 & 0,30 & 126 & 3a Réplica & 0,3090 & 0,2660 \\
\hline 130 & 0,1 & 0,7 & 0,30 & 127 & 3a Réplica & 0,2830 & 0,2760 \\
\hline 190 & 0,1 & 0,7 & 0,30 & 128 & 3a Réplica & 0,3000 & 0,2505 \\
\hline
\end{tabular}




\section{APÊNDICE C}

Análise de Variância dos modelos para os ensaios com a Ferramenta A. Avaliação dos valores observados durante os ensaios, dos valores preditos e dos resíduos.

\begin{tabular}{|c|r|r|r|}
\hline Ensaio & Observado & Previsto & Resíduos \\
\hline 1 & 0,062 & 0,056087 & 0,005913 \\
\hline 2 & 0,061 & 0,049627 & 0,011373 \\
\hline 3 & 0,043 & 0,031191 & 0,011809 \\
\hline 4 & 0,046 & 0,047253 & $-0,001253$ \\
\hline 5 & 0,066 & 0,077273 & $-0,011273$ \\
\hline 6 & 0,07767 & 0,047335 & 0,030335 \\
\hline 7 & 0,041 & 0,04273 & $-0,00173$ \\
\hline 8 & 0,04 & 0,035314 & 0,004686 \\
\hline 9 & 0,128 & 0,106987 & 0,021013 \\
\hline 10 & 0,1 & 0,090387 & 0,009613 \\
\hline 11 & 0,046 & 0,067732 & $-0,021732$ \\
\hline 12 & 0,085 & 0,073654 & 0,011346 \\
\hline 13 & 0,171 & 0,125576 & 0,045424 \\
\hline 14 & 0,0225 & 0,085497 & $-0,062997$ \\
\hline 15 & 0,092 & 0,076674 & 0,015326 \\
\hline 16 & 0,033 & 0,059118 & $-0,026118$ \\
\hline 17 & 0,055 & 0,060174 & $-0,005174$ \\
\hline 18 & 0,059 & 0,07694 & $-0,01794$ \\
\hline 19 & 0,046 & 0,026345 & 0,019655 \\
\hline 20 & 0,035 & 0,065632 & $-0,030632$ \\
\hline 21 & 0,137 & 0,087251 & 0,049749 \\
\hline 22 & 0,07267 & 0,080539 & $-0,007869$ \\
\hline 23 & 0,0333 & 0,043774 & $-0,010474$ \\
\hline 24 & 0,06 & 0,059584 & 0,000416 \\
\hline 25 & 0,124 & 0,132087 & $-0,008087$ \\
\hline 26 & 0,158 & 0,138712 & 0,019288 \\
\hline 27 & 0,072 & 0,083897 & $-0,011897$ \\
\hline 28 & 0,123 & 0,113045 & 0,009955 \\
\hline 29 & 0,124 & 0,156566 & $-0,032566$ \\
\hline 30 & 0,146 & 0,139713 & 0,006287 \\
\hline 31 & 0,094 & 0,09873 & $-0,00473$ \\
\hline 32 & 0,092 & 0,104399 & $-0,012399$ \\
\hline 33 & 0,073 & 0,056087 & 0,016913 \\
\hline 34 & 0,07 & 0,049627 & 0,020373 \\
\hline 35 & 0,022 & 0,031191 & $-0,009191$ \\
\hline
\end{tabular}

\begin{tabular}{|c|r|r|r|}
\hline Ensaio & Observado & Previsto & Resíduos \\
\hline 36 & 0,021 & 0,047253 & $-0,02625$ \\
\hline 37 & 0,061 & 0,077273 & $-0,01627$ \\
\hline 38 & 0,06067 & 0,047335 & 0,013335 \\
\hline 39 & 0,024 & 0,04273 & $-0,01873$ \\
\hline 40 & 0,023 & 0,035314 & $-0,01231$ \\
\hline 41 & 0,089 & 0,106987 & $-0,01799$ \\
\hline 42 & 0,076 & 0,090387 & $-0,01439$ \\
\hline 43 & 0,072 & 0,067732 & 0,004268 \\
\hline 44 & 0,079 & 0,073654 & 0,005346 \\
\hline 45 & 0,107 & 0,125576 & $-0,01858$ \\
\hline 46 & 0,103 & 0,085497 & 0,017503 \\
\hline 47 & 0,096 & 0,076674 & 0,019326 \\
\hline 48 & 0,077 & 0,059118 & 0,017882 \\
\hline 49 & 0,058 & 0,060174 & $-0,00217$ \\
\hline 50 & 0,082 & 0,07694 & 0,00506 \\
\hline 51 & 0,047 & 0,026345 & 0,020655 \\
\hline 52 & 0,06933 & 0,065632 & 0,003698 \\
\hline 53 & 0,051 & 0,087251 & $-0,03625$ \\
\hline 54 & 0,07933 & 0,080539 & $-0,00121$ \\
\hline 55 & 0,045 & 0,043774 & 0,001226 \\
\hline 56 & 0,072 & 0,059584 & 0,012416 \\
\hline 57 & 0,148 & 0,132087 & 0,015913 \\
\hline 58 & 0,15 & 0,138712 & 0,011288 \\
\hline 59 & 0,068 & 0,083897 & $-0,0159$ \\
\hline 60 & 0,128 & 0,113045 & 0,014955 \\
\hline 61 & 0,174 & 0,156566 & 0,017434 \\
\hline 62 & 0,16 & 0,139713 & 0,020287 \\
\hline 63 & 0,097 & 0,09873 & $-0,00173$ \\
\hline 64 & 0,107 & 0,104399 & 0,002601 \\
\hline 65 & 0,053 & 0,056087 & $-0,00309$ \\
\hline 66 & 0,052 & 0,049627 & 0,002373 \\
\hline 67 & 0,042 & 0,031191 & 0,010809 \\
\hline 68 & 0,05167 & 0,047253 & 0,004417 \\
\hline 69 & 0,067 & 0,077273 & $-0,01027$ \\
\hline 70 & 0,06456 & 0,047335 & 0,017225 \\
\hline & & & \\
\hline 53
\end{tabular}




\begin{tabular}{|c|r|r|r|}
\hline Ensaio & Observado & Previsto & Resíduos \\
\hline 71 & 0,022 & 0,04273 & $-0,02073$ \\
\hline 72 & 0,062 & 0,035314 & 0,026686 \\
\hline 73 & 0,113 & 0,106987 & 0,006013 \\
\hline 74 & 0,091 & 0,090387 & 0,000613 \\
\hline 75 & 0,057 & 0,067732 & $-0,010732$ \\
\hline 76 & 0,043 & 0,073654 & $-0,030654$ \\
\hline 77 & 0,129 & 0,125576 & 0,003424 \\
\hline 78 & 0,062 & 0,085497 & $-0,023497$ \\
\hline 79 & 0,112 & 0,076674 & 0,035326 \\
\hline 80 & 0,036 & 0,059118 & $-0,023118$ \\
\hline 81 & 0,044 & 0,060174 & $-0,016174$ \\
\hline 82 & 0,071 & 0,07694 & $-0,00594$ \\
\hline 83 & 0,038 & 0,026345 & 0,011655 \\
\hline 84 & 0,086 & 0,065632 & 0,020368 \\
\hline 85 & 0,1 & 0,087251 & 0,012749 \\
\hline 86 & 0,06633 & 0,080539 & $-0,014209$ \\
\hline 87 & 0,046 & 0,043774 & 0,002226 \\
\hline 88 & 0,07 & 0,059584 & 0,010416 \\
\hline 89 & 0,135 & 0,132087 & 0,002913 \\
\hline 90 & 0,13 & 0,138712 & $-0,008712$ \\
\hline 91 & 0,065 & 0,083897 & $-0,018897$ \\
\hline 92 & 0,113 & 0,113045 & $-0,000045$ \\
\hline 93 & 0,152 & 0,156566 & $-0,004566$ \\
\hline 94 & 0,153 & 0,139713 & 0,013287 \\
\hline 95 & 0,098 & 0,09873 & $-0,00073$ \\
\hline 96 & 0,093 & 0,104399 & $-0,011399$ \\
\hline 97 & 0,048 & 0,056087 & $-0,008087$ \\
\hline 98 & 0,045 & 0,049627 & $-0,004627$ \\
\hline 99 & 0,021 & 0,031191 & $-0,010191$ \\
\hline
\end{tabular}

\begin{tabular}{|c|c|c|c|}
\hline Ensaio & Observado & Previsto & Resíduos \\
\hline 100 & 0,037 & 0,047253 & $-0,01025$ \\
\hline 101 & 0,058 & 0,077273 & $-0,01927$ \\
\hline 102 & 0,05167 & 0,047335 & 0,004335 \\
\hline 103 & 0,041 & 0,04273 & $-0,00173$ \\
\hline 104 & 0,04 & 0,035314 & 0,004686 \\
\hline 105 & 0,102 & 0,106987 & $-0,00499$ \\
\hline 106 & 0,083 & 0,090387 & $-0,00739$ \\
\hline 107 & 0,059 & 0,067732 & $-0,00873$ \\
\hline 108 & 0,121 & 0,073654 & 0,047346 \\
\hline 109 & 0,144 & 0,125576 & 0,018424 \\
\hline 110 & 0,064 & 0,085497 & $-0,0215$ \\
\hline 111 & 0,076 & 0,076674 & $-0,00067$ \\
\hline 112 & 0,074 & 0,059118 & 0,014882 \\
\hline 113 & 0,067 & 0,060174 & 0,006826 \\
\hline 114 & 0,054 & 0,07694 & $-0,02294$ \\
\hline 115 & 0,052 & 0,026345 & 0,025655 \\
\hline 116 & 0,042 & 0,065632 & $-0,02363$ \\
\hline 117 & 0,088 & 0,087251 & 0,000749 \\
\hline 118 & 0,086 & 0,080539 & 0,005461 \\
\hline 119 & 0,048 & 0,043774 & 0,004226 \\
\hline 120 & 0,041 & 0,059584 & $-0,01858$ \\
\hline 121 & 0,133 & 0,132087 & 0,000913 \\
\hline 122 & 0,13 & 0,138712 & $-0,00871$ \\
\hline 123 & 0,076 & 0,083897 & $-0,0079$ \\
\hline 124 & 0,129 & 0,113045 & 0,015955 \\
\hline 125 & 0,147 & 0,156566 & $-0,00957$ \\
\hline 126 & 0,1536 & 0,139713 & 0,013887 \\
\hline 127 & 0,093 & 0,09873 & $-0,00573$ \\
\hline 128 & 0,103 & 0,104399 & $-0,0014$ \\
\hline
\end{tabular}


Análise de Variância dos modelos para os ensaios com a Ferramenta C. Avaliação dos valores observados durante os ensaios, dos valores preditos e dos resíduos.

\begin{tabular}{|c|c|c|c|}
\hline Ensaio & Observado & Previsto & Resíduos \\
\hline 1 & 0,088 & 0,113774 & $-0,025774$ \\
\hline 2 & 0,116 & 0,105758 & 0,010242 \\
\hline 3 & 0,105 & 0,108883 & $-0,003883$ \\
\hline 4 & 0,12048 & 0,107075 & 0,013405 \\
\hline 5 & 0,125 & 0,111578 & 0,013422 \\
\hline 6 & 0,1185 & 0,110489 & 0,008011 \\
\hline 7 & 0,109 & 0,111909 & $-0,002909$ \\
\hline 8 & 0,122 & 0,117028 & 0,004972 \\
\hline 9 & 0,258 & 0,272503 & $-0,014503$ \\
\hline 10 & 0,244 & 0,243011 & 0,000989 \\
\hline 11 & 0,234 & 0,260024 & $-0,026024$ \\
\hline 12 & 0,227 & 0,236741 & $-0,009741$ \\
\hline 13 & 0,2647 & 0,274068 & $-0,009368$ \\
\hline 14 & 0,2442 & 0,251503 & $-0,007303$ \\
\hline 15 & 0,2782 & 0,266811 & 0,011389 \\
\hline 16 & 0,2494 & 0,250454 & $-0,001054$ \\
\hline 17 & 0,154 & 0,146586 & 0,007414 \\
\hline 18 & 0,138 & 0,154684 & $-0,016684$ \\
\hline 19 & 0,132 & 0,123402 & 0,008598 \\
\hline 20 & 0,146 & 0,137708 & 0,008292 \\
\hline 21 & 0,157 & 0,150603 & 0,006397 \\
\hline 22 & 0,152 & 0,165628 & $-0,013628$ \\
\hline 23 & 0,088 & 0,132641 & $-0,044641$ \\
\hline 24 & 0,152 & 0,153874 & $-0,001874$ \\
\hline 25 & 0,298 & 0,310524 & $-0,012524$ \\
\hline 26 & 0,33035 & 0,297147 & 0,033203 \\
\hline 27 & 0,278 & 0,279753 & $-0,001753$ \\
\hline 28 & 0,27 & 0,272584 & $-0,002584$ \\
\hline 29 & 0,3012 & 0,318302 & $-0,017102$ \\
\hline 30 & 0,306 & 0,311852 & $-0,005852$ \\
\hline 31 & 0,2916 & 0,292752 & $-0,001152$ \\
\hline 32 & 0,287 & 0,292511 & $-0,005511$ \\
\hline
\end{tabular}

\begin{tabular}{|c|c|c|c|}
\hline Ensaio & Observado & Previsto & Resíduos \\
\hline 33 & 0,119 & 0,113774 & 0,005226 \\
\hline 34 & 0,096 & 0,105758 & $-0,00976$ \\
\hline 35 & 0,1 & 0,108883 & $-0,00888$ \\
\hline 36 & 0,0954 & 0,107075 & $-0,01168$ \\
\hline 37 & 0,088 & 0,111578 & $-0,02358$ \\
\hline 38 & 0,143 & 0,110489 & 0,032511 \\
\hline 39 & 0,098 & 0,111909 & $-0,01391$ \\
\hline 40 & 0,116 & 0,117028 & $-0,00103$ \\
\hline 41 & 0,288 & 0,272503 & 0,015497 \\
\hline 42 & 0,245 & 0,243011 & 0,001989 \\
\hline 43 & 0,2577 & 0,260024 & $-0,00232$ \\
\hline 44 & 0,232 & 0,236741 & $-0,00474$ \\
\hline 45 & 0,2778 & 0,274068 & 0,003732 \\
\hline 46 & 0,2596 & 0,251503 & 0,008097 \\
\hline 47 & 0,2829 & 0,266811 & 0,016089 \\
\hline 48 & 0,2636 & 0,250454 & 0,013146 \\
\hline 49 & 0,146 & 0,146586 & $-0,00059$ \\
\hline 50 & 0,162 & 0,154684 & 0,007316 \\
\hline 51 & 0,121 & 0,123402 & $-0,0024$ \\
\hline 52 & 0,143 & 0,137708 & 0,005292 \\
\hline 53 & 0,147 & 0,150603 & $-0,0036$ \\
\hline 54 & 0,179 & 0,165628 & 0,013372 \\
\hline 55 & 0,144 & 0,132641 & 0,011359 \\
\hline 56 & 0,157 & 0,153874 & 0,003126 \\
\hline 57 & 0,306 & 0,310524 & $-0,00452$ \\
\hline 58 & 0,288 & 0,297147 & $-0,00915$ \\
\hline 59 & 0,269 & 0,279753 & $-0,01075$ \\
\hline 60 & 0,298 & 0,272584 & 0,025416 \\
\hline 61 & 0,333 & 0,318302 & 0,014698 \\
\hline 62 & 0,3437 & 0,311852 & 0,031848 \\
\hline 63 & 0,2764 & 0,292752 & $-0,01635$ \\
\hline 64 & 0,308 & 0,292511 & 0,015489 \\
\hline & & & \\
\hline 54
\end{tabular}




\begin{tabular}{|c|c|c|c|}
\hline Ensaio & Observado & Previsto & Resíduos \\
\hline 65 & 0,099 & 0,113774 & $-0,014774$ \\
\hline 66 & 0,1044 & 0,105758 & $-0,001358$ \\
\hline 67 & 0,124 & 0,108883 & 0,015117 \\
\hline 68 & 0,1062 & 0,107075 & $-0,000875$ \\
\hline 69 & 0,1 & 0,111578 & $-0,011578$ \\
\hline 70 & 0,134 & 0,110489 & 0,023511 \\
\hline 71 & 0,11 & 0,111909 & $-0,001909$ \\
\hline 72 & 0,134 & 0,117028 & 0,016972 \\
\hline 73 & 0,29 & 0,272503 & 0,017497 \\
\hline 74 & 0,276 & 0,243011 & 0,032989 \\
\hline 75 & 0,278 & 0,260024 & 0,017976 \\
\hline 76 & 0,223 & 0,236741 & $-0,013741$ \\
\hline 77 & 0,298 & 0,274068 & 0,023932 \\
\hline 78 & 0,15754 & 0,251503 & $-0,093963$ \\
\hline 79 & 0,272 & 0,266811 & 0,005189 \\
\hline 80 & 0,23842 & 0,250454 & $-0,012034$ \\
\hline 81 & 0,138 & 0,146586 & $-0,008586$ \\
\hline 82 & 0,152 & 0,154684 & $-0,002684$ \\
\hline 83 & 0,152 & 0,123402 & 0,028598 \\
\hline 84 & 0,095 & 0,137708 & $-0,042708$ \\
\hline 85 & 0,157 & 0,150603 & 0,006397 \\
\hline 86 & 0,172 & 0,165628 & 0,006372 \\
\hline 87 & 0,132 & 0,132641 & $-0,000641$ \\
\hline 88 & 0,146 & 0,153874 & $-0,007874$ \\
\hline 89 & 0,3012 & 0,310524 & $-0,009324$ \\
\hline 90 & 0,306 & 0,297147 & 0,008853 \\
\hline 91 & 0,287 & 0,279753 & 0,007247 \\
\hline 92 & 0,27 & 0,272584 & $-0,002584$ \\
\hline 93 & 0,33035 & 0,318302 & 0,012048 \\
\hline 94 & 0,295 & 0,311852 & $-0,016852$ \\
\hline 95 & 0,278 & 0,292752 & $-0,014752$ \\
\hline 96 & 0,3069 & 0,292511 & 0,014389 \\
\hline
\end{tabular}

\begin{tabular}{|c|c|c|c|}
\hline Ensaio & Observado & Previsto & Resíduos \\
\hline 97 & 0,101 & 0,113774 & $-0,01277$ \\
\hline 98 & 0,127 & 0,105758 & 0,021242 \\
\hline 99 & 0,12 & 0,108883 & 0,011117 \\
\hline 100 & 0,104 & 0,107075 & $-0,00308$ \\
\hline 101 & 0,11 & 0,111578 & $-0,00158$ \\
\hline 102 & 0,079 & 0,110489 & $-0,03149$ \\
\hline 103 & 0,117 & 0,111909 & 0,005091 \\
\hline 104 & 0,117 & 0,117028 & $-2,8 \mathrm{E}-05$ \\
\hline 105 & 0,275 & 0,272503 & 0,002497 \\
\hline 106 & 0,263 & 0,243011 & 0,019989 \\
\hline 107 & 0,2589 & 0,260024 & $-0,00112$ \\
\hline 108 & 0,216 & 0,236741 & $-0,02074$ \\
\hline 109 & 0,276 & 0,274068 & 0,001932 \\
\hline 110 & 0,266 & 0,251503 & 0,014497 \\
\hline 111 & 0,276 & 0,266811 & 0,009189 \\
\hline 112 & 0,2505 & 0,250454 & 0,000046 \\
\hline 113 & 0,167 & 0,146586 & 0,020414 \\
\hline 114 & 0,144 & 0,154684 & $-0,01068$ \\
\hline 115 & 0,145 & 0,123402 & 0,021598 \\
\hline 116 & 0,131 & 0,137708 & $-0,00671$ \\
\hline 117 & 0,1675 & 0,150603 & 0,016897 \\
\hline 118 & 0,156 & 0,165628 & $-0,00963$ \\
\hline 119 & 0,137 & 0,132641 & 0,004359 \\
\hline 120 & 0,151 & 0,153874 & $-0,00287$ \\
\hline 121 & 0,302 & 0,310524 & $-0,00852$ \\
\hline 122 & 0,254 & 0,297147 & $-0,04315$ \\
\hline 123 & 0,27 & 0,279753 & $-0,00975$ \\
\hline 124 & 0,296 & 0,272584 & 0,023416 \\
\hline 125 & 0,329 & 0,318302 & 0,010698 \\
\hline 126 & 0,309 & 0,311852 & $-0,00285$ \\
\hline 127 & 0,283 & 0,292752 & $-0,00975$ \\
\hline 128 & 0,3 & 0,292511 & 0,007489 \\
\hline & & & \\
\hline
\end{tabular}

